\title{
Establishing Monitoring Programs for Travel Time Reliability
}




\section{TRANSPORTATION RESEARCH BOARD 2014 EXECUTIVE COMMITTEE*}

\section{OFFICERS}

CHAIR: Kirk T. Steudle, Director, Michigan Department of Transportation, Lansing

VICE CHAIR: Daniel Sperling, Professor of Civil Engineering and Environmental Science and Policy; Director, Institute of Transportation Studies,

University of California, Davis

EXECUTIVE DIRECTOR: Robert E. Skinner, Jr., Transportation Research Board

\section{MEMBERS}

Victoria A. Arroyo, Executive Director, Georgetown Climate Center, and Visiting Professor, Georgetown University Law Center, Washington, D.C. Scott E. Bennett, Director, Arkansas State Highway and Transportation Department, Little Rock

Deborah H. Butler, Executive Vice President, Planning, and CIO, Norfolk Southern Corporation, Norfolk, Virginia (Past Chair, 2013)

James M. Crites, Executive Vice President of Operations, Dallas-Fort Worth International Airport, Texas

Malcolm Dougherty, Director, California Department of Transportation, Sacramento

A. Stewart Fotheringham, Professor and Director, Centre for Geoinformatics, School of Geography and Geosciences, University of St. Andrews, Fife, United Kingdom

John S. Halikowski, Director, Arizona Department of Transportation, Phoenix

Michael W. Hancock, Secretary, Kentucky Transportation Cabinet, Frankfort

Susan Hanson, Distinguished University Professor Emerita, School of Geography, Clark University, Worcester, Massachusetts

Steve Heminger, Executive Director, Metropolitan Transportation Commission, Oakland, California

Chris T. Hendrickson, Duquesne Light Professor of Engineering, Carnegie Mellon University, Pittsburgh, Pennsylvania

Jeffrey D. Holt, Managing Director, Bank of Montreal Capital Markets, and Chairman, Utah Transportation Commission, Huntsville, Utah

Gary P. LaGrange, President and CEO, Port of New Orleans, Louisiana

Michael P. Lewis, Director, Rhode Island Department of Transportation, Providence

Joan McDonald, Commissioner, New York State Department of Transportation, Albany

Abbas Mohaddes, President and CEO, Iteris, Inc., Santa Ana, California

Donald A. Osterberg, Senior Vice President, Safety and Security, Schneider National, Inc., Green Bay, Wisconsin

Steven W. Palmer, Vice President of Transportation, Lowe's Companies, Inc., Mooresville, North Carolina

Sandra Rosenbloom, Professor, University of Texas, Austin (Past Chair, 2012)

Henry G. (Gerry) Schwartz, Jr., Chairman (retired), Jacobs/Sverdrup Civil, Inc., St. Louis, Missouri

Kumares C. Sinha, Olson Distinguished Professor of Civil Engineering, Purdue University, West Lafayette, Indiana

Gary C. Thomas, President and Executive Director, Dallas Area Rapid Transit, Dallas, Texas

Paul Trombino III, Director, Iowa Department of Transportation, Ames

Phillip A. Washington, General Manager, Regional Transportation District, Denver, Colorado

\section{EX OFFICIO MEMBERS}

Thomas P. Bostick, (Lt. General, U.S. Army), Chief of Engineers and Commanding General, U.S. Army Corps of Engineers, Washington, D.C. Alison J. Conway, Assistant Professor, Department of Civil Engineering, City College of New York, New York, and Chair, TRB Young Members Council Anne S. Ferro, Administrator, Federal Motor Carrier Safety Administration, U.S. Department of Transportation

David J. Friedman, Acting Administrator, National Highway Traffic Safety Administration, U.S. Department of Transportation

LeRoy Gishi, Chief, Division of Transportation, Bureau of Indian Affairs, U.S. Department of the Interior, Washington, D.C.

John T. Gray II, Senior Vice President, Policy and Economics, Association of American Railroads, Washington, D.C.

Michael P. Huerta, Administrator, Federal Aviation Administration, U.S. Department of Transportation

Paul N. Jaenichen, Sr., Acting Administrator, Maritime Administration, U.S. Department of Transportation

Therese W. McMillan, Acting Administrator, Federal Transit Administration

Michael P. Melaniphy, President and CEO, American Public Transportation Association, Washington, D.C.

Gregory Nadeau, Acting Administrator, Federal Highway Administration, U.S. Department of Transportation

Cynthia L. Quarterman, Administrator, Pipeline and Hazardous Materials Safety Administration, U.S. Department of Transportation

Peter M. Rogoff, Under Secretary for Policy, U.S. Department of Transportation

Craig A. Rutland, U.S. Air Force Pavement Engineer, Air Force Civil Engineer Center, Tyndall Air Force Base, Florida

Joseph C. Szabo, Administrator, Federal Railroad Administration, U.S. Department of Transportation

Barry R. Wallerstein, Executive Officer, South Coast Air Quality Management District, Diamond Bar, California

Gregory D. Winfree, Assistant Secretary for Research and Technology, Office of the Secretary, U.S. Department of Transportation

Frederick G. (Bud) Wright, Executive Director, American Association of State Highway and Transportation Officials, Washington, D.C.

Paul F. Zukunft, Adm., U.S. Coast Guard, Commandant, U.S. Coast Guard, U.S. Department of Homeland Security.

\footnotetext{
${ }^{\star}$ Membership as of July 2014 .
} 


\title{
Establishing Monitoring Programs for Travel Time Reliability
}

\author{
George F. List, Billy Williams, AND Nagui Rouphail \\ Institute for Transportation Research and Education \\ North Carolina State University \\ in association with \\ Rob Hranac, Tiffany Barkley, Eric Mai, ANd Armand Ciccarelli \\ Iteris/Berkeley Transportation Systems, Inc. \\ Lee Rodegerdts, Katie Pincus, and Brandon Nevers \\ Kittelson \& Associates, Inc. \\ ALAN F. KARR \\ National Institute of Statistical Sciences \\ Xuesong Zhou \\ University of Utah \\ JEFFREY WOJTOWICZ \\ Rensselaer Polytechnic Institute \\ JOSEPH SCHOFER \\ Northwestern University \\ AsAD KHATTAK \\ Planitek
}




\section{Subscriber Categories}

Highways

Data and Information Technology

Operations and Traffic Management

Planning and Forecasting 


\section{The Second Strategic Highway Research Program}

America's highway system is critical to meeting the mobility and economic needs of local communities, regions, and the nation. Developments in research and technology_such as advanced materials, communications technology, new data collection technologies, and human factors science-offer a new opportunity to improve the safety and reliability of this important national resource. Breakthrough resolution of significant transportation problems, however, requires concentrated resources over a short time frame. Reflecting this need, the second Strategic Highway Research Program (SHRP 2) has an intense, large-scale focus, integrates multiple fields of research and technology, and is fundamentally different from the broad, mission-oriented, discipline-based research programs that have been the mainstay of the highway research industry for half a century.

The need for SHRP 2 was identified in TRB Special Report 260: Strategic Highway Research: Saving Lives, Reducing Congestion, Improving Quality of Life, published in 2001 and based on a study sponsored by Congress through the Transportation Equity Act for the 21st Century (TEA-21). SHRP 2, modeled after the first Strategic Highway Research Program, is a focused, timeconstrained, management-driven program designed to complement existing highway research programs. SHRP 2 focuses on applied research in four areas: Safety, to prevent or reduce the severity of highway crashes by understanding driver behavior; Renewal, to address the aging infrastructure through rapid design and construction methods that cause minimal disruptions and produce lasting facilities; Reliability, to reduce congestion through incident reduction, management, response, and mitigation; and Capacity, to integrate mobility, economic, environmental, and community needs in the planning and designing of new transportation capacity.

SHRP 2 was authorized in August 2005 as part of the Safe, Accountable, Flexible, Efficient Transportation Equity Act: A Legacy for Users (SAFETEA-LU). The program is managed by the Transportation Research Board (TRB) on behalf of the National Research Council (NRC). SHRP 2 is conducted under a memorandum of understanding among the American Association of State Highway and Transportation Officials (AASHTO), the Federal Highway Administration (FHWA), and the National Academy of Sciences, parent organization of TRB and NRC. The program provides for competitive, merit-based selection of research contractors; independent research project oversight; and dissemination of research results.
SHRP 2 Report S2-L02-RR-1

ISBN: 978-0-309-27286-5

Library of Congress Control Number: 2014946502

(c) 2014 National Academy of Sciences. All rights reserved.

\section{Copyright Information}

Authors herein are responsible for the authenticity of their materials and for obtaining written permissions from publishers or persons who own the copyright to any previously published or copyrighted material used herein.

The second Strategic Highway Research Program grants permission to reproduce material in this publication for classroom and not-for-profit purposes. Permission is given with the understanding that none of the material will be used to imply TRB, AASHTO, or FHWA endorsement of a particular product, method, or practice. It is expected that those reproducing material in this document for educational and not-for-profit purposes will give appropriate acknowledgment of the source of any reprinted or reproduced material. For other uses of the material, request permission from SHRP 2.

Note: SHRP 2 report numbers convey the program, focus area, project number, and publication format. Report numbers ending in " $w$ " are published as web documents only.

\section{Notice}

The project that is the subject of this report was a part of the second Strategic Highway Research Program, conducted by the Transportation Research Board with the approval of the Governing Board of the National Research Council.

The members of the technical committee selected to monitor this project and review this report were chosen for their special competencies and with regard for appropriate balance. The report was reviewed by the technical committee and accepted for publication according to procedures established and overseen by the Transportation Research Board and approved by the Governing Board of the National Research Council.

The opinions and conclusions expressed or implied in this report are those of the researchers who performed the research and are not necessarily those of the Transportation Research Board, the National Research Council, or the program sponsors.

The Transportation Research Board of the National Academies, the National Research Council, and the sponsors of the second Strategic Highway Research Program do not endorse products or manufacturers. Trade or manufacturers' names appear herein solely because they are considered essential to the object of the report.

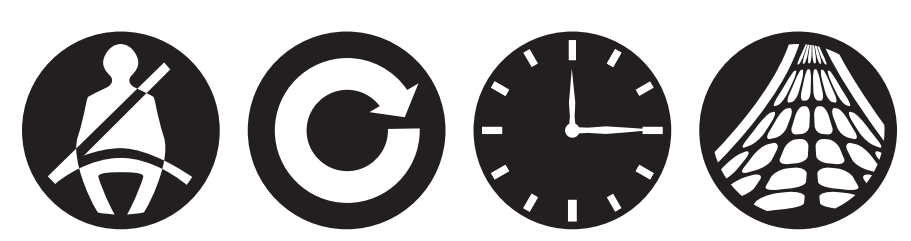

\section{SHRP 2 Reports}

Available by subscription and through the TRB online bookstore: www.TRB.org/bookstore

Contact the TRB Business Office: 202-334-3213

More information about SHRP 2: www.TRB.org/SHRP2 


\section{THE NATIONAL ACADEMIES Advisers to the Nation on Science, Engineering, and Medicine}

The National Academy of Sciences is a private, nonprofit, self-perpetuating society of distinguished scholars engaged in scientific and engineering research, dedicated to the furtherance of science and technology and to their use for the general welfare. On the authority of the charter granted to it by Congress in 1863, the Academy has a mandate that requires it to advise the federal government on scientific and technical matters. Dr. Ralph J. Cicerone is president of the National Academy of Sciences.

The National Academy of Engineering was established in 1964, under the charter of the National Academy of Sciences, as a parallel organization of outstanding engineers. It is autonomous in its administration and in the selection of its members, sharing with the National Academy of Sciences the responsibility for advising the federal government. The National Academy of Engineering also sponsors engineering programs aimed at meeting national needs, encourages education and research, and recognizes the superior achievements of engineers. Dr. C. D. (Dan) Mote, Jr., is president of the National Academy of Engineering.

The Institute of Medicine was established in 1970 by the National Academy of Sciences to secure the services of eminent members of appropriate professions in the examination of policy matters pertaining to the health of the public. The Institute acts under the responsibility given to the National Academy of Sciences by its congressional charter to be an adviser to the federal government and, on its own initiative, to identify issues of medical care, research, and education. Dr. Victor J. Dzau is president of the Institute of Medicine.

The National Research Council was organized by the National Academy of Sciences in 1916 to associate the broad community of science and technology with the Academy's purposes of furthering knowledge and advising the federal government. Functioning in accordance with general policies determined by the Academy, the Council has become the principal operating agency of both the National Academy of Sciences and the National Academy of Engineering in providing services to the government, the public, and the scientific and engineering communities. The Council is administered jointly by both Academies and the Institute of Medicine. Dr. Ralph J. Cicerone and Dr. C. D. (Dan) Mote, Jr., are chair and vice chair, respectively, of the National Research Council.

The Transportation Research Board is one of six major divisions of the National Research Council. The mission of the Transportation Research Board is to provide leadership in transportation innovation and progress through research and information exchange, conducted within a setting that is objective, interdisciplinary, and multimodal. The Board's varied activities annually engage about 7,000 engineers, scientists, and other transportation researchers and practitioners from the public and private sectors and academia, all of whom contribute their expertise in the public interest. The program is supported by state transportation departments, federal agencies including the component administrations of the U.S. Department of Transportation, and other organizations and individuals interested in the development of transportation. www.TRB.org 


\section{SHRP 2 STAFF}

Ann M. Brach, Director

Stephen J. Andrle, Deputy Director

Neil J. Pedersen, Deputy Director, Implementation and Communications

Cynthia Allen, Editor

Kenneth Campbell, Chief Program Officer, Safety

JoAnn Coleman, Senior Program Assistant, Capacity and Reliability

Eduardo Cusicanqui, Financial Officer

Richard Deering, Special Consultant, Safety Data Phase 1 Planning

Shantia Douglas, Senior Financial Assistant

Charles Fay, Senior Program Officer, Safety

Carol Ford, Senior Program Assistant, Renewal and Safety

Jo Allen Gause, Senior Program Officer, Capacity

James Hedlund, Special Consultant, Safety Coordination

Alyssa Hernandez, Reports Coordinator

Ralph Hessian, Special Consultant, Capacity and Reliability

Andy Horosko, Special Consultant, Safety Field Data Collection

William Hyman, Senior Program Officer, Reliability

Linda Mason, Communications Officer

Reena Mathews, Senior Program Officer, Capacity and Reliability

Matthew Miller, Program Officer, Capacity and Reliability

Michael Miller, Senior Program Assistant, Capacity and Reliability

David Plazak, Senior Program Officer, Capacity and Reliability

Rachel Taylor, Senior Editorial Assistant

Dean Trackman, Managing Editor

Connie Woldu, Administrative Coordinator

\section{ACKNOWLEDGMENTS}

This work was sponsored by the Federal Highway Administration in cooperation with the American Association of State Highway and Transportation Officials. It was conducted in the second Strategic Highway Research Program, which is administered by the Transportation Research Board of the National Academies. The project was managed by Abdelmename Hedhli, Visiting Professional for SHRP 2 Reliability. The research team would like to especially thank William Hyman for his guidance and counsel and Ralph Hessian for his early shepherding of the project. It is also important to thank the many individuals at the departments of transportation in California, Virginia, and Georgia whose assistance made it possible to do the field-based assessments. 


\section{F
Abdelmename Hedhli, SHRP 2 Visiting Professional, Reliability}

Travel time reliability can be defined as consistency of travel time over time. The primary goal of SHRP 2 Reliability research is to improve the reliability of highway travel times by mitigating the effects of events that cause travel times to fluctuate unpredictably. Through this research, seven sources of unreliable travel times have been identified: traffic incidents, work zones, demand fluctuations, special events, traffic control devices, weather, and inadequate base capacity.

This report documents the research of the L02 project, Establishing Monitoring Programs for Travel Time Reliability. The main work product from the project is the Guide to Establishing Monitoring Programs for Travel Time Reliability. The Guide discusses how to develop and use a travel time reliability monitoring system (TTRMS). (Accompanying the Guide is a brief, stand-alone document that provides suggestions for communicating information about time travel reliability using maps, figures, and tables. The document, Handbook for Communicating Travel Time Reliability Through Graphics and Tables, and the Guide are available at http://www.trb.org/Main/Blurbs/168764.aspx.) The purpose of this report is to describe the process that led to the development of the Guide and the Handbook.

A TTRMS can help operating agencies monitor system performance, understand the impacts of the various factors that influence travel time, and provide credible information to the system users about what travel time reliability to expect. With this information, operating agencies can make better decisions about what actions to take to help improve reliability. At the time this research was performed, most transportation agencies did not have these capabilities.

One of the most important findings of the L02 project is that reliability is best described by creating holistic pictures such as probability density functions (PDFs) and their associated cumulative density functions (CDFs). Thus, rather than characterize reliability in mathematical terms, graphs of the PDFs and CDFs make it easy for one to visualize reliability and various regimes consisting of different combinations of congestion levels and types of nonrecurring events (e.g., incidents, weather, and work zones).

The research began with a survey of the state of the art and state of the practice in travel time reliability monitoring systems worldwide. The team then focused on the TTRMS and its primary functions listed above. Finally, the team sought to validate the TTRMS concept by building prototypes of elements of the TTRMS in five locations: San Diego, Sacramento and Lake Tahoe, Northern Virginia, Atlanta, and New York City. Systems that can be used to develop distributions of travel times over long periods, for both highway segments and travel from origins to destinations, will be the foundation for analysis and decisions that improve reliability. 







$\begin{aligned} 88 & \text { CHAPTER } 7 \text { Case Studies } \\ 88 & \text { San Diego, California } \\ 91 & \text { Northern Virginia } \\ 93 & \text { Sacramento-Lake Tahoe, California } \\ 95 & \text { Atlanta, Georgia } \\ 97 & \text { New York and New Jersey } \\ 99 & \text { Berkeley Highway Laboratory } \\ 100 & \text { Use Cases } \\ 102 & \text { CHAPTER } 8 \text { Summary and Conclusions }\end{aligned}$

105 References 


\section{Executive Summary}

Within the second Strategic Highway Research Program (SHRP 2), Project L02 focused on creating a suite of methods by which transportation agencies could monitor and evaluate travel time reliability. Creation of the methods also produced an improved understanding of why and how travel times vary and the factors that create that variation.

This final report provides a brief narrative about what reliability is and how it can be measured and analyzed. A general finding is that reliability is best described by creating holistic pictures like probability density functions (PDFs) and their associated cumulative density functions (CDFs). PDFs are helpful for identifying multimodality or the existence of multiple operating conditions within the data being examined (Barkley et al. 2012; Guo et al. 2010; Fraley and Raftery 2009). CDFs are helpful for seeing if progress is being made in making a system more reliable or for comparing the reliability of one system against another.

A survey of the state of the art and state of the practice in travel time reliability monitoring systems (TTRMSs) worldwide guided the development of the methods. The survey showed that Europe and Asia were slightly ahead of the United States at the time the project started. A second survey among potential future users of the monitoring system guided its functional features. The potential users included various groups: (1) system administrators and their staffs, (2) highway system operators, (3) transit system operators, (4) freight service providers, (5) highway system users, (6) transit system users, and (7) freight system users. Each group of users had its own needs, with consistency being evident among the system operators (Groups 1,2,3, and 4) and system users (Groups 5, 6, and 7). The findings from the second survey were coalesced into a set of use cases that became the driving force behind the system's functional specifications.

One of the project's main products is the L02 Guide to Establishing Monitoring Programs for Travel Time Reliability, which describes how an agency should develop and use a TTRMS. The monitoring system is not intended to stand alone. Rather, it is intended to work with an existing traffic management system. The Guide follows the block diagram presented in Figure ES.1 to describe a TTRMS. Each module is shown as a box, and the inputs and outputs are shown as circles.

The three major modules of the monitoring system are a data manager, a computational engine, and a report generator. The data manager assembles incoming information from traffic sensors and other systems, such as weather data feeds and incident reporting systems, and places them in a database that is ready for analysis as "cleaned data." The computational engine works off the cleaned data to prepare pictures of the system's reliability: when it is reli-

able, when it is not, to what extent, under what conditions, and so forth. In Figure ES.1 this reliability is illustrated by "regime TT-PDFs" (i.e., travel time PDFs). The report generator responds to inquiries from users (system managers or travelers) and uses the computation engine to analyze the data and provide information that can then be presented to the inquirer or decision maker. 


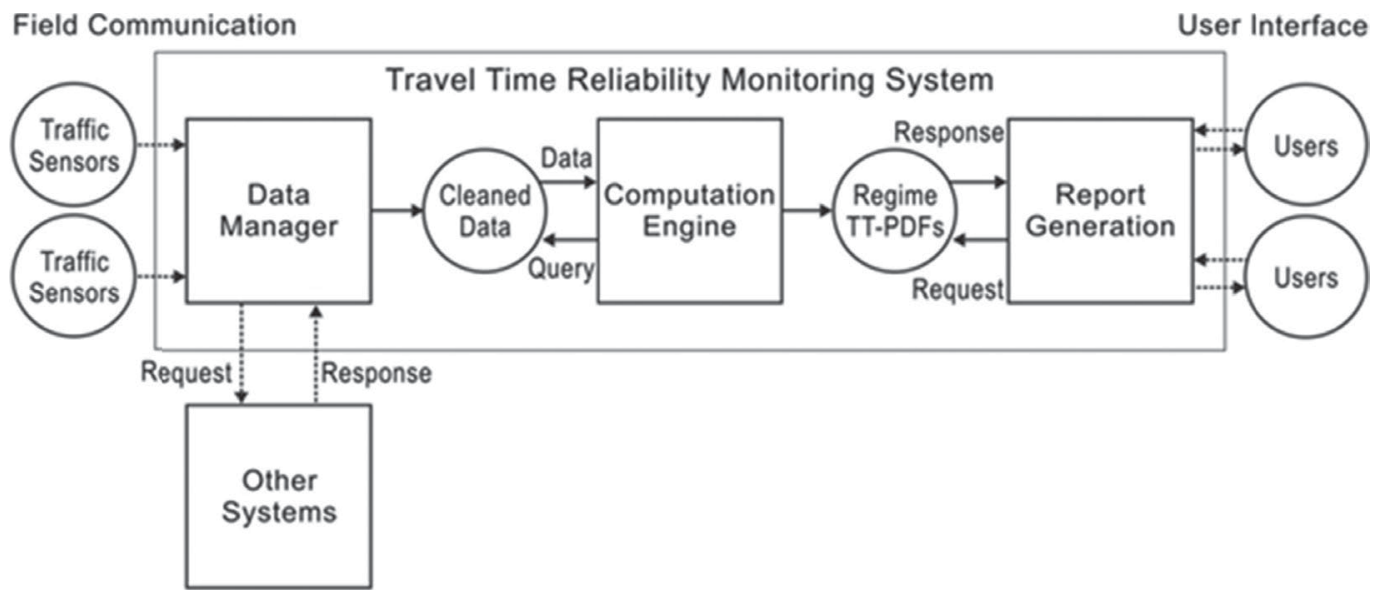

\section{Figure ES.1. Reliability monitoring system overview, with boxes for modules and circles for inputs and outputs.}

The Guide includes an executive summary, which gives agency managers a description of what a TTRMS is, why it is valuable, and how it can be used; and five chapters that describe the monitoring system:

- Chapter 1 (Introduction) provides an overview of travel time reliability.

- Chapter 2 (Data Collection and Management) discusses the types and application of various types of sensors, the management of data from those sensors, and the integration of data from other systems that provide input on sources of unreliability (e.g., weather, incidents). This Guide chapter addresses the left side of the diagram in Figure ES.1 and includes traffic sensors, other systems, and the data manager.

- Chapter 3 (Computational Methods) describes how PDFs can be derived from the variety of data sources. This represents the center part of the diagram in Figure ES.1 and includes the process of generating TT-PDFs that can be used to derive a variety of reports for users.

- Chapter 4 (Applications) provides five real-world case studies that were conducted as part of the project, as well as a set of use cases that show how the methods can be applied.

- Chapter 5 (Summary) concludes with a beginning-to-end discussion about how the Guide indicates travel time reliability should be analyzed under various conditions.

The Guide is supplemented by four appendices that provide additional detail to support the development and application of travel time monitoring systems:

- Appendix A (Monitoring System Architecture) presents examples of detailed data structures for the organization of various data sources. This appendix provides supporting detail for Chapter 2 of the Guide.

- Appendix B (Methodological Details) presents detailed discussions of the analytical methods that can be used to calculate travel time reliability measures from a variety of input sources. This document provides supporting detail for Chapter 3 of the Guide.

- Appendix C (Case Studies) presents a series of detailed case studies that explore various aspects of the Guide, including system architecture, analysis of recurrent and nonrecurring sources of congestion, and the application of a variety of use cases. This appendix provides supporting detail for Chapter 4 of the Guide.

- Appendix D (Use Case Analyses) illustrates the application of a variety of use cases for a TTRMS and provides supporting detail for Chapter 4 of the Guide.

Travel time reliability has been regarded by the L02 team as the absence of variability. That is to say, a system, segment, or route has reliable travel times if it has consistent travel times for 


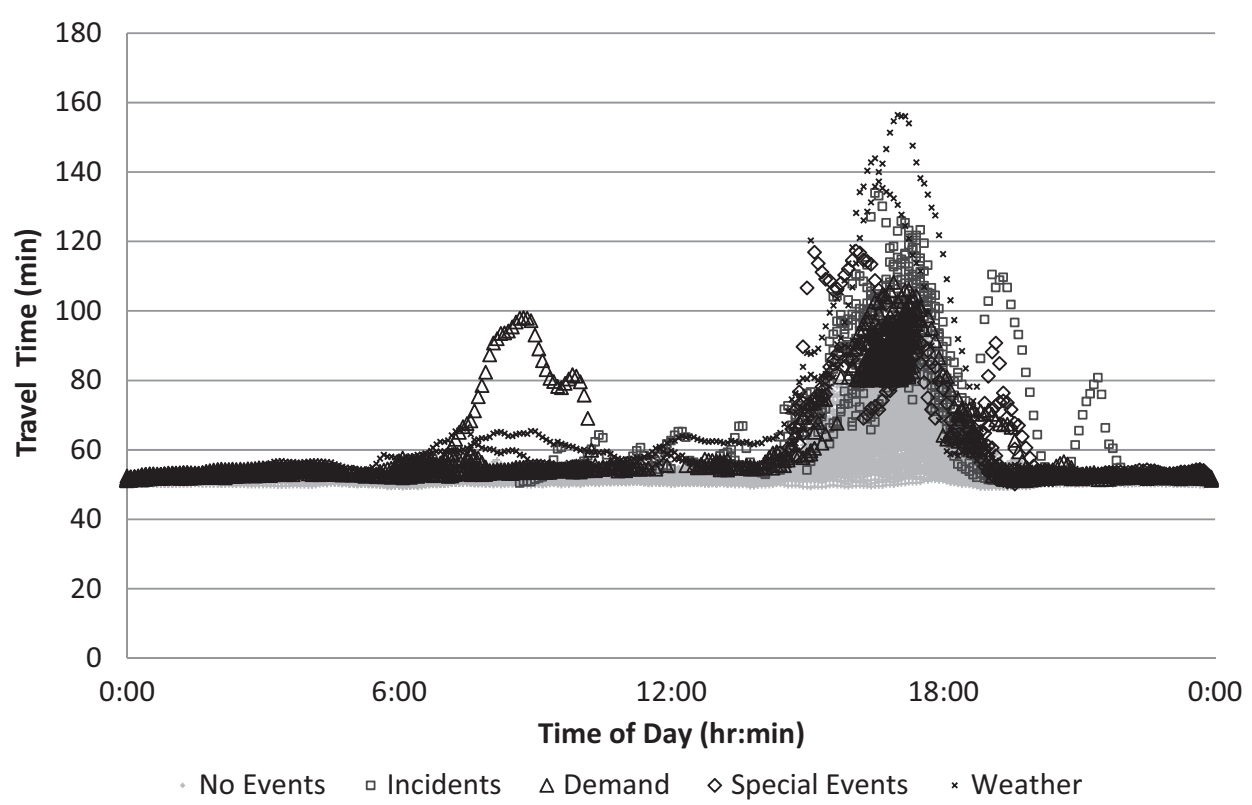

Figure ES.2. Variations in travel times by time of day across a year. Color figure available online at www.trb.org/Main/Blurbs/168765.aspx.

a given operating condition every time that condition arises. Figure ES.2 shows average travel times on workdays during 2011 for a route on I-5 in San Diego, California. It is clear that the travel times on this route are not always the same; unfortunately, the system is not completely reliable. Not only does the level of congestion have an effect, as shown by the data points for the "no events" condition, but nonrecurring events also have impacts.

Figure ES.2 is valuable for gaining an understanding of how the system is operating, but it does not provide a summary of that performance, nor does it provide helpful information in guiding system managers toward actions that might be taken to improve the facility's performance.

Through CDFs, the monitoring system takes the data displayed in Figure ES.2 and summarizes them in a fashion that makes the performance of the facility clear and helps stimulate ideas for mitigating actions. Figure ES.3 shows the CDFs for the different operating conditions that existed on a route on I-8 westbound during several months in 2011. It shows the cumulative distributions for the travel times during several operating regimes. The distributions show the percentage of time for each operating condition for which the travel time was a particular value or shorter. For example, when traffic incidents occur during heavy (recurrent) congestion, one-half (50\%) of the travel rates (in seconds per mile) are up to $70 \mathrm{~s} / \mathrm{mile}$. That is, $50 \%$ of the travel rates are this long or smaller. The 90th percentile travel rate is $110 \mathrm{~s} / \mathrm{mi}$, or, to put it another way, nine out of every 10 vehicles is traveling at that rate or faster.

With a little experience, an operator can learn how to effectively compare the distributions. For example, he or she can compare the distribution for high recurrent congestion and traffic incidents with high recurrent congestion without incidents. Without incidents, $50 \%$ of the vehicles are traveling at $58 \mathrm{~s} / \mathrm{mi}$ instead of $70 \mathrm{~s} / \mathrm{mi}$ - considerably faster. And at the 90th percentile, the difference is even more dramatic: $65 \mathrm{~s} / \mathrm{mi}$ versus $110 \mathrm{~s} / \mathrm{mi}$. Not only does this comparison indicate that the difference between the two conditions is dramatic, but it also suggests that taking action to mitigate these impacts would produce significant benefits in terms of improving reliability. The mitigating actions would be intended to cause the travel times (or travel rates) during incidents to get much closer to those when there are no incidents. Moreover, after the mitigating actions have been taken, a TTRMS can show how reliability improved.

To fulfill its mission as a decision support tool, the monitoring system needs to do four things, as illustrated by Figure ES.4. 


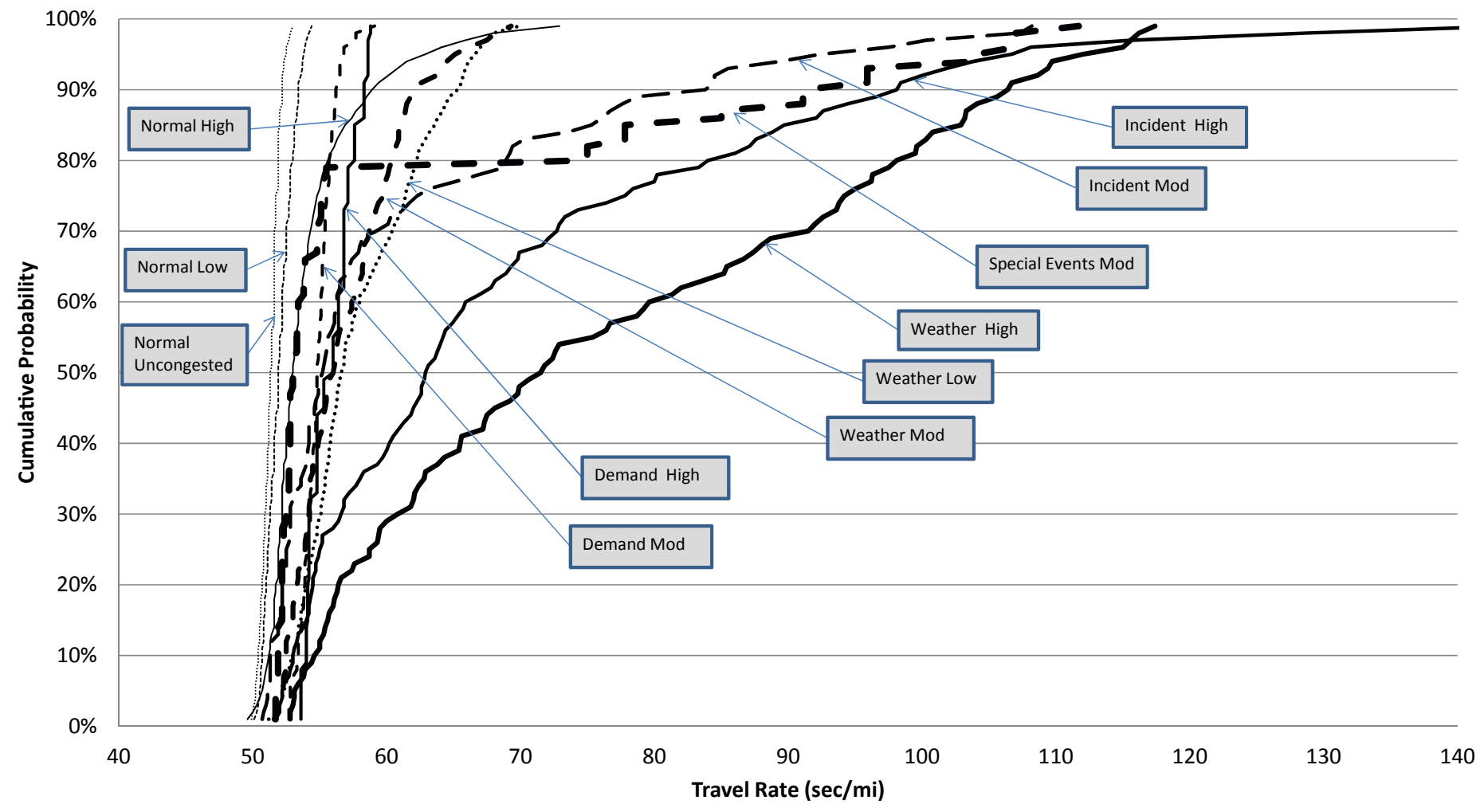

Figure ES.3. Effect on travel rates of congestion and nonrecurring incidents.

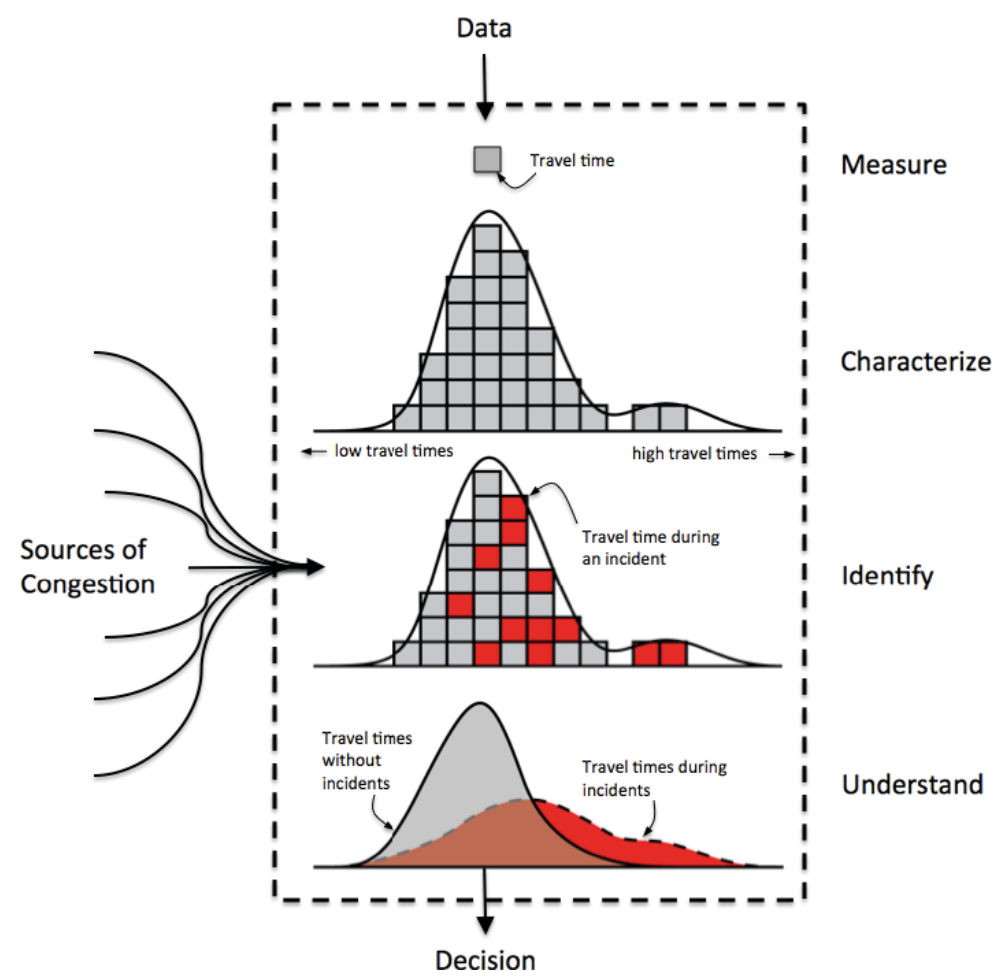

Figure ES.4. Information flow in a TTRMS. 
First, the monitoring system needs to measure travel times. This is a complex technical task due to the variability of traveler behavior and the plethora of types of measurement sensors. Correctly measuring travel times along a given route requires a great deal of systems development effort and statistical knowledge. The Guide serves as a primer on how to measure travel times effectively using available technologies and statistical techniques. Measuring an individual travel time is the foundational unit of analysis for reliability monitoring.

Second, the monitoring system needs to characterize the reliability of a given system. This is the process of taking a set of measured travel times and assembling them into a statistical model of the behavior of a given segment or route. The statistical paradigm outlined in the Guide uses PDFs to characterize the performance of a given segment or route, usually specific to a particular operating regime (a combination of congestion level and nonrecurring event). The Guide gives specific advice on the statistical decisions required to effectively characterize travel times. Characterizing the reliability of a segment or route is fundamental to making good decisions about how to improve the performance of that segment or route.

Third, the monitoring system needs to identify the sources of unreliability. Once the reliability of a segment or route has been characterized, transportation managers need to understand what caused the unreliability (and how to correct it). The Guide follows the causal list used by the Federal Highway Administration to describe why congestion arises, breaking these sources into the seven major influencing factors (two internal and five external) described previously (Federal Highway Administration 2008). It discusses how to pull in data for these influencing factors and effectively fuse them with the travel time data generated in previous steps. Identifying the travel times affected by these sources of congestion is required preparation for understanding system reliability.

Finally, the monitoring system needs to help operators understand the impact of these sources of unreliability on the system. This final step in turning raw data into actionable decisions requires both quantitative and qualitative methodologies: operators need clear visualizations of data, as well as quantifications. This dual approach supports both data discovery and final decision making about a given route. Understanding reliability is the key to good decision making about improving system reliability.

A monitoring system that accurately and consistently executes these four steps can be a powerful tool for traffic management. It enables decision makers to understand how much of their delay is due to unreliability and prompts ideas about how to mitigate that delay. For example, should a freeway operator deploy more service patrol vehicles (to clear incidents more quickly) or focus efforts on coordinating special event traffic (to reduce delay from stadium access)? A reliability monitoring system, as outlined in the Guide, can help an operator understand which of these activities is worth the investment, and what the payoff might be. Such systems add a new, powerful, practical traffic management tool to the system operators' arsenal. 


\section{Introduction}

Within the second Strategic Highway Research Program (SHRP 2), Project L02 focused on creating a suite of methods by which transportation agencies could monitor and evaluate travel time reliability. Creation of the methods also produced an improved understanding of why and how travel times vary and the factors that create that variation.

A spectrum of future users helped shape the system, including system operators (who want to make travel times more reliable) and system users, like the traveling public (who want to avoid travel delays and make sure they arrive at their destinations on time).

\section{Project Context}

Reliability is one of four focus areas that comprise SHRP 2, authorized by Congress in 2006. The purpose of the Reliability focus area is to "reduce congestion and improve travel time reliability through incident management, response, and mitigation" (Reliability Focus Area Overview 2009). Four thematic groupings have been established under this focus area:

- Data, metrics, analysis, and decision support;

- Institutional change, human behavior, and resource needs;

- Incorporating reliability into planning, programming, and design; and

- Fostering innovation to improve travel time reliability.

L02 was part of the first theme, providing guidance to operating agencies about how they can put better measurement methods into practice and understand the relationship that travel time reliability has to the seven major sources of nonrecurring congestion (Cambridge Systematics et al. 2003; Federal Highway Administration 2008):

- Traffic incidents;

- Weather;

- Work zones;
- Fluctuations in demand;

- Special events;

- Traffic control devices; and

- Inadequate base capacity.

\section{Work Products}

The primary work product from L02 is the Guide to Establishing Monitoring Programs for Travel Time Reliability, which is intended to be used by operating agencies to create, operate, and maintain a travel time reliability monitoring system (TTRMS). Accompanying the Guide is a brief, stand-alone document that provides suggestions for communicating information about time travel reliability using maps, figures, and tables. The document, Handbook for Communicating Travel Time Reliability Through Graphics and Tables, and the Guide are not included as part of this final report; they are available at http://www.trb.org/Main/Blurbs/168764.aspx.

The purpose of the final report is to describe the process that led to the development of the Guide: the steps that were taken and the materials that were developed. The information is presented in an order that makes it clear why a TTRMS is designed the way it is. The next section provides an overview of the study and a guide to the final report.

\section{Report Overview}

Chapter 1 provides a brief narrative about what reliability is and how it can be measured and analyzed. The description emerges from the findings of researchers worldwide, as well as the developments from this project. A general finding is that reliability is best described by creating holistic pictures like probability density functions (PDFs) and their associated cumulative density functions (CDFs) to portray the reliability performance of segments, routes, subnetworks, or systems. Tracking single values does not seem to be sufficient. This discussion is intended to help the reader understand 
why the TTRMS needed to be designed (as reflected in the functional specifications) as it was, what data it needed to collect, and how it needed to be prepared to respond to user inquiries. After reading this section, readers should find the remaining sections to be logical, intuitive extensions of the ideas presented.

Chapter 2 reports the findings from a survey of the state of the art and state of the practice in TTRMSs worldwide. It shows that Europe (Transport Research Centre 2010) and Asia had made substantial progress, while the systems in the United States were closer to being in their infancy than being mature, and that almost all of the systems in the United States were focused on reporting single-value statistical measures like the buffer time index. In addition, Chapter 2 summarizes a second survey conducted to determine the needs of TTRMS users. The needs seemed to be similar within specific groups: (1) system administrators and their staffs, (2) highway system operators, (3) transit system operators, (4) freight service providers, (5) highway system users, (6) transit system users, and (7) freight system users. Each group had its own needs, with consistency being evident among the system operators (Groups 1, 2, 3, and 4) and the system users (Groups 5, 6, and 7). The findings from the survey were coalesced into a set of use cases that became the drivers for the TTRMS functional specifications.

Chapter 3 describes the resulting functional specifications that were developed for the TTRMS. They were developed in response to the cases that emerged from the second survey (described in Chapter 2) and reflect an advance in the state of the art that should serve the user community for several decades. The specifications focused on three main functions that the TTRMS needed to be able to perform: (1) data collection, assembly, and quality control; (2) computation of basic reliability descriptions for segments and routes in the network; and (3) responses to user requests.

Chapter 4 discusses data collection and quality enhancement activities that need to be part of a TTRMS. Most of this material is in the Guide and is not repeated to avoid redundancy. The main point is that high-quality data must be available for a TTRMS to work effectively. Careful quality control on the incoming data is important. Imputation methods have value, and careful decisions are needed about how much data to archive.

Chapter 5 analyzes recommended sensor spacing and sampling rates. A method that focuses on accuracy in reproducing the actual vehicle trajectories reveals that half-mile and quarter-mile spacings have great value, and sampling rates near 30 seconds to a minute are very valuable.

Chapter 6 presents the suite of methods that were developed for the TTRMS so that it could create travel time reliability information from the data assembled. The main objective is to create PDFs for highway segments, and from these, density functions for routes. Four types of data feeds are given heavy emphasis: single-loop detectors, double-loop detectors, automated vehicle identification-equipped vehicles, and automated vehicle location-equipped vehicles.

Chapter 7 summarizes the validation efforts conducted to ensure that the TTRMS was hitting the right targets. The main aspect of this validation was a set of five case studies of TTRMS prototypes in San Diego, California; SacramentoLake Tahoe, California; Northern Virginia; Atlanta, Georgia; and New York and New Jersey. Each case study took advantage of locally available data feeds and data sources. A secondary product of the validation was a set of use case studies that demonstrated that the TTRMS could respond to all the various inquiries identified by the user community surveys.

Chapter 8 summarizes the findings and the lessons learned from the project. It is clear that although much has been learned from the L02 effort, many unanswered questions still need to be addressed.

\section{Travel Time Reliability}

This section provides an overview of the definition of travel time reliability and how it has been measured. Fundamental ways to measure travel time reliability are introduced. The intent of the discussion is to prepare the reader for the material that follows in the remaining sections of the report.

\section{Concepts}

Travel time reliability can be thought of as the absence of variability in travel times (Transport Research Centre 2010). If a system is reliable, people know how long it will take them to make a trip, regardless of when they want to leave. This reliability might be unconditional or dependent on something travelers can observe, like the weather conditions. If a freeway is perfectly reliable, then its travel time is always the same. It is either always the same under similar conditions, or more ideally, it is the same regardless of the conditions that exist. These ideas are similar to ideas about vehicle reliability. If a vehicle always starts when the key is turned on, then it starts reliably. Similarly, when a road is dry, its performance is always the same. When the road is wet or snow covered, the performance is slightly different, but it is always the same under similar conditions.

A difference exists between the way reliability was originally defined by Ebeling (1997) and the manner in which the term is presently being used in the transportation context. As Elefteriadou and Ciu (2007) point out, Ebeling (1997) suggested that reliability should be defined as "the probability that a component or system will perform a required function for a given period of time when used under stated operating conditions. It is the probability of a non-failure over time." 
This is slightly different from the idea of consistency, which has to do with the absence of variability.

In the transportation network context, Ebeling's definition implies that the system would be deemed reliable (formally speaking) if each traveler or shipper experienced actual times of arrival (ATA) that matched desired times of arrival (DTA) within some window, as shown in Figure 1.1. Depending on the utility (disutility) function that pertained to the trip, in some cases the difference between the ATA and DTA would be extremely important; in other cases, less so. For example, the disutility function for a trip to catch a plane would be sharply defined, but the one for a trip to the store might be less so.

If the ATA lies outside the DTA window, especially if the ATA is after the DTA, a reliable trip was not completed. Hence, the transportation system is reliable, technically speaking, if the ATAs all lie within their DTA window. Otherwise, the system has failed or not performed reliably. As Elefteriadou and Ciu (2007) point out, such a definition of reliability becomes well-defined.

In a more general sense, the reliability of the system can be measured using utility theory, as described by Hansson (2005) and discussed by many researchers, including Vickrey (1969), Lam and Small (2001), Noland and Small (1995), and Bates et al. (2001). Utility (of the trip) is maximized if the ATA is inside the DTA window. Conversely, disutility is greater if the ATA lies outside the DTA window; the aggregate disutility for all trips among all users is the "societal cost" of the system's unreliability. The function that evaluates the disutility may be symmetric or asymmetric depending on the situation, as shown in Figure 1.1b. Truckers incur significant penalties if they are either late or early in delivering shipments to the receivers. Individual travelers can be late for appointments or miss the opportunity to insert additional tasks like stopping for coffee or sleeping later if they are early.

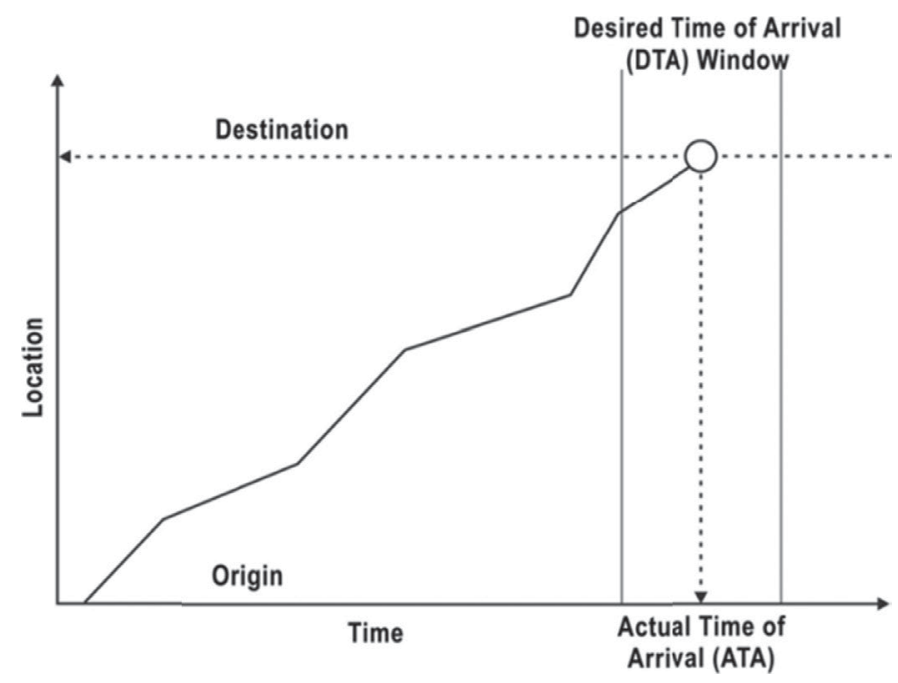

(a)
If the DTA windows for trips were known today, it would be possible to assess the system reliability on the basis of the percentage of ATAs that fall within their DTA windows. This would be a useful metric both for the entities making the trips and the organizations providing the service (e.g., the transportation management center [TMC] or transit system operator). The aggregate disutility could also be computed by summing the disutility values for each trip. Obviously, this world does not presently exist.

What can be observed today, at least in part, are travel times on segments and routes in the network. Some TMCs can monitor probes (vehicles equipped with tags) in areas where toll roads exist, and others can generate speed distributions at specific point locations in the network where sensors (speed traps) are installed.

\section{Implementable Ideas}

To implement these ideas, a TTRMS can establish desired travel times, or better yet, desired travel rates (DTRs) in seconds per mile so that the length of the facilities does not interfere with performance levels to be achieved on the segments and routes, consistent with Ebeling (1997). These DTRs can be dependent on the regime under which the system is operating (combination of the influencing factors), and they can be adjusted over time as the network conditions change (e.g., as demand grows or improvements are made).

A segment or route can be deemed as performing reliably if its actual travel rate (ATR) lies within the acceptable DTR window given the regime under which the segment or route is operating. The TMC team can monitor the number of segments or routes whose ATR lies within the DTR window; they can see how that number varies based on the network,

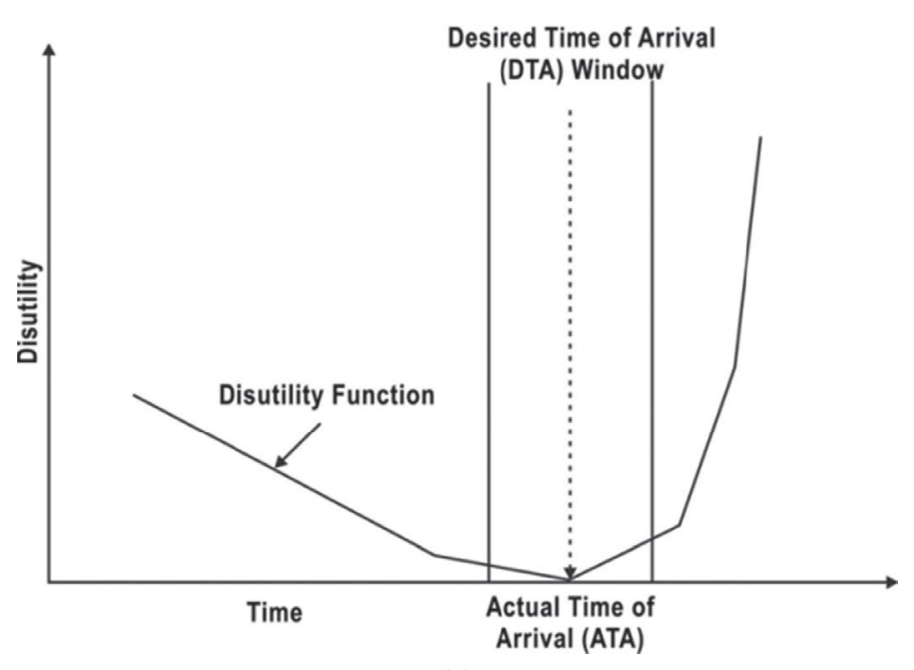

(b)

Figure 1.1. Basic reliability concepts: (a) DTA and ATA and (b) associated disutility functions. 
segment, or route operating conditions (e.g., an incident during high congestion); and actions can be identified to increase the number of segments or routes whose ATR is within their DTR window.

This paradigm can be extended to the system users. Trips can be considered successful if their ATR falls within an allowable DTR window based on the conditions under which the trip was made. Reliability can be measured by the percentage of trips whose ATR fall within the allowable DTR window. By extension, the aggregate disutility experienced by the travelers or shippers can be assessed, in principle, using disutility functions that compare the ATRs one at a time with their corresponding DTRs and then sum the results.

Service providers want to see if different ways to operate the system would be likely to produce better alignment between the ATRs and the DTRs (or if capacity investments are needed). Naturally, this decision making is aimed at variance reduction and shifts in the mean values, either lower or higher, so that the requisite confidence interval objectives are met given the desired travel time windows.

Decisions made by the team using the TTRMS become similar to the mean-variance trade-off analyses so prevalent in financial planning (Maginn et al. 2007). In this instance, the trade-off is between minimizing the mean (or median) travel times, as in building new network links or adding capacity (to reduce the mean or median travel rates), versus taking actions like improving incident response or managing the impacts of weather (Wang et al. 2009, 2011; Leng et al. 2009; Hainen et al. 2012) better so that the variation in travel rates is reduced, getting more of the ATRs within their DTR windows.

\section{Reliability Measures}

Although many reliability measures are in popular use today, like the travel time index and the buffer time index, the project team found it most fruitful to measure and assess reliabilityactually consistency - through PDFs. They portray the entire distribution of travel times (or travel rates) that arise across time, among vehicles, or on some other basis (e.g., among seasons).

An example of a PDF with which almost everyone is familiar is exam scores, such as the scores received on qualifying exams like the professional engineer's exam. People are ranked according to their percentile position (90\% have lower scores; $10 \%$ have higher scores), and the objective is to be in a top percentile. These same ideas pertain to travel time reliability. The distribution of travel times is the performance metric that should be monitored, and performance improves when any or all of the percentile positions have lower travel times (or travel rates).

Probability distributions are often presented in one of three ways (Karr 1993). The first way is via a histogram, in which bar heights represent the relative frequency with which specific conditions pertain. Figure 1.2 shows histograms of travel times for bus Route 20 in San Diego during the midday peak for various operating conditions: normal, and when the system was affected by a special event, an incident, or high demand.

The second way is via a PDF. A PDF portrays the same information as a histogram except that the bar heights have been normalized so that their sum equals 1.0 or $100 \%$ (this is the same as the area under the PDF equaling 1.0). Figure 1.3 shows PDFs for I-8 in San Diego under three conditions. In the PDF, as with the histograms, it is possible to see that some travel times are more common than others and that the distribution of the travel times is different for the various operating conditions (Barkley et al. 2012; Guo et al. 2010; Fraley and Raftery 2009). The various common operating conditions are often called modes in a statistical sense, and the PDF helps the analyst to spot these various modes because they stand out as high points in the PDF.

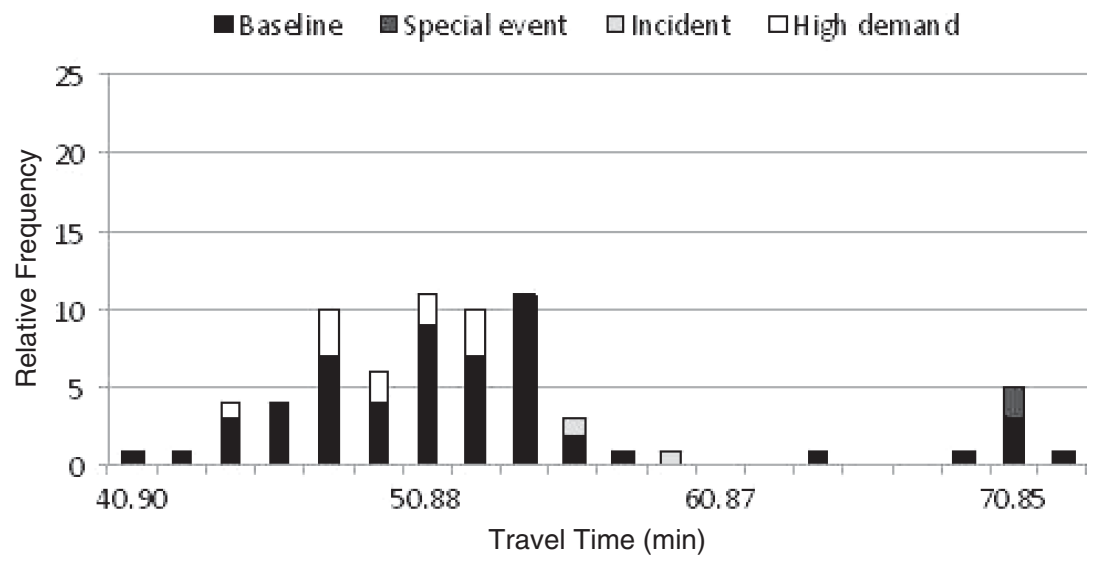

Figure 1.2. Example histograms for various event conditions. 

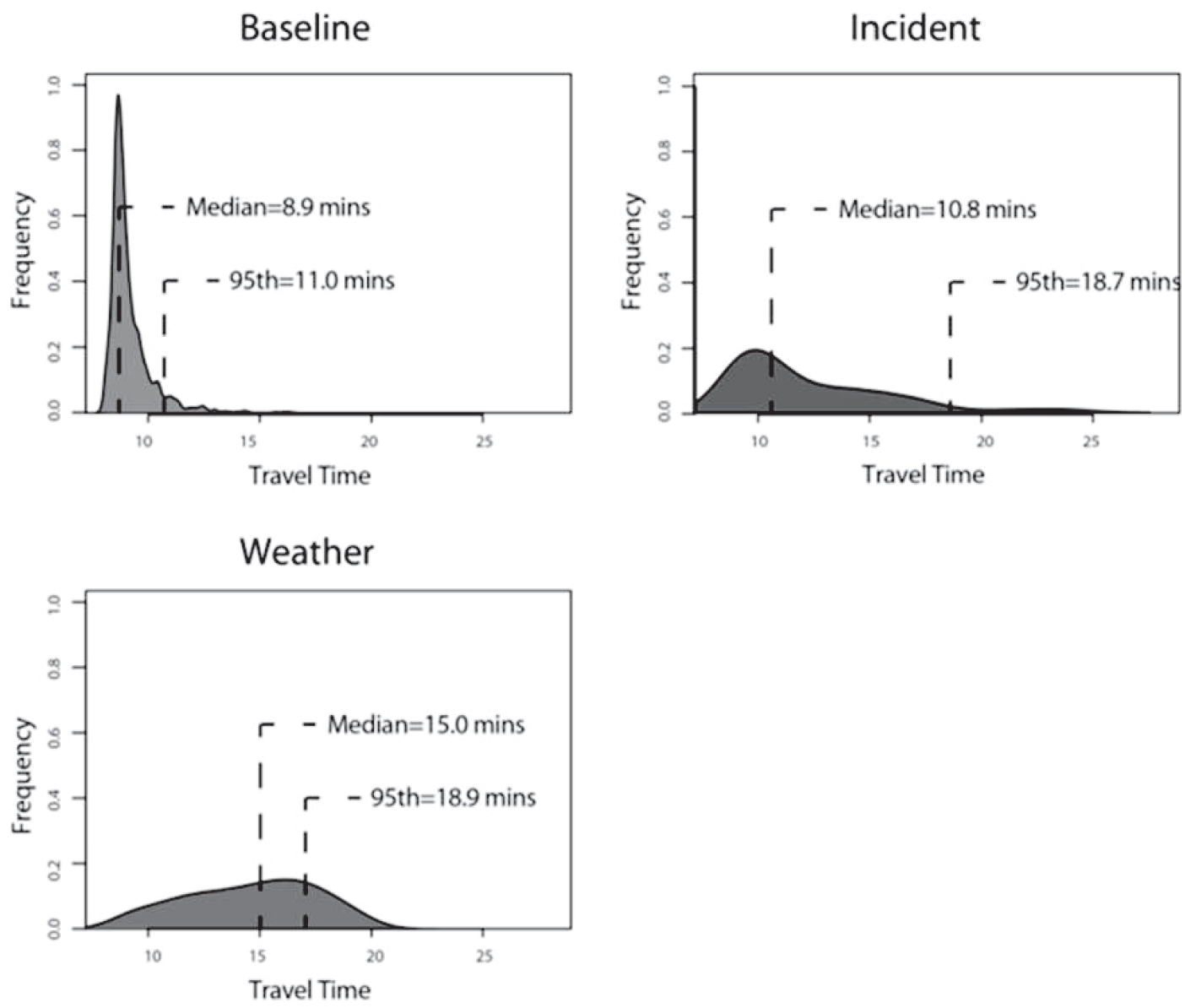

Figure 1.3. Example probability density functions (PDFs) for various event conditions.

The third way is via a CDF. A CDF is based on a PDF in that the value shown in the CDF at any point in the graph is the integral of the PDF up to that point (i.e., the area enclosed within the PDF above the horizontal axis). A property of the PDF is that its area sums to 1.0, which means the CDF ultimately rises to a maximum of 1.0. Figure 1.4 shows the CDFs for the various regimes associated with the performance of a different facility in San Diego (I-5 from the junction with I-805 to the exit for 8th Street in National City). As with the PDF, one can clearly see differences in the distribution of the travel rates (as compared to travel times) and that the distribution of rates for some regimes is much different than for others. It is through the use of these tools-the histogram, $\mathrm{PDF}$, and $\mathrm{CDF}$ - that the case studies and use cases reach conclusions about the influence of various factors on the travel times and travel rates.

Figures 1.3 and 1.4 show that the distributions of travel times are often multimodal. That is, in a statistical sense, they have several local maximums (or in the case of the CDFs, multiple inflection points at which the slope gets smaller and then larger again). For individual vehicle travel times this multimodality can arise when the observations come from two traffic streams, such as separate lanes for high-occupancy vehicles (HOVs) and non-HOV vehicles (or tagged and nontagged vehicles), or cars and trucks when the trucks have different speed limits, even when the data are collected at the same point in time. Another example is individual vehicle travel times for an arterial, on which some vehicles progress between traffic signals without stopping, but others do not. Multimodality can also arise when the data come from different operating conditions, as in a set of average travel times for the same 5-minute time slice across a year. In fact, multimodality should be expected. Absence of multimodality would indicate that the operating conditions do not matter; that is, the travel time is consistent regardless of incidents, the weather, and so forth. At least today, this is not the case.

Because the term mode is used in other ways in transportation, in this report the word regime is used instead of mode to describe these various operating conditions (or variations of a given condition). Moreover, common traffic engineering names (e.g., congested, uncongested, transition, incident, and weather) are used to describe these regimes. The regimes help enhance the quality of the PDFs. They keep the PDFs from 
TR-CDFs by Regime for the I-5 Route

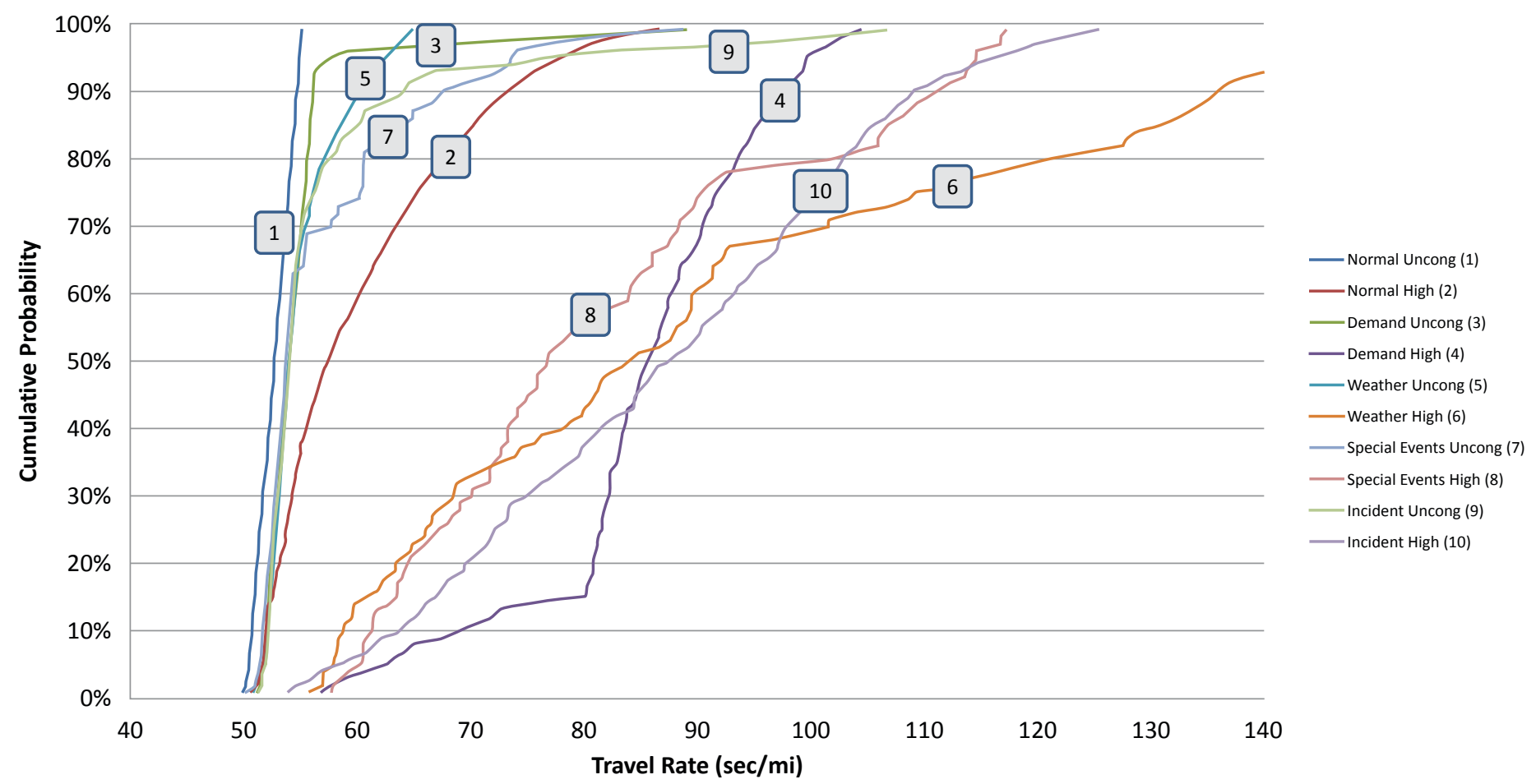

Figure 1.4. Example cumulative density functions (CDFs) under various regimes (operating conditions).

Color figure available online at www.trb.org/Main/Blurbs/168765.aspx.

being noisy, and they help maximize the incremental value derived from data acquired every day.

The last concept-and an important one-is that all the reliability metrics of interest can be derived from these PDFs. The PDFs completely describe the travel times or travel rates (travel times per unit distance). Hence, the typical metrics of interest for characterizing reliability—planning index, buffer index, average, median, 95th percentile, or others-can be computed on the basis of the PDFs. As a result, these PDFs, supplemented by ancillary information about the environment (e.g., weather, incidents) that exists (or will exist) in the time frame of the analysis, represent sufficient information to answer the questions about measuring reliability (see also Tu et al. 2008). 


\section{Survey of Existing Systems and User Needs}

This chapter presents two components of data gathering: a survey of existing travel time reliability monitoring systems (TTRMSs) and an assessment of user needs for information that might be produced by those systems.

\section{Survey of Existing Reliability Monitoring Systems}

One task in the overall project was to determine what reliability monitoring systems already existed worldwide, including in the United States. The results are current as of 2010. Of particular interest was the capability of these systems to monitor travel times and assess reliability and how, and to what extent, this information is disseminated to various constituencies. Also of interest was (1) plans for expanding such systems, (2) the manner in which the needs of the end users are solicited and incorporated into the plans for future enhancements, and (3) the ways in which reliability data are being used to make operational, tactical, and strategic decisions about managing the performance of the system (or why this is not occurring).

It quickly became apparent that Europe and Asia were somewhat ahead of the United States in addressing the issue of travel time reliability monitoring. A good example of this from Europe is the Transport Research Centre (2010) study on improving reliability on surface transportation networks.

The top 25 major U.S. metropolitan areas were studied. Travel monitoring websites were visited to see what information is currently provided related to travel times and travel time reliability. Based on this investigation, a list of commercial service providers was created that included providers that operate behind the scenes and those that convey information to end users.

\section{Findings}

The survey showed that the collection, processing, and dissemination of traffic content have become a sizable business over the past decade. As the focus of this task report is on how travel time and travel time reliability are measured and conveyed by traffic monitoring systems, a brief overview is given to orient the reader to the traffic content business world.

Listed in Table 2.1 are seven types of data collected for use in traffic content applications. Multiple companies collect incident data so they can calculate delays (due to demand exceeding capacity), disseminate delay information, and offer drivers alternate routes. One company, TransGuide, explicitly records the number of nonarriving vehicles that crossed an upstream data collection point but did not cross the downstream point of interest.

Available technology offers a variety of possible data collection technologies, everything from probe vehicles to video cameras to loop detectors, as shown in Tables 2.2 and 2.3. Some entities specialize in a single method of data collection. For instance, TRANSCOM, TrafficGauge, AirSage, SpeedInfo, and Traffax use tag readers, proprietary devices, cell phones, solar-powered radar sensors, and Bluetooth device media access control address readers, respectively. Inrix and Traffic.com collect transportation data via multiple methods and then carefully fuse the data to create a comprehensive picture of current and future traffic conditions.

Whether agencies implement a single method or multiple methods, there are approximately six basic steps that they can follow:

1. Decide on the raw data to collect (Data Set 1, Data Set 2, Data Set $n$ ).

2. Collect the data with sensors placed in the network. The sensors can be fixed, partially mobile, or fully mobile. The sensors can be owned outright, or sensor data can be bought from others or shared.

3. Record metadata (i.e., catalog information) on the sensor operations. This includes level of sensor quality, malfunctions, and level of (sensor) reliability. 
Table 2.1. Information Collected by Traffic Data Collection Companies

\begin{tabular}{|l|c|c|c|c|c|}
\hline $\begin{array}{l}\text { Type of Data } \\
\text { Collected }\end{array}$ & NavTeq $^{a}$ & Inrix $^{a}$ & TRANSCOM $^{b}$ & TransGuide $^{b}$ & TranStar $^{b}$ \\
\hline Speeds & & & $X$ & & \\
\hline Travel times & & & $X$ & $X$ & \\
\hline $\begin{array}{c}\text { Number of nonarriving } \\
\text { vehicles }\end{array}$ & $\mathrm{X}$ & & $\mathrm{X}$ & & \\
\hline Incident data & $\mathrm{X}$ & & $\mathrm{X}$ & & $\mathrm{X}$ \\
\hline $\begin{array}{c}\text { Construction and } \\
\text { work zone data }\end{array}$ & $\mathrm{X}$ & $\mathrm{X}$ & $\mathrm{X}$ & & $\mathrm{X}$ \\
\hline Event data & & & & \\
\hline Historical data & & & & \\
\hline
\end{tabular}

a Private company.

${ }^{b}$ Public agency or consortium.

4. Run algorithms that combine data, choose the most reliable pieces of data (when multiple ones exist), and impute data for spots that are missing or potentially erroneous.

5. Convert data into usable traffic information; augment with nontraffic information such as weather and parking.

6. Disseminate traffic information to users (e.g., sell to other companies, give to consumers).
Tables 2.4 and 2.5 show what information is disseminated and how it is disseminated, respectively. Everything from work zone information to weather updates is disseminated, as well as travel content. One challenge with reaching those who choose to drive is to convey enough detail about traffic conditions and route alternatives to enable drivers to make informed choices. Some companies convey general

Table 2.2. Data Collection Methods

\begin{tabular}{|c|c|c|c|c|c|c|}
\hline Data Collection Method & NavTeq $^{a}$ & Inrix ${ }^{a}$ & TRANSCOM $^{b}$ & TransGuide $^{b}$ & TranStar $^{b}$ & AirSage $^{a}$ \\
\hline \multicolumn{7}{|l|}{ Probe vehicles } \\
\hline E-ZPass tag readers & & & $x$ & & & \\
\hline GPS fleets & $x$ & $x$ & & & & \\
\hline Phone data (crowdsourcing) & $x$ & & & & & \\
\hline GPS enabled & & & & & & $\mathrm{x}$ \\
\hline Triangulation & & & & & & $x$ \\
\hline Bluetooth data & $x$ & & & & & \\
\hline Proprietary sensors & $x$ & & & & & \\
\hline Government sensors & $x$ & $X^{c}$ & & & & \\
\hline Incident data & $x$ & & & & & \\
\hline Event data & $x$ & & & & & \\
\hline Historical data & $x$ & $\mathrm{x}$ & & & & \\
\hline Highway-embedded sensors & & $x$ & & & & \\
\hline Video monitors and cameras & & $x$ & & $x$ & $x$ & \\
\hline FM radio stations & & $x$ & & & & \\
\hline Local traffic monitoring centers & & $x$ & & & & \\
\hline Speed sensors & & & & & $x$ & \\
\hline
\end{tabular}

Note: GPS = Global Positioning System.

a Private company.

${ }^{b}$ Public agency or consortium.

${ }^{c}$ Data collected via SmartDust network. 
Table 2.3. Data Collection by Select State DOTs

\begin{tabular}{|c|c|c|c|c|c|c|c|}
\hline \multirow[b]{2}{*}{ Data Collection Method } & \multicolumn{2}{|c|}{ Rural } & \multicolumn{2}{|c|}{ Midsized } & \multicolumn{3}{|c|}{ Large } \\
\hline & $\begin{array}{l}\text { WSDOT } \\
(1-90,1-5)\end{array}$ & $\begin{array}{l}\text { Caltrans } \\
\text { District } 3\end{array}$ & $\begin{array}{c}\text { Albany, } \\
\text { New York }\end{array}$ & $\begin{array}{c}\text { Orlando, } \\
\text { Florida }\end{array}$ & $\begin{array}{l}\text { Los Angeles, } \\
\text { California }\end{array}$ & $\begin{array}{c}\text { San Francisco, } \\
\text { California }\end{array}$ & $\begin{array}{l}\text { Atlanta, } \\
\text { Georgia }\end{array}$ \\
\hline \multicolumn{8}{|l|}{ Probe vehicles } \\
\hline Tag readers & & $x$ & $x$ & $x$ & & $x$ & \\
\hline GPS fleets & Snow plows & & & & & & \\
\hline Phone data & & & & & & $x$ & X (ending) \\
\hline Bluetooth data & & & & & & $x$ & \\
\hline Highway-embedded sensors & $x$ & $\begin{array}{l}\text { Loops and } \\
\text { WIM }\end{array}$ & $x$ & $\begin{array}{l}\text { Loops and } \\
\text { radar }\end{array}$ & $\begin{array}{l}\text { Loops and } \\
\text { WIM }\end{array}$ & Loops and WIM & \\
\hline Video monitors and cameras & & & & & & & $x$ \\
\hline Incident data & $x$ & & $x$ & $x$ & & & $x$ \\
\hline Event data & Weather & & $x$ & $x$ & & & $x$ \\
\hline
\end{tabular}

Source: Bureau of Transportation Statistics website (2010): http://www.rita.dot.gov/bts.

Note: DOT = department of transportation; WSDOT = Washington State DOT; WIM = weigh in motion .

Table 2.4. Types of Information Disseminated

\begin{tabular}{|l|c|c|c|c|c|}
\hline Type of Information & NavTeq & Inrix & TRANSCOM $^{b}$ & TransGuide $^{b}$ & TranStar $^{b}$ \\
\hline Speeds & $\mathrm{X}$ & & & & \\
\hline Spot speeds & & & & & \\
\hline Average speeds & & $\mathrm{X}$ & & & \\
\hline Travel times & & & $\mathrm{X}$ & & \\
\hline Origin-destination pairs & & & $\mathrm{X}$ & & \\
\hline Path & & & $\mathrm{X}$ & & \\
\hline Expected & & & & & $\mathrm{X}$ \\
\hline Average & & & & & \\
\hline Personalized updates & & & & & $\mathrm{X}$ \\
\hline Map data & $\mathrm{X}$ & $\mathrm{X}$ & & & $\mathrm{X}$ \\
\hline Incident data & $\mathrm{X}$ & $\mathrm{X}$ & $\mathrm{X}$ & $\mathrm{X}$ & $\mathrm{X}$ \\
\hline Construction and work zone data & $\mathrm{X}$ & & $\mathrm{X}$ & $\mathrm{X}$ & \\
\hline Congestion and flow data & $\mathrm{X}$ & $\mathrm{X}$ & & $\mathrm{X}$ & \\
\hline Weather data & & & & & $\mathrm{X}$ \\
\hline Real-time traffic data & & & & & $\mathrm{X}$ \\
\hline Historical data & & & & & \\
\hline Incident location & & & & \\
\hline Quickest route to incidentc & & & & \\
\hline Stalled vehicle location & & & & \\
\hline Privacompany & & & & \\
\hline
\end{tabular}

a Private company.

b Public agency or consortium.

c Issued to emergency personnel. 
Table 2.5. Methods of Information Dissemination

\begin{tabular}{|c|c|c|c|c|c|}
\hline Method of Dissemination & NavTeq $^{a}$ & Inrix ${ }^{a}$ & TRANSCOM $^{b}$ & TransGuide $^{b}$ & TranStar $^{b}$ \\
\hline Internet & $x$ & & $\mathrm{x}$ & $x$ & $x$ \\
\hline RSS feed & & & & & $x$ \\
\hline Twitter & & & & & $x$ \\
\hline \multicolumn{6}{|l|}{ E-mail } \\
\hline Cell phone and mobile alerts & & & & & $x$ \\
\hline Low-power television stations & & & & $\mathrm{x}$ & \\
\hline Highway advisory radio & & & & & $x$ \\
\hline Dynamic message signs, VMS & & & $\mathrm{x}$ & $x$ & $x$ \\
\hline $\mathrm{AM} / \mathrm{FM}$ radio & $\mathrm{x}$ & & & & \\
\hline Satellite radio & $x$ & & & & \\
\hline Broadcast and cable TV & $\mathrm{x}$ & & & & \\
\hline Wireless applications & $\mathrm{x}$ & & & & \\
\hline GPS navigation device for dynamic rerouting ${ }^{c}$ & & $\mathrm{x}$ & & & \\
\hline In-car service for dynamic rerouting ${ }^{d}$ & & $\mathrm{x}$ & & & \\
\hline
\end{tabular}

information about specific road segments, such as freeway links (e.g., a 5-minute delay between Exits 2 and 3), and others cater to individuals desiring information and guidance tailored to their needs (e.g., congestion ahead, take Exit 2, turn left on Main Street to avoid work zone).

Once a traffic content message is packaged, it can be delivered in a variety of ways, as shown in Table 2.5. The most common method is via an internet website. Several providers augment a website with mobile applications (e.g., Twitter, SMS text alerts sent to cell phones) and others, especially state or local DOTs, convey information directly on or near affected facilities (via variable message signs [VMS] and highway advisory radio). The most personalized type of information dissemination is guidance through navigation devices that offer real-time traffic updates. The following section covers detailed examples of traffic content dissemination using websites; however, much of this content can be conveyed using other methods discussed.

\section{User Interfaces}

Nearly every major metropolitan area in the United States has a travel time monitoring and reporting system. Although multiple communication means can disseminate reliability information (e.g., radio announcements, VMS, and smartphones), websites are commonly used, largely because of the amount of information that is communicated. Four or five highway-oriented traffic websites in a single metropoli$\tan$ area are common (and there may be additional public transportation websites). One of these is often maintained by the government and operated in affiliation with the local transportation management center (TMC). The others are mainly private sites maintained by service providers. At present these websites are generally difficult to find by using a general search engine like Google or Yahoo. The best way to find them is to go to the Federal Highway Administration (FHWA) website (http://www.fhwa.dot.gov/trafficinfo/ index.htm) and drill down through the subpages to find the website for the metropolitan area of interest.

Figure 2.1 shows the main map page for the Chicago, Illinois, area public traffic information website. Color-coded maps are common, with the colors depicting speeds, periodically updated, on individual highway segments. Incidents and construction areas are also almost always shown along with other significant landmarks, like airports.

The maps are sometimes supplemented by tables that depict travel times, speeds, and distances for the instrumented highways. Figure 2.2 shows tables that provide current travel time, average travel time, distance, and current average speed. The speeds and travel times currently come from point sensors. (See the Inrix discussion for more details about other sensors.) The level of congestion is also identified with a green, yellow, or red dot, except for the segments that are not instrumented. 


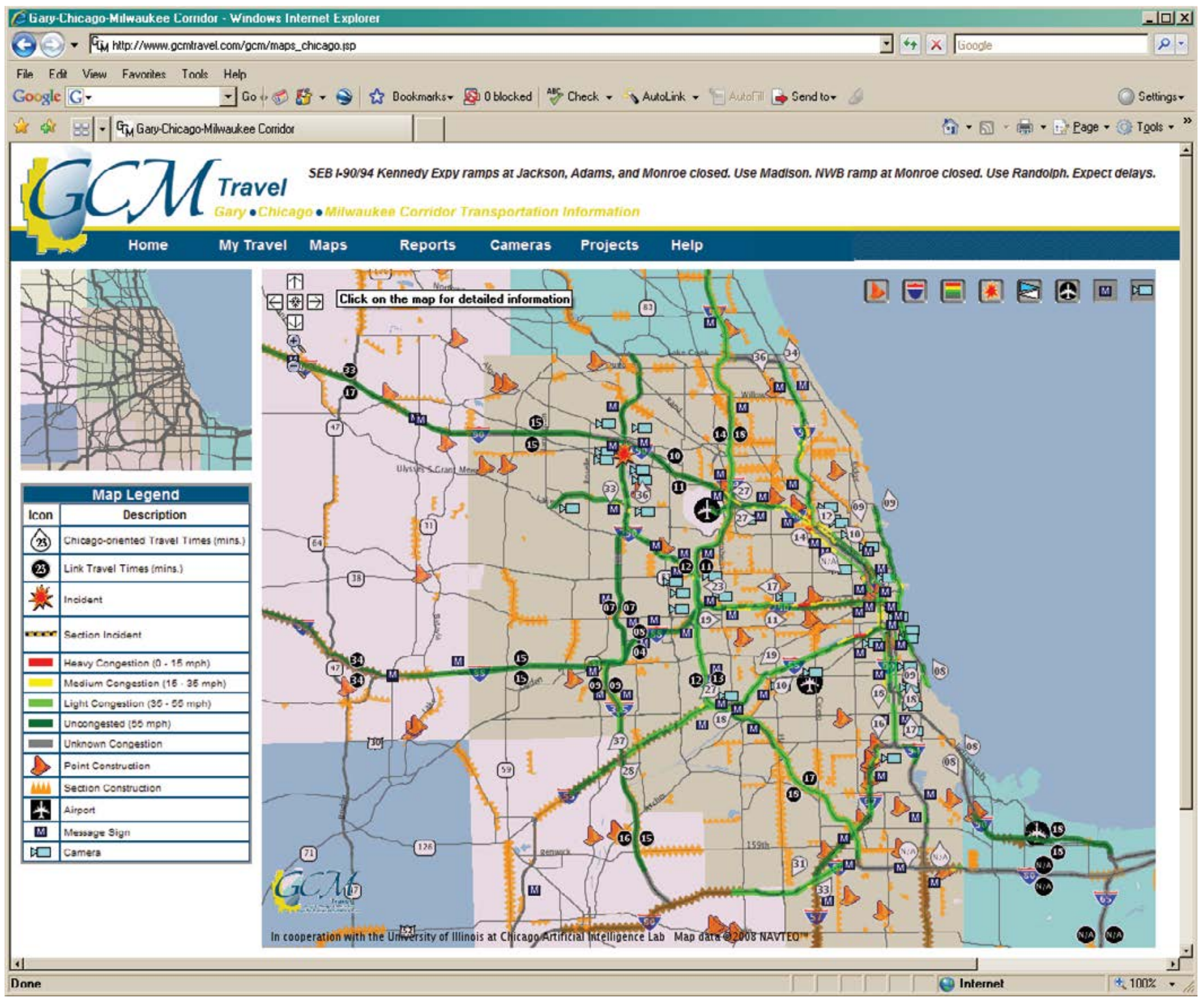

Source: Travel Midwest (2013).

Figure 2.1. Traffic speeds map for the greater Chicago area.

Color figure available online at www.trb.org/Main/Blurbs/168765.aspx.

For this Chicago website, drilling down into the average travel time field yields a more detailed picture, and one that is useful in terms of travel time reliability. Figure 2.3 shows that for this freeway segment and direction, the current travel time is 10.88 minutes, the average is 13.17 minutes, the difference is -2.29 minutes, and the average is based on 186 sample days. The time-of-day trend shows high travel times in the a.m. peak that start to rise about 5:00 a.m. and return to nominal nighttime, free-flow conditions by about 3:00 p.m. On the day the website was visited (July 28, 2009), unlike most days, there was a major spike in travel time at 2:30 p.m., most likely caused by an incident. The yellow band shows the normal range of travel times (apparently plus or minus one standard deviation, as indicated by the reference to $68 \%$ ), and the blue lines indicate travel times at free-flow speed $(55 \mathrm{mph})$, medium traffic congestion ( $35 \mathrm{mph}$ ), and heavy congestion (15 mph).

These graphs provide travel time reliability information, which is probably why they were created, but there is no evidence that they are being integrated into the travel time information presented in the higher-level maps. Nor is there a quick, easy, and obvious way to reach these reliability graphs from the travel time map.

Table 2.6 summarizes the characteristics of the travel time websites in each of the 25 largest metropolitan areas in the United States. Many of these areas have a website that 


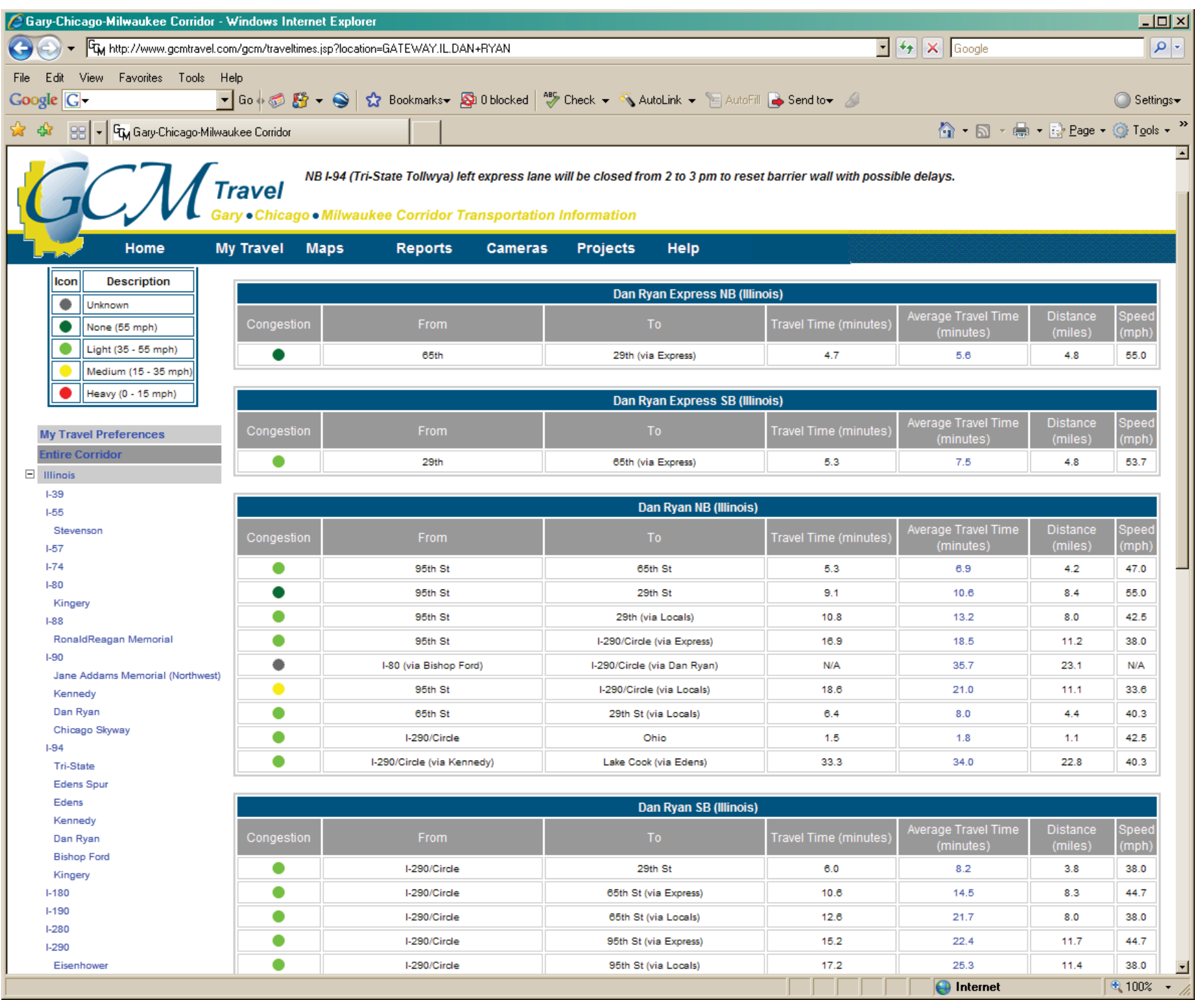

Source: Travel Midwest (2013).

Figure 2.2. Current congestion and travel times for a freeway segment.

Color figure available online at www.trb.org/Main/Blurbs/168765.aspx.

example, this is true for Chicago; Dallas-Fort Worth, Texas; Atlanta; and Detroit, Michigan. Others, including those in California and Texas, use a website shell that was created for statewide use. Some cities (e.g., Philadelphia and Pittsburgh, Pennsylvania; Washington, D.C.; and Sacramento) use commercial providers.

Some of these websites are partnerships, with one entity maintaining the website and another, in the background, doing the data assembly and data processing. A good example of such a partnership is found in New York City, where commercial vendor BeattheTraffic provides travel time information, and Inrix is responsible for assembling and processing the data behind the scenes.
A travel time website that directly addresses travel time reliability (i.e., consistency) is used in Seattle. Although the color-coded map of traffic conditions looks typical of most sites, as shown in Figure 2.4, there are lower levels that provide additional detail.

Clicking on the "Best time to leave" link on the left-hand side of the map shown in Figure 2.4 leads in two clicks to the tool shown in Figure 2.5. This interactive tool allows the traveler to specify an origin and a destination and receive an estimate of the time needed to ensure that for 19 out of 20 trips (95\% of the time) the destination will be reached on time. In the example window, a trip from Lynnwood to Bellevue is to be completed by 9:00 a.m. The website reports 


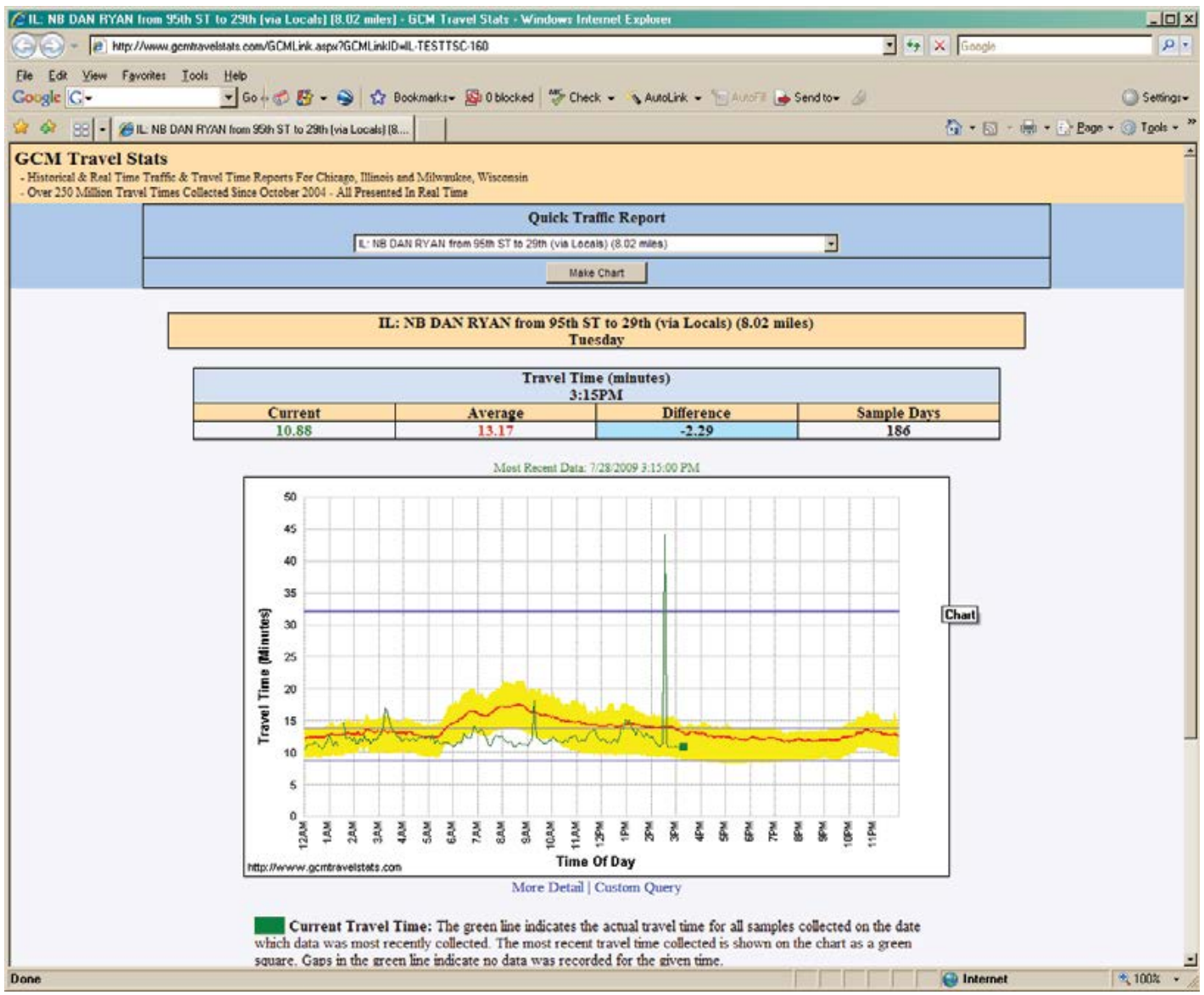

Source: Travel Midwest (2013).

Figure 2.3. Travel time reliability trends for a freeway segment.

Color figure available online at www.trb.org/Main/Blurbs/168765.aspx.

\section{Table 2.6. Travel Time Information for the Top 25 Metropolitan Areas}

\begin{tabular}{|c|c|c|c|}
\hline Rank & Metropolitan Area & Population & Website(s) and Features \\
\hline 1 & $\begin{array}{l}\text { New York-Northern New Jersey-Long Island } \\
\text { Edison, N.J. } \\
\text { Nassau-Suffolk, N.Y. } \\
\text { Newark-Union, N.J. } \\
\text { New York-White Plains-Wayne, N.Y. and N.J. }\end{array}$ & $\begin{array}{r}19,006,798 \\
2,325,224 \\
2,863,849 \\
2,121,076 \\
11,696,649\end{array}$ & $\begin{array}{l}\text { http://www.trips } 123 . c o m / t r a f f i c \_m a i n . a s p \\
\text { This component of the Trips123.com website is currently } \\
\text { under construction and is coming soon. } \\
\text { Event list does exist. } \\
\text { http://www.beatthetraffic.com/ajax/traffic/map.sapx?regionid } \\
\quad=15 \& \text { viewname=New+York+City (Inrix) } \\
\text { Color-coded speed maps, travel times on segments. }\end{array}$ \\
\hline 2 & $\begin{array}{l}\text { Los Angeles-Long Beach-Santa Ana, Calif. } \\
\text { Los Angeles-Long Beach-Glendale, Calif. } \\
\text { Santa Ana-Anaheim-Irvine, Calif. }\end{array}$ & $\begin{array}{r}12,872,808 \\
9,862,049 \\
3,010,759 \\
\end{array}$ & $\begin{array}{l}\text { http://caltrans511.dot.ca.gov/ } \\
\text { http://map.commuteview.net/CommunityView/html/es_main } \\
\text {.html?7 } \\
\text { Travel times, average speeds, time of update. }\end{array}$ \\
\hline 3 & $\begin{array}{l}\text { Chicago, III., Ind., and Wisc. } \\
\text { Chicago-Naperville-Joliet, III. } \\
\text { Gary, Ind. } \\
\text { Lake County-Kenosha County, III. and Wisc. }\end{array}$ & $\begin{array}{r}9,569,624 \\
7,990,248 \\
702,458 \\
876,918 \\
\end{array}$ & $\begin{array}{l}\text { http://gcmtravel.com/gcm/maps_chicago.jsp } \\
\text { Current travel time, average travel time, average speed. }\end{array}$ \\
\hline 4 & $\begin{array}{l}\text { Dallas-Fort Worth-Arlington, Tex. } \\
\text { Dallas-Plano-Irving, Tex. } \\
\text { Fort Worth-Arlington, Tex. }\end{array}$ & $\begin{array}{l}6,300,006 \\
4,226,003 \\
2,074,003\end{array}$ & $\begin{array}{l}\text { http://www.trans-vision.org } \\
\text { Shows speeds with colors for ranges. }\end{array}$ \\
\hline 5 & $\begin{array}{l}\text { Philadelphia-Camden-Wilmington, Pa., N.J., Del., } \\
\quad \text { and Md. } \\
\text { Camden, N.J. } \\
\text { Philadelphia, Pa. } \\
\text { Wilmington, Del., Md., and N.J. }\end{array}$ & $\begin{array}{r}5,838,471 \\
1,250,569 \\
3,892,194 \\
695,708 \\
\end{array}$ & $\begin{array}{l}\text { http://www.traffic.com/controller/myTraffic } \\
\text { Gives route, travel time at speed limit, current travel time, } \\
\text { delay, average speed. }\end{array}$ \\
\hline 6 & Houston-Sugar Land-Baytown, Tex. & $5,728,143$ & $\begin{array}{l}\text { http://traffic.houstontranstar.org/layers/ } \\
\text { Speed map, speed charts for specific segments, build route. }\end{array}$ \\
\hline
\end{tabular}


Table 2.6. Travel Time Information for the Top 25 Metropolitan Areas (continued)

\begin{tabular}{|c|c|c|c|}
\hline Rank & Metropolitan Area & Population & Website(s) and Features \\
\hline 7 & $\begin{array}{l}\text { Miami-Fort Lauderdale-Pompano Beach, Fla. } \\
\text { Fort Lauderdale-Pompano Beach-Deerfield Beach, Fla. } \\
\text { Miami-Miami Beach-Kendall, Fla. } \\
\text { West Palm Beach-Boca Raton-Boynton Beach, Fla. }\end{array}$ & $\begin{array}{l}5,414,772 \\
1,751,234 \\
2,398,245 \\
1,265,293\end{array}$ & $\begin{array}{l}\text { http://www.beatthetraffic.com/traffic/map. } \\
\text { aspx?regionid=27\&viewname=Miami } \\
\text { Distance, sensor percentage, current trip time, ideal trip time, } \\
\text { average speed. } \\
\text { http://www.traffic.com/Miami-Traffic/Miami-Traffic-Reports.html } \\
\text { Gives route, travel time at speed limit, current travel time, } \\
\text { delay, average speed. }\end{array}$ \\
\hline 8 & Atlanta-Sandy Springs-Marietta, Ga. & $5,376,285$ & $\begin{array}{l}\text { http://www.georgianavigator.com/perl/trips } \\
\text { Point-to-point travel times by highway, not chained. }\end{array}$ \\
\hline 9 & $\begin{array}{l}\text { Washington-Arlington-Alexandria, D.C., Va., Md., } \\
\text { and W.V. } \\
\text { Bethesda-Gaithersburg-Frederick, Md. }\end{array}$ & $\begin{array}{l}5,358,130 \\
1,176,401\end{array}$ & $\begin{array}{l}\text { http://traffic.yahoo.com/maps_result?csz=washington, } \\
\text { DC\&country=us\&trf=1 } \\
\text { Color-coded map for speeds, plus incidents; path distance } \\
\text { and travel time, but not delay. }\end{array}$ \\
\hline 10 & $\begin{array}{l}\text { Boston-Cambridge-Quincy, Mass. and N.H. } \\
\text { Boston-Quincy, Mass. } \\
\text { Cambridge-Newton-Farmington, Mass. } \\
\text { Peabody, Mass. } \\
\text { Rockingham County-Stafford County, N.H. }\end{array}$ & $\begin{array}{r}4,522,858 \\
1,884,659 \\
1,482,478 \\
736,457 \\
419,264\end{array}$ & $\begin{array}{l}\text { http://www.boston.com/traffic } \\
\text { (Boston Globe) limited "slowness" qualitative. } \\
\text { http://www.beatthetraffic.com/traffic/map.aspx?regionid=52\& } \\
\text { viewname=Boston } \\
\text { Powered by Inrix. } \\
\text { http://www.smarttraveler.com/scripts/bosmap. } \\
\text { asp?city=bos\&cityname=Boston } \\
\text { Travel times and updating time stamp (seems to be current } \\
\text { time), table of travel conditions. }\end{array}$ \\
\hline 11 & $\begin{array}{l}\text { Detroit-Warren-Livonia, Mich. } \\
\text { Detroit-Livonia-Dearborn, Mich. } \\
\text { Warren-Troy-Farmington, Mich. }\end{array}$ & $\begin{array}{l}4,425,110 \\
1,949,929 \\
2,475,181\end{array}$ & $\begin{array}{l}\text { http://mdotwas } 1 . \text { mdot.state.mi.us/public/drive/rtt.cfm } \\
\text { Color-coded congestion map, speed brackets, table of aver- } \\
\text { age speed trends for some locations. }\end{array}$ \\
\hline 12 & Phoenix-Mesa-Scottsdale, Ariz. & $4,281,899$ & $\begin{array}{l}\text { http://www.az511.com/RoadwayConditions/index.php } \\
\text { Color-coded average speeds on major links. }\end{array}$ \\
\hline 13 & $\begin{array}{l}\text { San Francisco-Oakland-Fremont, Calif. } \\
\text { Oakland-Fremont-Hayward, Calif. } \\
\text { San Francisco-San Mateo-Redwood City, Calif. }\end{array}$ & $\begin{array}{l}4,274,531 \\
2,504,071 \\
1,770,460\end{array}$ & $\begin{array}{l}\text { http://traffic.511.org/traffic_map.asp? } \\
\text { Travel times, average speeds, time of update. } \\
\text { Predict-a-trip, different routes, but not reliability. }\end{array}$ \\
\hline 14 & Riverside-San Bernardino-Ontario, Calif. & $4,115,871$ & See Los Angeles. \\
\hline 15 & $\begin{array}{l}\text { Seattle-Tacoma-Bellevue, Wash. } \\
\text { Seattle-Bellevue-Everett, Wash. } \\
\text { Tacoma, Wash. }\end{array}$ & $\begin{array}{r}3,344,813 \\
2,559,174 \\
785,639\end{array}$ & $\begin{array}{l}\text { http://www.wsdot.wa.gov/traffic/seattle } \\
\text { Color-coded speed map, average and current travel times by } \\
\text { highway segment. } \\
95 \% \text { travel time estimator, HOV lane performance comparisons. }\end{array}$ \\
\hline 16 & Minneapolis-St. Paul-Bloomington, Minn. and Wisc. & $3,229,878$ & $\begin{array}{l}\text { http://www.dot.state.mn.us/tmc/trafficinfo/map/refreshmap.html } \\
\text { Color-coded speed map. }\end{array}$ \\
\hline 17 & San Diego-Carlsbad-San Marcos, Calif. & $3,001,072$ & $\begin{array}{l}\text { http://www.dot.ca.gov/dist11/d11tmc/sdmap/showmap.php } \\
\text { Shows speeds. }\end{array}$ \\
\hline 18 & St. Louis, Mo.-III. & $2,816,710$ & $\begin{array}{l}\text { http://www.traffic.com/St-Louis-Traffic/St-Louis-Traffic-roads } \\
\text {.html?AWOPARTNER=GATEWAYGUIDE }\end{array}$ \\
\hline 19 & Tampa-St. Petersburg-Clearwater, Fla. & $2,733,761$ & $\begin{array}{l}\text { http://www. } 511 \text { tampabay.com } \\
\text { Color-coded speed map, estimated travel times. }\end{array}$ \\
\hline 20 & Baltimore-Towson, Md. & $2,667,117$ & $\begin{array}{l}\text { http://www.chart.state.md.us/travinfo/speedData.asp } \\
\text { Color-coded map, table of current speeds. }\end{array}$ \\
\hline 21 & Denver-Aurora, Colo. & $2,506,626$ & $\begin{array}{l}\text { http://www.cotrip.org/speed.htm } \\
\text { Color-coded speed map, travel times. }\end{array}$ \\
\hline 22 & Pittsburgh, Pa. & $2,351,192$ & Commercial vendors, color-coded maps, travel times. \\
\hline 23 & Portland-Vancouver-Beaverton, Ore. and Wash. & $2,207,462$ & $\begin{array}{l}\text { http://www.tripcheck.com } \\
\text { Color-coded speed map, delay indicators. }\end{array}$ \\
\hline 24 & Cincinnati-Middletown, Ohio & $2,155,137$ & $\begin{array}{l}\text { http://www.artimis.org } \\
\text { Color-coded speed map, normal times, current times, delays. }\end{array}$ \\
\hline 25 & Sacramento, Calif. & $2,109,832$ & http://BeatTheTraffic.com \\
\hline
\end{tabular}

Note: $\mathrm{HOV}=$ high-occupancy vehicle. 


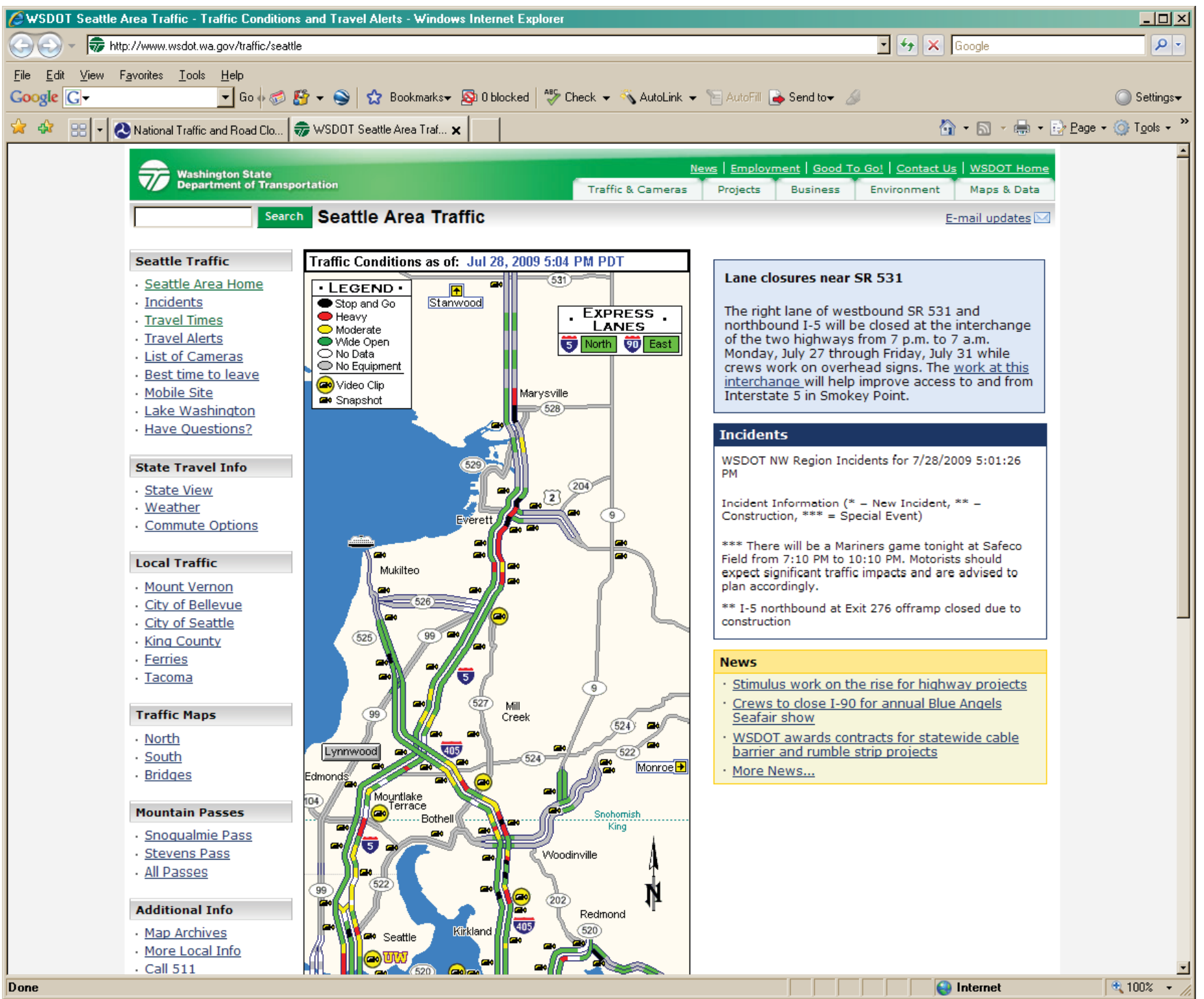

Source: Washington State Department of Transportation (2013).

Figure 2.4. Seattle area traffic conditions map.

Color figure available online at www.trb.org/Main/Blurbs/168765.aspx.

that the traveler needs to leave Lynnwood at 8:08 a.m. and allow 52 minutes for the trip to ensure that the destination will be reached by 9:00 a.m. However, the resultant text shown in the dialogue box on the right-hand side of the screen in Figure 2.5 can be confusing or misleading to the average driver. The text states, "Your 95\% Reliable Travel Time is 52 minutes. $95 \%$ of the time you would need to leave at 8:08 AM to arrive by 9:00 AM." The WSDOT text may be misinterpreted to mean that if you leave after 8:08 a.m., then $95 \%$ of the time you will be late. This potential confusion due to the verbiage chosen points to the need for a standard and the crucial role of the L14 project to determine the best lexicon to convey reliability thoughts to various user groups (in this case, drivers).

No other transportation website was found to provide this functional capability. Other websites can provide travel times for specific trips, but none specifically addresses reliabilityadjusted travel times in a direct manner. Querying the WSDOT website regarding "reliability" leads to this webpage and several others. One web page of interest talks about reliability in the context of the difference between travel times in the HOV lanes and the regular (mixed-flow) freeway links and asserts that this is a "reliability" result. In a sense, it is true that restricted-use lanes have more reliable travel times, and 


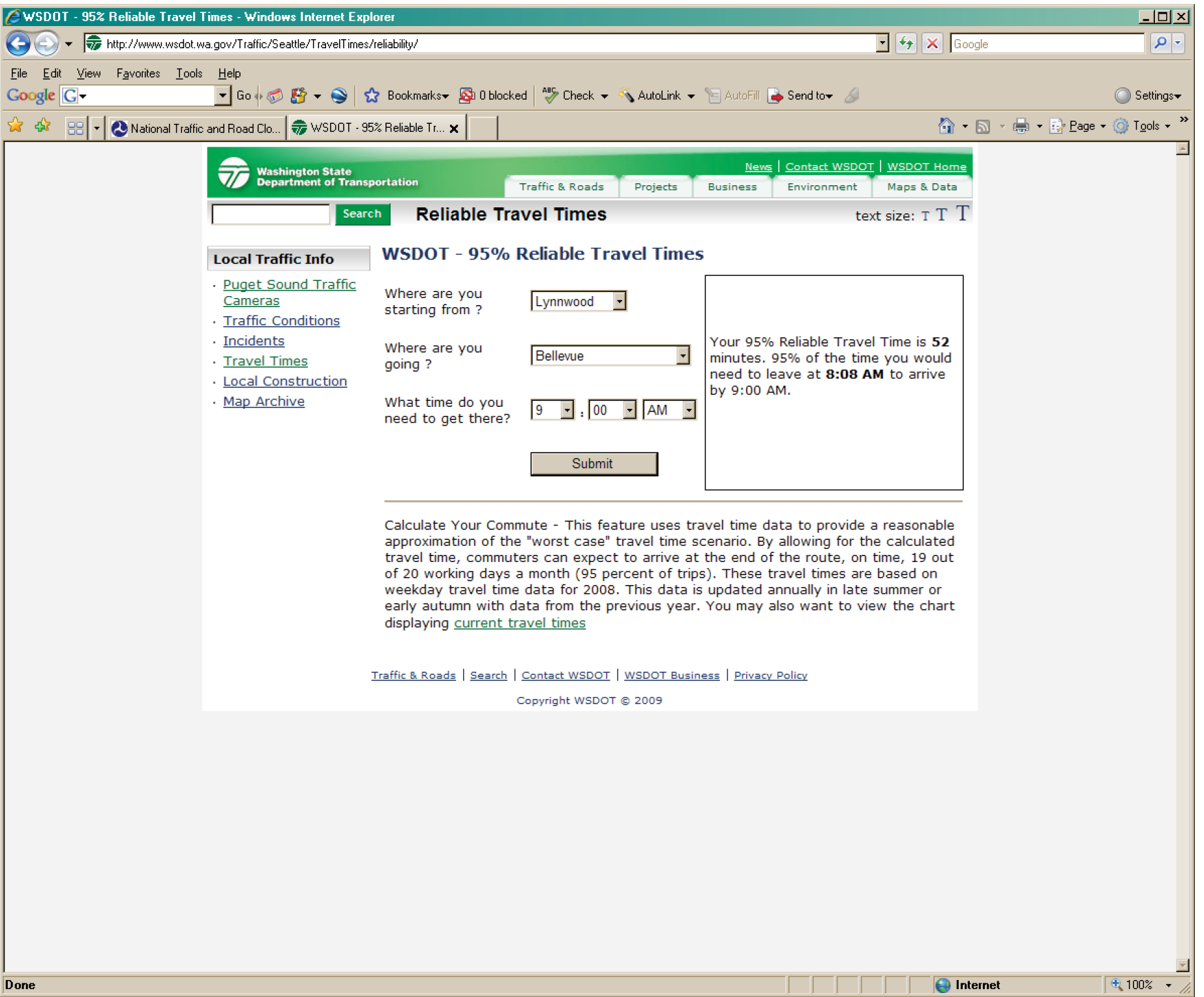

Figure 2.5. 95\% reliability travel time calculator.

if more people use them, reliability improves. The HOV lanes are likely to have more reliable travel times because there is less traffic. The travel times during peak hours are much lower, as well, which one would expect.

The common set of reliability measures (e.g., as shown in http://ops.fhwa.dot.gov/publications/tt_reliability/) discussed in the literature is as follows:

- Buffer index: Computed as the difference between the 95th percentile travel time and the average travel time, normalized by the average travel time.

- Planning time index: Computed as the 95th percentile travel time index divided by the free-flow travel time index.
- Skew statistic: Computed as the ratio of (90th percentile travel time minus the median) divided by (the median minus the 10th percentile).

- Misery index: Computed as the difference between the average of the travel times for the $0.5 \%$ to $5 \%$ longest trips and the average travel time, normalized by the average travel time (useful primarily for rural conditions).

- Failure or on-time measure: Computed as the percentage of trips with travel times less than a threshold (calibrated factor [e.g., 1.3] * mean travel time).

It is not obvious that any of the current website developers are actively pursuing the use of these measures on their websites. 
The limit seems to be travel time trends and comparisons of current travel times with averages. An example would be a Traffic .com function that lets the traveler get directions and driving times for one or more routes, including the current level of delay, as shown in Figure 2.6. It is not clear that the delay is intended to provide a particular likelihood that the trip will be completed in the time listed, but it is being estimated and reported.

The Houston TranStar website provides speed charts for specific freeway links, as shown in Figure 2.7. The average from the current day (shown in red) is compared with the trailing 3-month average based on the day of the week (shown in green). In the case of the specific link queried, there was a significant drop in speed early in the morning that was strikingly different from the 3-month average.
Several commercial companies provide travel time information for metropolitan areas throughout the country. The most common are Traffic.com, BeattheTraffic, Iteris, TrafficGauge, traffic.yahoo.com, and SmarTraveler.

The format of the information provided by these companies is virtually the same for all locations, populated, of course, with local information. The credit given for the source of the travel time information varies by location. More comprehensive data about these and other companies can be found in the L02 Guide's appendices.

The list of companies assembling and processing travel time information is more difficult to discern, but a partial list includes the Performance Measurement System (PeMS), especially for California and along the West Coast; Inrix, especially

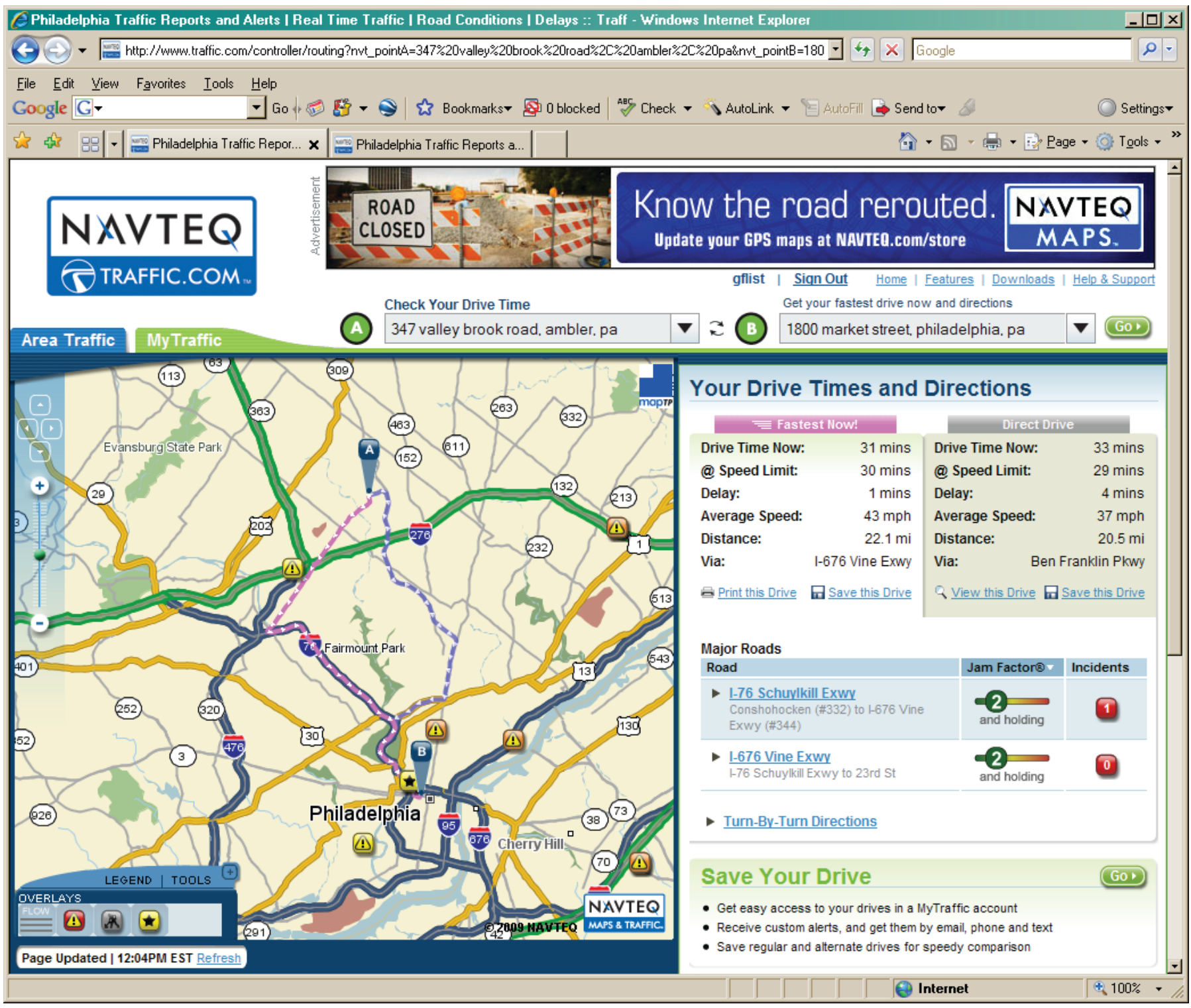

Source: Traffic.com (2013).

Figure 2.6. An example of conveying travel time trends.

Color figure available online at www.trb.org/Main/Blurbs/168765.aspx. 


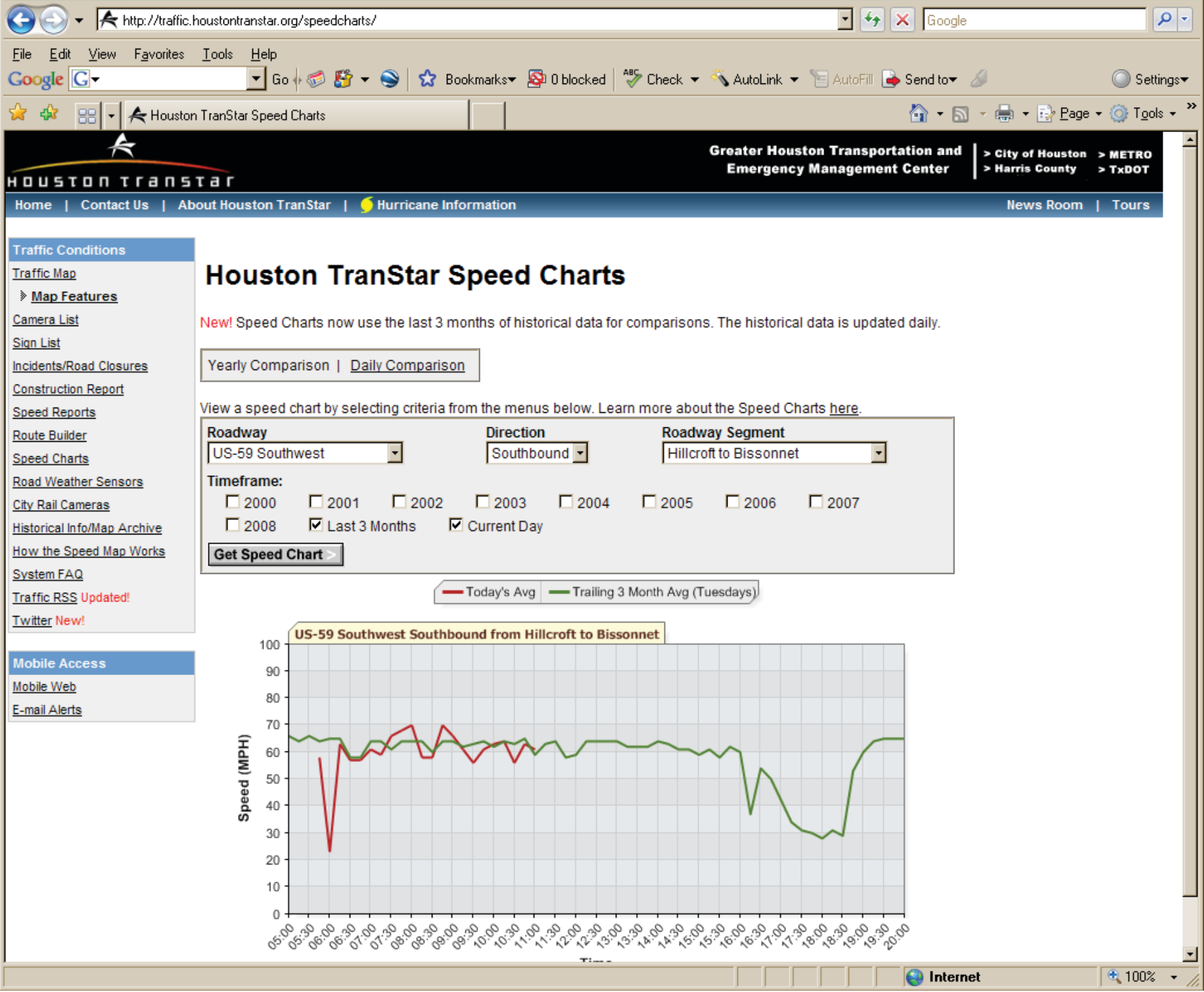

Source: Houston TranStar (2013).

Figure 2.7. A speed chart for a link in the Houston network.

Color figure available online at www.trb.org/Main/Blurbs/168765.aspx.

on the East Coast; OpenRoads, especially in Virginia; Iteris; and Highway Information Systems, especially in North Carolina.

Websites are able to communicate a large amount of information that is useful to a traveler before beginning a trip. Other methods of communicating travel time reliability, such as radio announcements, VMS, and smartphones, are useful for travelers who do not have access to a computer, particularly once they are en route to their destination.

Radio broadcasts usually provide a range of expected travel times or compare the current travel times to a normal condition. For example, a broadcast might say the travel time between two locations is 3 minutes longer than the average travel time.
VMS disseminate similar types of travel time reliability information as radio broadcasts. Radio broadcasts are accessible throughout the service area of a particular radio station, but VMS are permanently located on specific roadways in the network. Some agencies, such as the Maryland DOT, also show the messages that are currently being displayed on their VMS on their website. Travelers can also access travel time and reliability information through applications on smartphones. For example, the Google Maps application for Blackberry phones has a Traffic option that shows the relative speeds on major roadways based on either current traffic conditions or historic data. 


\section{Assessment of User Needs}

A functioning reliability monitoring system must meet the needs of many types of users, because different users perceive and value deviations from the expected travel time in different ways. In this research, users are classified into the following broad groups:

- Passenger travelers;

- Freight movers;

- Policy makers;

- Roadway system managers; and

- Transit system managers.

Understanding the differences in user needs is fundamental to laying the framework for an effective monitoring system (Xiong et al. 2007). Passenger travelers think about reliability in terms of either deviation in relation to the total trip time or how often they are able to arrive within a particular time window. Freight movers think about reliability in terms of whether trips are taking longer or shorter than expected (Morris et al. 1998). Policy makers are typically performing high-level evaluations of output measures and responding to concerns about whether their agency is meeting expectations and satisfying benchmarks. System managers are directly responsible for protecting and improving reliability on their network and are most affected by the issues limiting the effectiveness of an agency in providing reliable travel.

Several factors internal to the system are associated with time-varying relationships between demand and capacity, as well as roadway incidents. External factors include weather, special events, and infrastructure failures and the performance of complementary and competing modes. Travelers, operators (carriers), shippers, and other network users gather and use reliability information in travel and shipping decisions. What they learn affects departure times, mode choice, path choice, and even destination and location choices. Businesses and families make some location decisions (residential and work location choices) partly based on expected network reliability. This indicates that reliability information is useful in a variety of time frames, from near-term real time to longterm decisions and trends.

Different users need and use different kinds of information on system reliability. Highway managers need technical, quantitative information, both (near) real-time data for operations management and archived historical trend data for strategic and investment planning. Travelers use qualitative, anecdotal and objective, quantitative information on reliability for trip planning.

Users of reliability information receive it from two original sources: direct experience and reports gathered through organized monitoring processes. Information moves in complicated ways. Anecdotal (experiential reports) may move into formal monitoring systems through word of mouth to travelers or locators, for example, or through the media to the community and policy makers.

Accurate, timely, and comprehensive reliability data facilitate better decisions by all users. These data will (1) help travelers get the best use out of the network, (2) help managers improve reliability, and (3) guide decision makers to using more costeffective measures that enhance and protect system reliability.

SHRP 2 Project L11, Evaluating Alternative Operations Strategies to Improve Travel Time Reliability, conducted an extensive literature review, including traveler and shipper modeling efforts that have explicitly used or tried to use reliability measures. These studies are important because they represent empirical, analytic tests of the relationships between the behavior of travelers and shippers and reliability. Such modeling studies can tell us what kinds of reliability measures are associated with traveler and shipper behaviors. Such associations are not necessarily indications of causality, but by combining these results with the strong understanding of traveler and shipper behaviors gained in the interview process, it is possible to generate a useful basis for identifying the most important reliability measures from a user perspective.

At the time of L02, Project L11 was an ongoing project intended to provide both short-term and long-term perspectives on innovative ideas leading to practical tools that can be implemented on a system to improve the travel time reliability of that system. L11 emphasized travel time reliability from the standpoint of everyday users, including those engaged in freight and passenger transport in both urban and rural areas.

Tasks 1 through 3 of L11 focused on a review of users' current and future travel time reliability needs and identified goals for improving reliability. Users, in this case, comprised a broadly defined group encompassing the following subgroups:

- Passenger travelers;

- Freight movers;

- Policy makers;

- Roadway system managers; and

- Transit system managers.

The user needs identified by L11 were summarized in SHRP 2 L11 Technical Memorandum 1 and SHRP 2 L11 Technical Memorandum 2. Travel time reliability is defined in these memoranda as the variation in travel time for the same trip from day to day. Through focus group interviews, L11 found that most roadway users have the same desire for reliable roadway performance-free-flow travel all of the time-but know that this is unrealistic and instead plan their lives and businesses around expected conditions. Unexpected conditions can degrade the user's confidence in the overall reliability of the system and can increase costs of travel. 
The comprehensive literature review of travel time reliability user needs embedded within the work of L11 produced the following list of earlier efforts:

- Guide to Effective Freeway Performance Measurement (NCHRP Research Results Digest 312);

- Cost-Effective Performance Measures for Travel Time Delay, Variation, and Reliability (NCHRP Report 618);

- Identification and Analysis of Best Practices (SHRP 2 Project L01);

- Analytic Procedures for Determining the Impacts of Reliability Mitigation Strategies (SHRP 2 Project L03);

- Institutional Architectures to Advance Operational Strategies (SHRP 2 Project L06);

- Archive for Reliability and Related Data (SHRP 2 Project L13);

- Measuring Performance Among State DOTs (AASHTO);

- Statewide Incident Reporting Systems (NCHRP 20-07Task 215);

- Guide to Benchmarking Operational Performance Measures (NCHRP 20-07-Task 202);

- Traffic Incident Management Self-Assessment National Executive Summary Report (FHWA); and

- Freight Data from Intelligent Transportation System Devices (WSDOT).

The L02 project team coordinated its efforts with the team for L13, Archive for Reliability and Related Data, and L14, Traveler Information and Travel Time Reliability. Project L14 started in 2010 and was slated to take two years. Its focus was on identifying the right combination of words, numbers, and symbols to communicate information about travel time reliability to travelers. Although the topics are similar, the focus of L02 and L14 are unique: L02 is focused on data monitoring, and L14 is focused on communicating information to travelers. The interface between the two projects lies in the exchange of information that is gathered from the monitoring system developed in L02 with the communication strategy recommended in L14. It was critical that the information needs for the messages developed in L14 could be accommodated through the performance measures collected, imputed, and calculated as part of L02. At the time of this final report, it did not appear that the L14 project team would identify performance measures that required data not already collected or calculated as part of L02.

\section{Needs of Passenger Travelers and Freight Movers}

The needs of highway users in relation to travel time reliability and the factors influencing reliability were identified for both passenger travelers and freight movers by the L11 project team.

\section{Passenger Travelers}

The group of users comprising passenger travelers represents individual vehicle users who drive to work, recreational centers of activity, school, or other types of individual destinations. As Khattak et al. (1994), Carrion and Levinson (2010), Tilahun and Levinson (2010), Small et al. (2005), Fosgerau and Engelson (2011), Fosgerau and Karlstrom (2010), Jenelius et al. (2011), Batley and Ibanez (2009), and Higatani et al. (2009) demonstrate, individual travelers are known to highly value travel time reliability (especially information about unexpected events) because it allows them to save travel time and avoid schedule delays (i.e., late arrival at destination). In addition, Khattak et al. (2003) point out that a substantial portion of travelers seem willing to pay for personalized dynamic information.

The passenger traveler focus group interviews indicated that if the travel time actually experienced matches the expectation of the passenger traveler, then the travel time is considered reliable. Deviations from the expected travel time are perceived differently by users according to the context of their trip. For example, travel time deviations when travelers undertake nondiscretionary work trips are considered more onerous than deviations on discretionary trips. As a result, the performance measures used to describe reliability were selected based on a trip's purpose and the frequency and flexibility of that trip.

Four reliability measures were identified based on the defined user categories for passenger travelers and freight movers. Figure 2.8 illustrates these measures, and how they are calculated, on a travel time chart. For comparisons of various possible measures, see Lomax et al. (2003) and $\mathrm{Pu}$ (2011). The four measures are

1. Planning time (95th percentile travel time): Average trip duration in minutes and seconds for $95 \%$ or less of all trips. This measure estimates the extent of delay during the heaviest traffic days.

2. Buffer index: The difference between the 95th percentile travel time and the average travel time, divided by the average travel time. This represents the extra time (in minutes or as a ratio) that travelers must add to their average travel time when planning trips to ensure on-time arrival. The buffer index increases as reliability worsens.

3. Planning time index: The 95th percentile travel time divided by the free-flow travel time index. The planning time index can also be understood as the ratio of travel time on the worst day (or two days) of the month compared with the time required to make the same trip at free-flow speeds. Consequently, the planning time index represents the total travel time that should be planned when an adequate buffer time is included.

4. Travel time index: The ratio of the average travel time in the peak period to the travel time at free-flow conditions. 


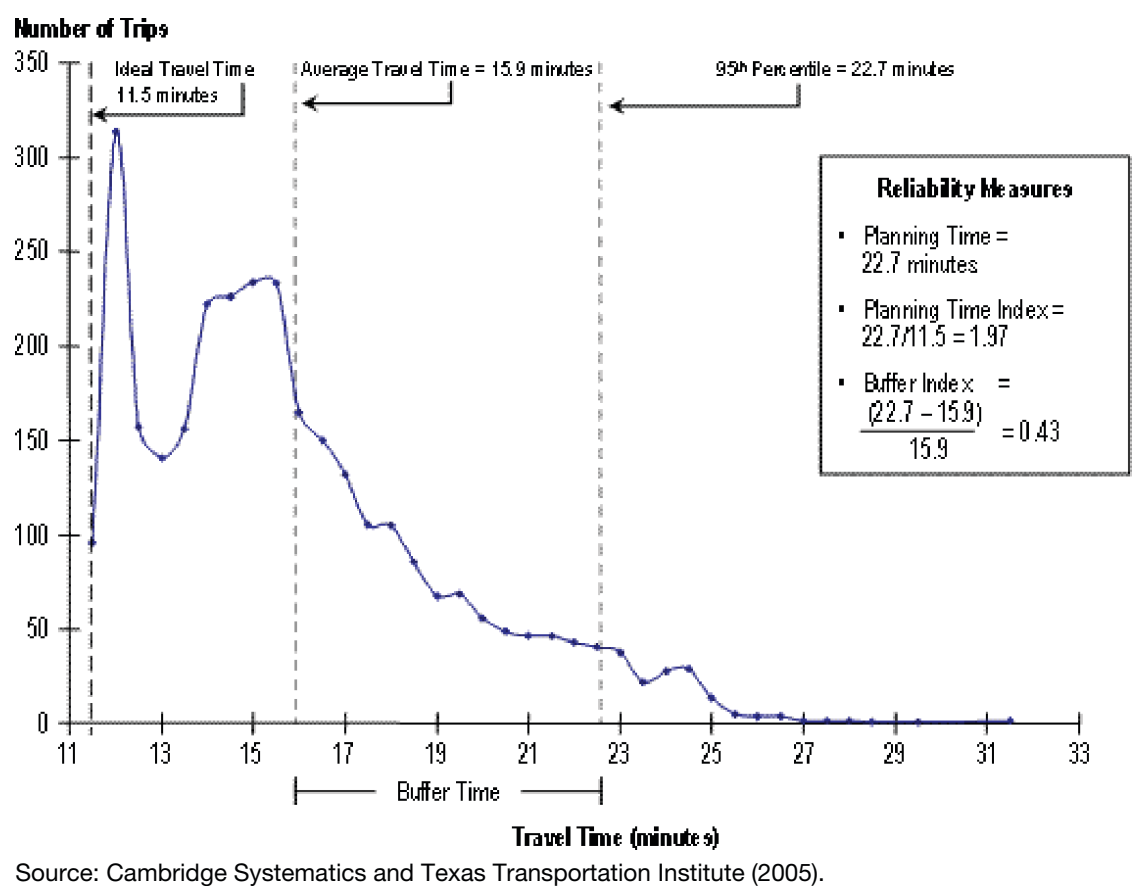

Figure 2.8. IIlustration of reliability measures. (Travel time index $=$ average travel time in the peak period divided by the ideal travel time.)

Table 2.7 summarizes the recommended performance measures for passenger travelers, grouped according to trip purpose for daily travel, and accompanied by a general assessment of the relative importance or severity of a reliability issue.

Daily, constrained trips are those for which the user experiences day-to-day variability in travel time (due to recurring congestion and incident or nonrecurring congestion) and desires to arrive at the destination at a fixed time (or within a small time window). Reliability can be defined for these trips as the invariability in desired (or required) arrival time at the final destination from day to day. Travelers can incur schedule delay costs, which are a penalty for early or late arrival; these costs are discussed in detail in Small et al. (1999). Typically, late schedule delay costs are higher than early schedule delay

Table 2.7. Needs and Travel Time Reliability Performance Measures for Passenger Travelers

\begin{tabular}{|l|l|l|l|l|}
\hline $\begin{array}{l}\text { Broad Classification } \\
\text { by Trip Purpose }\end{array}$ & $\begin{array}{c}\text { Detailed } \\
\text { Classification } \\
\text { by Trip Purpose }\end{array}$ & $\begin{array}{c}\text { Importance } \\
\text { or Severity } \\
\text { of Reliability }\end{array}$ & $\begin{array}{c}\text { Primary User } \\
\text { Information Need }\end{array}$ & $\begin{array}{c}\text { Recommended } \\
\text { Reliability } \\
\text { Measure }\end{array}$ \\
\hline Daily, constrained trips & $\begin{array}{l}\text { Work } \\
\text { Pick up and drop } \\
\text { off children }\end{array}$ & $\begin{array}{l}\text { High } \\
\text { High }\end{array}$ & $\begin{array}{c}\text { Delay during heaviest } \\
\text { traffic days. }\end{array}$ & $\begin{array}{c}\text { Planning time } \\
\text { index }\end{array}$ \\
\hline $\begin{array}{c}\text { Daily, unconstrained } \\
\text { trips }\end{array}$ & $\begin{array}{l}\text { Shopping } \\
\text { Return home }\end{array}$ & $\begin{array}{l}\text { Low } \\
\text { High-medium }\end{array}$ & $\begin{array}{c}\text { Additional time neces- } \\
\text { sary to generally } \\
\text { arrive on time. }\end{array}$ & Buffer index \\
\hline $\begin{array}{c}\text { Occasional, } \\
\text { constrained trips }\end{array}$ & $\begin{array}{l}\text { Appointments } \\
\text { Leisure }\end{array}$ & High & $\begin{array}{l}\text { Travel time during } \\
\text { peak period versus } \\
\text { off-peak period. }\end{array}$ & Travel time index \\
\hline $\begin{array}{c}\text { Occasional, } \\
\text { unconstrained trips }\end{array}$ & Leisure & Low & $\begin{array}{c}\text { Additional time neces- } \\
\text { sary to generally } \\
\text { arrive on time. }\end{array}$ & Buffer index \\
\hline
\end{tabular}

Source: Adapted from SHRP 2 Project L11 Technical Memorandum 1, Exhibits 2 and 4 (http://www.trb.org/Main/ Blurbs/168142.aspx). 
costs. Furthermore, due to travel time uncertainty, travelers may not be able to properly plan their daily activities. Results of the focus group interviews showed that unreliability has the most severe impact on daily, constrained trips and yields the heaviest potential consequences, such as showing up late to work, stress on others relying on the delayed traveler, and potential monetary losses. It is critical that users performing daily, constrained trips plan a total travel time (including a buffer) that assumes a general worst-case scenario so that they can schedule their departure to ensure an on-time arrival. Because the planning time index estimates how bad delay will be during the heaviest traffic days and conveys to the user the total travel time that should be planned when an adequate buffer time is included, it is recommended as the reliability measure for daily, constrained trips. Examples of daily, constrained trips include work commutes with fixed arrival times and picking up children from day care, where parents incur monetary fines for late arrival.

Daily, unconstrained trips are those for which the user experiences the day-to-day variability in travel time, but there is no fixed arrival time requirement against which a measure of schedule delay can be calculated. Reliability can be defined for these trips as the invariability in travel time from day to day. The consequences of unreliability for these types of trips are typically less severe than for daily, constrained trips, and users generally only desire to know how much time they should add to their average travel time to arrive generally on time, which is why the buffer index is the recommended performance measure. Examples of daily, unconstrained trips include shopping or returning home from work.

Occasional, constrained trips are those for which the user does not experience day-to-day variability but does have temporal constraints on arrival time. Reliability for these trips can be defined as the ability to reach the destination on time. The consequences of unreliability in these types of trips are similar in severity to those for daily, constrained trips and may involve significant inconveniences or monetary losses for the user. These trips often occur during or adjacent to peak periods; therefore, it is of interest to the user to know the ratio of the travel time during the peak period to the travel time under primarily free-flow conditions (a travel time the occasional user can easily relate to). The travel time index provides this ratio. Examples of occasional, constrained trips include appointments or leisure trips to scheduled events.

Occasional, unconstrained trips are those for which the user does not experience day-to-day variability and does not have a fixed arrival time requirement against which a measure of schedule delay can be calculated. Reliability for these trips can be defined in terms of how close the experienced travel time is relative to the expected travel time. The severity of the consequences of unreliable trips in this category is typically low, due to the flexibility in arrival time. As these trips occur during off-peak hours, the basis for trip planning is the average travel time to the destination; the user's primary interest is how much time to add to this average to generally arrive on time. Similar to daily, unconstrained trips, the buffer index is the recommended performance measure for this category. Examples include leisure trips that do not involve scheduled events.

\section{Freight Movers}

Freight movers represent an important subset of users of the transportation network. The high cost of operating and maintaining commercial vehicles typically causes carriers to put a high value on travel time and late schedule delays. As Khattak et al. (2008) point out, carriers who ship high-value and perishable goods are willing to pay to avoid travel time uncertainty and associated costs. Most freight drivers accumulate their own information on travel times and reliability through experience and peer-to-peer information sharing. Others get reliability information through intermediaries or vendors who gather information from primary sources before packaging and marketing it. Many carriers use route guidance devices on their shipping vehicles and information technology to track shipments.

Passenger travelers generally think about reliability in terms of either deviation in relation to the total trip time or how often they are able to arrive within a particular time window. In contrast, focus group interviews indicated that freight movers generally perceive reliability in terms of their ability to predict trip times. If the frequency of trips taking much longer than expected begins to increase, freight movers will see the system as unreliable. This perception will result in actions such as moving times and routes to when reliable travel is available (carriers often travel during off-peak times in congested urban areas), widening time windows for delivery, increasing prices for services, and spreading congested delivery routes across vehicles so late deliveries compound less severely throughout the day.

The L11 focus group interviews found that most shippers are relatively insensitive to reliability problems and commonly provide carriers with little flexibility. The interviews also suggested that travel time reliability is not a key concern of shippers and is not an issue that has made it to their strategic level of operations planning. This result needs further investigation and clearly cannot be generalized. For shippers that carry perishable or time-sensitive goods, travel time reliability is expected to be critical. Furthermore, it seems that shippers incur additional costs due to traffic congestion, mainly due to incident congestion.

Freight movers were classified into one of eight groups to provide a manageable matrix in which to define the effects of reliability and the needs of this particular subset of users. 
Table 2.8. Classification by Characteristics and Needs of Freight Movers

\begin{tabular}{|c|c|c|c|c|c|}
\hline Group No. & $\begin{array}{l}\text { Level of } \\
\text { Schedule } \\
\text { Flexibility }\end{array}$ & $\begin{array}{l}\text { Level of } \\
\text { Operational } \\
\text { Adaptability }\end{array}$ & $\begin{array}{l}\text { Cost of } \\
\text { Variability }\end{array}$ & Primary User Information Need & Example Company \\
\hline 1 & Flexible & Complete & High & $\begin{array}{l}\text { 1. Travel time variability on preferred } \\
\text { routes and alternate routes through- } \\
\text { out the day. } \\
\text { 2. Estimate of on-time delivery } \\
\text { reliability. }\end{array}$ & $\begin{array}{l}\text { Refrigerated carrier that operates in a very } \\
\text { congested arterial network; e.g., grocery } \\
\text { store deliveries by large company. }\end{array}$ \\
\hline 2 & Flexible & None & High & $\begin{array}{l}\text { 1. Travel time variability on preferred } \\
\text { routes throughout the day. } \\
\text { 2. Estimate of on-time delivery reliability. }\end{array}$ & Carrier that pays drivers by the hour. \\
\hline 3 & Inflexible & Complete & High & $\begin{array}{l}\text { 1. Travel time variability on preferred } \\
\text { routes and alternate routes during } \\
\text { specific delivery time windows. } \\
\text { 2. Estimate of on-time delivery reliability. }\end{array}$ & $\begin{array}{l}\text { Carrier required to meet tight time windows } \\
\text { for delivery; e.g., delivery companies like } \\
\text { FedEx, or residential moving company. }\end{array}$ \\
\hline 4 & Inflexible & None & High & $\begin{array}{l}\text { 1. Travel time variability on preferred } \\
\text { routes during specific delivery time } \\
\text { windows. } \\
\text { 2. Estimate of on-time delivery reliability. }\end{array}$ & $\begin{array}{l}\text { Carrier that moves air freight or fresh sea- } \\
\text { food and must deliver in tight time } \\
\text { window. }\end{array}$ \\
\hline 5 & Flexible & Complete & Low & $\begin{array}{l}\text { 1. Travel time variability on preferred } \\
\text { routes and alternate routes through- } \\
\text { out the day. } \\
\text { 2. Estimate of mean travel time. }\end{array}$ & Carrier that moves bulk natural resources. \\
\hline 6 & Flexible & None & Low & $\begin{array}{l}\text { 1. Travel time variability on preferred } \\
\text { routes throughout the day. } \\
\text { 2. Estimate of mean travel time. }\end{array}$ & Carrier that has no delivery time windows. \\
\hline 7 & Inflexible & Complete & Low & $\begin{array}{l}\text { 1. Travel time variability on preferred } \\
\text { routes and alternate routes during } \\
\text { specific delivery time windows. } \\
\text { 2. Estimate of mean travel time. }\end{array}$ & Moving companies. \\
\hline 8 & Inflexible & None & Low & $\begin{array}{l}\text { 1. Travel time variability on preferred } \\
\text { routes during specific delivery time } \\
\text { windows. } \\
\text { 2. Estimate of mean travel time. }\end{array}$ & $\begin{array}{l}\text { Small, temperature-controlled trucking } \\
\text { company. }\end{array}$ \\
\hline
\end{tabular}

Source: Adapted from SHRP 2 Project L11 Technical Memorandum 1, Exhibit 3 (http://www.trb.org/Main/Blurbs/168142.aspx).

Table 2.8 displays this classification scheme along with the criteria on which the classifications were made: (1) level of schedule flexibility, (2) level of operational adaptability, and (3) cost of variability. An example of a type of freight moving company is displayed under each category to provide some context as to the type of user represented. A brief description of the three classification criteria is as follows:

\section{Level of schedule flexibility}

a. Flexible: Carrier can change schedule (departure times) to less-congested times or wider time windows with few consequences

b. Inflexible: Carrier is meeting another outgoing vehicle or has limited timing flexibility and narrow delivery windows;

2. Level of operational adaptability

a. Complete: Carrier can change route, has many deliveries, or has large fleet of interchangeable vehicles b. None: Carrier has small fleet, many deliveries, or few route choices; and

3. Cost of variability

a. High: Carrier experiences significant costs from travel time variability due to high inventory or carries burden of variability

b. Low: Cost of variable travel times is small.

Freight shippers and carriers incorporate expected roadway conditions into their equipment and staffing decisions. Included in those decisions is the importance of on-time delivery reliability, which is extremely important for some freight movers (e.g., as part of a just-in-time manufacturing activity), but of only modest importance for others (e.g., delivery of garbage to a landfill). For freight movements for which ontime delivery is extremely important, additional time is often built into the delivery schedule (which requires the carrier to supply additional equipment and resources) to account for 
unreliable travel conditions. This increases the cost of those deliveries, but at a lower cost to the carrier (and ultimately the shipper) than if the delivery was late. Shipments of goods with lower monetary late penalties are scheduled with less give in the schedule, allowing carriers to maintain fewer redundant vehicles and drivers. Carriers charge lower overall shipping costs for these movements, but they are delivered less reliably. Consequently, trip reliability and its importance are directly (but not necessarily fully) accounted for in the price of the freight transportation service. Because of the competitive environment of the trucking industry, significant changes in roadway reliability are reflected in the price of trucking services. That is, a more reliable roadway network will result in lower costs to the carriers, who will typically pass those savings along to the shippers in order to remain competitive.

The L11 team conducted detailed interviews of different users within the freight industry and found not only that the needs of freight movers and passenger travelers differ, but also that even within the group defined as freight movers, planners and policy makers have different needs from truck drivers and dispatchers. Planners and policy makers are generally more interested in forecasting travel time and reliability for use in long-term route planning and route cost estimation. Truck drivers and dispatchers are typically more interested in real-time data due to their need to adjust routes in progress to meet schedules and deadlines in the near term.

Within the category of freight movers, the type of trip also dictates the type of reliability information that is useful for the freight mover. Trips fall into two broad categories: fulltruckload trips, for which an entire trailer full of merchandise is picked up at one location and delivered to another; and lessthan-truckload trips, for which trucks make a series of pickups and deliveries along a route. Full-truckload trips require information about one origin-destination pair, but lessthan-truckload trips require more complicated trip-chaining capabilities.

Because time sensitivity is generally a focus in the trucking industry, truck drivers and dispatchers will sometimes make use of real-time communication technologies such as directconnect units that allow dispatchers to instantly communicate to drivers information that may affect travel time and give the driver alternatives for managing the route and travel time. Trucking companies also make use of satellite tracking technology (similar to the OnStar-type systems contained in passenger cars) so that dispatchers can receive real-time information on the location of vehicles and data regarding each vehicle's behavior (i.e., speeds, heading, and braking information).

\section{Needs of Agencies}

The current needs of transportation agencies, in relation to travel time reliability and the factors influencing reliability, were identified in L11 for policy makers and highway system managers. The ability of transportation agencies to provide reliable travel on the transportation system is typically limited by one or more of these factors:

- Limitations due to availability of resources and jurisdictional boundaries;

- Limitations due to ability to predict the occurrence of disruptions (e.g., incidents or adverse weather);

- Adequate access to tools and procedures to remove disruptions quickly or supply additional, short-term capacity increases to compensate for capacity lost due to a disruption; and

- Adequate knowledge of which tools work most effectively for given disruptions and the ability to gain feedback on the performance of measures that are applied to improve travel reliability.

An agency with a well-managed reliability-focused performance measurement system enjoys planning and programming benefits, including

- Improvement of information provided to decision makers in support of strategic planning and programming, facilitating improvements in operations and planning;

- Assistance for agency executives in documenting accomplishments, providing a method for justifying the value of program investments and system improvements; and

- Improved understanding of the value of one type of project or system improvement versus another, enabling costbenefit analysis to be integrated into the agency's budgeting processes.

The key to understanding the needs of agencies in relation to reliability is to recognize that agencies and users (travelers) look at reliability statistics differently. Roadway agencies care about their roads; customers care about their activities and trips. Although roadway agencies care about the customers' trips, their primary concerns are where, when, how often, and to what extent congestion occurs on their roadways. Each agency has financial obligations to deal with their roads, not others' roads, and they must care more significantly about their own roads' performance.

\section{Policy Makers}

Policy makers are responsible for decisions typically related to funding for infrastructure capacity expansion, investment in operations management systems, and transportation system monitoring and information-dissemination technologies. Broadly speaking, metropolitan planning organizations (MPOs), DOT planning departments, and legislative bodies are all members of this group. Policy makers do not typically 
have a direct impact on the day-to-day procedures of monitoring travel time reliability; however, the decisions made at the policy level regarding the focus of improvements and spending (e.g., improved safety versus increased efficiency) have a trickle-down effect on an agency's effectiveness when it comes to providing reliable travel times to users. In general, policy makers and planning organizations are concerned with strategic and tactical plans, with a focus on recurrent traffic congestion. Few transportation agencies have adopted policies that mention managing their transportation systems for reliability; however, many agencies' transportation management objectives actually improve travel time reliability while working to improve roadway capacity, efficiency, and safety.

The current practice of monitoring travel time reliability among governmental and legislative bodies uses reliability performance measures (if the agency is tracking them) to determine how well the agency is performing (output measures). This practice differs from monitoring the effect those actions have on overall changes in travel time or delay experienced (outcome measures). Monitoring output measures is important for policy makers and allows them to respond to legislative and taxpayer concerns about whether their agency is fulfilling its promises and obligations to legislators and citizens. Policy makers will need a specific set of charts or visual tools to make funding decisions about the transportation system.

\section{Roadway System Managers}

Transportation system managers are responsible for real-time and day-to-day operations of road networks, and include persons and entities such as transportation management center (TMC) operators, state DOTs, and traffic information providers. Roadway system managers, who may make operational decisions and select and implement intelligent transportation systems, are directly responsible for protecting and improving reliability; they are the agency personnel most affected by issues limiting the effectiveness of an agency in providing reliable travel. TMCs need and use travel time and reliability information to respond effectively to incidents and other events. Their needs are broadly characterized by surveillance, data processing, event response, and information dissemination to travelers and carriers. The L11 project identified some of the most commonly voiced concerns of roadway system managers:

- Lack of consistent, accurate traffic, travel, and reliability data;

- Lack of budgetary resources to expand their data collection programs;

- Travel times affected by factors or circumstances out of their control (e.g., adverse weather);

- Modest or unnoticeable improvement in travel time reliability following an action;
- Resistance to the adoption of performance measures because of concerns about adding additional processing and workload for already overloaded employees; and

- Lack of a current baseline against which to set goals.

Roadway system managers have three ways they can improve the reliability experienced by travelers:

1. Improve the routine operation of roadways through infrastructure improvements.

2. Reduce the number of disruptions that occur on the system or the duration of delay with the disruptions that do occur (or both).

3. Deliver quality and timely information to their customers to allow the user to take action to improve his or her overall travel experience.

To provide a more reliable travel experience for their customers, roadway system managers need tools and resources that allow them to better manage and improve their existing transportation system. Such resources allow them to maximize the performance of their system while minimizing the frequency and severity of events (factors) that cause disruption. The major factors causing disruption and affecting reliability are identified as incidents, weather, work zones, fluctuations in demand, special events, traffic control devices, and inadequate base capacity (Cambridge Systematics and Texas Transportation Institute 2005). Specifically, the factors to consider in evaluating reliability are recurring and incident (nonrecurring) congestion.

Recurrent congestion occurs predictably during peak hours and at bottleneck locations (e.g., lane drops or weaving sections). Incident congestion is relatively unpredictable and can occur during peak or off-peak hours and at any location along the roadway. In both cases, demand exceeds capacity and queues or delays are observed. However, in the case of incidents, the available capacity is further constricted by the occurrence of an event, such as a crash, vehicle disablement, or debris on the road. Typically, traffic incident occurrence is highly correlated with peak hours, complicating traffic operations. Fluctuation in demand created by the need of people to participate in daily activities at certain times and inadequate base capacity are principally responsible for the creation of recurrent congestion. Operational factors that further contribute to recurring congestion include adverse weather (e.g., people drive at reduced speeds on slippery roads), special events, work zones, and traffic control devices. Factors that contribute to incident (nonrecurring) congestion can include adverse weather (e.g., flooding reduces available capacity), traffic control devices (e.g., improperly timed ramp meters and traffic signals; see Bo and Hiroaki [2008] for more discussion), work zones, roadway geometry, speeds, and driver 
and vehicle factors (e.g., driver distractions and equipment failure). A variety of factors contribute to traffic congestion, which means that to make operational decisions about the transportation system, system managers need a different set of visual and analytical tools than policy makers.

\section{Reliability Experts}

The L02 study team reached out to three groups as part of the interview effort. The first group (Group A) included individuals who work with a TTRMS for a highway or transit agency. The second group (Group B) included experts in the field of reliability and performance monitoring; this group was primarily members of the L02 Technical Coordinating Committee. Although interviews have not yet been conducted with individuals in Group A, several Group B people interviewed could also be included in Group A. The third group (Group C) included service providers in the area of travel time reliability monitoring. Given the surveys conducted by L11, the L02 project team did not conduct interviews with passenger travelers or freight movers. Rather, the results related to user needs from the L11 focus group discussions were used.

\section{Group A: Individuals Who Work with Monitoring Systems}

The L02 team identified 10 to 15 agencies for the Group A interviews based on existing relationships and recommendations from others in the profession. Table 2.9 lists these agencies, as well as a general summary of the types of facilities

Table 2.9. Extent of Travel Time Monitoring by Agency and Type of Trip

\begin{tabular}{|c|c|c|c|c|c|c|c|}
\hline \multirow[b]{2}{*}{ Organization } & \multicolumn{3}{|c|}{ Urban Highway Agency } & \multicolumn{2}{|c|}{$\begin{array}{l}\text { Rural Highway Agency } \\
\text { or Resort Area }\end{array}$} & \multicolumn{2}{|c|}{ Transit Agency } \\
\hline & Commuter & $\begin{array}{l}\text { Truck or } \\
\text { Delivery }\end{array}$ & Transit & Recreational & $\begin{array}{l}\text { Truck or } \\
\text { Delivery }\end{array}$ & Commuter & Recreational \\
\hline Florida DOT & $\mathrm{x}$ & $\mathrm{X}$ & & $x$ & $\mathrm{x}$ & & \\
\hline Utah DOT & $\mathrm{x}$ & $\mathrm{x}$ & & $x$ & $x$ & & \\
\hline WSDOT & $\mathrm{x}$ & $\mathrm{X}$ & & $x$ & $x$ & & \\
\hline Georgia Regional Transportation Authority & $\mathrm{x}$ & $\mathrm{x}$ & $x$ & & & & \\
\hline San Antonio-Bexar City MPO (Texas) & $x$ & $x$ & & & & & \\
\hline Capital Area MPO (Austin, Tex.) & $x$ & $x$ & & & & & \\
\hline Puget Sound Regional Council (Seattle, Wash.) & $x$ & $x$ & $x$ & & & & \\
\hline $\begin{array}{l}\text { Metropolitan Transportation Commission } \\
\text { (San Francisco, Calif.) }\end{array}$ & $x$ & $x$ & $x$ & & & & \\
\hline $\begin{array}{l}\text { Greater Cleveland Regional Transit Authority } \\
\text { (Ohio) }\end{array}$ & & & & & & $x$ & $x$ \\
\hline TriMet (Portland, Ore.) & & & & & & $x$ & $x$ \\
\hline Chicago Transit Authority (Illinois) & & & & & & $x$ & $x$ \\
\hline Virginia DOT & $\mathrm{x}$ & $x$ & & $\mathrm{x}$ & $\mathrm{x}$ & & \\
\hline Ontario Ministry of Transportation & $x$ & $\mathrm{x}$ & & $x$ & $x$ & & \\
\hline Port Authority of New York and New Jersey & $x$ & $x$ & & & & & \\
\hline Kansas DOT (Kansas City Scout) & $x$ & $x$ & & & & & \\
\hline Missouri DOT (Kansas City Scout) & $\mathrm{x}$ & $x$ & & $\mathrm{x}$ & $x$ & & \\
\hline Wisconsin DOT & $x$ & $x$ & & $x$ & $x$ & & \\
\hline King County Metro (greater Seattle) & & & & & & $x$ & $x$ \\
\hline Mid-America Regional Council-Kansas City & $x$ & $x$ & $x$ & & & & \\
\hline $\begin{array}{l}\text { Southern California Association of } \\
\text { Governments }\end{array}$ & $\mathrm{x}$ & $x$ & & & & & \\
\hline Jet Express, Inc. & & $x$ & & & $x$ & & \\
\hline Bonneville County, Idaho, MPO & $\mathrm{x}$ & $\mathrm{X}$ & & & & & \\
\hline
\end{tabular}


and trips those agencies monitor. The following agencies were interviewed:

- WSDOT;

- TriMet (Portland, Oregon);

- Virginia DOT;

- Ontario Ministry of Transportation;

- Port Authority of New York and New Jersey;

- Kansas DOT (Kansas City Scout);

- Missouri DOT (Kansas City Scout); and

- Jet Express, Inc.

The key for this effort was to ensure that agencies of different types, generally including urban highway agencies, rural highway agencies and resort areas, and transit agencies, would all be represented throughout the course of the interview process. In addition to conducting interviews with these three types of agencies, the L02 project team considered different trip types, including recreational, commuter, truck or delivery, and transit trips.

\section{Group B: Individuals Who Are Leaders in the Field of Reliability}

The L02 project team invited all Technical Coordinating Committee members to participate in small group teleconference discussions. These teleconferences comprised the core of the interview process and allowed the L02 team to participate in more in-depth discussions regarding performance monitoring and travel time reliability.

The $\mathrm{L} 02$ project team developed a set of questions to guide the discussions with Group B members. Each focus group interview was unique, and flexibility was built into the discussions to allow ideas to flow from the participants while still providing guidance to gather information on key aspects of travel time reliability. The primary goal of these questions was to answer the "who, what, where, when, and why" questions of monitoring travel time reliability. These questions were organized into five general categories and provided to the members of each interview before their scheduled interview time. For each category, Table 2.10 provides example questions, a summary of the key takeaway points, and the relative amount of information received.

As Table 2.10 shows, the team received medium to high amounts of feedback under four of the five general categories. Education (for both agency staff members and the traveling public) and outreach efforts related to reliability monitoring had limited amounts of feedback, with many individuals mentioning the ongoing efforts of the Transportation Research Board, AASHTO, and FHWA, but not much discussion regarding specific educational efforts of staff within different agencies. In addition, there was very little discussion about public educational outreach programs on reliability.

Table 2.10. Interview Categories for Reliability Leaders and Information Received

\begin{tabular}{|c|c|c|c|}
\hline Category & Key Questions & Key Takeaway Points & $\begin{array}{l}\text { Relative Amount } \\
\text { of Information } \\
\text { Received }\end{array}$ \\
\hline $\begin{array}{l}\text { 1. Data Collec- } \\
\text { tion Practices } \\
\text { and Travel } \\
\text { Time Mea- } \\
\text { surement } \\
\text { Tools }\end{array}$ & $\begin{array}{l}\text { Do you currently use travel time reliability as a per- } \\
\text { formance measure for your system? If so, how } \\
\text { do you measure it? Where, when, and for what } \\
\text { facilities, areas, corridors, or O-D pairs do you } \\
\text { measure it? } \\
\text { What information is gathered to monitor travel time } \\
\text { reliability? How do you obtain travel time } \\
\text { information? } \\
\text { Are the travel time reliability results archived and/ } \\
\text { or reported? }\end{array}$ & $\begin{array}{l}\text { Many new and emerging data collection technolo- } \\
\text { gies exist, but agencies are still using inductive } \\
\text { loops as the most common source for travel } \\
\text { time and speed data. } \\
\text { Quality control and management of tools and data } \\
\text { are very time intensive and take more resources } \\
\text { than most agencies have available. } \\
\text { Partnerships with other public and private agen- } \\
\text { cies are vital when it comes to assembling the } \\
\text { resources necessary to accurately record and } \\
\text { archive data. }\end{array}$ & Medium \\
\hline $\begin{array}{l}\text { 2. Communica- } \\
\text { tion to Users }\end{array}$ & $\begin{array}{l}\text { What information is presented to the users of your } \\
\text { system, and how is it presented? } \\
\text { In the future, what reliability information can you } \\
\text { envision being delivered to system users and in } \\
\text { what forms? } \\
\text { Do you provide pretrip information to users on } \\
\text { system conditions? If so, what media is this } \\
\text { communicated through? }\end{array}$ & $\begin{array}{l}\text { A few agencies are experimenting with reporting } \\
\text { reliability measures. Overall, most users seem } \\
\text { more interested in knowing travel times rather } \\
\text { than travel time variance. } \\
\text { Reliability measures seem to be more useful when } \\
\text { communicating pretrip information. } \\
\text { Users are demanding travel time information on } \\
\text { alternate routes. } \\
\text { Providing travel time or arrival information causes } \\
\text { users to perceive the system as reliable. } \\
\text { With all of the technology available, agencies } \\
\text { need to better understand the most effective } \\
\text { and efficient means by which to communicate } \\
\text { reliability information. }\end{array}$ & High \\
\hline
\end{tabular}


Table 2.10. Interview Categories for Reliability Leaders and Information Received (continued)

\begin{tabular}{|c|c|c|c|}
\hline Category & Key Questions & Key Takeaway Points & $\begin{array}{l}\text { Relative Amount } \\
\text { of Information } \\
\text { Received }\end{array}$ \\
\hline $\begin{array}{l}\text { 3. Business } \\
\text { Processes } \\
\text { and Future } \\
\text { Monitoring } \\
\text { Plans }\end{array}$ & $\begin{array}{l}\text { To what extent do you incorporate information } \\
\text { about travel time reliability into day-to-day } \\
\text { operations? } \\
\text { Do you have quantitative or qualitative goals with } \\
\text { respect to reliability? What are the challenges } \\
\text { you face with setting reliability goals? } \\
\text { Are there gaps in the travel time information you } \\
\text { use that need filling? Are there other deficiencies } \\
\text { that need improvement? }\end{array}$ & $\begin{array}{l}\text { Using reliability measures is a goal of many } \\
\text { agencies, but the way they are used varies. } \\
\text { Examples are planning and programming, user } \\
\text { cost assessments, and performance } \\
\text { assessments. } \\
\text { Need to develop reliability initiatives at the } \\
\text { national level and encourage partnerships at the } \\
\text { local level to more easily reach goals estab- } \\
\text { lished by initiatives. } \\
\text { Few agencies monitor reliability on roadways } \\
\text { other than freeways. }\end{array}$ & High \\
\hline $\begin{array}{l}\text { 4. Performance } \\
\text { Measures }\end{array}$ & $\begin{array}{l}\text { What travel time reliability performance measures } \\
\text { or indices do you monitor? Are these measures } \\
\text { archived, tracked, or analyzed in any way? } \\
\text { Under what system conditions do you monitor } \\
\text { travel time reliability (relating to the seven fac- } \\
\text { tors influencing reliability)? } \\
\text { What spatial and temporal levels of detail do you } \\
\text { capture in your existing monitoring system and } \\
\text { would you prefer more or less detail? }\end{array}$ & $\begin{array}{l}\text { Understanding the "why" behind the variability is } \\
\text { important for agencies to mitigate the problem } \\
\text { behind the variability. } \\
\text { Agencies would like more guidance on evaluating } \\
\text { performance measures on a network level. } \\
\text { Need to identify measures most clearly portrayed } \\
\text { to the public and that are not facility or mode } \\
\text { specific. }\end{array}$ & Medium \\
\hline $\begin{array}{l}\text { 5. Education } \\
\text { and } \\
\text { Outreach }\end{array}$ & $\begin{array}{l}\text { What resources do you most commonly use to } \\
\text { educate your organization on travel time reliabil- } \\
\text { ity monitoring practices? } \\
\text { Does your organization provide public information } \\
\text { programs to educate users on how to use travel } \\
\text { time reliability monitoring resources? } \\
\text { Do users generally feel the system is reliable and, } \\
\text { if so, why? If not, what do you think could be } \\
\text { implemented to change their perception? }\end{array}$ & $\begin{array}{l}\text { The traveling public is intuitively aware of reliability } \\
\text { concepts, but this intuition must be enhanced } \\
\text { with educational tools that are marketable and } \\
\text { easily accessible to the public. } \\
\text { It is important to share information among agen- } \\
\text { cies to advance the research and implementa- } \\
\text { tion of reliability programs. } \\
\text { Effective outreach strategies must be centered on } \\
\text { what users perceive and value and what they will } \\
\text { listen to and comprehend in regard to reliability } \\
\text { reporting. } \\
\text { The guidebook ought to (1) compile best prac- } \\
\text { tices, (2) provide specific examples, (3) pro- } \\
\text { vide guidance on reporting reliability for all } \\
\text { user types, and (4) address integration with } \\
\text { the private sector. }\end{array}$ & Low \\
\hline
\end{tabular}

Note: $\mathrm{O}-\mathrm{D}=$ origin-destination.

\section{Use Cases}

Based on all of the interviews conducted and the earlier L11 work, a set of 51 use cases was developed. These use cases were intended to form the functional specifications for a TTRMS and were designed to fit the template shown in Table 2.11. Each use case provides a definition of the type of person asking the question (user), the question being posed, the steps involved in answering the question, the inputs needed to answer the question, and the result expected.

Three additional notes about the use cases are important. First, even though people think about on time as meaning not missed, there is no guarantee about being on time. Here on time means arriving with a certain probability of not being late (or possibly early, as is often the case for freight shipments). Second, unless the text says otherwise, TT-PDF always refers to the travel time probability density function

\section{Table 2.11. Use Case Template}

\begin{tabular}{|l|l|}
\hline User & Type of TTRMS user posing the question. \\
\hline Question & $\begin{array}{l}\text { A description of the inquiry and why it would be } \\
\text { posed. }\end{array}$ \\
\hline Inputs & $\begin{array}{l}\text { A list of the actions that have to be performed to } \\
\text { answer the question. }\end{array}$ \\
\hline $\begin{array}{l}\text { The data and information needed to answer the ques- } \\
\text { tion. This description helps users understand the } \\
\text { inputs required and helps programmers understand } \\
\text { the data inputs that must be assembled. }\end{array}$ \\
\hline Result & The system output at the completion of the use case. \\
\hline
\end{tabular}


for individual vehicle travel times; TT-CDF refers to the travel time cumulative density function. Third, fairly technical information is presented for the results (e.g., TT-PDFs for the routes that might be selected). This does not mean that such information is the only way to convey the results. Rather, it implies that such information is the basis for the answer; the communication paradigm might be simpler, as in a single number (e.g., from L14).

The use cases are clustered around types of TTRMS users most likely to make the inquiry. They are also broken down into providers and consumers (i.e., the supply and demand sides of system use). The stakeholders, shown in Table 2.12, come from four categories:

- Policy and planning support: Agency administrators and planners who have responsibility for and make capital investment and operational decisions about the system;

- Overall highway system: Operators of the roadway system (supply), including its freeways, arterials, collectors, and local streets; and drivers of private autos, trucks, and transit vehicles (demand);

- Transit subsystem: Operators of transit systems that operate on the highway network, primarily buses and light rail (supply) and riders (demand); and
Table 2.12. User Types and Their Classification

\begin{tabular}{|c|c|c|}
\hline System User Type & $\begin{array}{l}\text { Service Provider } \\
\text { (Supply) }\end{array}$ & User (Demand) \\
\hline $\begin{array}{l}\text { Policy and planning } \\
\text { support }\end{array}$ & $\begin{array}{l}\text { Administrators and } \\
\text { planners }\end{array}$ & na \\
\hline $\begin{array}{l}\text { Overall highway } \\
\text { system }\end{array}$ & $\begin{array}{l}\text { Highway system } \\
\text { operators (public } \\
\text { or private) }\end{array}$ & $\begin{array}{l}\text { Privately owned vehi- } \\
\text { cle drivers, taxi } \\
\text { drivers, limousine } \\
\text { drivers }\end{array}$ \\
\hline Transit subsystem & $\begin{array}{l}\text { Transit operators, } \\
\text { transit vehicle } \\
\text { operators }\end{array}$ & Transit passengers \\
\hline Freight subsystem & $\begin{array}{l}\text { Carriers, freight } \\
\text { movers, truck } \\
\text { drivers }\end{array}$ & $\begin{array}{l}\text { Freight customers } \\
\text { (including both } \\
\text { shippers and } \\
\text { receivers) }\end{array}$ \\
\hline
\end{tabular}

Note: na $=$ not applicable

- Freight subsystem: Freight service suppliers (supply) and shippers and receivers that make use of those services (demand).

The use cases, which are listed in Table 2.13, are categorized consistent with Table 2.12 into groups that pertain to agency administrators and planners, system operators and

Table 2.13. Use Cases for a Travel Time Reliability Monitoring System

\begin{tabular}{|c|c|c|}
\hline Category & Subgroup & Use Case \\
\hline $\begin{array}{l}\text { System administrators } \\
\text { and planners }\end{array}$ & $\begin{array}{l}\text { Administrators } \\
\text { Planners }\end{array}$ & $\begin{array}{l}\text { AE1: See what factors affect reliability } \\
\text { AE2: Assess the contributions of the factors } \\
\text { AE3: View the travel time reliability of a subarea } \\
\text { AE4: Assist planning and programming decisions } \\
\text { AE5: Document agency accomplishments } \\
\text { AE6: Assess progress toward long-term reliability goals } \\
\text { AE7: Assess the reliability impact of a specific investment } \\
\text { AP1: Find the facilities with highest variability } \\
\text { AP2: Assess the reliability trends over time for a route } \\
\text { AP3: Assess changes in the hours of unreliability for a route } \\
\text { AP4: Assess the sources of unreliability for a route } \\
\text { AP5: Determine when a route is unreliable } \\
\text { AP6: Assist rural freight operations decisions }\end{array}$ \\
\hline $\begin{array}{l}\text { Roadway network } \\
\text { managers and users }\end{array}$ & $\begin{array}{l}\text { Managers } \\
\text { Drivers-constrained trips } \\
\text { Drivers-unconstrained } \\
\text { trips }\end{array}$ & $\begin{array}{l}\text { MM1: View historical reliability impacts of adverse conditions } \\
\text { MM2: Be alerted when the system is struggling with reliability } \\
\text { MM3: Compare a recent adverse condition with prior ones } \\
\text { MM4: Gauge the impacts of new arterial management strategies } \\
\text { MM5: Gauge the impacts of new freeway management strategies } \\
\text { MM6: Determine pricing levels using reliability data } \\
\text { MC1: Understand departure times and routes for a trip } \\
\text { MC2: Determine a departure time and route just before a trip } \\
\text { MC3: Understand the extra time needed for a trip } \\
\text { MC4: Decide how to compensate for an adverse condition } \\
\text { MC5: Decide en route whether to change routes } \\
\text { MU1: Determine the best time of day to make trip } \\
\text { MU2: Determine how much extra time is needed }\end{array}$ \\
\hline
\end{tabular}


Table 2.13. Use Cases for a Travel Time Reliability Monitoring System (continued)

\begin{tabular}{|c|c|c|}
\hline Category & Subgroup & Use Case \\
\hline \multirow[t]{4}{*}{ Transit system } & Transit planners & $\begin{array}{l}\text { TP1: Determine routes with the least travel time variability } \\
\text { TP2: Compare exclusive bus lanes with mixed-traffic operations }\end{array}$ \\
\hline & Transit schedulers & $\begin{array}{l}\text { TS1: Acquire reliability data for building schedules } \\
\text { TS2: Choose departure times to minimize arrival uncertainty }\end{array}$ \\
\hline & Transit operators & $\begin{array}{l}\text { TO1: Identify routes with the poorest reliability } \\
\text { TO2: Review reliability for a route } \\
\text { TO3: Examine the potential impacts of bus priority on a route } \\
\text { TO4: Assess a mitigating action for an adverse condition }\end{array}$ \\
\hline & Transit passengers & $\begin{array}{l}\text { TC1: Determine the on-time performance of a trip } \\
\text { TC2: Determine an arrival time just before a trip } \\
\text { TC3: Determine a friend's arrival time } \\
\text { TC4: Understand a trip with a transfer }\end{array}$ \\
\hline \multirow[t]{2}{*}{ Freight system } & Freight service providers & $\begin{array}{l}\text { FP1: Identify the most reliable delivery time } \\
\text { FP2: Estimate a delivery window } \\
\text { FP3: Identify how to maximize the probability of an on-time } \\
\text { delivery } \\
\text { FP4: Assess the on-time probability for a scheduled shipment } \\
\text { FP5: Assess the impacts of adverse highway conditions } \\
\text { FP6: Determine the start time for a delivery route } \\
\text { FP7: Find the departure time and routing for a set of deliveries } \\
\text { FP8: Solve the multiple vehicle routing problem under } \\
\text { uncertainty } \\
\text { FP9: Alter delivery schedules in real time }\end{array}$ \\
\hline & Freight customers & $\begin{array}{l}\text { FC1: Minimize shipping costs due to unreliability } \\
\text { FC2: Determine storage space for just-in-time deliveries } \\
\text { FC3: Find the lowest-cost reliable origin } \\
\text { FC4: Find the warehouse site with the best distribution reliability }\end{array}$ \\
\hline
\end{tabular}

users, transit passengers, schedulers or operators, and freight customers or operators.

Only one of the use case analysis procedures is described here in detail. Table 2.14 shows Use Case AE1, which focuses on the contributions of various factors to the reliability of a segment or route.

\section{Summary}

The traffic content business is a complex, growing field. The range of data sources available is growing constantly. Public agencies and private firms are using a wide array of technologies to assemble the data on which their travel time assessments are based. Overall, however, with a few exceptions, travel time reliability information is seldom made available to potential users in a format that can help them make informed travel decisions. There is substantial variation in the format and sources by which reliability information is disseminated by agencies.

The array of individuals and firms that want to make use of travel time reliability information is rich and expansive. In general, agency administrators and planners want summary information about system performance. They want to know how various factors (e.g., growing demand, inclement
Table 2.14. See What Factors Affect Reliability (AE1)

\begin{tabular}{|l|l|}
\hline User & Agency administrator \\
\hline Question & What factors affect reliability? \\
\hline Steps & $\begin{array}{l}\text { 1. Select the system of interest (e.g., a region or set } \\
\text { of facilities). } \\
\text { 2. Select the time frame for the analysis: the date } \\
\text { range, days of the week, and times of day. } \\
\text { 3. Assemble travel time (travel rate) observations for } \\
\text { the system for the time frame of interest. }\end{array}$ \\
$\begin{array}{l}\text { 4. Label each observation in terms of the regime } \\
\text { that was operative at the time the observation } \\
\text { was made (i.e., each combination of nominal con- } \\
\text { gestion and nonrecurring event, including none). }\end{array}$ \\
$\begin{array}{l}\text { 5. Prepare TR-PDFs for each regime identified. } \\
\text { 6. Analyze the contributions of the various factors } \\
\text { so that the differences in impacts can be } \\
\text { assessed. }\end{array}$ \\
\hline Inputs & $\begin{array}{l}\text { Travel times and rates for the system and date range } \\
\text { of interest plus information about the nominal sys- } \\
\text { tem loading that would have been expected and } \\
\text { any nonrecurring events. }\end{array}$ \\
\hline Result & $\begin{array}{l}\text { A set of TR-PDFs that portray the impacts of various } \\
\text { factors on travel time reliability. }\end{array}$ \\
\hline
\end{tabular}

Note: TR-PDF = travel rate probability density function. 
weather) affect reliability so they can make investment decisions or formulate policies to help ensure system reliability will be acceptable. System operators, transit operators, and freight service providers think in terms of service provided: whether trips take longer or shorter than they ought to or they promised they would. These inquirers want technical, quantitative information, both (near) real-time data for operations management and archived historical trend data for strategic and investment planning. Drivers, transit riders, and shippers want qualitative, anecdotal and objective, quantitative information about reliability. They think in terms of deviations in trip time relative to the total trip time or how often they (or their shipments) are able to arrive within a particular time window. What they experience affects departure times, mode choice, route choice, and even destination and location choices. Moreover, they make location decisions based on expected network reliability. Factors that affect reliability are clearly of interest to all system users. Some factors are internal to the system, such as its operational control (e.g., signal timing), base capacity, and maintenance (e.g., work zones); others relate to the users, like incidents, unusually high demand, and special events; and still others are related to exogenous factors like weather and the performance of complementary and competing modes. 


\section{CHAPTER 3 \\ Functional Specifications}

A travel time reliability monitoring system (TTRMS) is intended to be an add-on to existing traffic management systems. Its structure is shown in Figure 3.1. Inside the main box are the three major modules: the data manager, the computational engine, and the report generator. The data manager assembles incoming data from traffic sensors and other systems, such as weather data feeds and incident reporting systems, and places them in a database that is ready for analysis as "cleaned data." The computational engine works off the cleaned data to prepare pictures of the system's reliability: when it is reliable, when it is not, to what extent, under what conditions, and so forth. In Figure 3.1 this is illustrated by "regime TT-PDFs" (i.e., travel time probability density functions) that show the distribution of travel times under various conditions (regimes). The report generator responds to inquiries from users (system managers or travelers) and uses the computation engine to analyze the data and provide information that can then be presented to the inquirer or decision maker.

\section{Analytical Process}

A TTRMS uses four key steps, as illustrated in the conceptual diagram of information flow shown in Figure 3.2.

First, a TTRMS measures travel times. This is a complex technical task due to the variability of traveler behavior and the plethora of types of measurement sensors. Correctly measuring travel times along a given route requires a great deal of systems development effort and statistical knowledge. This report serves as a primer on how to effectively measure travel times using available technologies and statistical techniques. Measuring an individual travel time on a segment or route is the foundational unit of analysis for reliability monitoring.

Second, a TTRMS characterizes the reliability of a given system. This is the process of taking a set of measured travel times and assembling them into a statistical model of the behavior of a given segment or route. The statistical paradigm outlined in this report is that of using PDFs to characterize the performance of a given segment or route, usually specific to a particular operating regime (a combination of congestion level and nonrecurring events). This report gives specific advice on the statistical decisions required to effectively characterize the travel times. Characterizing the reliability of a segment or route is fundamental to making good decisions about what to do to improve the performance of that segment or route.

Third, a TTRMS identifies the sources of unreliability. Once the reliability of a segment or route has been characterized, transportation managers need to understand the correlates of unreliability (and how to correct it). The report follows the list of factors that FHWA uses to describe why congestion arises, breaking these sources into the seven major influencing factors (two internal and five external) described previously (Federal Highway Administration 2008). It discusses how to organize data into time intervals when these influencing factors were at work and produce descriptions of travel time reliability (TT-PDFs) associated with these various factors. Identifying the travel times affected by these sources of congestion is required preparation for understanding system reliability.

Finally, a TTRMS helps operators understand the impact of these sources of unreliability on the system. For example, to mitigate the impact of incidents, service patrols and changeable message signs that can reroute traffic may be considered; to mitigate work zone congestion, construction traffic mitigation and smart work zones may be considered. This final step in turning raw data into options and actionable decisions requires both quantitative and qualitative methodologies: operators need clear visualizations of data, as well as quantifications. This dual approach supports both data discovery and final decision making about a given segment or route. Understanding reliability is the key to good decision making about improving system reliability.

A TTRMS enables decision makers to understand how much of the delay is due to unreliability and prompts ideas about how to mitigate that delay. For example, should a freeway operator 


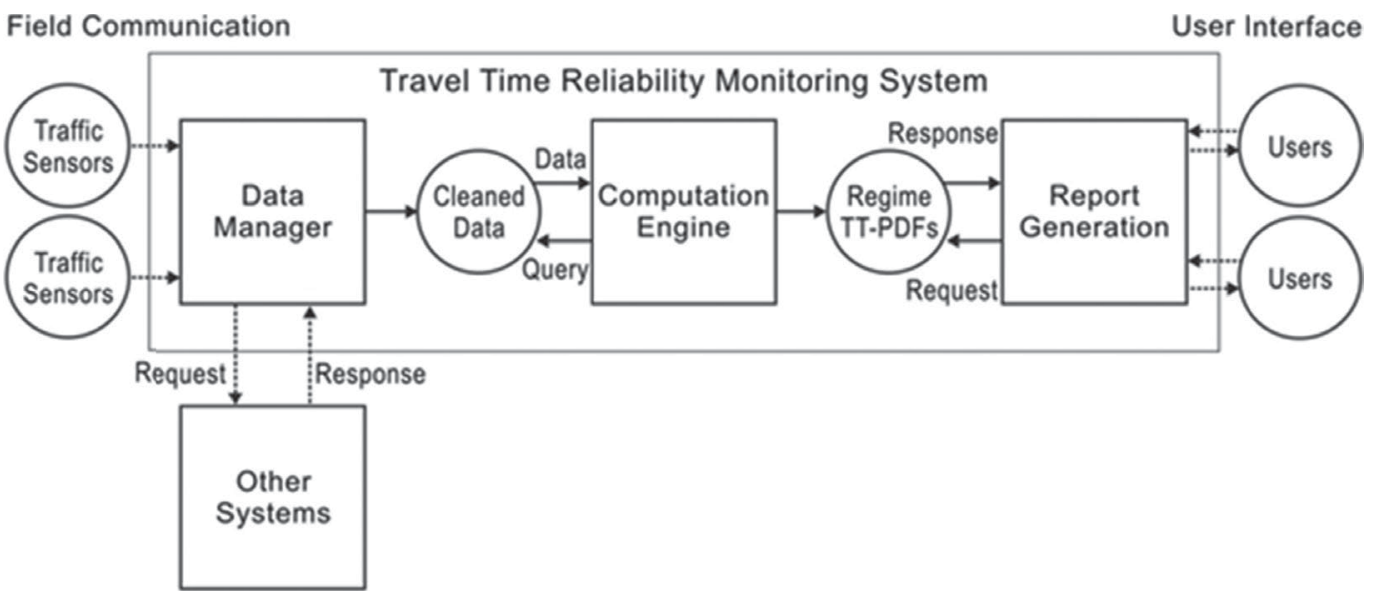

Figure 3.1. Reliability monitoring system overview.

deploy more service patrol vehicles (to clear incidents more quickly) or focus efforts on coordinating special event traffic (to reduce delay from stadium access)? Although knowledge about the effectiveness of various mitigation actions can be scarce, service patrols in urban areas are known to be effective in ameliorating incident effects and reducing their durations; to help reduce congestion caused by special event traffic, changeable message signs can effectively divert travelers to alternate routes when displaying the right content and placed appropriately at decision points. A reliability monitoring system, as outlined in this report, can help an operator understand which of these activities is worth the investment, and what the payoff might be. Such systems add a new, powerful, practical traffic management tool to the arsenal of system operators.

\section{Key Features}

This section describes the key features that the L02 study team believes need to be part of any TTRMS.

\section{Monuments}

Travel times should be based on travel times to and from monuments. A monument is a measurement point to and from

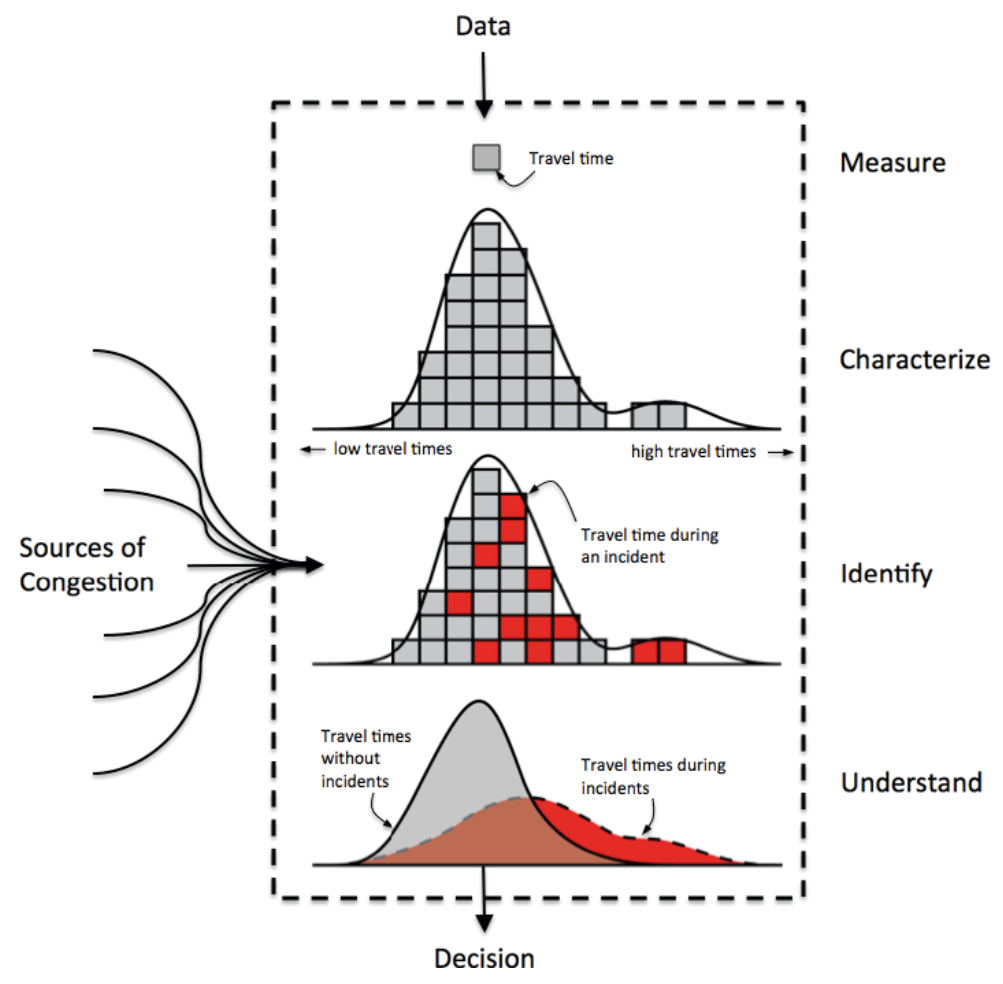

Figure 3.2. Information flow in a TTRMS. 
which travel times are measured. As illustrated in Figure 3.3, the monuments should be at the midpoints of the physical links. This placement removes the travel time ambiguity that arises if intersections and interchanges are used.

Vehicle trajectories between the monuments are all the same. They include the same delays associated with the turning movements. The correct turning movement delay is included in each monument-to-monument travel time. This is clearly important for arterials, but it is also important for freeways. Ramp movements can have different travel times (e.g., direct ramp or loop ramp, as well as any traffic control on the ramp, such as a signal, which is sometimes the case in Los Angeles).

The monuments need to be locations that the traffic management center uses to monitor the system, such as the locations of system detectors on both the freeway and arterial networks. This positioning minimizes the database management tasks involved in keeping track of where the monuments are located. Monuments can also be linked to the location of toll tag readers and automated vehicle identification (AVI) sensors. They should not be placed at locations where standing queues occur.

\section{Fundamental Units of Data}

Every TTRMS will be based on some set of fundamental units of data. The L02 study team worked most often with 5-minute average speeds from system (loop) sensors and individual vehicle travel times (from AVI- or automated vehicle location [AVL]-equipped vehicles). In the case studies, finer-grained

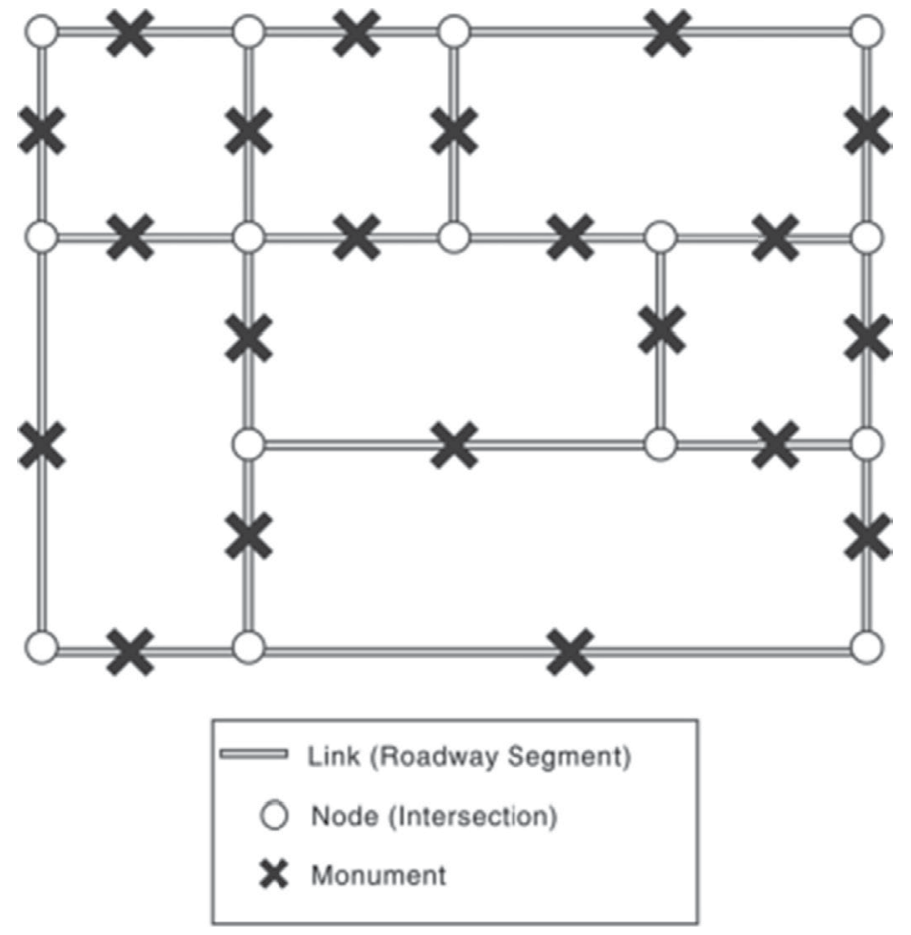

Figure 3.3. Illustration of monuments. system sensor data were often available (down to 30-second intervals), but they was not used. Aggregated values based on individual vehicle travel times (e.g., averages) also could have been developed, but they were not. This final report and the Guide most often refer to 5-minute system detector data and individual vehicle travel times.

An advantage to the system (loop) detectors is that they provide information that is based on all the vehicles in the traffic stream (Enam and Al-Deek 2006). The disadvantage is that no individual vehicle data are provided. The individual vehicle data (e.g., speed) are observed but are not reported by the monitoring station.

An advantage to the AVI- and AVL-based data is that data for individual vehicles are reported (List, Demers et al. 2005a; List, Wallace et al. 2005b; List and Demers 2006; Demers et al. 2006a; Demers et al. 2006b; Byon et al. 2006; Dion and Rakha 2006; Feng et al. 2011; Fontaine and Smith 2005; Li et al. 2006; Hoeitner et al. 2012; Vanajakshi et al. 2009; Liu et al. 2010; Xiaoliang and Koutsopoulos 2008; Lin et al. 2003; Ma and Koutsopoulos 2010; Pan et al. 2007; Soriguera and Thorson 2007; Quiroga and Bullock 1998; Kaparias et al. 2008; Wasson et al. 2008; De Fabritiis et al. 2008; Ma et al. 2009; Liu et al. 2007; Wojtowicz et al. 2008; Yamamoto et al. 2006; Yamazaki et al. 2012). These data include speeds, travel times and, in the case of AVL data, complete trajectories (Cetin et al. 2005; Yang et al. 2011; Ernst et al. 2012; Haghani et al. 2010). The disadvantage is that only vehicles equipped with discoverable Bluetooth devices or tags are observed, which means there can be a bias in the observations vis-à-vis the overall traffic stream. See Kwon et al. (2007) and Martchouk et al. (2011) for an interesting discussion on this topic.

Investigators have also used buses, trucks, and other vehicles as probes for collecting travel time data, but these information sources are not reviewed in detail here. Studies that have examined these sources include Hall and Nilesh (2000), Berkow et al. (2008), Bertini et al. (2005), Chakroborty and Kikuchi (2004), and Uno et al. (2009).

\section{Imputation to Fill Data Voids}

It is important to use imputation to fill voids caused by missing data. This topic is discussed more fully below; see also Wang et al. (2008). To monitor travel time reliability, high-quality, real-time data must be available. Missing data interferes with this objective. Within obvious limits, these missing data values should be estimated. This pertains to data like spot speeds (spot rates) from system detectors, as well as segment and route travel time data obtained from AVI- and AVL-based systems.

\section{Real-Time Data for Nonrecurring Events}

Information about nonrecurring events needs to be collected in real time from sources that provide such information. Some 
monitoring systems already collect incident data and make them available for current and future analysis. But weather and special events data are often not collected. Much of these data are perishable; if they are not collected as events unfold, they can be lost. When that happens, it becomes either very labor intensive or impossible to determine why specific travel times arose. For special situations or special analyses it may be possible to assemble this information ex post facto (the L02 study team did so several times for the case studies and use case analyses), but for operating agencies this is not a reasonable option.

This design feature has several implications. One is that the sources for this information have to be identified, and realtime data feeds have to be established. Another is that data structures need to be created to store the data. A third is that fields have to be added to the travel time monitoring records so that linkages are created between the travel times and the nonrecurring events. Finally, tools and techniques have to be developed that allow the monitoring system to automatically link nonrecurring events to travel time observations. This is not trivial because the nonrecurring events may be on adjacent facilities — upstream, downstream, or even in the opposite direction —of the segment where the unusual travel times arose.

\section{Regimes for Data Classification}

A TTRMS needs to classify travel time observations on the basis of the regime (operating condition) that was operative at the time when the travel times were obtained. This avoids misinterpreting and misunderstanding the impacts of congestion and nonrecurring events.
The study team recommends that these regimes should be based on a combination of a nominal congestion condition (e.g., uncongested or low, moderate, or high congestion) and a nonrecurring event condition (e.g., none, weather, incident, special event) as shown in Figure 3.4. Ultimately, it is for these conditions that the PDFs are developed and by which, through the PDFs, the reliability performance of the segment, route, or facility is understood and analyzed and for which actions are taken to improve reliability.

For most practical applications, it appears sufficient to assess the congestion condition at a 5-minute granularity. One minute seems too short, and 15 minutes is too long. In 15 minutes, the operating conditions can change dramatically, especially during heavy congestion.

The nonrecurring event categories should be consistent with FHWA's seven sources of congestion. The insufficient base capacity condition is captured by the congestion condition categories (i.e., situations when the demand-to-capacity ratio is high enough that sustained queuing occurs). The highdemand category is equivalent to fluctuations in demand.

\section{Travel Rates in Addition to Travel Times}

A TTRMS should focus on analyzing travel rates as well as travel times. The travel rate is obtained by dividing the travel time by the distance traveled. Travel rates make it possible to compare the performance of one segment with another and one route with another (in terms of the distribution of the travel rates involved). Spot rates, which are the inverses of spot speeds, are also important to study. They are measured at a specific location by observing the speed and computing the inverse.

\begin{tabular}{|c|c|c|c|c|c|c|}
\hline \multicolumn{7}{|c|}{ Reliability Regimes } \\
\hline & \multicolumn{6}{|c|}{ Nonrecurring Condition } \\
\hline & \multirow[b]{2}{*}{ None } & \multicolumn{5}{|c|}{ One of Several } \\
\hline Condition & & Weather & Incident & $\begin{array}{c}\text { High } \\
\text { Demand }\end{array}$ & $\begin{array}{c}\text { Special } \\
\text { Event }\end{array}$ & $\begin{array}{l}\text { Work } \\
\text { Zone }\end{array}$ \\
\hline \multicolumn{7}{|c|}{ Uncongested } \\
\hline \multicolumn{7}{|l|}{ Low } \\
\hline \multicolumn{7}{|l|}{ Moderate } \\
\hline High & & & & & & \\
\hline
\end{tabular}

Figure 3.4. Classifying travel time observations by operating regime. 


\section{Probability Density Functions and Cumulative Density Functions}

A TTRMS should focus on creating and analyzing TT-PDFs and travel rate PDFs. Through the case studies and use cases, it was found that the PDFs and cumulative density functions (CDFs) were both necessary and sufficient to address the reliability issues involved or the questions posed. A corollary is that a TTRMS can produce other metrics derived from the PDF (e.g., the travel time index or the buffer time index), and it does so by analyzing the PDF.

Figure 3.5 shows the kinds of CDFs that a TTRMS should produce. It plots the distribution of 5-minute average travel rates on I-8 westbound in San Diego across a 3-month period under various regimes.

Because the plots are CDFs, each point on each line shows how many 5-minute average travel times for that regime were equal to or less than the value shown on the $x$-axis. For example, when inclement weather occurs during heavy (recurrent) congestion, one-half $(50 \%)$ of the travel rates (in seconds per mile) are up to $70 \mathrm{~s} / \mathrm{mi}$. That is, $50 \%$ of the travel rates are this long or smaller. The 90th percentile travel rate is $110 \mathrm{~s} / \mathrm{mi}$. Or put another way, nine out of every 10 vehicles is traveling at that rate or faster.

The value comes from comparing one CDF with another. For example, analysts can compare the distribution for high recurring congestion and inclement weather with high recurring congestion without inclement weather. Without inclement weather, $50 \%$ of the vehicles are traveling at $52 \mathrm{~s} / \mathrm{mi}$ instead of $70 \mathrm{~s} / \mathrm{mi}$ - considerably faster. And at the 90 th percentile, the difference is even more dramatic: $58 \mathrm{~s} / \mathrm{mi}$ versus $110 \mathrm{~s} / \mathrm{mi}$.

Not only does Figure 3.5 indicate that the difference between the two conditions is large, but it also suggests that taking appropriate actions to mitigate these impacts would produce significant benefits in terms of improving reliability. The mitigating actions would be intended to cause the travel times (or travel rates) during incidents to get much closer to those when there are no incidents. Moreover, after the mitigating actions were taken, the TTRMS would be able to show how reliability improved.

\section{Times for Individual Vehicles and System Averages}

A TTRMS should be designed to collect and analyze individual vehicle travel times, as well as averages from system detectors. Although aggregated system data are far more common today, individual vehicle travel times address issues of system performance from the users' perspective.

Figure 3.6 illustrates how these measures are related. At any given point in time (e.g., during a given 5-minute time period on a given day), vehicles traverse a given segment or route. They produce travel times that can be summarized by a distribution. Two examples are shown in the upper part of

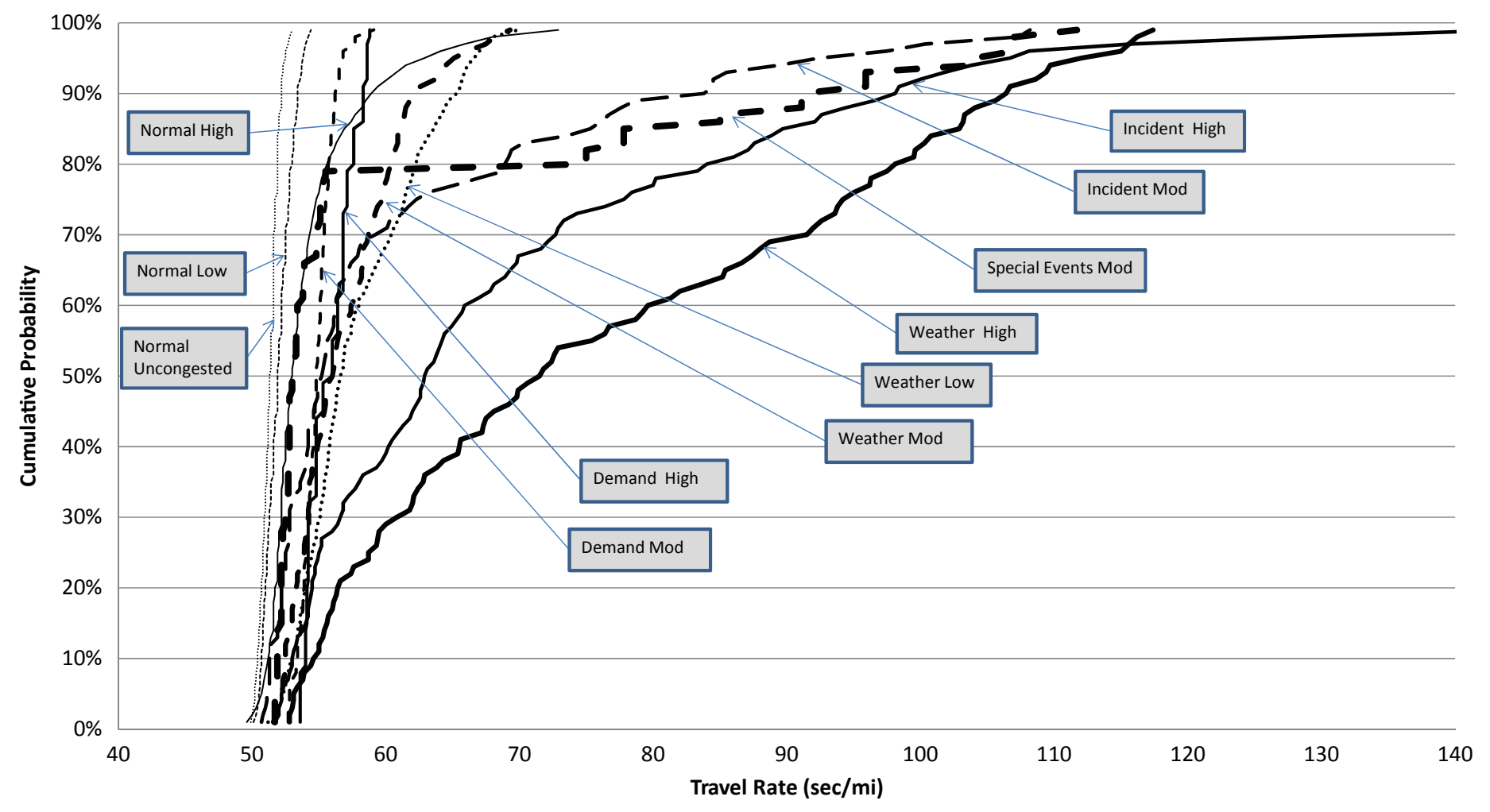

Figure 3.5. Effect on travel rates of congestion and nonrecurring incidents. 

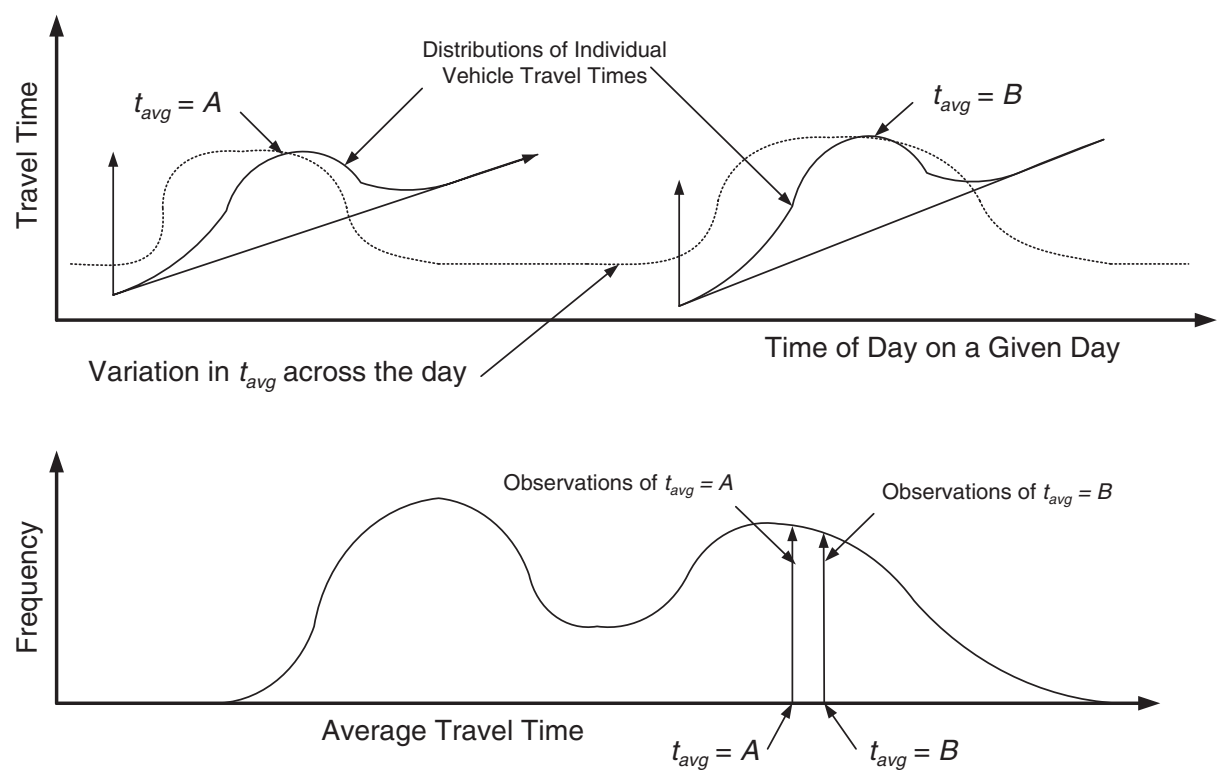

Figure 3.6. System average and individual vehicle travel times: (top) genesis of travel time data and (bottom) resulting distribution of $\mathrm{t}_{\text {avg. }}$

Figure 3.6: one toward the beginning of the day, and another toward the end. System detectors (e.g., loops and cameras) observe spot speeds (spot rates) for all of the vehicles, but only at specific locations. Bluetooth sensors, toll tag readers, and similar devices observe travel times for some of the vehicles.

Across an extended time frame, say a year, a distribution of the average travel times can be created as shown in the lower part of Figure 3.6. This distribution can be based on the same 5-minute time period each day (which analysts often use) or some collection of 5-minute time periods (such as the morning peak) that represents a given operating condition. It is these distributions of average travel times that system operators use to monitor the performance of their networks and make assessments of where and when corrective actions should be taken to reduce the variability in travel times (i.e., improve reliability).

The distributions of individual vehicle travel times can also be developed and studied if the data are available so that the system performance received by (given to) the individual users can also be assessed. At present it is uncommon for system managers to examine these distributions, but as vehicle-monitoring technologies become more prevalent, it is likely that such information will be used for decision-making purposes.

\section{Segment-Level Travel Times}

Segment-level travel times are the fundamental building blocks in terms of travel time measurements for a highway network. A segment is a path between two monuments. In the case of system-level detectors, segments are often defined as being sections of freeways (or arterials) immediately upstream and downstream of a system detector as illustrated in Chapter 6, Figure 6.2; see Kwon et al. (2000). For AVI-based systems, segments are often links (one-way arcs) between AVI monitoring stations. For AVL-based systems, segments can be defined to and from whatever locations seem most useful or appropriate, still in keeping with the notion of where to locate monuments.

\section{Nonparametric Analysis Techniques}

A key feature of a TTRMS is its analysis of PDFs using nonparametric techniques; more simply, it focuses on the entire density function (Rosenblatt 1956; Silverman 1986). As described above, the density functions are frequently multimodal, and the details of each mode are critical in understanding what is happening or has happened from a reliability perspective. It seems that no parametrically based distribution, even a multimodal parametrically based distribution, can serve adequately as a building block on which a TTRMS can be based. Figure 3.7 illustrates this point in the context of travel times between South Lake Tahoe and Placerville, California, along US-50. Notice the extraordinarily rich diversity in the shapes of the CDFs.

\section{Route PDFs from Segment PDFs Using Correlation}

Since the data for specific routes is likely to be too thin to estimate route-level PDFs and CDFs directly, such information has to be synthesized by combining segment-level data. The 


\section{TT-CDFs for South Lake Tahoe to Placerville}

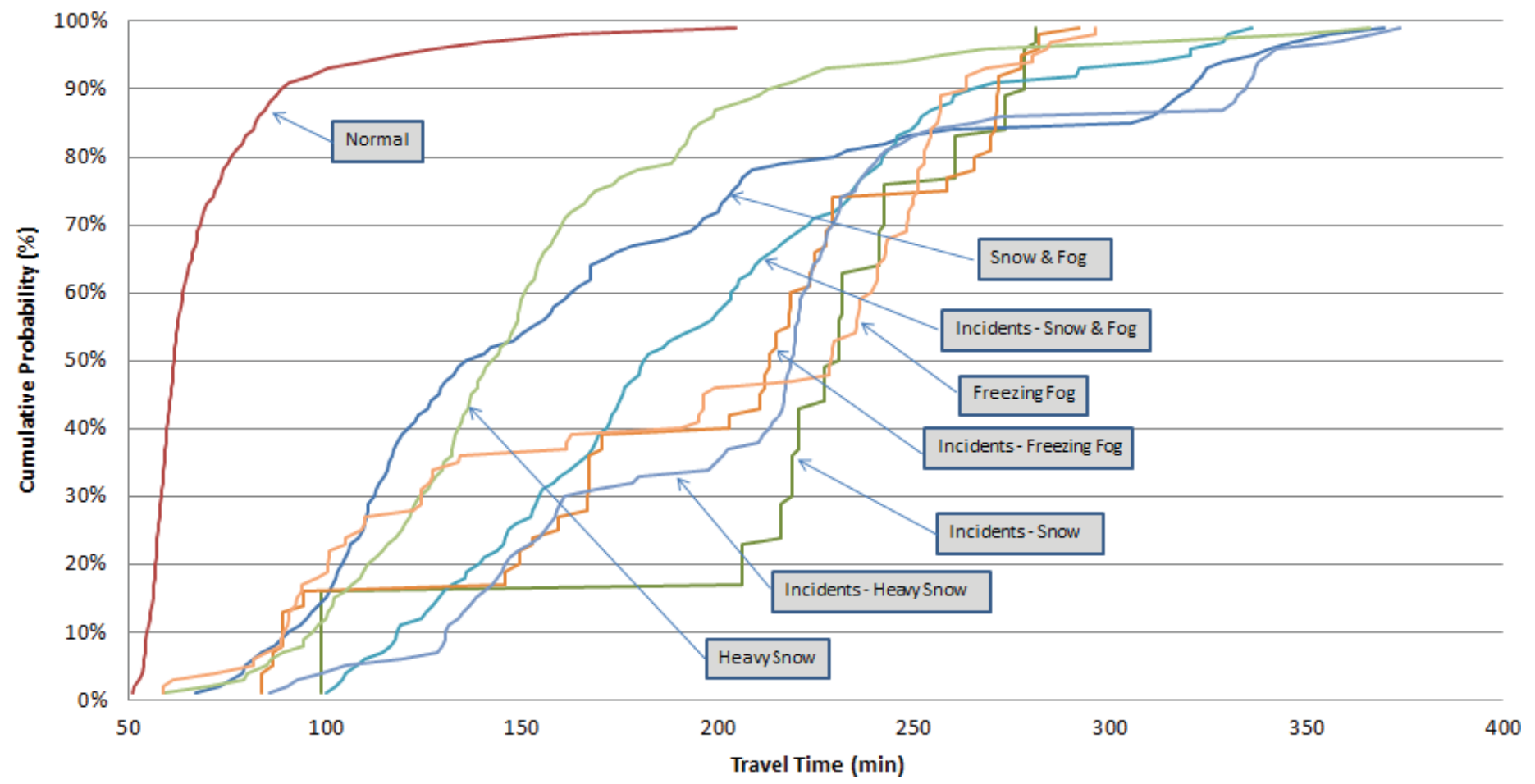

Figure 3.7. Variations in TT-CDFs for trips from South Lake Tahoe to Placerville.

Color figure available online at www.trb.org/Main/Blurbs/168765.aspx.

TTRMS has to be able to do this. Chapter 6 describes ways to combine segment-level data, but the main stipulation is that the correlation in travel times (travel rates) from one segment to the next has to be taken into account. The travel time observations are inherently correlated because the driver populations overlap between adjacent segments, and drivers are at least somewhat consistent in their speed management.

Several methods for combining segment PDFs have been developed. They are described comprehensively in the Guide and its appendices and portrayed briefly in Chapter 6. Other types of modeling efforts include Dong and Mahmassani (2011), Sun and Gao (2012), Ishak et al. (2007), Feng et al. (2012), Van Hinsbergen and van Lint (2008), Ramezani and Geroliminis (2012), Rice and van Zwet (2004), Susilawati et al. (2011), van Lint and van Zuylen (2005), van Lint et al. (2008), and Jintanakul et al. (2009).

\section{PDFs As the Basis for Archiving}

Many options exist about what data to archive for use in reliability analyses. Some experts suggest keeping everything. Because these people tend to think about keeping the observations of average speeds for the system detectors (loop detectors) at an interval of every 30 seconds (or every minute) or so, this is not unreasonable. Data storage is becoming cheap; and by keeping everything, the raw data are then available for future analysis. Of course, they are not keeping the actual observations of individual vehicle detection events, or speeds. They are keeping summaries (averages) based on those data.

Whether it is wise to keep everything in the context of AVIor AVL-related data is not so clear. For AVI systems this would mean keeping every time stamp for every vehicle observed at every AVI location. For AVL-based systems, this would mean keeping every GPS ping. Most likely, these options are not reasonable. Moreover, there are liability issues associated with storing such information.

For system detector data, like loops, it does seem logical to keep everything. In this context, keeping everything means keeping the average speeds, volume counts, occupancies, and so forth that are collected every 30 seconds or every minute from every detector in the system. A 5-minute level of granularity is probably the upper bound on the interval between archived observations that is still useful for reliability analyses. Fifteen minutes is too coarse. In 15 minutes, a lot can happen during the peak hours. It also makes sense to add fields that indicate the regime that was extant when the data were collected. This field could be the region identifier itself or a combination of two fields: one that indicates the nominal congestion level that would have been present under normal conditions and a second that indicates the nonrecurring event (including none) that was occurring (including none) during the 5-minute time period. 
For AVI- or AVL-based data, it seems valuable to record segment-level CDFs on a periodic basis. Even though some researchers are experimenting with parametrically based procedures (Guo et al. 2012; Hesham et al. 2006), periodically recording segment-level CDFs is more useful than storing the parameters for a preselected density function. The study team could not identify a parametrically based density function that worked well.

The study team used two mechanisms to create these CDFs. In the first instance, the 51 most recent AVI- or AVL-based travel time observations were recorded on a periodic basis. This number of observations was chosen so that a data point would be recorded for every 2 nd percentile up to and including the 100th percentile. Every 5 minutes was the most common frequency with which this was done, although every 15 minutes seems like a plausible answer for archiving purposes, as well. The vehicle IDs were not kept (and for liability reasons they probably should not be), although keeping them makes it possible to track individual vehicles across successive segments. In the second instance, the 51 AVI- or AVL-based observations were recorded every time 25 new observations were obtained, which means half of the samples overlap from one set of stored values to the next. Of course, other variations are possible, such as having only 10 , or none, of the values overlap.

The other piece of information that seems logical to include along with the 51 observations is the time span covered by those observations: the difference between the time of the newest and the oldest observations. The time span gives an indication of how closely the 51 observations correspond to the time period to which they were assigned (e.g., the 5-minute time period in the case of the first mechanism, and the time stamp of the last observation in the second). Given the penetration rates that exist today and the locations where the Bluetooth data were recorded, this time span tended to be about an hour at night and only 10 to 15 minutes during the peak hours. It is helpful that there is more traffic during the peak hours, when these CDFs are most important and change most significantly.

Of course, for special studies or situations for which detailed analysis is desired, keeping everything still makes sense.

\section{Summary}

A TTRMS is intended to be an add-on to an existing traffic management system. It is broken down into three major modules: a data manager, a computational engine, and a report generator. The data manager assembles incoming information from traffic sensors and other systems (e.g., weather data feeds and incident reporting systems) and places them in a database that is ready for analysis as "cleaned data." The computational engine works off the cleaned data to prepare pictures of the system's reliability: when it is reliable, when it is not, to what extent, under what conditions, and so forth. In Figure 3.1 this is illustrated by "regime TT-PDFs." The report generator responds to inquiries from users-system managers or travelers-and uses the computation engine to analyze the data and provide information that can then be presented to the inquirer or decision maker.

The value of a TTRMS comes from helping agencies understand the reliability performance of their systems and monitor how reliability improves over time. It equips them to answer questions like the following:

- What is the distribution of travel times in the system?

- How is the distribution of travel times (or rates) affected by recurrent congestion and nonrecurring events?

- How are freeways and arterials performing relative to reliability performance targets set by the agency?

- Are capacity investments and other operational actions helping improve the reliability of the travel times?

- Are operational improvement actions and capacity investments helping to improve the travel times and their reliability? 


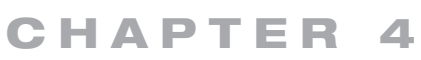 \\ Data Collection, Assembly, and Cleaning}

As the project unfolded, it became increasingly apparent that clean and complete data were critically important if meaningful travel time reliability information was to be obtained. Karr et al. (2006) provide a valuable examination of data quality issues. This necessity proved to be one of the main insights derived from a team decision to focus on using field data rather than simulation to develop and test the TTRMS.

\section{Data Quality}

Two main data quality issues emerged during the project. The first related to AVI sensor data. The second pertained to AVLbased time stamp and location observations.

\section{Passage Times for AVI Sensors}

For AVI-based sensors, attributing passage times-that is, deciding when a given vehicle passes the sensor-can be challenging. For toll tag readers (which are also AVI sensors) this issue is not significant because the time stamp corresponds to when communication with the tag takes place. But for other AVI sensors for which no specific transaction occurs, the invehicle device is likely to be within range of the sensor for an extended period of time, and a time within that window is the best choice for the time stamp.

The reason this is important is measurement error. It is important to avoid creating noise in the travel time values by being imprecise about when a specific vehicle passes a specific location. If the travel times between sensors are about 60 to 120 seconds and the time stamps have a variation of \pm 10 seconds on when the sensor was actually passed, then the travel times can be as much as 20 seconds shorter or up to 20 seconds longer than the actual travel time. This is an error of $\pm 33 \%$ if the travel time is actually 60 seconds.

This problem surfaced for the study team when studying the Bluetooth data along US-50 between Sacramento and
South Lake Tahoe, California. Figure 4.1 shows the media access control (MAC) ID responses from a Bluetooth device that was detected by one of the Bluetooth readers along US- 50 .

In this instance, the device is observable only for $20 \mathrm{sec}-$ onds, and the signal strength peaks at between 7 and $10 \mathrm{sec}-$ onds. Hence, the assignment of a passage time in this instance is clear. It should be at about 9 seconds.

However, the team's understanding is that most Bluetooth readers do not monitor signal strength to determine a passage time. Rather, they use the average of the first and last times the device was observed. In the case of the vehicle whose detection is shown in Figure 4.1, this is not likely to be a problem. It was first observed at zero seconds and last observed at 17 seconds, so the average would be 8.5 , which is also when the strongest signal strength was observed.

But the use of this average time can be problematic. Figure 4.2 shows another vehicle that was within range of the sensor for about 700 seconds (almost 12 minutes). Plotted again is the signal strength of the device's response versus time. It seems likely that the device was closest to the sensor about 15 to 20 seconds after coming into range. It could be that 15 seconds is the best passage time to use.

Perhaps two values are better than one. If two values were used, the first would be used to compute the travel time "to" this sensor, and the second, to compute the travel time "from" this sensor to the next. Measurement error would be minimized. But using the 15 -second value would add about 10 minutes for the travel time from this sensor to the next one visited; this 10 minutes was time actually spent near the sensor, not traveling to the next one. Unless the distance to the next sensor was more than 100 minutes away (almost 2 hours), use of the 15-second value would introduce a measurement error of more than $10 \%$.

It might be best to use this data processing rule: if the difference between the first and last time stamp is short (say, less than 20 seconds), then use the time stamp from the strongest signal response. Otherwise, use two values, one of which 
For a single device at node 58

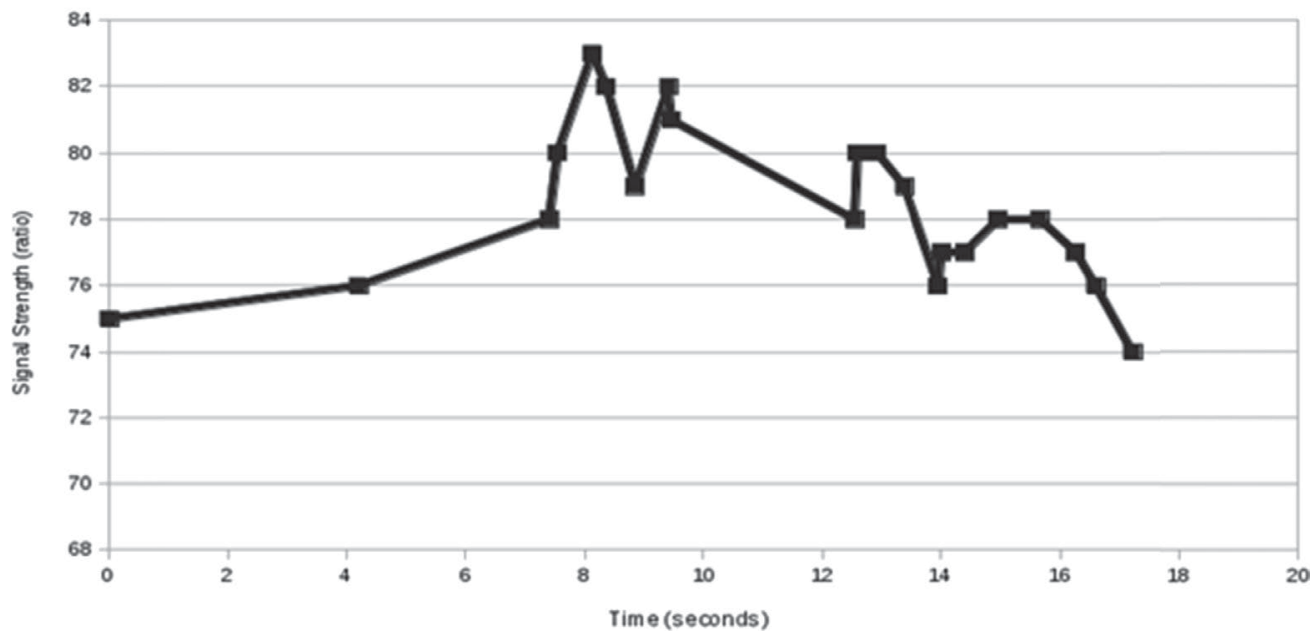

Figure 4.1. MAC ID responses for a vehicle.

corresponds to the earliest observed time and the other, to the last.

\section{Times and Locations for AVL-Equipped Vehicles}

AVL technologies track vehicles as they travel. Hence, entire trips can be observed, including the path employed. Moreover, actual travel (and not trip times) can be computed for segments and routes by comparing the time stamps for when the vehicles pass specific locations in the network. Trips that involve stops can be removed so that their trip times do not bias the travel times or the times associated with the stops, and other side-trips can be removed so that actual travel times are obtained. Hellinga and $\mathrm{Fu}$ (2002) provide an example of how to remove biases.

AVL data are not intrinsically tied to the underlying highway network. As Figure 4.3 shows, the latitudes and longitudes reported are based on the information at the disposal of the GPS device, not the physical location of the highway segment being traversed.

Hence, AVL data need to be matched to specific segments for the data to be used in estimating travel times. One way to do this is through map-matching algorithms. The data received from the vehicle-based sensors (longitude, latitude, point speed, bearing, and time stamps) are snapped to segments in the study network. Map matching is one of the core data processing

\section{Signal strength $(Y)$ versus time $(X)$}

$F \propto x$ a single device a node 56

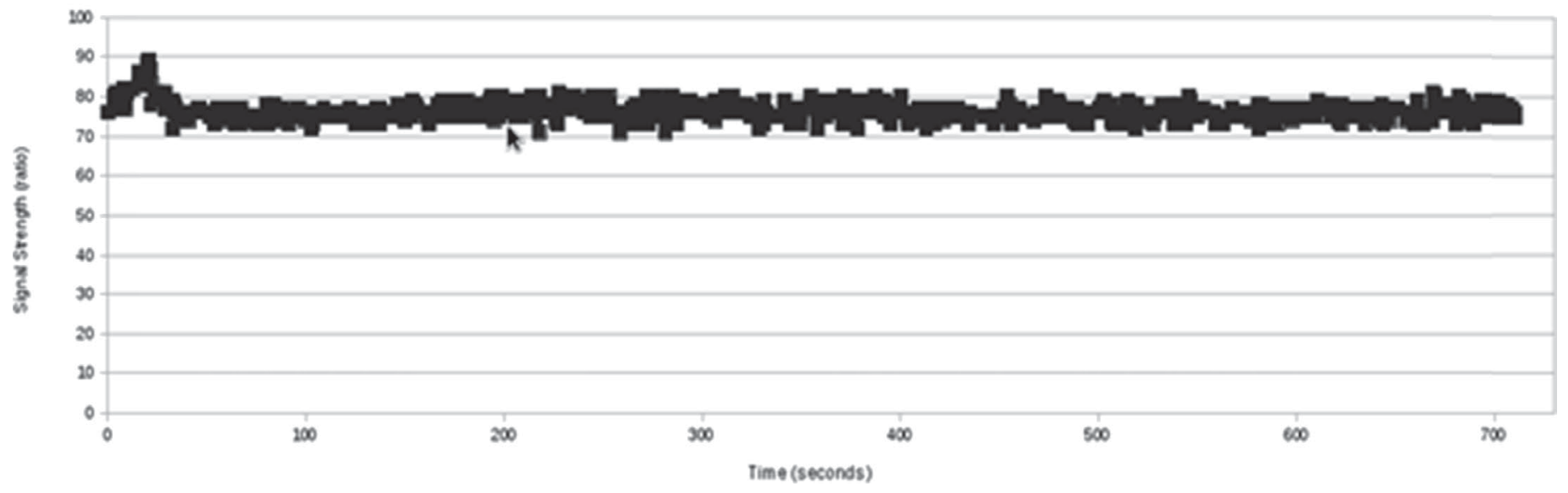

Figure 4.2. MAC ID responses for a second vehicle. 


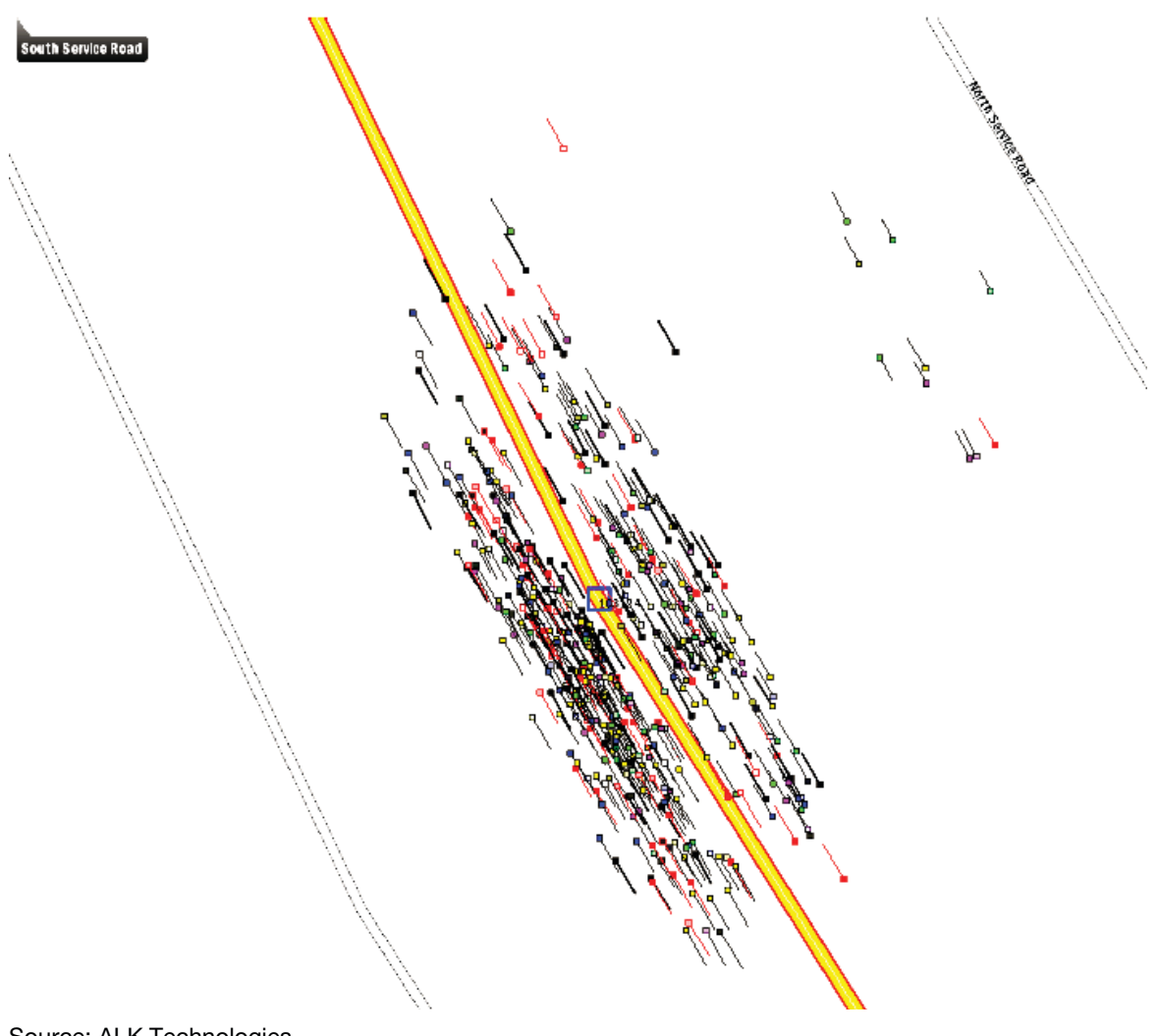

Source: ALK Technologies.

Figure 4.3. Locations and headings reported by AVL-equipped vehicle trips.

Color figure available online at www.trb.org/Main/Blurbs/168765.aspx.

algorithms for associating AVL-based travel time measurements with a route. A typical GPS map-matching algorithm uses the latitude, longitude, and bearing of a probe vehicle to search nearby roads. It then determines which route the vehicle is traveling and the resulting segment and route travel times.

In many cases, as shown in Figure 4.4, there can be multiple answers to the map-matching problem.

Various GPS data mining methods have been developed to find the closest or most probable match. Map-matching algorithms for transportation applications can be divided into four categories: geometric, topological, probabilistic, and advanced. Geometric algorithms use only the geometry of the link; topological algorithms also use the connectivity of the network. In probabilistic approaches, an error region is first used to determine matches, and then the topology is used when multiple links or link segments lie within the created error region. Advanced algorithms include Kalman filtering, Bayesian inference, belief theory, and fuzzy logic.

Most AVL-based systems use monuments to compute segment and route travel times. One technique for establishing the time stamps associated with monuments involves filtering the pings to select the one that is closest to the monument. This was the technique employed in selecting the pings displayed in Figure 4.3. There is no control over when the pings are issued (every few seconds), and the expectation is that a ping will be issued when the vehicle is near each monument. A second technique involves having the vehicles generate their own monument-to-monument travel times. When an AVL-equipped vehicle passes a monument it creates a message packet indicating the monument it just passed, the associated time stamp, the previous monument passed, the time stamp associated with that previous monument passage, and the next monument in the path. In this case, data records similar to the AVI detector-to-detector records are created and can be used to create segment- and route-specific travel times. In some systems the path followed is also included in the data packet, so the route followed is also known.

\section{Imputation}

Imputation is the process by which voids in the data are filled by estimation based on data from nearby or similar detectors. The details about data collection, assembly, and cleaning are addressed in Appendix A of the Guide. Figure 4.5 illustrates the idea. Concurrent data from nearby sensors are used to estimate a value for the missing data item. 


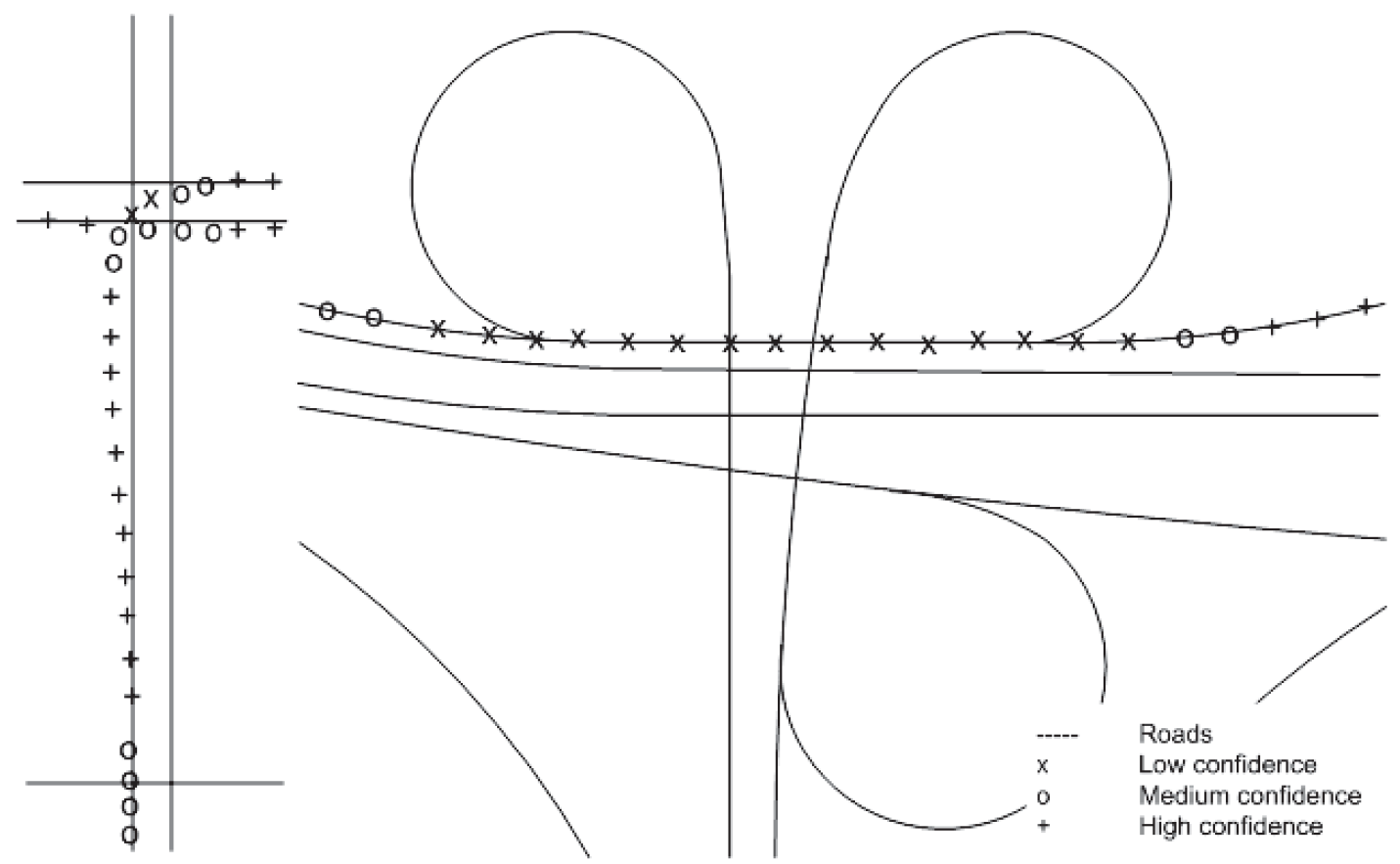

Figure 4.4. Example of map-matching challenges for AVL data.

The imputed value is computed based on one or more formulas and the input data. The value is marked as being synthesized, and when possible, a confidence in the value is saved, as well (Chen et al. 2003.)

One of several options involves using occupancies and volumes from the detectors in adjacent locations. Infrastructurebased detectors can be considered neighbors if they are in the same location in different lanes or if they are in adjacent locations upstream or downstream of the bad detector. In this approach, an offline regression analysis is used to continuously determine the relationship between each pair of neighbors in the system. The dependent variable is the flow or occupancy at a detector (when the detector is good), and the independent variables are the flow or occupancy at adjacent detectors. When a detector is broken, its flow and occupancy values can be determined by using the estimated regression parameters.

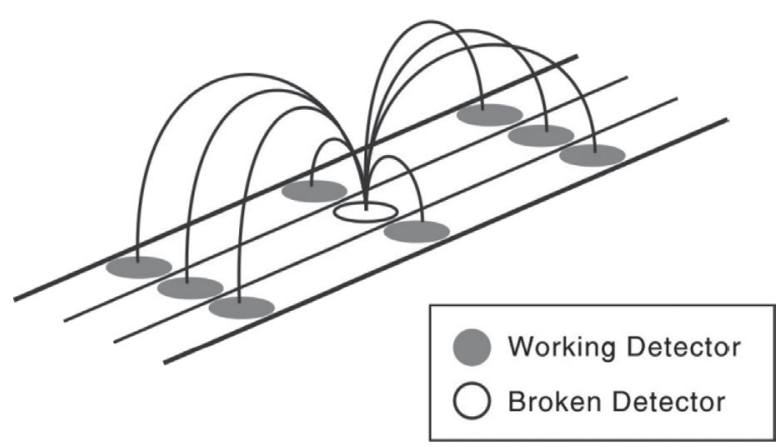

Figure 4.5. Imputation of traffic data.
The regression equations can take the form given in Equations 4.1 and 4.2 as follows:

$q_{i}(t)=\alpha_{0}(i, j)+\alpha_{1}(i, j) \cdot q_{j}(t)$

$k_{i}(t)=\beta_{0}(i, j)+\beta_{1}(i, j) \cdot k_{j}(t)$

where

$$
\begin{aligned}
(i, j) & =\text { a pair of detectors; } \\
q & =\text { flow; } \\
k & =\text { occupancy; } \\
t & =\text { a specified time period (e.g., } 5 \text { minutes); } \\
& \text { and }
\end{aligned}
$$

$\alpha_{0}, \alpha_{1}, \beta_{0}, \beta_{1}=$ parameters estimated between each pair of loops using 5 days of historical data.

The parameters represented by $\alpha$ and $\beta$ can be determined for any pair of loops that report data to a historical database.

Notably, there are some limitations associated with using linear regression because the observations used for estimation are not independent, and the values of flow and occupancy have to be positive.

Another imputation need that surfaced during the project pertains to filling in missing segment travel times for AVIor AVL-based data. The use of super segments seems to be the best way to impute travel times (and travel time distributions) for segments whose endpoint detector is malfunctioning. Figure 4.6 illustrates this idea. If AVI Detector B is broken, the super Segment A-C provides a way to impute vehicle travel times for both Segments A-B and B-C. 


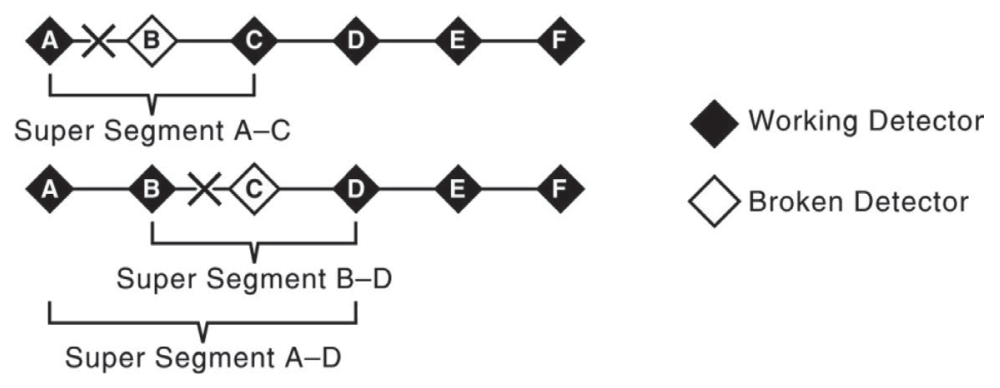

Figure 4.6. Super segment examples.

When all three detectors are working properly, regression equations can be developed that predict the travel times for Segments A-B and B-C based on the travel time for Segment $\mathrm{A}-\mathrm{C}$. When Detector B is malfunctioning, these equations can be used to impute individual vehicle travel times (or the average or some other percentile value such as the median) based on the travel time observations between Segment A and C. The same idea applies to Segments B-C and $\mathrm{C}-\mathrm{D}$ if Detector $\mathrm{C}$ is malfunctioning, only there are two super segments that could be used to impute the missing values (i.e., super Segments A-D and B-D). The super segment that is the best predictor of the travel times on the subject segment (which might be either Segment B-C or C-D) should be used to impute the missing travel times.

When infrastructure-based detection is present, one can use the point speeds (spot rates) from those sensors to adjust or cross check the imputed distribution of travel times. Equations (e.g., regression) can also be developed to use the system detector data directly to do this, and the infrastructure-based point speeds can be used directly to estimate average travel times for the subject segments.

A temporal median approach, equivalent to the one described above for infrastructure-based imputation, can also be used. A temporal median is the median of the historical, nonimputed route travel time values reported for that segment for the same day of the week and time of day over the most recent several weeks. Although data imputation is sometimes necessary, imputing data when there are too many nonfunctioning sensors can reduce the value of the imputation and the results.

\section{Nonrecurring Event Data}

Nonrecurring event data should be collected in real time, not after the fact. These data tend to be perishable and consequently hard to find after the event is over. The primary nonrecurring events that affect reliability are incidents, weather, construction, and special events. The ability of agencies to collect data on these events, and the types of data they can collect, will vary between locations.

\section{Transportation Incidents}

There are many viable sources for collecting incident data. Most state (and some local) emergency response agencies use computer-aided dispatch systems to respond to incidents; these systems have feeds that can be used by transportation agencies. The benefit of this data source is that it is in real time, but the drawback is that the data have not been cleaned (e.g., incident locations may not be clearly specified, and durations may be inaccurate). Many state DOTs have databases with cleaned-up incident records for state highways (e.g., the Caltrans Accident Surveillance and Analysis System) for the purpose of performing detailed analyses. These sources can also be leveraged for reliability monitoring. Another potential source for incident data is the local TMC, where operators usually enter incident information into their management software. Finally, private sources such as Traffic.com often collect incident data at a high level of specificity from various sources, including video, mobile (patrol) units, and emergency communication frequencies. Although many potential sources for incident data exist, these data are often incomplete, many times lacking severity indicators, clearance times, and exact incident locations.

The following variables can be used to relate traffic incidents with travel time variability: location, date, type, starting time and duration, full time to clearance, severity, and lanes affected. Transit incidents, such as bus collisions or disablements, can disrupt the operations of a transit system and cause major delays. Such incidents are increasingly being detected by the AVL systems used by transit agencies.

\section{Weather}

One source or option for weather data is existing weather stations operated by various governmental organizations or research bodies. The most accurate sources of weather information are the Automated Surface Observing System and Automated Weather Observing System stations maintained and used for real-time airport operations by the Federal Aviation Administration. Another good source is an online interface from the National Climatic Data Center of the National 
Oceanic and Atmospheric Administration, which provides hourly, daily, and monthly weather summaries for 1,600 U.S. locations. For mountainous rural areas, the major sources of weather-related delay are closures and chain-control stations. These data are frequently available from rural traffic management centers, although collecting feeds of such data is rare and problematic. One of the richer sources of these data may be highway advisory radio networks, which broadcast closure and chain-control locations and are frequently available via statewide feed. Any weather data obtained from sources not directly on a monitored route will have to be associated with nearby routes in the system.

Another option for collecting weather data is to directly install environmental sensor stations at key roadway locations. Many states use these to build road weather information systems that archive weather data for use in roadway-related decision making.

The following variables can be used to relate weather with travel time variability: air temperature, type of precipitation, amount of precipitation, visibility, wind speed, pavement temperature, and surface condition.

Transit agencies can use similar methods to monitor weather conditions and develop operational plans to help them deal with potential disruptions in service and variability in travel times during a variety of adverse weather events.

\section{Work Zones}

There are a few sources for construction-related lane closures. Many states have lane-closure systems that serve as a communication interface between contractors and state agencies to facilitate lane-closure management; this data source can be obtained in real time. Private sources are another option; for example, Traffic.com reports both scheduled and unscheduled construction events. Another option is to manually obtain construction-related information from changeable message sign logs or feeds.

The following variables can be used to relate work zones with travel time variability: start time and duration, start and end locations, and lanes affected; see also Haseman et al. (2010).

\section{Special Events}

One option for special events is to manually review calendars for major event venues near a route. Another option is to obtain event data from TMCs, many of which collect event logs to know when and where to activate event-based signaltiming plans.

The following variables can be used to relate special events with travel time variability: location, routes affected, duration, type of event, and attendance.

\section{Data Storage}

The data storage regime for the nonrecurring events is dependent on exactly which variables are collected, and at what granularity. The spatial and temporal resolution of nonrecurring events data is an important consideration that affects the strength of the relationships developed with travel time variability. Data on nonrecurring events, to some degree, must be aggregated to the same temporal and spatial resolution, in that all the data need to be spatially collected by route and temporally collected for each day in the analysis period. Collecting data on some of the sources at higher spatial and temporal resolutions would lead to more accurate analysis.

The data on nonrecurring events does not need to be stored in the same tables as the route travel times, because the analysis to link travel time variability with its causes is typically a manual exercise. Thus, the database for nonrecurring events can be uniquely designed to store the data that each agency is able to collect.

\section{Summary}

It cannot be overstressed that high-quality data need to be available for a TTRMS to be effective and useful. Although it is possible to do some degree of reflective, ex post facto analyses of system performance on the basis of weak data, real-time decision making by system operators and users cannot be done effectively if the data are weak.

This chapter has addressed the issue of collecting and managing the data feeds needed to assess and manage travel time reliability. Two main data feeds are reviewed: (1) the travel time data collected from system detectors and AVI- and AVLequipped vehicles and (2) nonrecurring event data. Both are critical to properly analyze and manage system performance. The first source provides evidence of the traffic load on the system, as well as the travel times being provided. The second source indicates whether there were extenuating circumstances under which the system was functioning at the time when the travel times were observed. 


\section{онАВ TER 5 Sensor Spacing and Sampling for
Travel Time Reliability Monitoring}

\section{Introduction}

Operating agencies have historically created monitoring systems that use sensors placed at strategic locations along their freeway networks. Figure 5.1 shows a section of freeway in California where there are 10 sensors in 5 miles, or a sensor about every 0.5 miles. This is a bit dense, but typical. A spacing of a mile or more is common. Of course, putting sensors at an equal spacing has no particular value; they need to be installed either at locations where congestion rarely occurs (like the first, fifth, ninth, and 10th sensors) so flow rates can be monitored, or at places where bottlenecks arise (like the second, third, fourth, fifth, and eighth sensors) so that queuing can be detected.

The advent of vehicle-based sensing technologies, including those that provide speeds for short TMC segments, are revolutionizing these ideas because sensor placement becomes less of an issue: nothing has to be installed in the roadway surface. Moreover, actual travel times can be observed if the vehicles are reidentified (e.g., by using their MAC IDs or tag numbers).

In addition, and different from sensing the general health or status of the network, which is the purpose of the sensor deployments shown above, monitoring travel time reliability has a different objective. One needs to sense the status of the system (in time or in space) in a way that produces a defensible image of the travel times that are occurring, as well as their changes in time and space.

For example, Figure 5.2 shows the temporal pattern of AVI-based travel time observations on I-5 in Sacramento, south of US-50, for February 18, 2011, when there was an incident immediately preceding the p.m. peak. The rise and fall in travel times during the incident is dramatic: growing from 5 to 35 minutes in the span of 20 minutes and then dropping back to about 7 minutes in another 30 minutes. The travel times in the p.m. peak, which are typical for this location, rise from 5 minutes (without the incident) to 12 minutes in an hour and a half and then fall back to 5 minutes in another hour and a half.

To adequately observe such transients, especially the first, from the incident, one would have to sample the travel times every 1 to 2 minutes so that the rapid rise, as well as the subsequent fall, could be observed. The p.m. peak that follows could adequately be monitored with samples at every 5 to 10 minutes.

Of course, a difference exists between how many samples are needed ex post facto to reproduce an observed waveform, like the ones discussed above, compared with monitoring the travel times that unfold in real time. Not only are the rates of change unknown, but latency (how long will it be after the event occurs) becomes an issue. In the examples above, a monitoring rate of every 15 minutes would be too slow to spot the incident in any meaningful way, and it would be adequate but not ideal to observe the p.m. peak. An interval of a minute would be adequate for both. A sampling rate of 5 minutes would detect both, but it would provide a less-responsive and less-accurate representation of the incident-related transient. These data tend to suggest that a sampling rate of 5 minutes or shorter is likely to be adequate.

In the spatial domain it is more difficult to understand what is adequate. The challenges are twofold. The first is to observe the vehicle trajectories in a suitable manner-in space, not in time-to create defensible travel times. The second is to identify a spacing that allows one to pinpoint the places of reliability trouble, in terms of queuing and momentary slowups, so that corrective actions can be taken. Fortunately, the objective is not to reproduce the exact vehicle trajectories. As Figure 5.3 shows, reproducing the exact vehicle trajectories would require a sample to be taken approximately every 10 feet because the transient slow-downs or speed-ups span only 30 to 50 feet, and adequately representing them would require five or so observations.

Two concepts are helpful in bounding the lower end of the spatial sampling interval: the spatial geometry of highway 


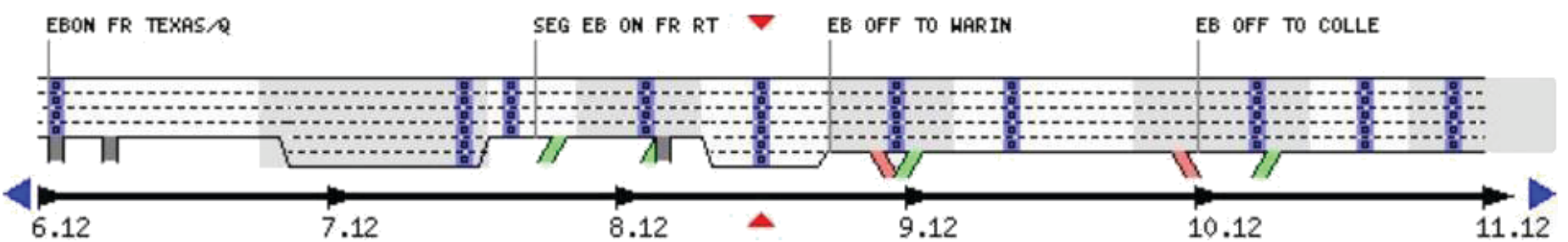

Figure 5.1. Typical sensor spacing on a freeway.

Individual Vehicle Travel Times / I-5 Southbound

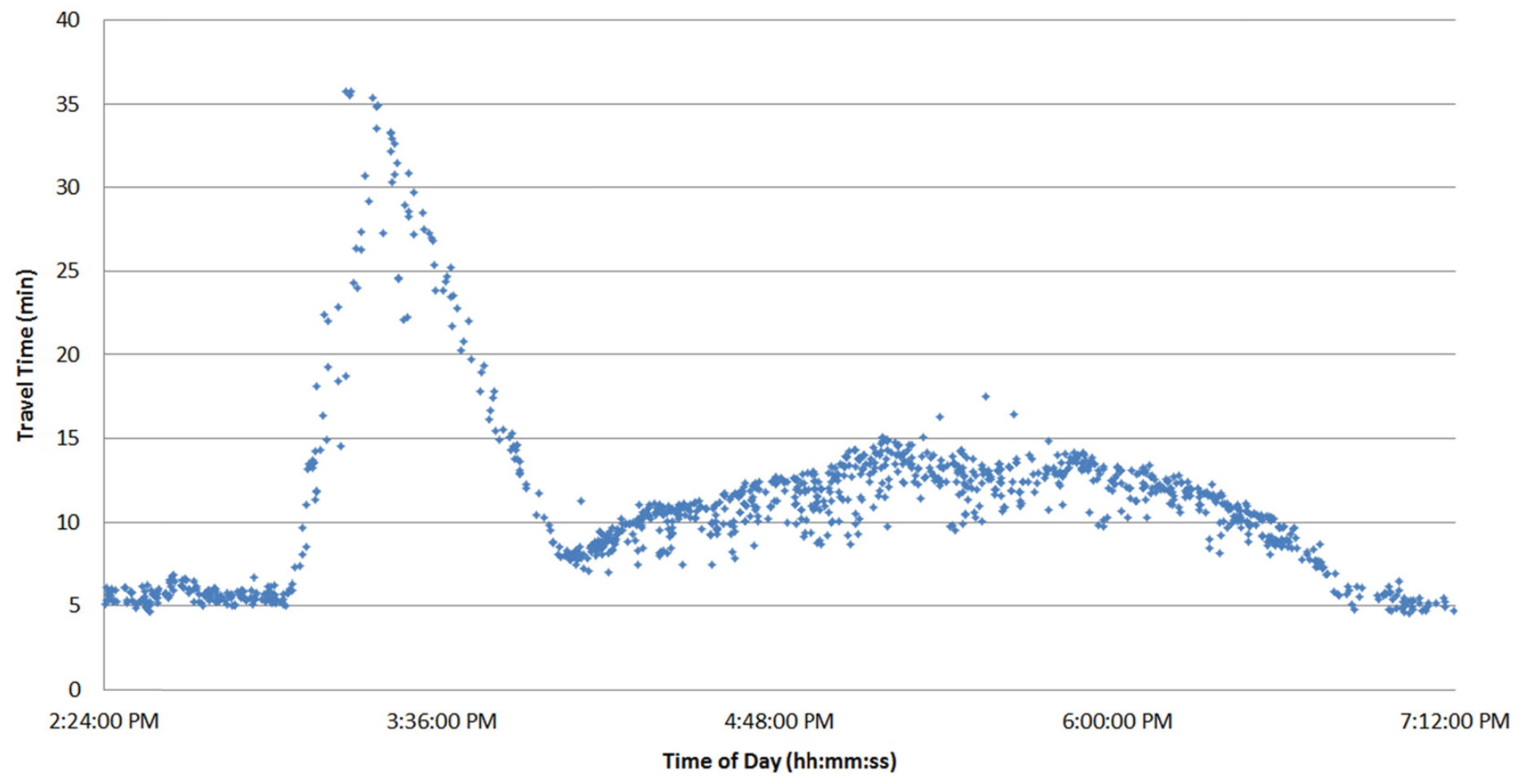

Figure 5.2. An example of two travel time transients: an incident followed by a p.m. peak.

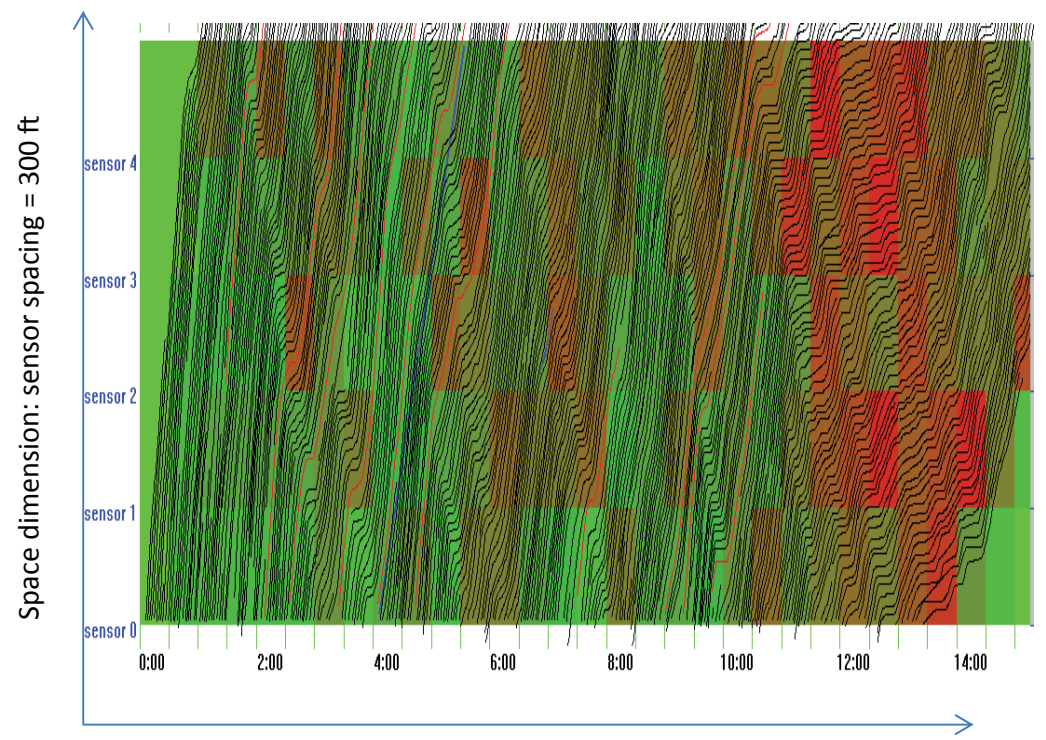

Time dimension: 8:00 indicates $8 \mathrm{~min}, 00 \mathrm{~s}$

Figure 5.3. Vehicle trajectories in space and time.

Color figure available online at www.trb.org/Main/B/urbs/168765.aspx. 
design and expectations about how long it should take before an incident can be identified. First, ramp lengths and weaving sections are rarely shorter than 300 to 500 feet, so detector spacing shorter than this would be difficult to implement. Second, and in a separate dimension, shockwaves travel at rates in the range of 10 to $30 \mathrm{mph}$ ( 15 to $45 \mathrm{ft} / \mathrm{s}$ ), so sensors placed 500 feet apart would be able to detect growing queues 10 to 30 seconds after their formation; at 1,000 feet, detection would occur between 20 and 60 seconds.

\section{A Formal Technique}

To treat the topic more formally, a procedure focused on the information contained in the sampled data and the ability of the sampled data to reproduce the actual, underlying waveform can be used to gain a sense of how closely the detectors need to be spaced. Three questions need to be addressed:

1. What criteria should be used to determine the sampling rates?

2. What methodology can be used to approximate continuous time-series from discrete data samples?

3. How should minimum and practically acceptable temporal and spatial sampling rates be selected?

\section{Quantifying Information Gains}

A fundamental question is how to select a measure or a set of criteria that can quantify information gain or accuracy improvement at various locations. For link travel time estimation applications, link traffic flow volume, origin-destination flow coverage, and link travel time estimation errors have been widely used as criteria for determining the priority of point detector locations.

In comparison, the essential goal of traffic sensor network design for travel time reliability monitoring applications covers not only reducing average estimation errors for link travel times (Park et al. 2007; Lyman and Bertini 2008), but also capturing the day-to-day and within-day dynamics under both recurring and nonrecurring conditions. If the day-to-day or within-day travel time distributions are expressed in terms of PDFs or CDFs, then the criteria of minimizing the average link travel time estimation errors might not adequately emphasize, and may possibly ignore, many nonrecurring and important random sources such as incidents. In this study, a Kolmogorov-Smirnov (K-S) test, a nonparametric test for the equality of continuous, one-dimensional probability distributions, can be used to see if the CDFs constructed from sample sequences significantly differ from the ground-truth CDFs of travel times under different sensor spacing and reporting configuration scenarios.

\section{Approximating Temporal Patterns from Discrete Samples}

If traffic measurements (from a continuous traffic process) are available at some time interval (say, 30 seconds) and spatial spacing (say, every 0.1 mile), one can strive to select a pattern-smoothing method that will identify statistically significant systemwide trends (due to incidents, weather conditions, or special events) while filtering out the noise associated with driving behavior or measurement errors. A wide range of time-series-based methods exist for traffic state estimation, including autoregressive moving average models and Bayesian learning models, as well as Kalman filtering. Overall, the above methods predominantly operate in the time domain and are suitable for estimating time-dependent dynamics. However, these methods face modeling difficulties in identifying the underlying system process (signals) variability, which is compounded by multiple components, such as day-to-day trends, within-day variability, and nonrecurring events.

An innovative technique adapts a digital signal processing method to process the raw travel time measurements and uses a spectrum analysis framework to transform travel times (analogous to signals in a digital signal processing model) from the time-series domain to the frequency domain, in which a large data set will be decomposed into components of different frequencies. Mathematically, the generalized model shown in Equation 5.1 is used to fit the travel timeseries $x_{t}$ :

$x_{t}=a_{0}+\sum\left[a_{k} * \cos \left(\lambda_{k} * t\right)+b_{k} * \sin \left(\lambda_{k} * t\right)\right]($ for $k=1$ to $q)$

where

$$
\begin{aligned}
t & =\text { sampling interval; } \\
x_{t} & =\text { travel time sampled at } t ; \\
k & =\text { a specific wavelength; and } \\
a_{k} \text { and } b_{k}= & \text { magnitudes of the cosine and sine waves for } \\
& \text { wavelength } k, \text { respectively. }
\end{aligned}
$$

The length of the sampling interval $|t|$ can be 1 minute (along time dimension) or 1 foot (along space dimension); $1 /|t|$ is the sampling frequency. Sine waves of wavelength $L$ can be identified by using a sampling rate of about $L / 8$ or higher, which provides four samples in every half cycle.

\section{Example: Modeling Approach Using Fast Fourier Transformation}

The above modeling approach can be applied using standard fast Fourier transformation (FFT) techniques. This first example focuses on the time domain. Seven weekdays 


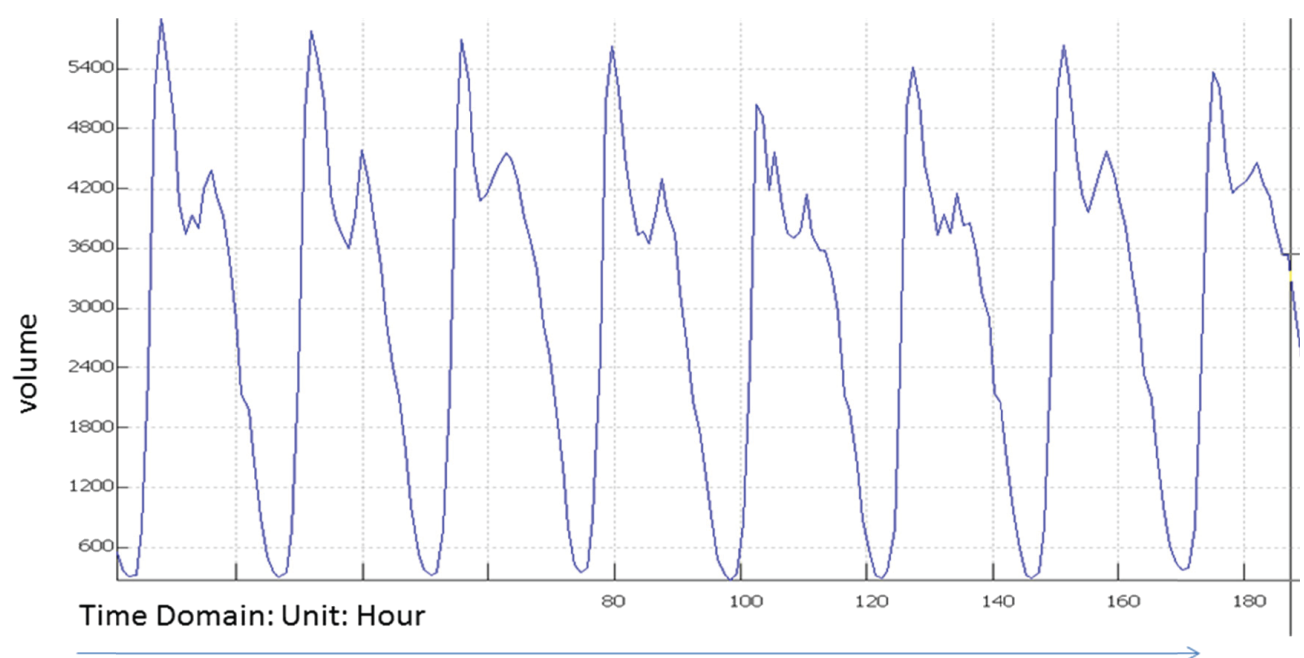

Figure 5.4. Time-series of weekday volumes observed by PeMS, February 1 to February 10, 2006.

of travel volume data, represented as the time-series in Figure 5.4, are mapped to the frequency domain representation in Figure 5.5 using a standard FFT.

The spectrum analysis in Figure 5.5 clearly indicates at least seven to 10 major waves or harmonics in the observed data, each one representing a frequency component with a different cycle length. For example, the first wave has a frequency of $1 / 0.04$ per hour, which corresponds to a daily 24-hour cycle.
Using the first three frequency components (up to a 6.7-hour wavelength, a frequency of $1 / 0.15$ cycles/hour), it is possible to capture the day-by-day trends, as seen in Figure 5.6. Using the general rule of eight samples per cycle, a wavelength of 6.7 hours can be sensed by taking samples every 50 minutes.

If shorter wavelengths are included (e.g., down to 3.33 hours), the within-day dynamics can be captured at a finer resolution, as illustrated in Figure 5.7. To obtain eight samples

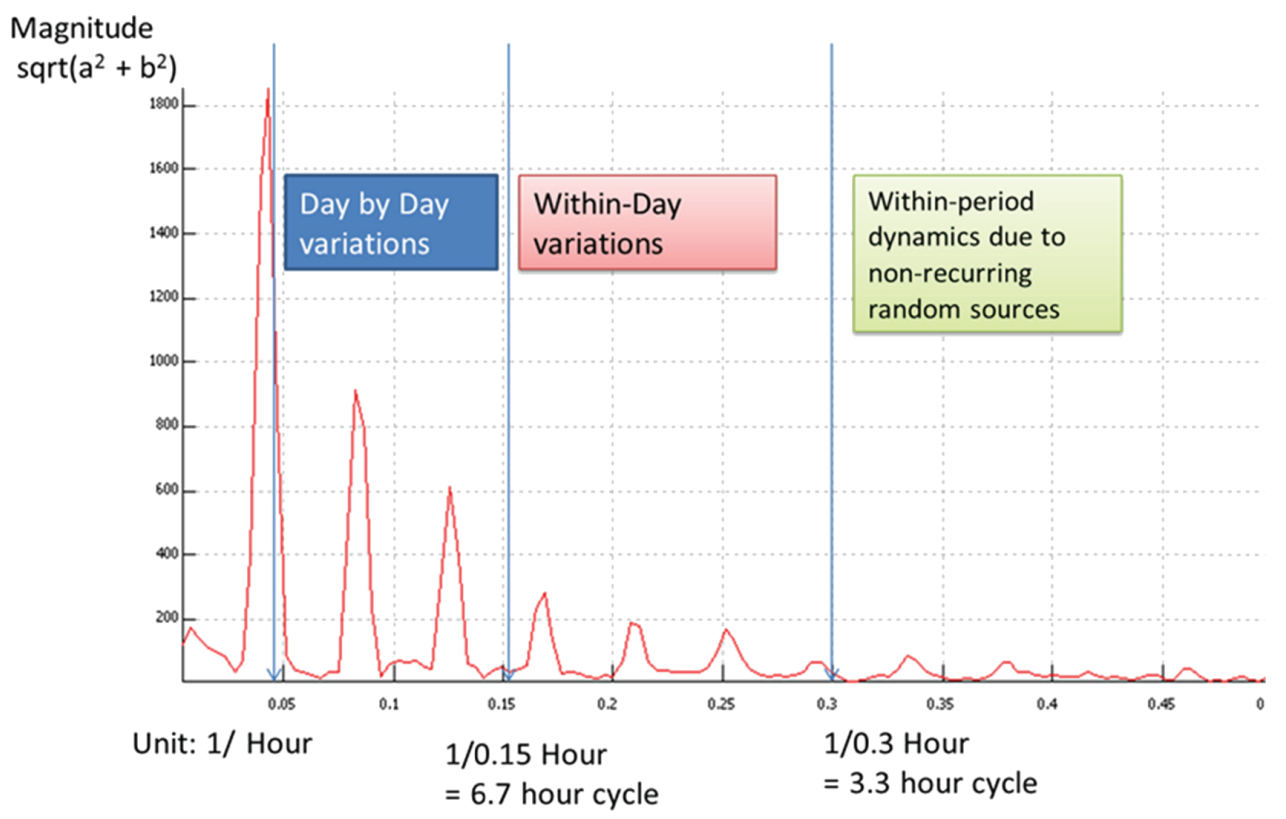

Figure 5.5. Frequency domain representation for travel flow data along time dimension. 


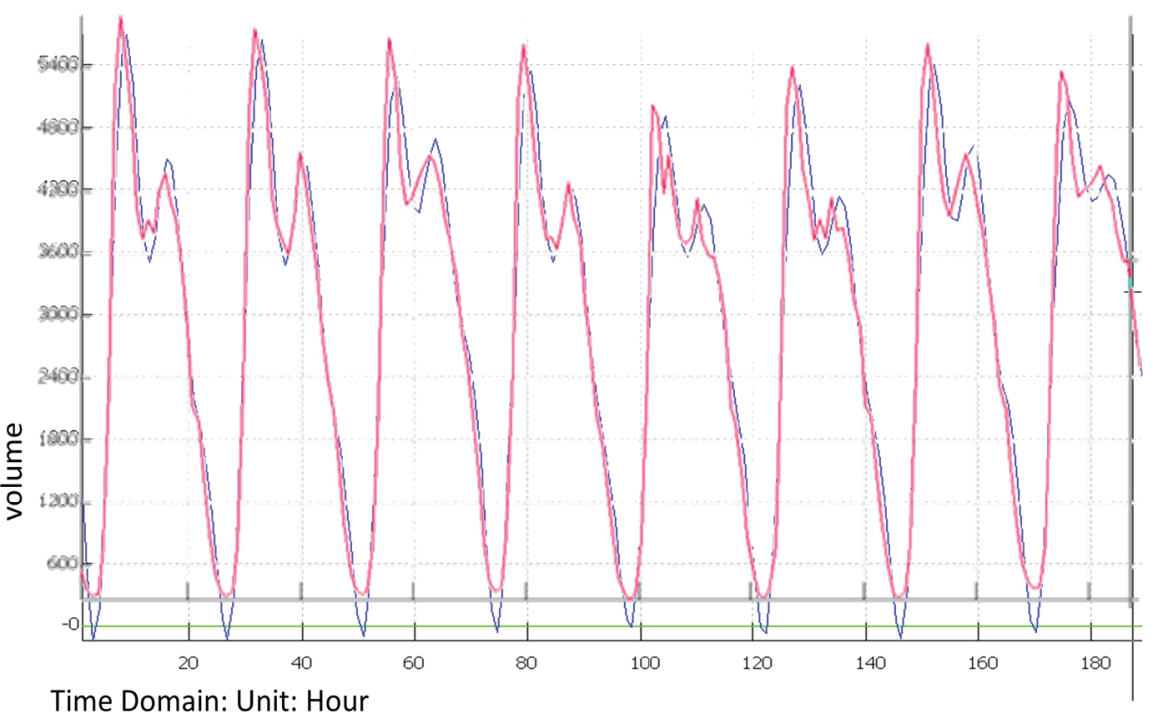

Figure 5.6. Reconstructed time-series data that capture day-to-day trends, restored by using a cutoff frequency $=0.15,3$ harmonics (blue = reconstructed time-series; red = original time-series). Color figure available online at www.trb.org/Main/Blurbs/168765.aspx.

of a 3.33-hour wavelength, sampling every 25 minutes would be needed.

\section{Temporal Sampling Rates}

After identifying the distribution of wavelengths within the sampled data (e.g., the PeMS data), one can use the classic
Nyquist-Shannon sampling theorem to determine the theoretical minimum sampling rate. That is, if a function $x_{t}$ contains no frequencies higher than $B$ hertz, it is completely determined from a series of sample points spaced $1 / 2 B$ seconds apart. In practical digital signal processing applications, a practically acceptable sampling rate is about $1 / 8 B$, which filters out possible measurement errors and other

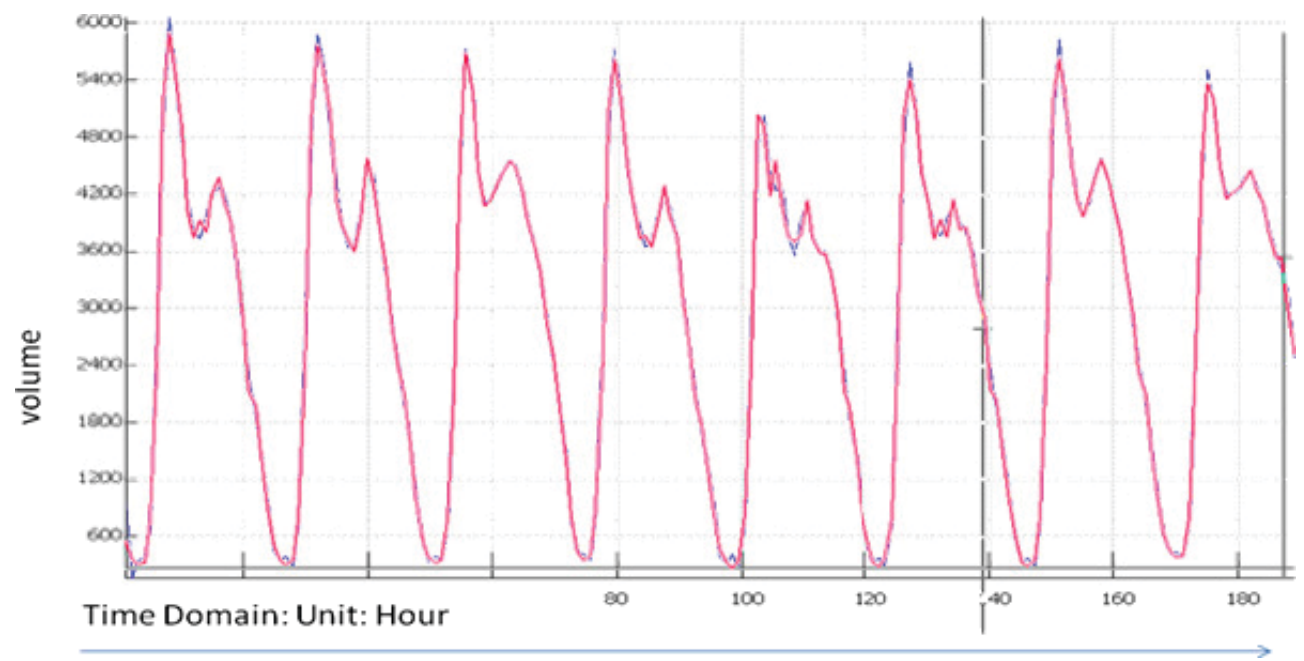

Figure 5.7. Reconstructed time-series data that capture within-day dynamics, restored by using a cutoff frequency $=0.3,7$ harmonics (blue $=$ reconstructed time-series; red = original time-series).

Color figure available online at www.trb.org/Main/Blurbs/168765.aspx. 
random factors (e.g., heterogeneous driving behavior in this application).

In the above specific example of traffic flow estimation, Figure 5.7 suggests a system frequency of $B=0.45$; that is, a minimum temporal sampling rate of about $1 / 2 B=2.2$ hours is required to fully capture the within-day variation, and a sampling rate of $1 / 8 B=16$ minutes satisfies the practical considerations. Interestingly, the latter coincides with the common practice of 15- to 30-minute time intervals for sampling traffic flows.

\section{Approximating Spatial Patterns from Discrete Samples}

To evaluate the travel time or traffic speed frequency distribution along the space dimension, one can again apply FFT to a sequence of GPS traces to identify trends of spatial variations. The notion of spatial variations is somewhat more difficult to comprehend, but once understood, its application becomes sensible and obvious. The following examples illustrate the concept. If a car is moving in a recursive stop-and-go pattern every 0.5 mile on a freeway, then its speed frequency profile should include a wavelength of 0.5 mile (from one stop to the next). If a car periodically stops at a sequence of intersections with a spacing of 0.3 miles, then the spectrum analysis should find a spatial wavelength of about 0.3 miles (again stop to stop). The complexity of geometric roadway features and traffic dynamics means that spatial frequency distributions might be much more difficult to identify than the travel speed frequency distribution on a single location.

\section{Example One}

In the following numerical example, five GPS traces are used from vehicle trajectories that cover multiple freeway segments for a length of 35,520 feet (6.7 miles) to find acceptable spatial sampling rates. The second-by-second location data are converted to a spatial resolution of 20 feet for a total of 1,776 samples. Figure 5.8 gives the spatial frequency analysis results. As expected, the spatial-dimension spectrum pattern is less clear than the time-dimension spectrum pattern in Figure 5.5, although in general the magnitude of waves decreases as the frequency increases.

Because it is difficult to determine the cutoff frequency from the spectrum analysis results, the reconstructed timeseries curves and K-S statistics are compared for three levels of spacing: 1,000, 1,500, and 2,000 feet. The analysis results are shown in Figures 5.9 and 5.10.

For distances of 100 to 1,500 feet, Table 5.1 lists the absolute percentage differences and K-S statistics for each of the

(text continues on page 60)

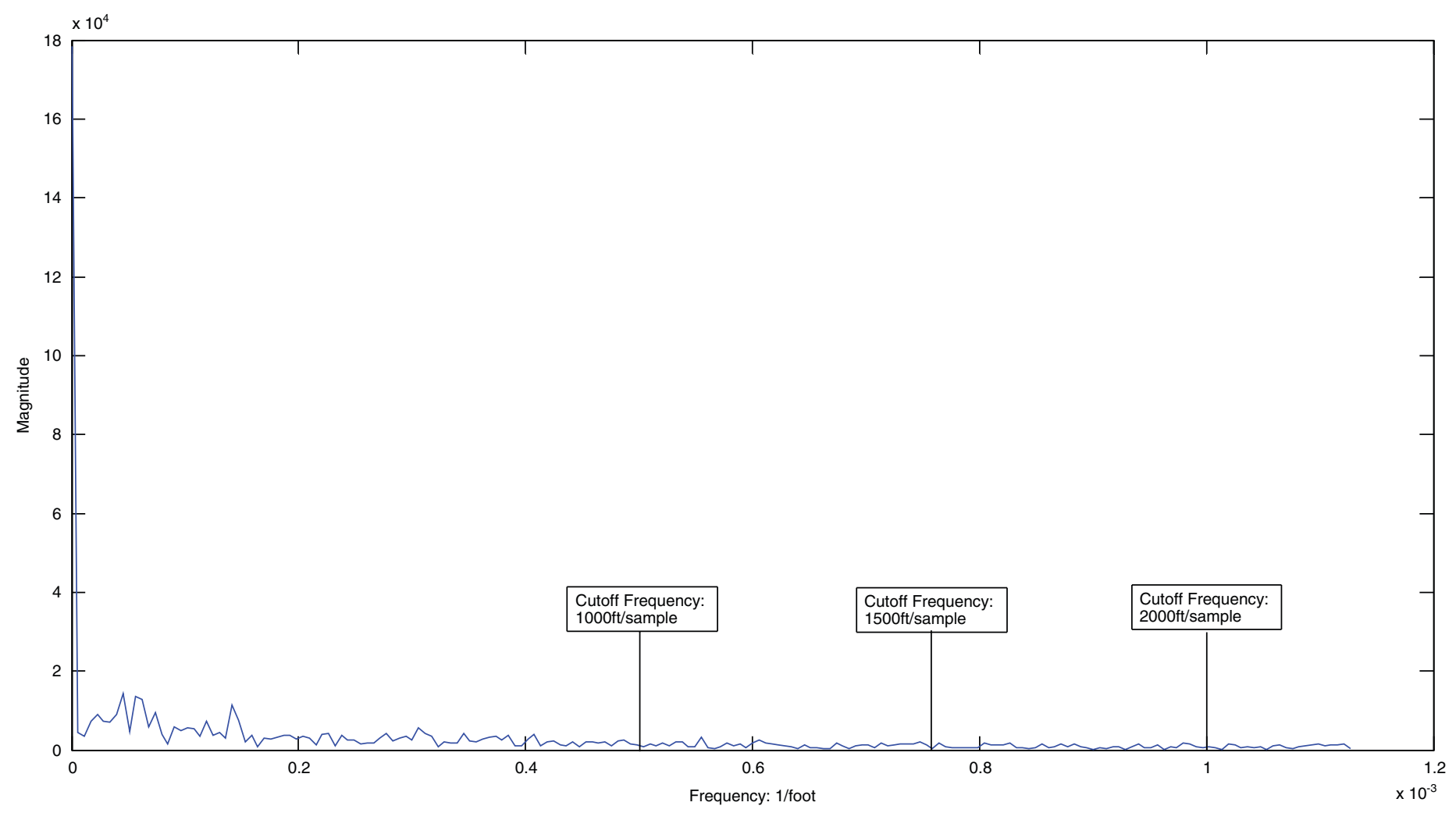

Figure 5.8. Frequency domain representation for GPS location-based speed data along space dimension. 


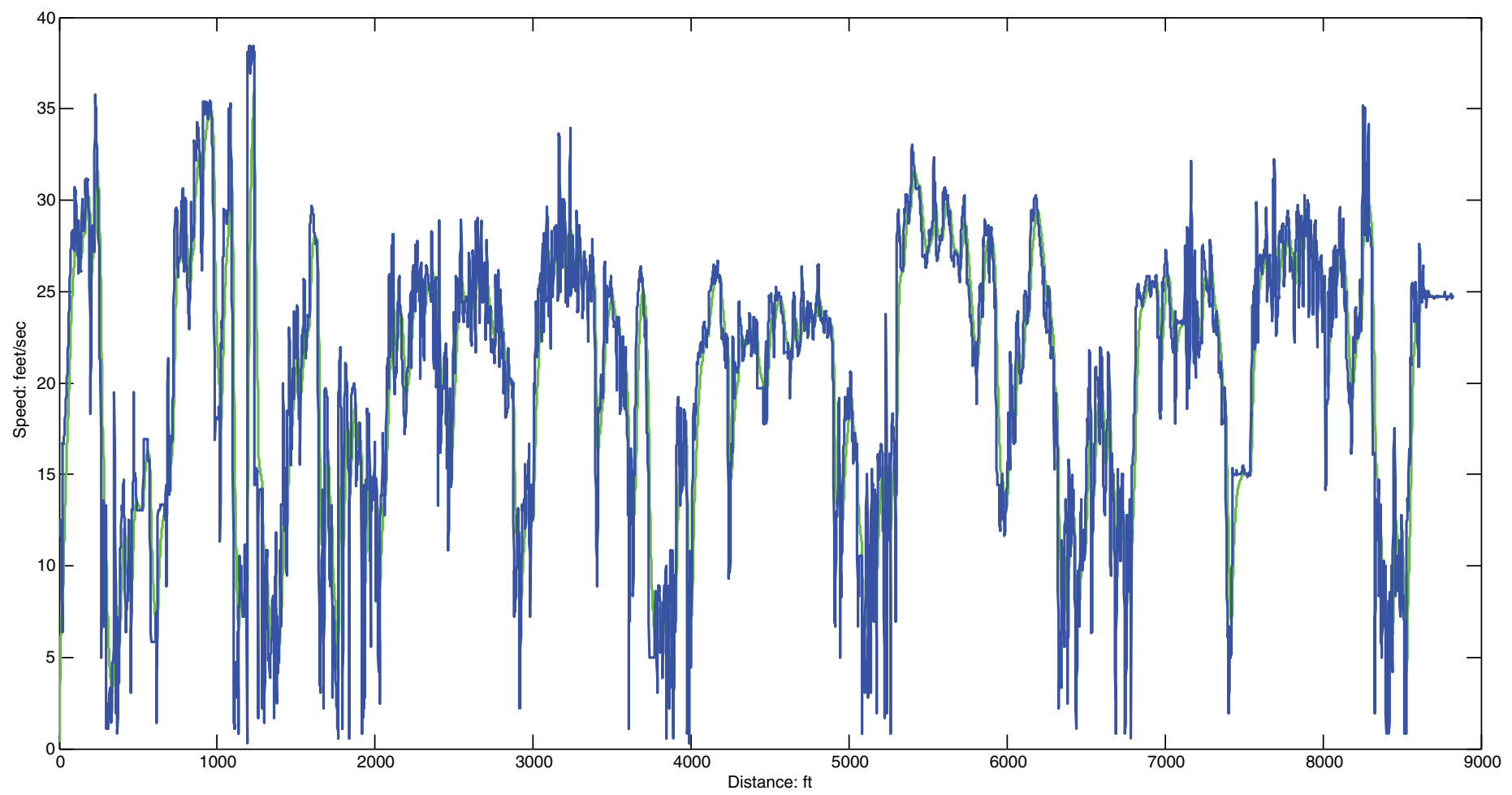

(a)

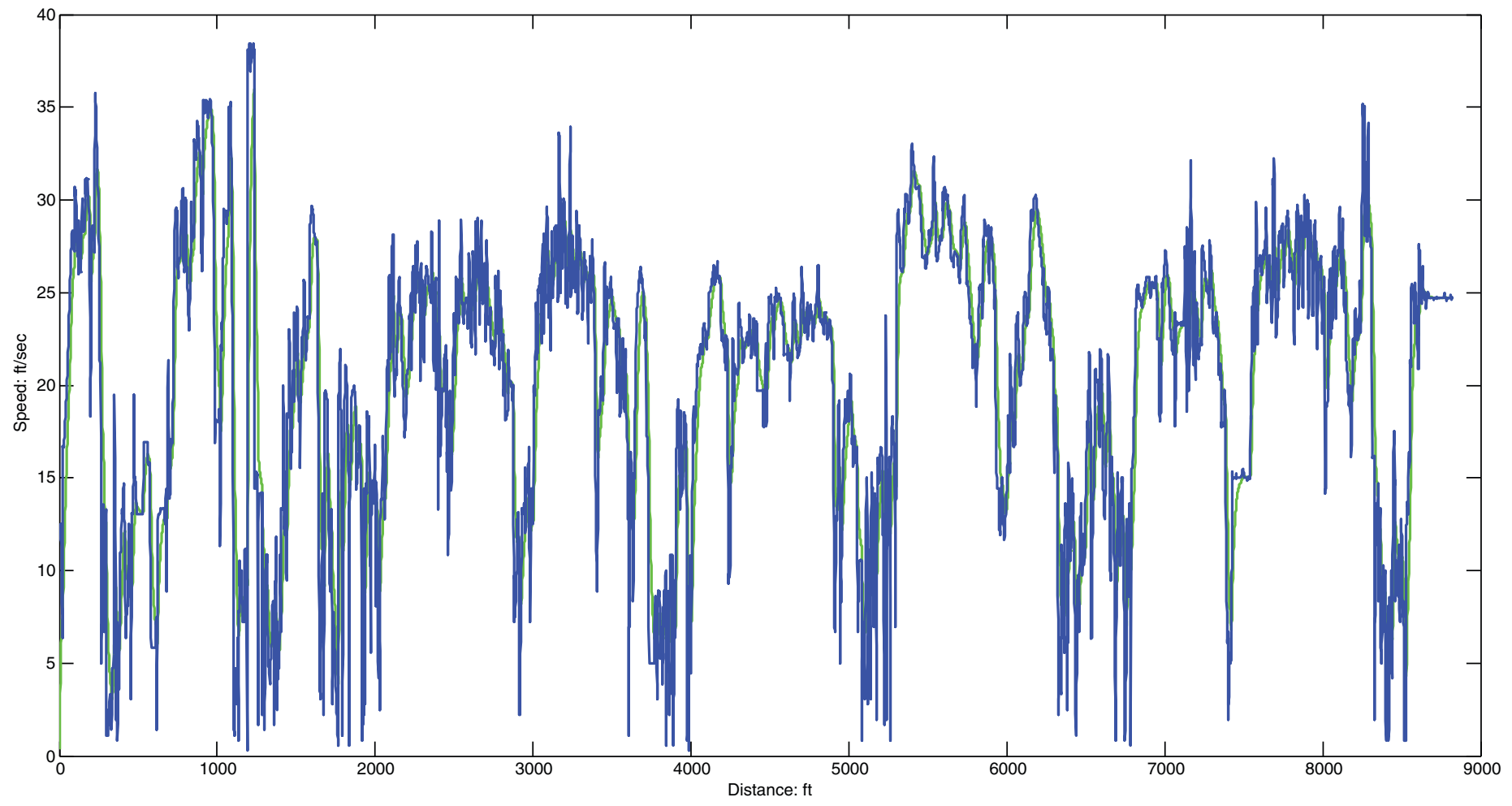

(b)

Figure 5.9. Reconstructed speed time-series for GPS traces under cutoff frequencies of (a) 1,000, (b) 1,500, and (c) 2,000 ft/sample. (Continued on next page.)

Color figure available online at www.trb.org/Main/Blurbs/168765.aspx. 


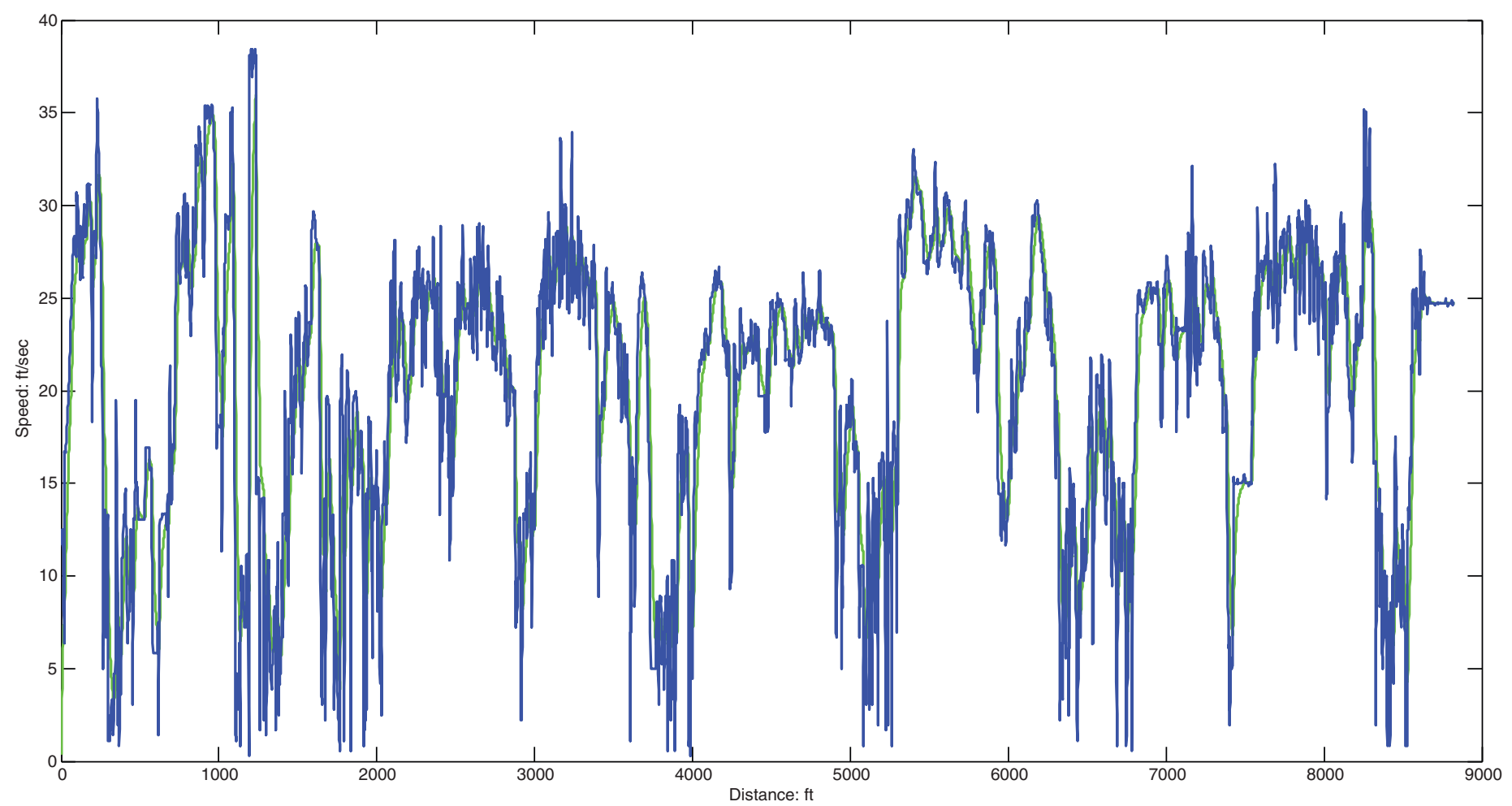

(c)

Figure 5.9. (continued)

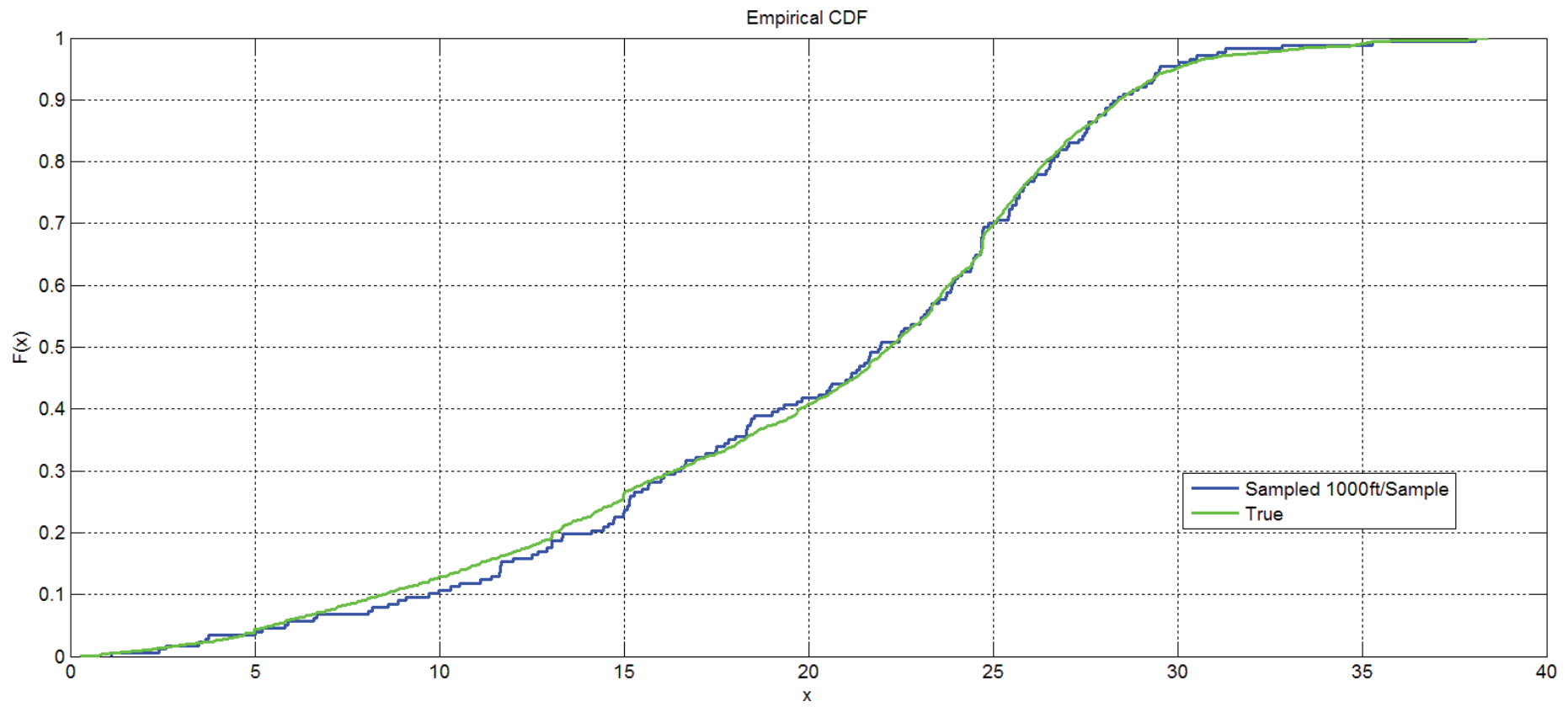

(a)

Figure 5.10. Reconstructed and ground-truth traffic speed CDFs under sampling spacing of (a) 1,000, (b) 1,500, and (c) 2,000 ft/sample. (Continued on next page.)

Color figure available online at www.trb.org/Main/Blurbs/168765.aspx. 


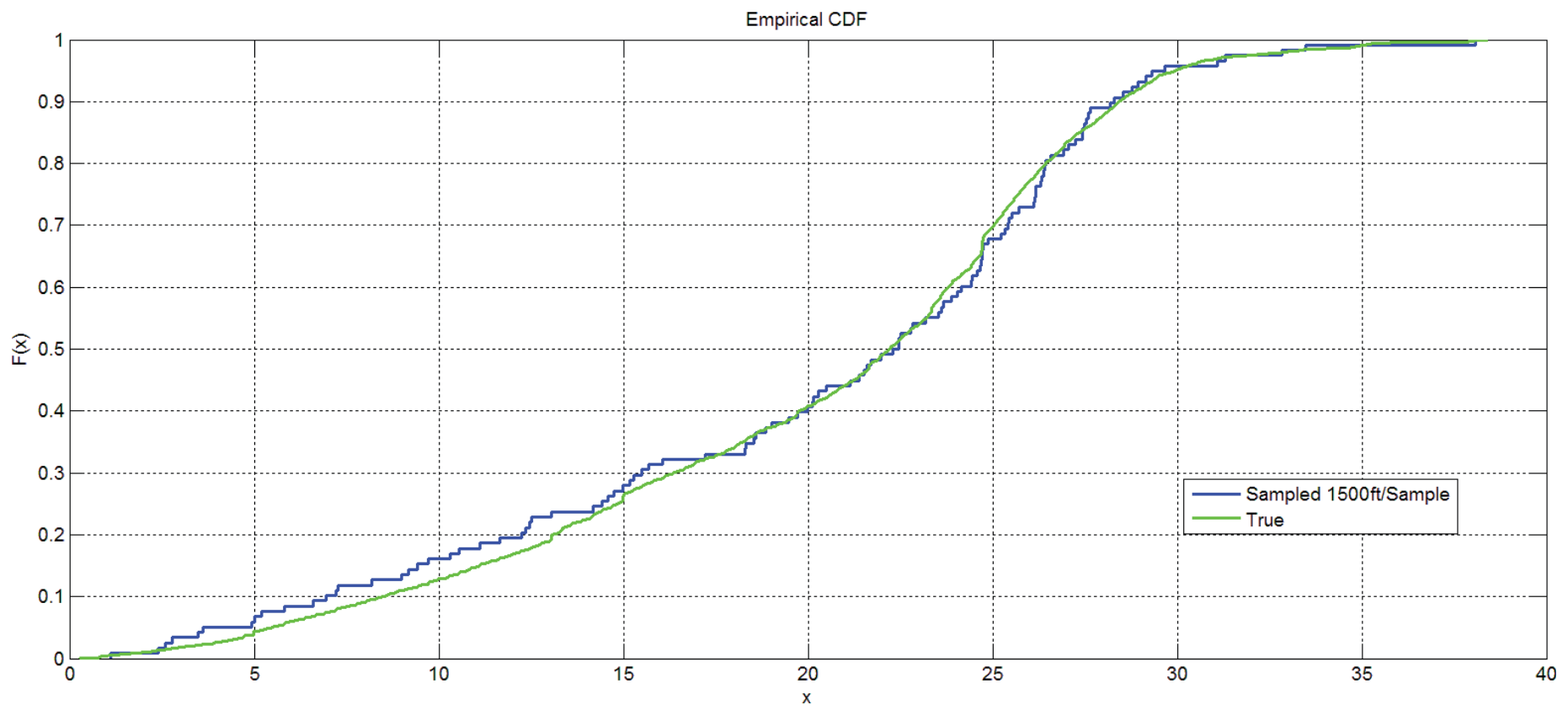

(b)

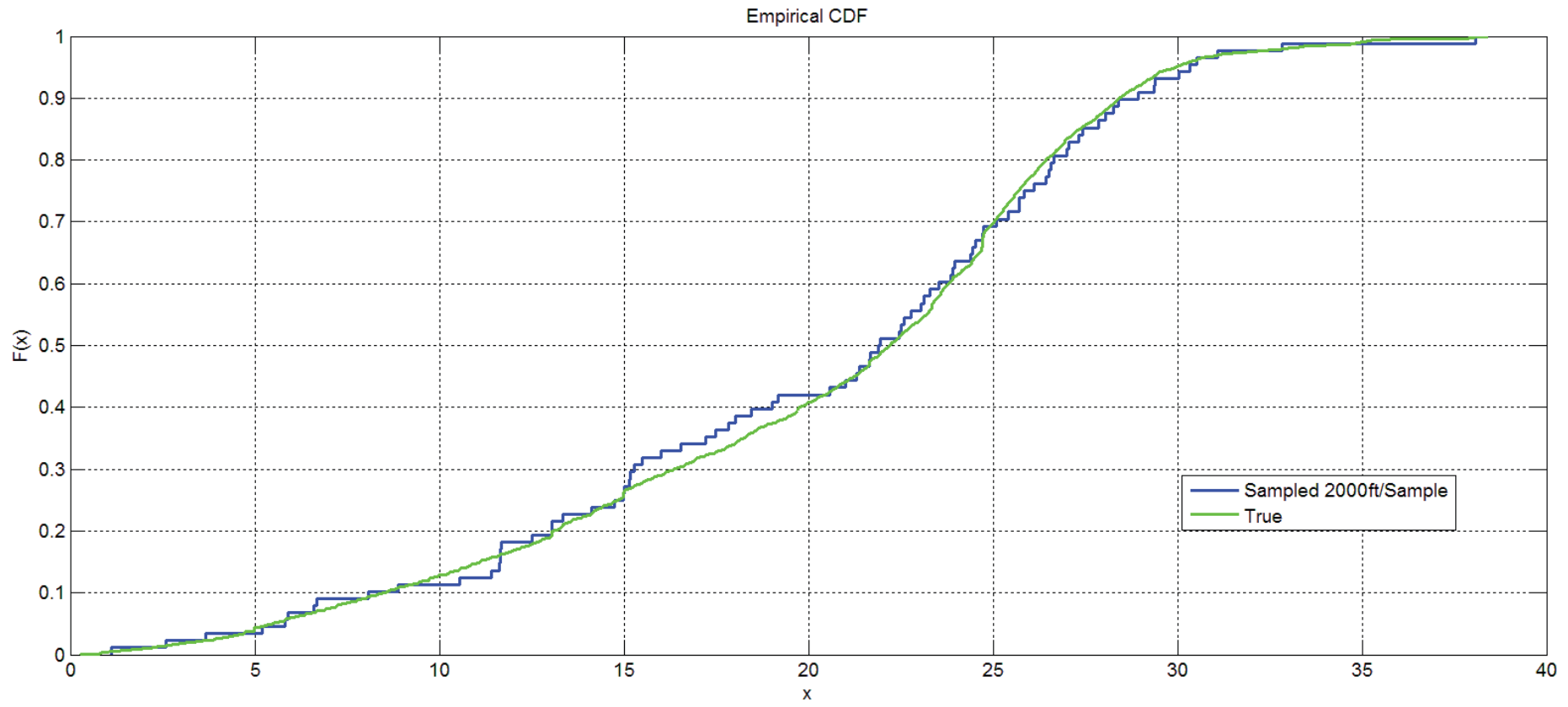

(c)

Figure 5.10. (continued) 
Table 5.1. Percentage Travel Speed Differences and Absolute Differences for K-S Value for Different Detector Spacing

\begin{tabular}{|l|c|c|}
\hline $\begin{array}{l}\text { Detector } \\
\text { Spacing (ft) }\end{array}$ & $\begin{array}{c}\text { Difference of } \\
\text { Travel Speed } \\
\text { CDF (\%) }\end{array}$ & $\begin{array}{c}\text { Maximum Absolute } \\
\text { Difference by } \\
\text { K-S Statistic }\end{array}$ \\
\hline 100 & 2.05 & 0.01 \\
\hline 200 & 3.05 & 0.01 \\
\hline 400 & 4.94 & 0.02 \\
\hline 500 & 4.12 & 0.02 \\
\hline 1,000 & 6.38 & 0.04 \\
\hline 1,500 & 13.71 & 0.05 \\
\hline
\end{tabular}

sampled CDF functions. The table suggests that a cutoff frequency of 1,500 feet can deliver statistically sound approximations to the final travel speed CDF curves.

\section{Example Two}

In the second experiment, the point speed data from the GPS traces are converted to travel rates ( $1 /$ speed). The spectrum pattern still lacks a clear indication of what the cutoff frequency should be. In general, identifying the cutoff frequency is difficult in its own right and may require a large data set to uncover the inherent patterns. The above analysis results show $1 / B=1,500$ feet is a reasonable estimation of system frequency, which leads to a suggested minimum spacing of $1 / 2 B=750$ feet or a slightly impractical spacing of $1 / 8 B=200$ to 300 feet for better approximation results.

Using the NGSIM vehicle trajectory data from I-80 in Oakland, California, it is possible to further identify the vehicle-by-vehicle travel time frequency distribution in Figure 5.11 , which indicates $1 / B=0.02 \mathrm{~Hz}$ (= 50 seconds) as being a logical cutoff frequency. At the minimum sampling rate of $1 / 2 B$, this indicates a need to maintain a sampling interval of 25 to 30 seconds to obtain high-quality travel time variability distributions.

By using the sampling rates of 30 seconds and 300 feet, the aggregated cell-based traffic state representation illustrated in Figure 5.12 is obtained. Compared with the background vehicle traffic trajectories, which contain significant stopand-go shockwaves, the recommended space-time sampling interval appears to reasonably capture the traffic dynamics under this severe congestion condition.

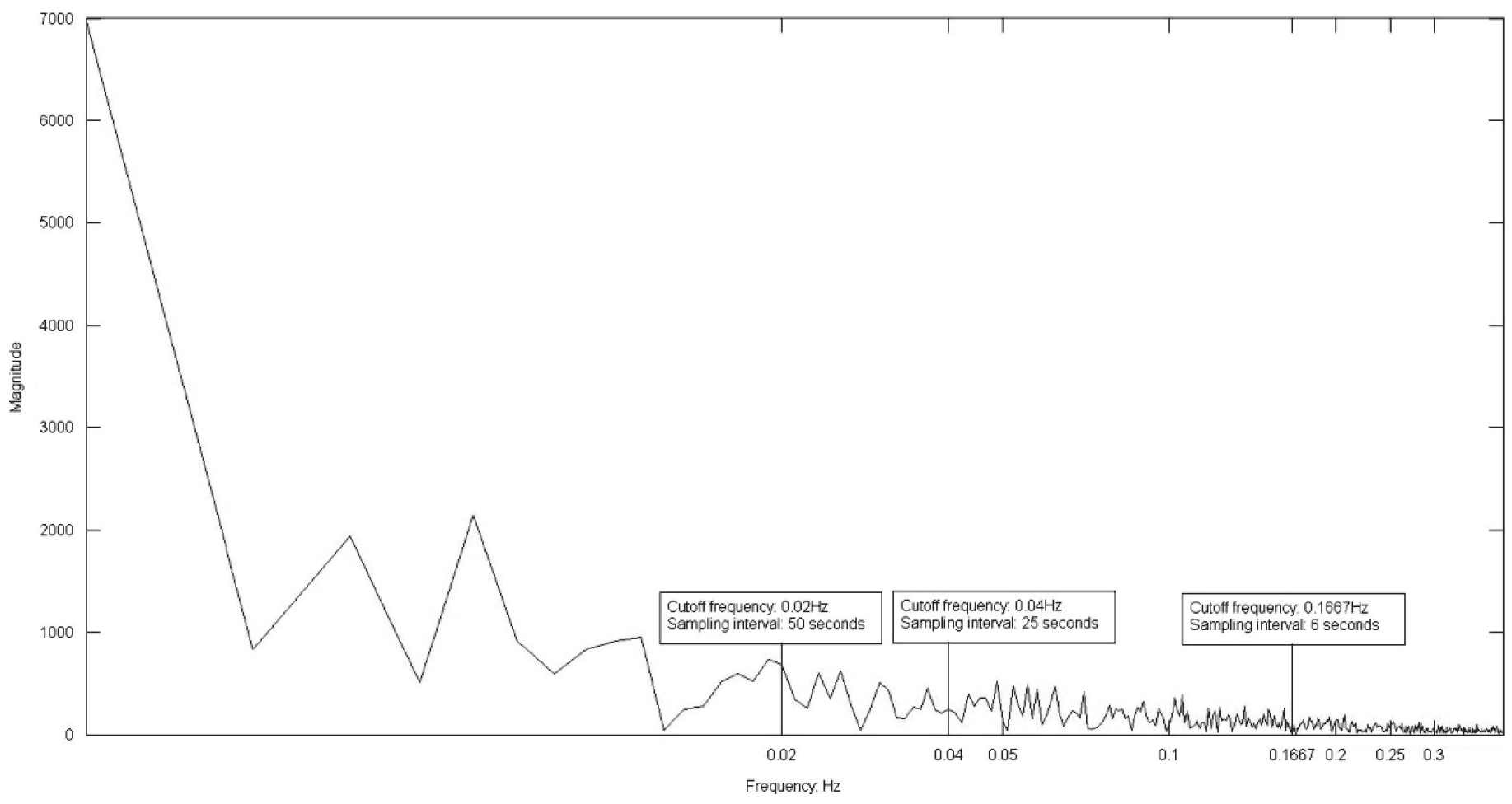

Figure 5.11. Frequency distribution for end-to-end travel time data along a freeway segment based on an NGSIM data set. 


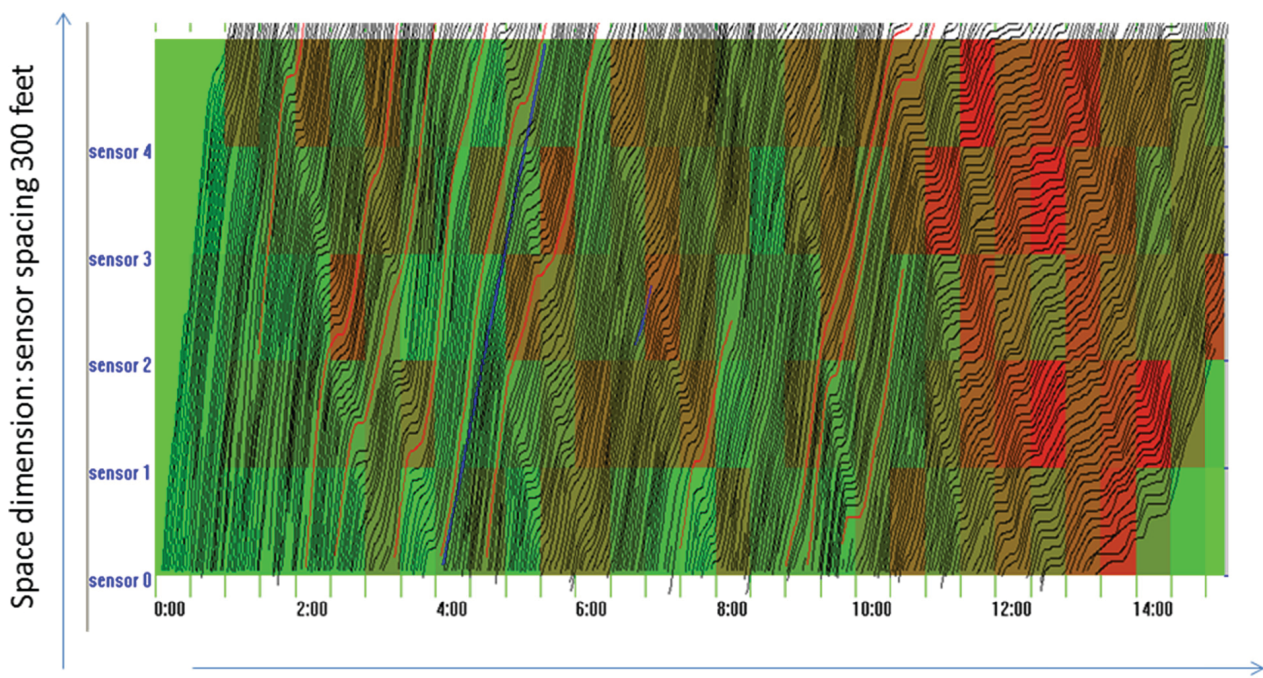

Time dimension, 8:00 indicates $8 \mathrm{~min}: 00$ seconds

Figure 5.12. Space-time vehicle trajectory and aggregated density representation with a sampling rate of 30 seconds and 300 feet (green to red represents aggregated density from low to high).

Color figure available online at www.trb.org/Main/Blurbs/168765.aspx.

\section{Summary}

This chapter has examined the issue of sampling rates in both time and distance to capture acceptable pictures of the trends in travel time reliability, especially on freeway facilities. The following conclusions are drawn:

- Temporal sampling intervals of 1 to 5 minutes should be adequate for most situations when both recurring and nonrecurring events occur, although 30 seconds is somewhat better.

- Longer sampling intervals can be used when transients are not expected (e.g., off peak) or when separate means exist for detecting incidents.

- Spatial sampling intervals of 750 to 1,500 feet are desirable in locations where queuing transients are expected.

- Longer spatial sampling intervals can be used when queuing is not expected or a separate means exists for detecting incidents. 


\section{онАРтE⿱ \\ Data Processing and Analysis}

Data processing and analysis lie at the heart of a travel time reliability monitoring system (TTRMS). This chapter provides an overview of TTRMS data processing and analysis. More elaborate descriptions can be found in the Guide (Chapter 3 and Appendix B).

\section{Processing Steps}

The processing steps employed by a TTRMS are shown in Figure 6.1. The cascading steps transform the raw data into information about travel times and travel time reliability.

The reliability analysis process starts with the definition of the monuments (real or virtual monitoring points) as the locations to and from which travel times will be measured and monitored. As explained in Chapter 3, monuments should be located between (and not at) the network junctions so that turning movement delays do not confound the reliability analysis. Undoubtedly, there are logical locations for these monitoring points, such as lane additions and drops and the locations of toll tag readers and automated vehicle identification (AVI) monitors. It seems that most transportation management center (TMC) systems assign segments to system detectors as illustrated by Figure 6.2.

Once the monuments have been established, the incoming data can be processed to prepare segment-level travel times, which are the basis for the reliability analysis and assessment.

The data from infrastructure-based sensors must be enhanced to provide segment-level travel times. Imputation is used to fill voids when data are missing and is augmented with average speed information when such information was not collected directly. For useful discussions on inferring speeds for singleloop detectors, see Wosyka and Pribyl (2012), van Zwet et al. (2003), Zou et al. (2008, 2009), and Shen and Hadi (2011). Further inference transforms these spot speeds into average segment-level travel times that can be extended further to develop synthetic distributions of individual vehicle travel times where and when needed.
The data from AVI- and automated vehicle location (AVL)based systems need to be processed, as well, but in a different way. One has to be sure that the AVI- and AVL-based observations actually pertain to the segments of interest. In the case of AVI data, the sensors are typically located above or adjacent to the roadway, so it is highly likely that the observations pertain to the facility of interest. For AVL-based systems, map matching is required to determine which facilities the observations pertain to. The GPS coordinates are often not sufficiently precise to make this linkage clear. Once suitable observations have been identified, the data can be summarized directly to create segment-level PDFs of the individual vehicle travel times, as well as averages (for comparison and use with the system detector-based data).

The segment travel times and rates are then combined to develop route-level travel times and rates. The combination process is not trivial because strong correlations exist among the times observed on adjacent segments; however, it is possible to generate these multisegment density functions. Of course, if the AVL or AVI data are sufficiently numerous that direct observations of route-level travel times exist, then the travel times and travel time distributions can be observed directly.

Nonrecurring event data are collected from external sources so that the operative conditions in the network can be correctly characterized for any given point in time and location. Variable values based on these data are added to the segmentand route-level travel time data so that the effects of these conditions can be ascertained (and the effects of mitigating actions assessed). Congestion-level information also needs to be added so that its impacts can be seen and assessed. Combinations of congestion level and nonrecurring events form regimes, the principal categories of system operation for which the reliability performance is differentiated. A view of the processing steps is found in Figure 6.3. This portrayal connects the four types of data feeds. It also shows how those feeds have to be processed to generate segment- and route-level PDFs. 


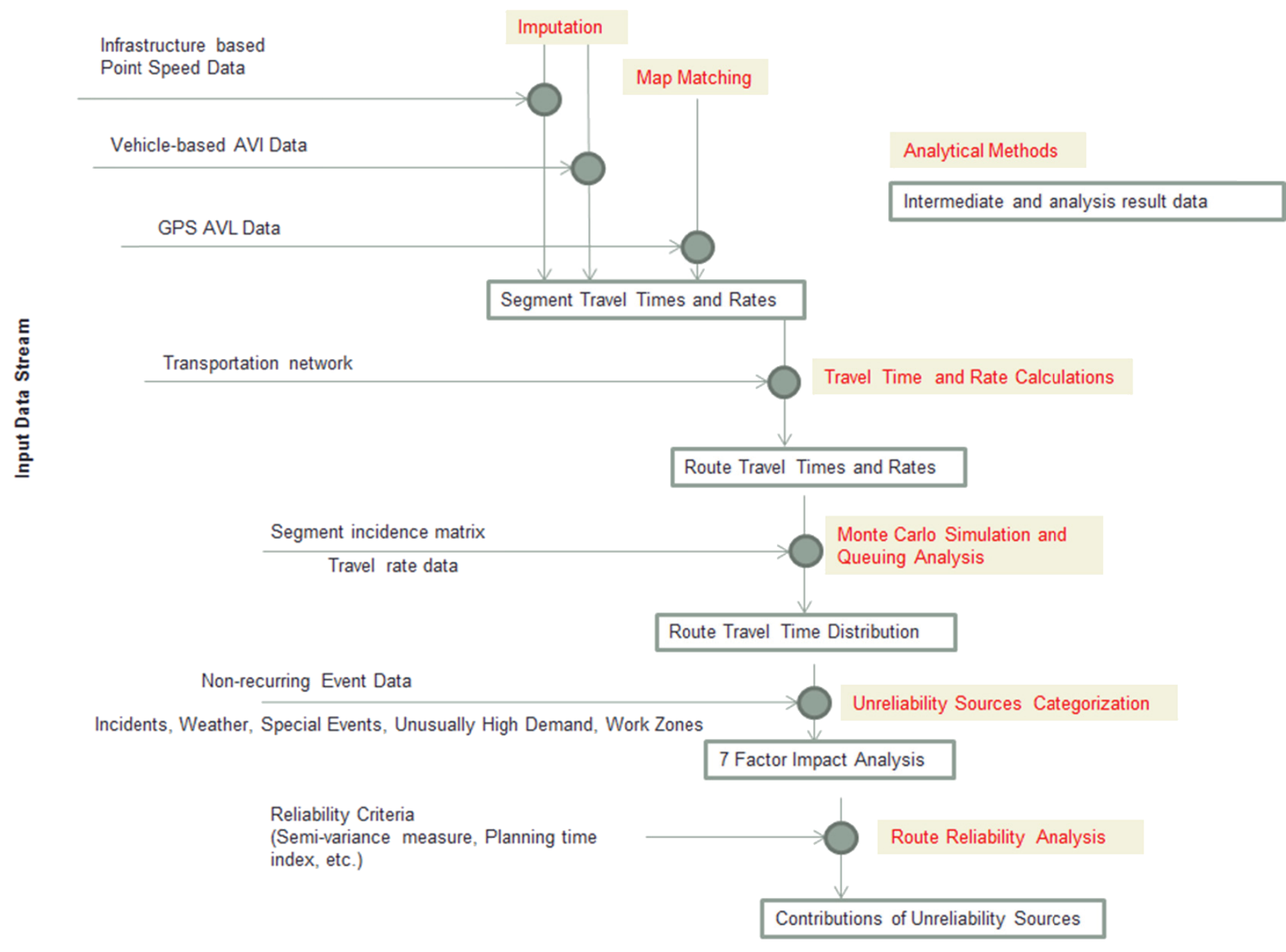

Figure 6.1. Steps in the reliability analysis process.

Yet another perspective is provided by Table 6.1. The narrative in the table indicates how various types of information can be obtained from the various data feeds typically available.

\section{Segment Travel Time Calculations}

Segment travel times and their PDFs lie at the heart of a TTRMS. It is via these times and their distributions that reliability performance is assessed and improvements over time are monitored. It is also via these data that route-level travel times and PDFs are developed, as well as area- and sub-area-wide aggregate assessments. It is critical that highquality segment travel times and their PDFs be developed from whatever data sources are available.

Most agencies base their segment travel times on speeds obtained from system detectors (loops) or third-party sources (e.g., Inrix), or both. In the first case, average spot rates (actually speeds) are collected at specific locations, and in the second, average speeds are related to TMC segments.

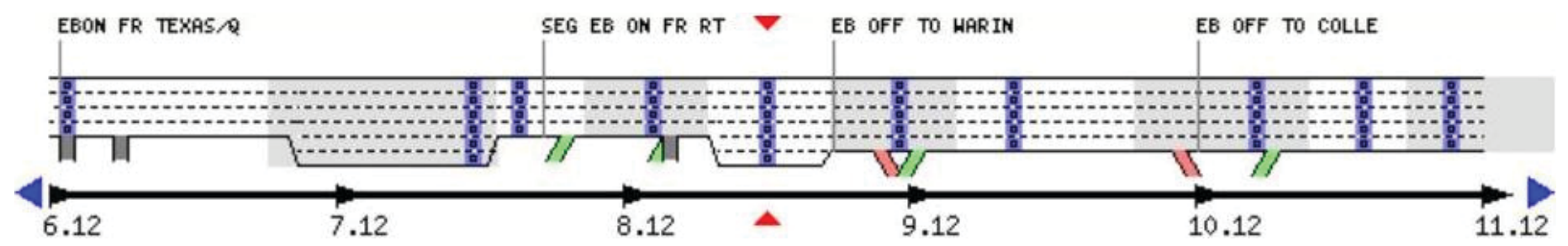

Figure 6.2. Freeway segments and segment boundaries from legacy systems. 


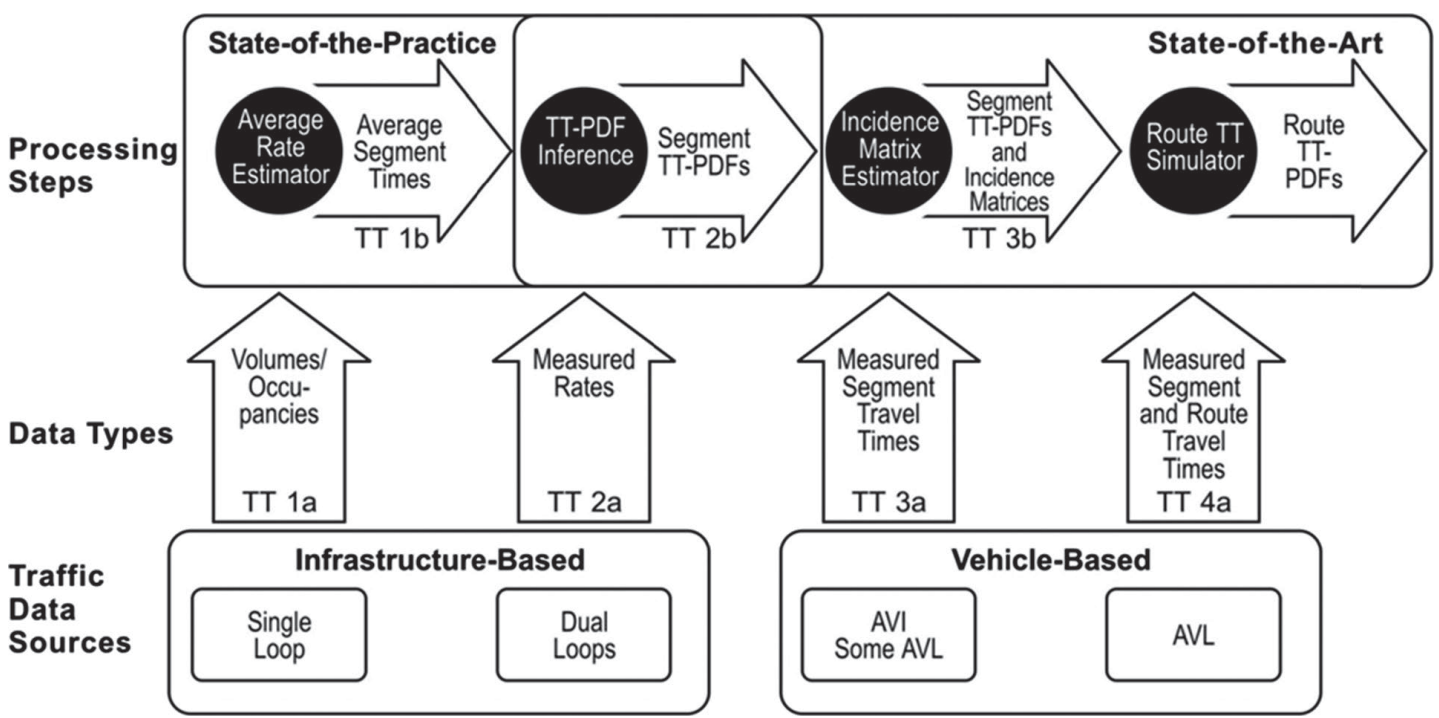

Figure 6.3. Data processing and integration to yield segment and route PDFs.

Table 6.1. Creating Reliability Information from Data Feeds

\begin{tabular}{|c|c|c|c|c|}
\hline \multicolumn{5}{|c|}{ Generating PDFs and Measures of Interest } \\
\hline \multirow[b]{2}{*}{$\begin{array}{l}\text { Enhancement or } \\
\text { Metric }\end{array}$} & \multicolumn{4}{|c|}{ Data Type } \\
\hline & $\begin{array}{c}\text { Type } 1 \\
\text { Single Loop }\end{array}$ & $\begin{array}{c}\text { Type } 2 \\
\text { Double Loop }\end{array}$ & $\begin{array}{l}\text { Type } 3 \\
\text { AVI }\end{array}$ & $\begin{array}{l}\text { Type } 4 \\
\text { AVL }\end{array}$ \\
\hline Passage times & na & na & $\begin{array}{l}\text { Use signal strength or } \\
\text { bounce-back time }\end{array}$ & $\begin{array}{l}\text { Use passage times for } \\
\text { latitude-longitude locations }\end{array}$ \\
\hline Average spot rates & $\begin{array}{l}\text { Use occupancy, flow, and } \\
\text { assumed vehicle length }\end{array}$ & $\begin{array}{l}\text { Directly computed by } \\
\text { the sensor }\end{array}$ & Not needed & Not needed \\
\hline $\begin{array}{l}\text { Spot rates for indi- } \\
\text { vidual vehicles }\end{array}$ & Cannot be obtained & Could be obtained & $\begin{array}{l}\text { Use signal strength or } \\
\text { bounce-back times }\end{array}$ & $\begin{array}{l}\text { Use GPS speeds at latitude- } \\
\text { longitude locations }\end{array}$ \\
\hline $\begin{array}{l}\text { Average times or } \\
\text { rates for segments }\end{array}$ & $\begin{array}{l}\text { Combine adjacent sensor } \\
\text { spot rates }\end{array}$ & $\begin{array}{l}\text { Combine adjacent sen- } \\
\text { sor spot rates }\end{array}$ & $\begin{array}{l}\text { Determine from adjusted } \\
\text { IV-PDFs }\end{array}$ & $\begin{array}{l}\text { Determine from adjusted } \\
\text { IV-PDFs }\end{array}$ \\
\hline Segment IV-PDFs & $\begin{array}{l}\text { Use average times or } \\
\text { rates and IV-PDF typi- } \\
\text { cal of the traffic } \\
\text { conditions }\end{array}$ & $\begin{array}{l}\text { Use average times or } \\
\text { rates and IV-PDF typi- } \\
\text { cal of the traffic } \\
\text { conditions }\end{array}$ & $\begin{array}{l}\text { Adjust the observed IV-PDFs } \\
\text { to account for unequipped } \\
\text { vehicles }\end{array}$ & $\begin{array}{l}\text { Adjust the observed IV-PDFs } \\
\text { to account for unequipped } \\
\text { vehicles }\end{array}$ \\
\hline Incidence matrices & $\begin{array}{l}\text { Base on field studies or } \\
\text { similar segment-to- } \\
\text { segment flow condi- } \\
\text { tions elsewhere }\end{array}$ & $\begin{array}{l}\text { Base on field studies or } \\
\text { similar segment-to- } \\
\text { segment flow condi- } \\
\text { tions elsewhere }\end{array}$ & $\begin{array}{l}\text { Use equipped vehicles on } \\
\text { adjacent segments }\end{array}$ & $\begin{array}{l}\text { Use equipped vehicles on } \\
\text { adjacent segments }\end{array}$ \\
\hline $\begin{array}{l}\text { AVG-PDFs for seg- } \\
\text { ments or routes }\end{array}$ & $\begin{array}{l}\text { Add estimated segment } \\
\text { or route times or rates }\end{array}$ & $\begin{array}{l}\text { Add estimated segment } \\
\text { or route times or rates }\end{array}$ & $\begin{array}{l}\text { Compute from segment or } \\
\text { route IV-PDFs }\end{array}$ & $\begin{array}{l}\text { Compute from segment or } \\
\text { route IV-PDFs }\end{array}$ \\
\hline IV-PDFs for routes & $\begin{array}{l}\text { Simulation based on IV- } \\
\text { PDFs and coincidence } \\
\text { matrices }\end{array}$ & $\begin{array}{l}\text { Simulation based on IV- } \\
\text { PDFs and coinci- } \\
\text { dence matrices }\end{array}$ & $\begin{array}{l}\text { Use equipped vehicles or sim- } \\
\text { ulation based on IV-PDFs } \\
\text { and coincidence matrices }\end{array}$ & $\begin{array}{l}\text { Use equipped vehicles or sim- } \\
\text { ulation based on IV-PDFs } \\
\text { and coincidence matrices }\end{array}$ \\
\hline
\end{tabular}

Note: $n a=$ not applicable; IV-PDF = individual vehicle travel time or travel rate probability density function (TT-PDF or TR-PDF) for the time frame of interest (e.g., the a.m. peak); AVG-PDF = average TT-PDF or TR-PDF for a segment or route for the time frame of interest (e.g., a year or the winter). 
An advantage to the system (loop) detectors is that they base the speeds on all the vehicles in the traffic stream, not just equipped vehicles. Two disadvantages are that no individual vehicle spot speeds are reported (although they are observed), and the data do not actually reflect segment travel times.

A growing number of agencies are obtaining data from third-party sources. AVI- and AVL-equipped vehicles are the ultimate source of the TMC segment data these companies provide, but the reported data do not typically indicate how many vehicles were observed for the values reported or the speeds for the individual vehicles.

A few agencies have installed their own Bluetooth sensors or tag sensors to obtain individual vehicle travel times. These data truly are segment travel times, but only for the equipped vehicles. Because only some vehicles are observed (vehicles equipped with discoverable Bluetooth devices or those equipped with tags), there can be a bias in the observations vis-à-vis the overall traffic stream.

This discussion assumes a TTRMS that can work with data both from system detectors and individual vehicle-monitoring systems, so developing distributions of individual vehicle travel times and average travel times are both considered. As Figure 3.6 shows, the two are related. Moreover, assuming the individual vehicle travel times are not biased (which they might be), the means from the individual vehicle travel times should match the mean travel times (from the spot rates) reported by the system (loop) sensors. The study team checked this correspondence on I-5 in Sacramento and found that the two did match closely, although the system detector average travel times tended to lag behind the averages from the individual vehicle observations and miss some of the variation that occurred.

The discussion below also assumes that the travel times are tagged by additional information that indicates the operating condition (regime) that pertains to each observation. This means the data, however selected from the overall data set, can be categorized for further analysis based on the regimes represented in the selection. This stipulation, in turn, means the influence of associative (causal) factors can be studied.

\section{Individual Vehicle TT-PDFs from AVI or AVL Data}

In this instance, the development of PDFs for individual vehicle travel times is straightforward. The one stipulation is that the observation points have to be at both ends of the segment; if they are not, some form of interpolation has to be used. For AVL systems, interpolation is almost always required because the vehicles may not report their status exactly at the segment end points unless they have been told to do that. (In some AVL systems, vehicles can be instructed to do so.)
Observations may be biased vis-à-vis the overall traffic stream if the equipped vehicles can traverse the segment in some manner that the unequipped vehicles cannot or do not. This might be the case if there were a toll booth in the middle of the segment and the equipped vehicles could pass through the toll booth without stopping, but the unequipped vehicles could not.

There are also minor issues about whether the vehicle data to employ should be based on time of entry into the segment, time of exit, or some other rule. Of course, when the averages are being computed in real time, the vehicle travel times are not observed until the vehicles exit the segment. Most analysts seem to use the time of entry as the criterion for selection. The analyses conducted in this study used that rule.

Several types of individual vehicle PDFs can be developed from these data. The first type of individual vehicle PDF is the PDF for a specific time span during the day (e.g., a 5-minute time period) based on some period of time (e.g., an entire year). A year's worth of observations makes it possible to examine the extent to which the distribution of travel times (rates) varies, along with the impact of congestion when no nonrecurring event exists, the impact of nonrecurring events, and the consistency that does or does not exist within observations for the same operating condition (regime).

The second type is the distribution of individual vehicle travel times for some time span during the day (e.g., 7:00 to 9:00 a.m. on workdays), as well as a period of time (e.g., a year). Embedded in such data is a mix of both nonrecurring event conditions and congestion conditions. That is, the data will represent a mix of regimes.

A third type is the distribution of average travel times for some time span (e.g., a 5-minute time period) when all of the observations have the same operating condition (regime). An example would be uncongested with no nonrecurring event. A fourth type is all the observations for an entire year. This data set would clearly represent a wide range of regimes, which implies it would likely be multimodal. Such a data set would be ideal for studying the differences among regimes in terms of the distribution of travel times.

\section{Individual Vehicle TT-PDFs from System Sensor (Loop) Data}

Tracking individual vehicle TT-PDFs from detectors is challenging, but it can be done. The task would be simpler if system sensors reported individual vehicle spot rates. At present these data are observed, but not reported. Perhaps in the future sensors will be able to report such data. The detector would not have to report each vehicle speed observation. Rather, it could report the sum of the squares of the vehicle speeds and the sum of the cubes of the vehicle speeds. These two additional data items would be sufficient. 
Table 6.2. Bluetooth Observations from the Berkeley Highway Laboratory

\begin{tabular}{|l|c|c|c|c|r|}
\hline \multirow{2}{*}{ Condition } & \multicolumn{5}{|c|}{ Observation Counts by Day and Condition } \\
\cline { 2 - 6 } & January 13 & January 20 & January 22 & January 24 & Total \\
\hline Free flow & 1,183 & 1,446 & 1,727 & 1,566 & 5,922 \\
\hline Transition into peak & 121 & 328 & 160 & 126 & 735 \\
\hline Transition from peak & 84 & 310 & 80 & 149 & 623 \\
\hline Peak (congested) & 1,099 & 639 & 594 & 552 & 2,884 \\
\hline Total & 2,487 & 2,723 & 2,561 & 2,393 & 10,164 \\
\hline
\end{tabular}

Assuming that only the average speeds and the number of vehicles observed are available, the following procedure can be used. It requires field studies for a limited number of locations and regimes to establish distributions of individual vehicle spot rates (or spot speeds) for typical operating conditions (combinations of congestion levels and nonrecurring events). Assuming these field studies have been conducted, then the observed average spot rates (spot speeds) and occupancies can be used to find a regime that best matches the current conditions. On the basis of this result, one of the distributions of spot rates can be chosen. The average in the selected distribution can be adjusted up or down so that it matches the average spot rate that has been observed. The resulting distribution of spot rates can be multiplied by the segment length to estimate the distribution of individual vehicle travel times.
Examples of spot rate distributions can be seen in data from the Berkeley Highway Laboratory (BHL; a section of I-80 located adjacent to Berkeley, California), where individual vehicle travel times were recorded on select days in January 2011. Hundreds of observations were recorded for each of several regimes, as shown in Table 6.2.

Figure 6.4 shows the TR-PDFs for the free-flow regime overall and for each day. Notice that the distributions are all similar, and the variances are relatively small. The minimum is about $50 \mathrm{~s} / \mathrm{mi}(72 \mathrm{mph})$, the 50 th percentile is about $70 \mathrm{~s} / \mathrm{mi}(51 \mathrm{mph})$, and the 95 th percentile is about $86 \mathrm{~s} / \mathrm{mi}$ (42 mph). The coefficient of variation is about 0.15 . In this instance, this TR-PDF could be used to estimate off-peak PDFs for individual vehicles for all the times during the year when the facility was lightly loaded.

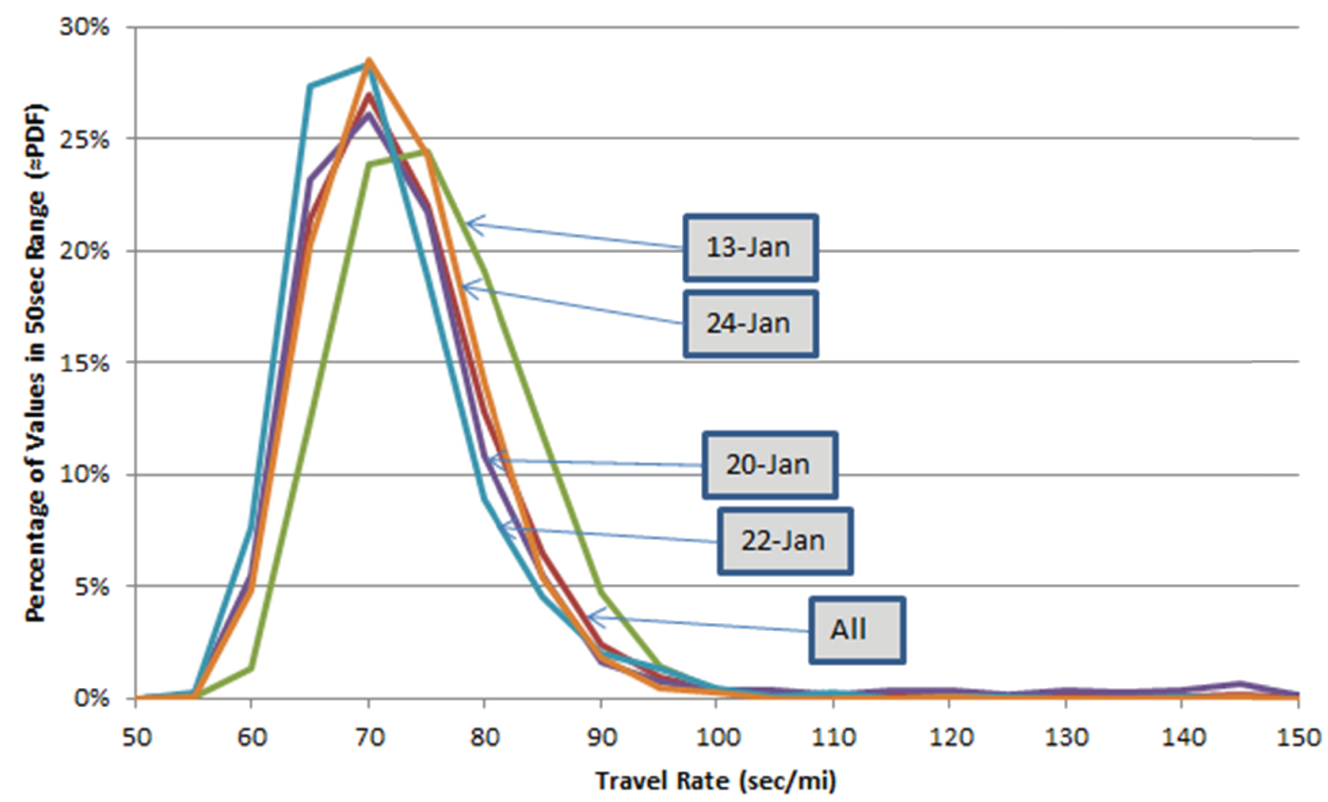

Figure 6.4. Off-peak travel rates measured by Bluetooth sensors on a 4,500-ft segment for the Berkeley Highway Laboratory.

Color figure available online at www.trb.org/Main/Blurbs/168765.aspx. 


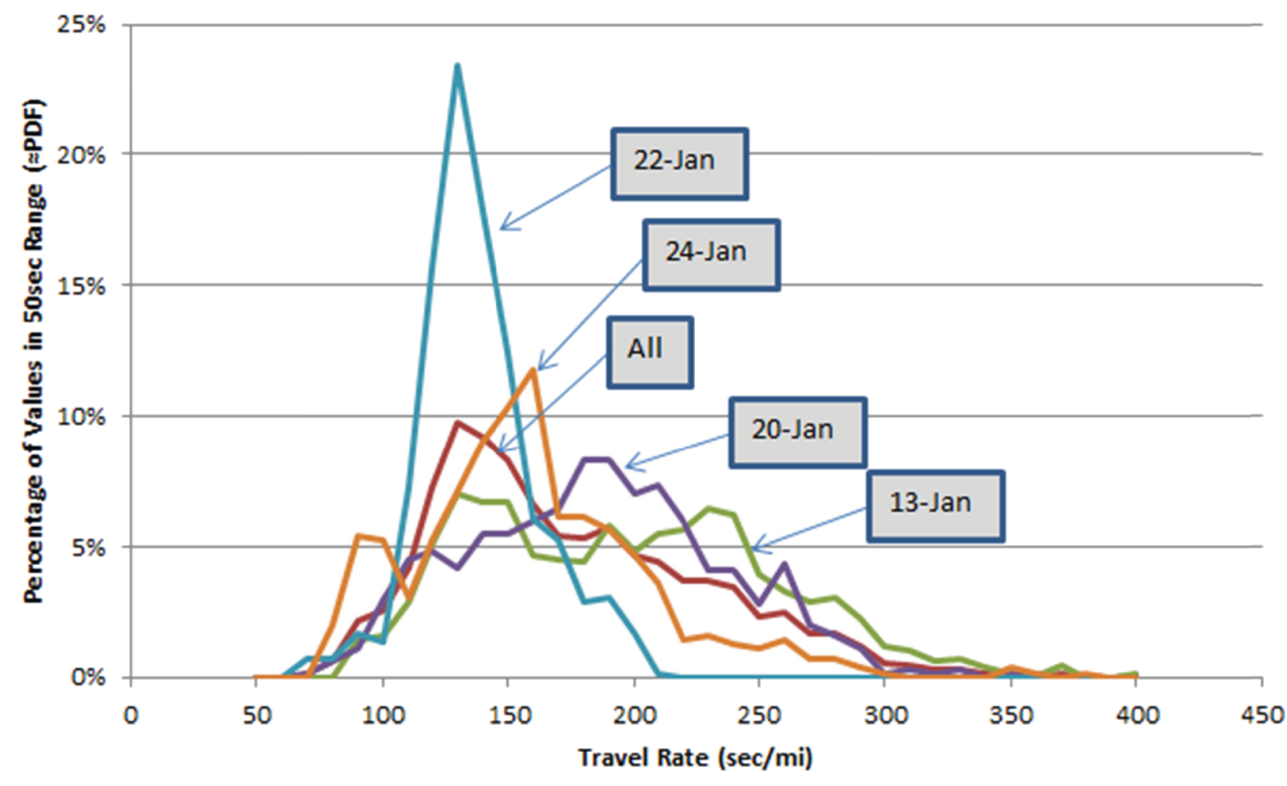

Figure 6.5. Approximate peak condition travel rates measured by Bluetooth sensors on a 4,500-ft segment for the Berkeley Highway Laboratory.

Color figure available online at www.trb.org/Main/Blurbs/168765.aspx.

In contrast, the TR-PDFs during the peak period congestion involve significantly larger travel rates, a wider distribution, and much more variability day to day, as shown in Figure 6.5. The minimum travel rate is about $60 \mathrm{~s} / \mathrm{mi}(60 \mathrm{mph})$, the 50th percentile ranges from 150 to $190 \mathrm{~s} / \mathrm{mi}$ (19 to $24 \mathrm{mph}$ ), and the 95th percentile ranges from 180 to $360 \mathrm{~s} / \mathrm{mi}$ (10 to $20 \mathrm{mph}$ ). Two reasonable options are (1) to use the overall PDF for all the days and adjust it to the median travel rate (Arezoumandi and Bham 2011) being observed at a given point in time or (2) to select the PDF whose median travel rate most closely matches the extant travel rate and then adjust that PDF to the extant travel rate.

The transitions to and from the peak flow conditions are more challenging, but the data still provide good guidance. Figure 6.6 shows the TR-PDFs for the transition to peak flow conditions observed on the four days. Evidence of both

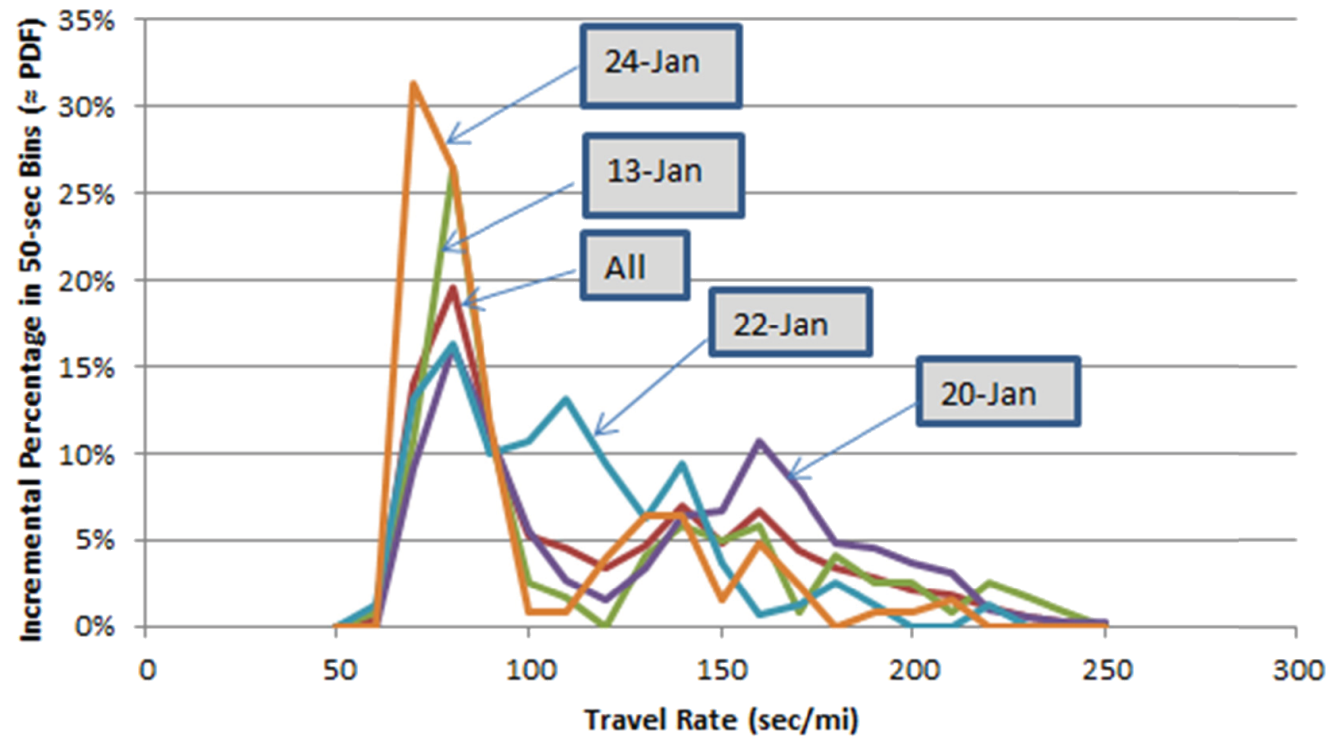

Figure 6.6. Approximate transition to peak condition travel rates measured by Bluetooth sensors on a 4,500-ft segment for the Berkeley Highway Laboratory. Color figure available online at www.trb.org/Main/B/urbs/168765.aspx. 
off-peak and peak conditions can be seen. The density functions appear to be multimodal (bimodal). The minimums are about $60 \mathrm{~s} / \mathrm{mi}(60 \mathrm{mph})$, the median ranges from 90 to $130 \mathrm{~s} / \mathrm{mi}$ (30 to $40 \mathrm{mph}$ ), and the 95th percentile ranges from 160 to $400 \mathrm{~s} / \mathrm{mi}$ (10 to $20 \mathrm{mph}$ ).

Summary distributions can be developed from these synthesized individual vehicle travel times like the ones developed for the actual observations. The one caveat is that the synthesized observations are inherently tied to the underlying system detector observations and the frequency of those observations. For example, if the system detector observations are only available every 5 minutes, then the synthesized individual vehicle travel time observations are available only every 5 minutes, as well, unless additional inference is used to synthesize individual vehicle travel times for intervening points in time.

\section{Average Segment Travel Times from AVI or AVL Data}

For AVI and AVL data, average segment travel times can be computed by averaging the individual vehicle travel times. The same types of PDFs identified in the previous two sections pertain to the averages derived from AVI and AVL data. The one difference is that there may be a bias in the results obtained if the AVI- or AVL-equipped vehicles have driving attributes that are different from the unequipped vehicles.

\section{Average Segment TT-PDFs from System (Loop) Sensor Data}

The development of PDFs from system (loop) sensor data for average segment travel times is both simple and complex. It is simple because the data reported by the system (loop) sensors are average spot speeds at specific locations. For thirdparty data feeds, they are also average speeds for specific short highway segments (TMC segments); the fundamental observations are average speeds based on observations from equipped vehicles.

The complexity arises from the fact that the observations are only spot rates. They are not observations of travel times across the segment. In most cases, the agency associates specific sections of the highway network with each system (loop) detector. This is illustrated by Figure 6.2. Moreover, agencies generally assume that the average spot rates (inverses of the average speeds) observed by the system sensors are the travel rates for the entire segment. Field studies can be conducted to establish adjustment coefficients if the match is not exact under certain conditions.

\section{Route Travel Time Calculations}

Route TT-PDFs are also of great interest in monitoring the performance of a given system. The routes can be short, such as a sequence of segments across a few miles, or long, such as from a significant traffic origin to a significant destination.

Route TT-PDFs are clearly of interest to system users, as well. It is these travel times, rather than the segment travel times, that they will actually experience and to which they will relate. Moreover, route TT-PDFs are useful when an agency wants to portray to various stakeholders information about the reliability of the system and how it has improved over time.

Route travel times are challenging because they are difficult to observe. For any specific origin-destination pair, the data tend to be too sparse to allow the estimation of route TTPDFs directly. Obtaining route TT-PDFs requires combining segment-level PDFs in a manner that will produce credible route-level PDFs.

This section describes three procedures for developing route-level PDFs from the segment-level data. The first procedure is based on Monte Carlo simulation of the traffic flow behavior on successive segments combined with incidence matrices for connecting those results. The second procedure uses a lane-by-lane Monte Carlo simulation of a cascading sequence of bottleneck locations to estimate the overall travel time distributions. The third procedure adds travel times for identical percentiles across the segments to obtain the routelevel PDF. All three procedures have value.

\section{Importance of Correlation}

It is clear that correlation exists among segment travel times, especially when the segments are short. This phenomenon affects how segment-level TT-PDFs are combined to form route-level TT-PDFs. One cannot add the variances by assuming that the TT-PDFs are uncorrelated. To illustrate, Figure 6.7 shows scatterplots for individual vehicle travel times on subsequent segments along a 6-mile section of freeway in Sacramento, California. The sequence of AVI monitoring stations is $39,9,10$, and 11 . Travel times are TT3909, TT0910, and TT1011. The scales in minutes for the travel times are shown along the left-hand and bottom sides of Figure 6.7. The scatterplots above the diagonal show the correspondence between travel times on adjacent segments (TT3909 versus TT0910 and TT0910 versus TT1011) and two segments away (3909 versus 1011). Each one is plotted against the overall travel time (TT3909 versus TT39-9-10-11; TT0910 versus TT39-9-10-11; and TT1011 versus TT39-9-10-11). The scatterplots are symmetric about the diagonal. 


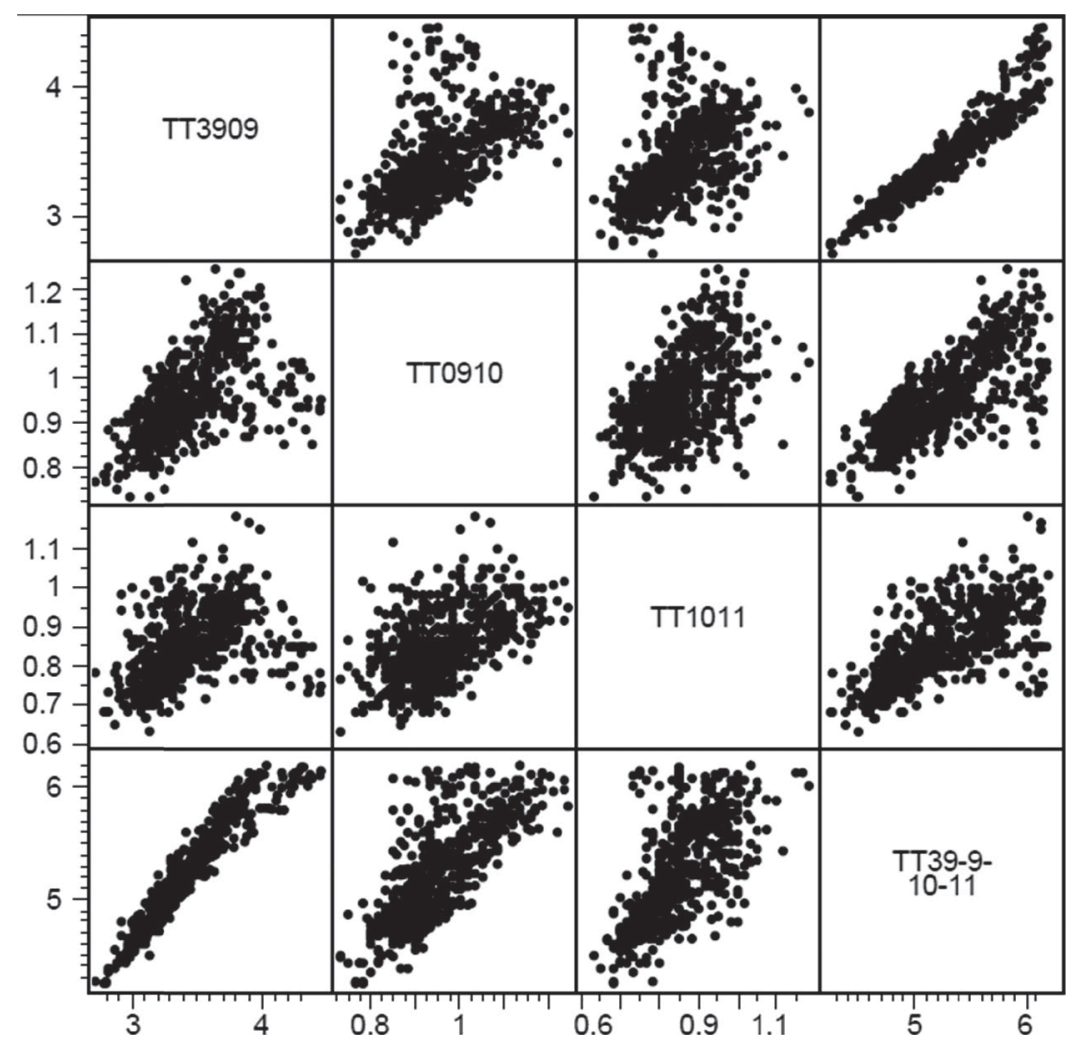

Figure 6.7. Correlations among individual vehicle travel times for a sequence of three segments along I-5 in Sacramento.

Most significantly, not only do the travel times on adjacent segments show a significant degree of correlation, but the travel times on each segment are correlated with the overall travel time. The scatter does not increase dramatically as the segments become further separated, which would be the case if the travel times were uncorrelated. In fact, the correlation between the travel times is strong, as shown by the top righthand scatterplot, which shows the correspondence between travel times on the first segment (TT3909) and the overall travel times (TT39-9-10-11). Only tightly correlated travel times could produce scatterplots that look like this.

\section{Monte Carlo Model with Incidence Matrices}

The first method of estimating route-level PDFs uses segmentlevel TT-PDFs and incidence matrices that indicate the correspondence (correlation) between rates on adjacent segments. The method is based on $\mathrm{Hu}$ (2011), who studied this idea using a VISSIM model of the BHL section of I-80 eastbound in San Francisco. The facility is five lanes wide and experiences significant congestion during the afternoon peak. Using the model, AVI-like data were generated for two adjacent segments, $\mathrm{AB}$ and $\mathrm{BC}$, and those distributions were combined to produce the $\mathrm{PDF}$ for $\mathrm{AC}$.
The incidence matrix was developed using the following procedure, which could also be used by operating agencies conducting short field studies:

1. Observe vehicles traversing Segments $A B, B C$, and $A C$, and note their travel times (and rates) for Segments $A B$, $\mathrm{BC}$, and $\mathrm{AC}$.

2. Create a small number (say, 10) of travel rate bins for both Segments $\mathrm{AB}$ and $\mathrm{BC}$.

3. Create an incidence matrix that shows the frequency with which specific bin-to-bin combinations of the travel rates arise (e.g., a travel rate on Segment $\mathrm{AB}$ in $\mathrm{Bin} X$ and a travel rate on Segment BC in Bin Y).

4. Use the following procedure to generate a PDF for the travel rate on Segment AC:

a. Select a first random variable $x_{1}$.

b. Select a travel rate $\tau_{A B}$ based on $x_{1}$.

c. Identify the Segment $A B$ travel rate bin in which $\tau_{A B}$ belongs.

d. Use $\tau_{A B}$ and the length of Segment $A B$ to determine when the vehicle will arrive at the beginning of Segment BC.

e. Select a second random variable $x_{2}$.

f. Identify the Segment BC travel rate bin from which $\tau_{B C}$ should be obtained based on $x_{2}$. 
g. Select a third random variable $x_{3}$.

Select the BC travel rate $\tau_{B C}$ on the basis of the lower and upper bounds for the $\mathrm{BC}$ travel rate bin and the value of $x_{3}$.

h. Compute the travel rate $\tau_{A C}$ by using the expression $\tau_{A C}=\left(\tau_{A B} * d_{A B}+\tau_{B C} * d_{B C}\right) / d_{A C}$.

The process needs to be repeated for every successive combination of segments in the route. A sufficiently large number of realizations generated in this manner will result in creating a defensible TT-PDF for the route.

An example of an incidence matrix can be seen in Table 6.3. The left-hand column shows the ranges of travel rates experienced by vehicles as they traversed upstream Segment AB. The top row shows travel rates pertaining to the vehicles as they traversed downstream Segment BC. The values in the matrix show the percentages of vehicles that experienced specific combinations of upstream and downstream rates. For example, $24 \%$ of the vehicles experienced an upstream rate between 80 and $100 \mathrm{~s} / \mathrm{mi}$ and a downstream rate between 70 and $80 \mathrm{~s} / \mathrm{mi}$. Interpreted a different way, the matrix also shows that $37 \%(8 \%+24 \%+5 \%)$ of the vehicles experienced travel rates between 80 and $100 \mathrm{~s} / \mathrm{mi}$. Of those vehicles, $21 \%$ ( 8 of 37) experienced travel rates between 60 and $70 \mathrm{~s} / \mathrm{mi}$ on the downstream Segment BC, 65\% (24 of 37) had travel rates between 70 and $80 \mathrm{~s} / \mathrm{mi}$, and 14\% (5 of 37) had travel rates between 80 and $90 \mathrm{~s} / \mathrm{mi}$.

The value of using this incidence matrix can be seen in Figure 6.8, which shows the close correspondence between

Table 6.3. Example of an Incidence Matrix

\begin{tabular}{|l|l|l|l|l|l|l|l|}
\hline \multirow{2}{*}{$\begin{array}{l}\tau_{A B} \\
(\mathbf{s} / \mathrm{mi})\end{array}$} & \multicolumn{7}{|c|}{$\tau_{B C}(\mathbf{s} / \mathrm{mi})$} \\
\hline 60 & 60 & 70 & 80 & 90 & 100 & 110 \\
\hline 80 & & & & & & & \\
\hline 100 & & & $8 \%$ & $24 \%$ & $5 \%$ & & \\
\hline 120 & & & $6 \%$ & $21 \%$ & $7 \%$ & $1 \%$ & \\
\hline 140 & & & $1 \%$ & $7 \%$ & $2 \%$ & & \\
\hline 160 & & & $1 \%$ & $3 \%$ & $2 \%$ & & \\
\hline 180 & & & $1 \%$ & $2 \%$ & $1 \%$ & & \\
\hline 200 & & & & $2 \%$ & $1 \%$ & & \\
\hline 220 & & & & $1 \%$ & $1 \%$ & & \\
\hline 240 & & & & $1 \%$ & $1 \%$ & & \\
\hline 260 & & & & & & & \\
\hline 280 & & & & & & & \\
\hline 300 & & & & & & & \\
\hline$>300$ & & & & & & & \\
\hline
\end{tabular}

\section{Simulated vs Actual Route Travel Times}

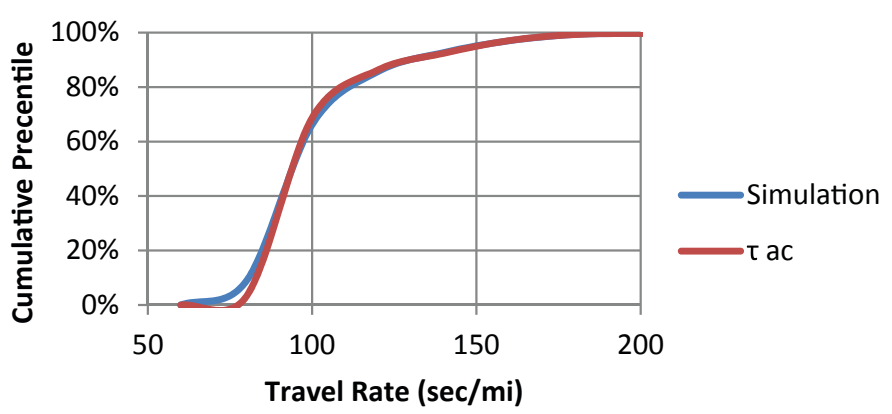

Figure 6.8. Simulated versus actual travel rates for a route.

Color figure available online at www.trb.org/Main/Blurbs/168765.aspx.

the distribution of route travel rates estimated by the Monte Carlo procedure and the distribution that pertained to the actual vehicle travel rates.

\section{Point Queue-Based Model}

In the second procedure, Monte Carlo simulation is again used, but within a different paradigm. A probe- and point queue-based end-to-end travel time prediction model is used to estimate the route-level travel time distribution. Vehicles pass through the network in specific lanes, and their overall travel times are recorded.

The procedure captures the important traffic-related factors that affect end-to-end travel times: the prevailing congestion level, queue discharge rates at bottlenecks, and flow rates associated with merges and diverges. Based on multiple random scenarios and a vector of arrival times, the experienced delay at each bottleneck along the corridor is recursively estimated to produce end-to-end travel time distributions. The model incorporates stochastic variations of bottleneck capacity and demand to explain the travel time correlation between sequential links.

Figure 6.9 provides an illustration of a system that has been studied using this model.

In each Monte Carlo simulation a probe vehicle is assumed to enter the network at a prescribed time (e.g., 7:00 a.m.). The probe vehicle proceeds at free-flow speed to the first downstream bottleneck, assumes a position in the queue (based on the estimated number of vehicles ahead of it), waits to be discharged, and when discharged proceeds downstream to the next bottleneck location. A set of analytical equations is developed to calculate the number of queued vehicles ahead of the probe vehicle as it proceeds through the network. Ultimately, its arrival time at the downstream location is noted, and its travel time and travel rate are recorded. Assembling these simulation run results in a data set of travel times that allows the distribution of travel times and rates to be reported.

An illustration of the results obtained is presented in Figure 6.10. One can immediately see how the model 


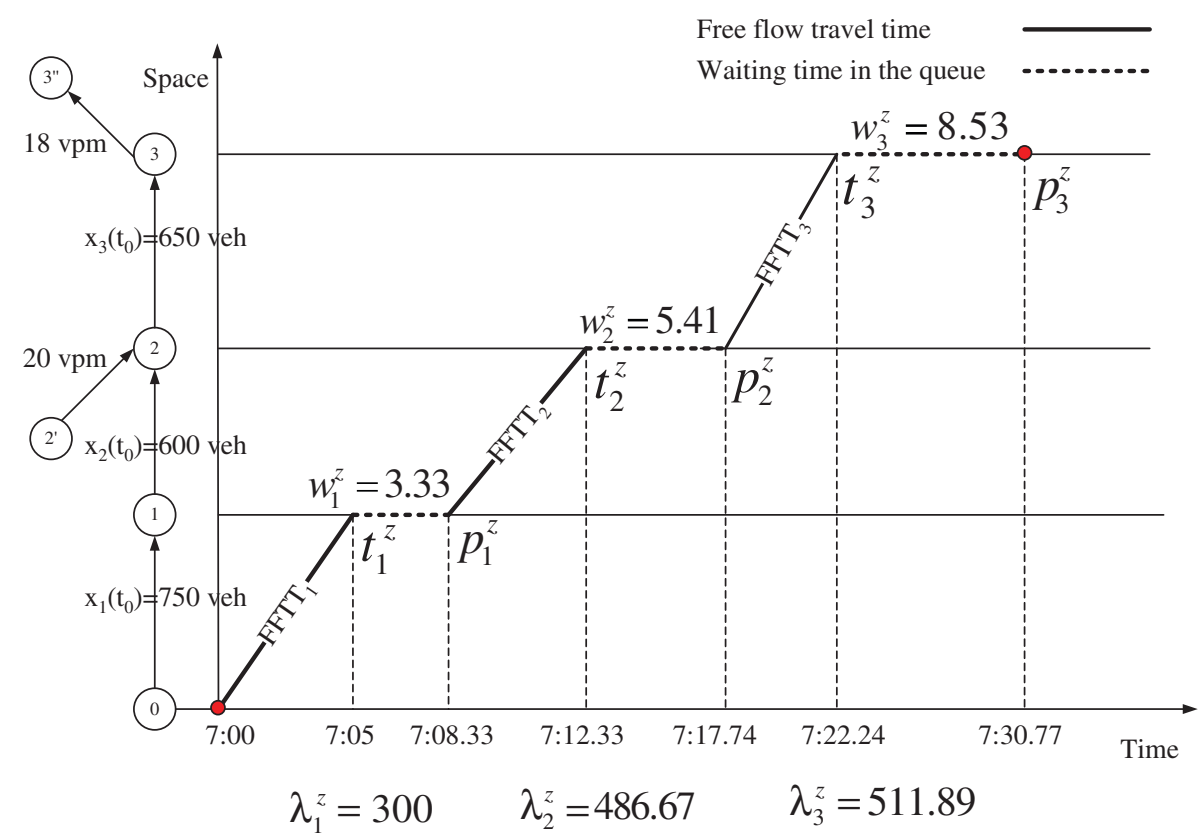

Figure 6.9. Example of a network simulated using the point queue-based model.

captures the richness in the distribution of travel times that actually arises for vehicles as they proceed through the network and the simulation model's ability to mimic that distribution.

\section{Comonotonicity-Based Model}

The third model is the comonotonicity-based procedure, a technique for adding segment variability. This procedure is based on the idea that one can add travel times for identical percentiles across the segments to obtain the route-level PDF. When it is possible to do this, the system exhibits comonotonicity, which implies that individual percentile values from each of a set of random variables can be added together to obtain the percentile values for the distribution of the sum (Dhaene et al. 2002a, 2002b).

The hypothesis is defensible if drivers are consistent in the speeds they want to achieve and the manner in which they drive. In other words, if a specific driver travels through the network on two (or more) separate days, under similar

\section{Lane-Based End-to-End Travel Time Distribution (5:00 p.m. $-5: 15$ p.m.)}

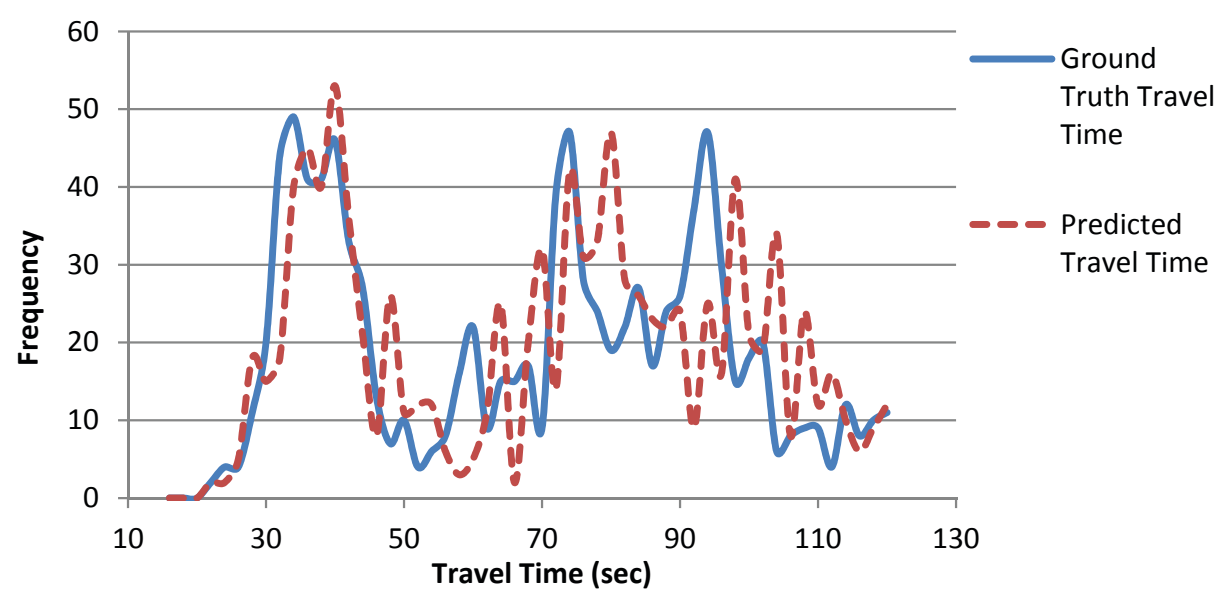

Figure 6.10. Example of actual versus simulated travel times using the point queue-based model. 
network conditions, there will be minimal variation in his or her driving behavior.

This technique was tested using Bluetooth data collected on I-5 in Sacramento. First, the hypothesis of driver consistency was tested. Every individual media access control (MAC) ID that appeared more than once for a given regime condition was tracked, and its corresponding average travel time $\left(\tilde{\tau}_{n}^{i}\right)$, standard deviation of travel times $\left(\tilde{\sigma}_{n}^{i}\right)$, and coefficient of variation $\left(C_{v}^{i}=\tilde{\tau}_{i}^{n} / \tilde{\sigma}_{i}^{n}\right)$ were computed. In these expressions $\tilde{\tau}_{n}^{i}$ is the average of $n$ observed travel times for a specific MAC ID $i, \tilde{\sigma}_{n}^{i}$ is the standard deviation of $n$ observed travel times for the corresponding MAC ID $i$, and $C_{v}^{i}$ is the coefficient of variation for the corresponding MAC ID $i$. Each dot in Figure 6.11 represents a specific MAC ID; its $x$-value represents the average travel rate in seconds per mile, and the corresponding $y$-value represents the coefficient of variation.

\section{Avg vs CV (Normal + Uncongs)}

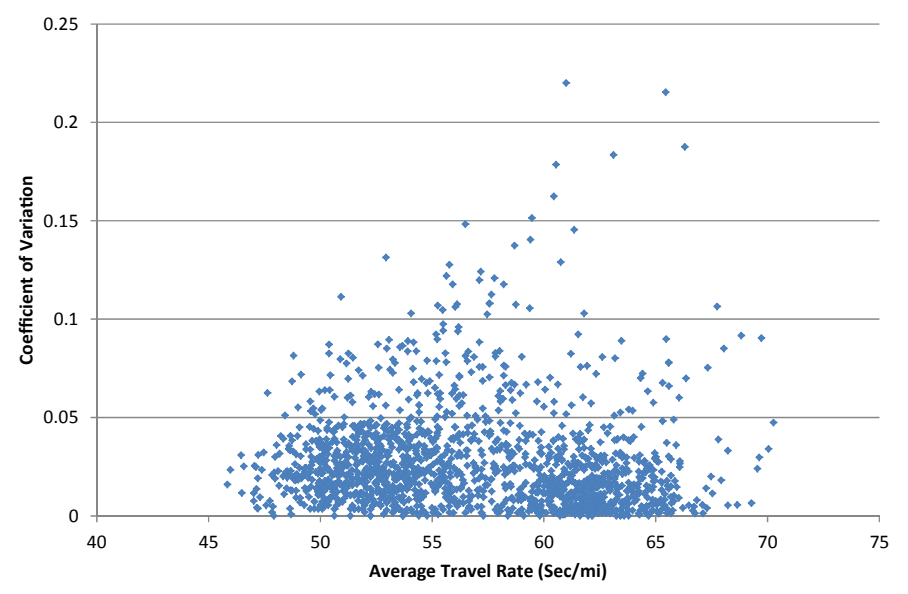

(a)

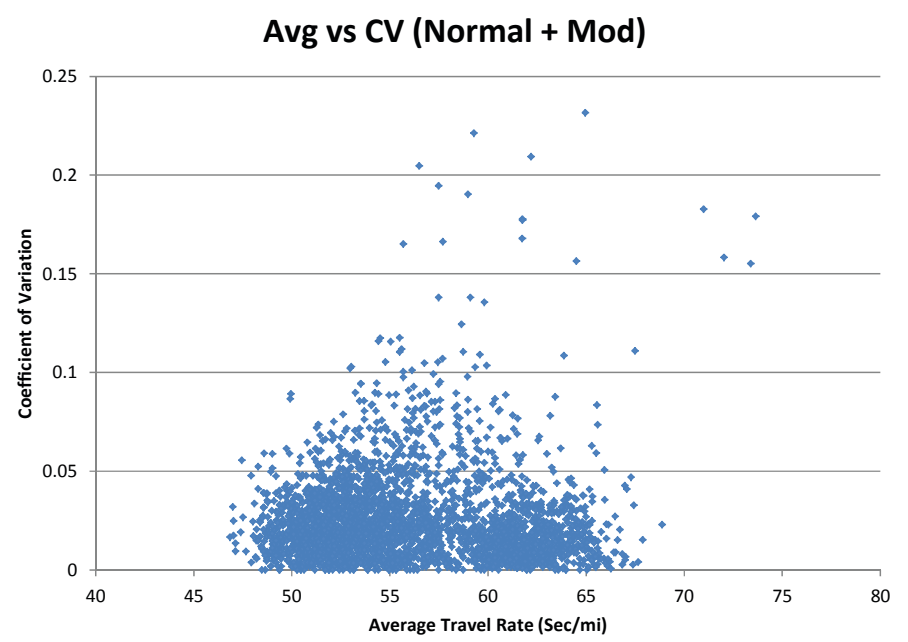

(c)
One can see that the variation in individual driver travel times under the normal, uncongested regime is almost negligible. The same is true for the normal, low-congestion regime. The variation in travel times grows as the network operating conditions become more congested.

The applicability of comonotonicity was tested using the I-5 data. Table 6.4 compares the southbound travel times for four regimes on I-5 predicted by summing the segment travel times against the overall route travel time. For example, beginning from the left-hand side of each section of the table, the second, third, and fourth columns show the percentile travel times for Segments 39-9, 9-10, and 10-11, respectively, based on the travel times for those individual segments. The fifth column shows the travel times obtained if these percentile values are simply summed. That is, the values in the fifth column do not represent the percentiles of any underlying distribution. They are the algebraic sums of the percentile-based travel

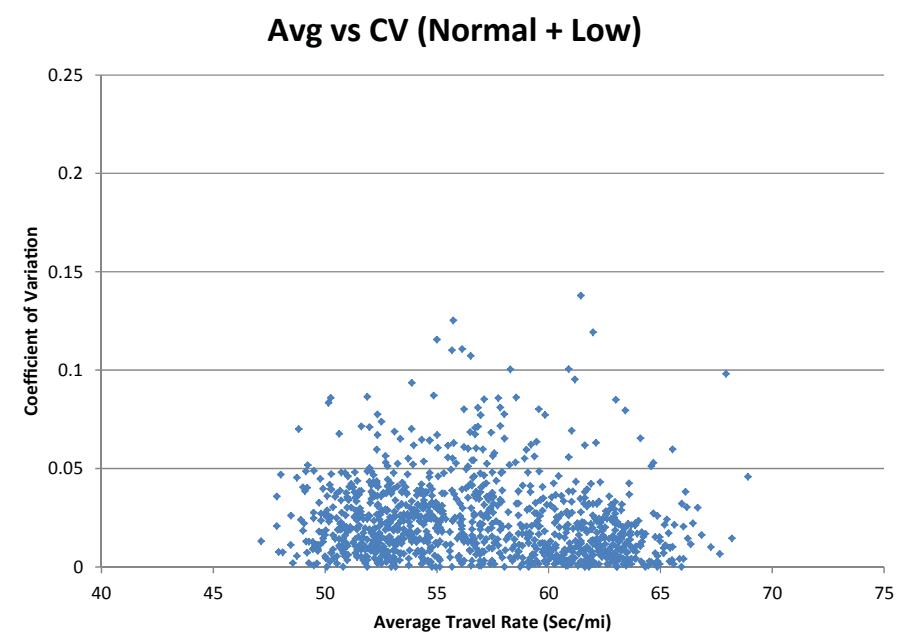

(b)

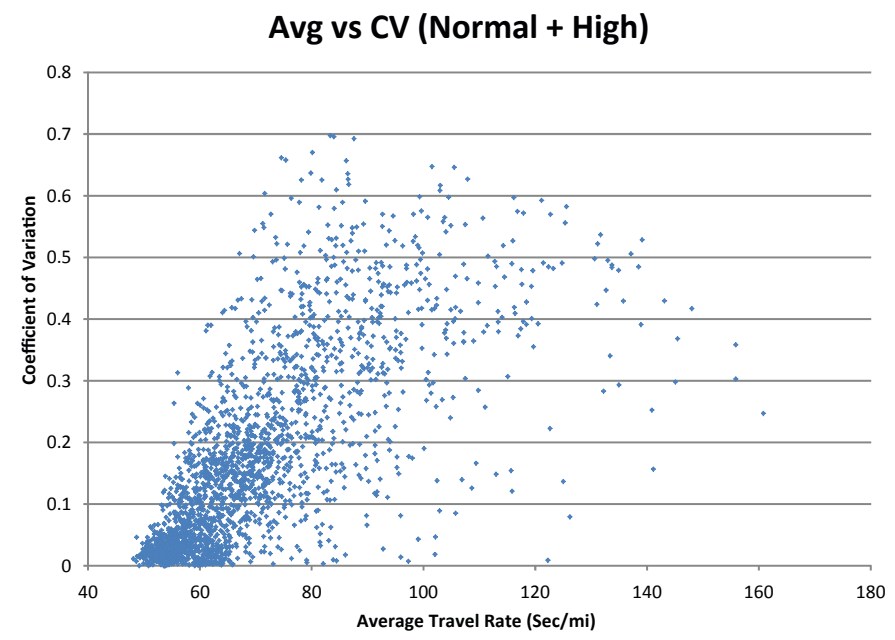

(d)

Figure 6.11. Average travel rate versus coefficient of variation plot for different MAC IDs under normal and (a) uncongested and (b) low-, (c) moderate-, and (d) high-congestion regimes. 
Table 6.4. Comparison of Actual Percentile Travel Times for a Given Route with Values Obtained by Summing Travel Times for the Same Percentile on the Individual Segments

\begin{tabular}{|c|c|c|c|c|c|c|c|c|c|c|c|c|c|}
\hline \multirow[b]{2}{*}{ Percentile } & \multicolumn{6}{|c|}{ Segment Travel Times (Uncongested) } & & \multicolumn{6}{|c|}{ Segment Travel Times (Low Congestion) } \\
\hline & $\begin{array}{l}\text { Seg } \\
39-9\end{array}$ & $\begin{array}{l}\text { Seg } \\
9-10\end{array}$ & $\begin{array}{c}\text { Seg } \\
10-11\end{array}$ & Sum & $\begin{array}{l}\text { Route } \\
39-11\end{array}$ & Diff & Percentile & $\begin{array}{l}\text { Seg } \\
39-9\end{array}$ & $\begin{array}{l}\text { Seg } \\
9-10\end{array}$ & $\begin{array}{c}\text { Seg } \\
10-11\end{array}$ & Sum & $\begin{array}{l}\text { Route } \\
39-11\end{array}$ & Diff \\
\hline $5 \%$ & 0.810 & 0.757 & 0.778 & 4.450 & 4.500 & $1.11 \%$ & $5 \%$ & 0.806 & 0.743 & 0.778 & 4.417 & 4.467 & $1.12 \%$ \\
\hline $10 \%$ & 0.829 & 0.773 & 0.814 & 4.566 & 4.600 & $0.74 \%$ & $10 \%$ & 0.824 & 0.773 & 0.797 & 4.534 & 4.567 & $0.72 \%$ \\
\hline $15 \%$ & 0.843 & 0.788 & 0.833 & 4.650 & 4.667 & $0.36 \%$ & $15 \%$ & 0.838 & 0.788 & 0.814 & 4.617 & 4.650 & $0.71 \%$ \\
\hline $20 \%$ & 0.856 & 0.803 & 0.852 & 4.733 & 4.733 & $0.00 \%$ & $20 \%$ & 0.849 & 0.803 & 0.833 & 4.691 & 4.717 & $0.55 \%$ \\
\hline $25 \%$ & 0.866 & 0.818 & 0.861 & 4.792 & 4.800 & $0.17 \%$ & $25 \%$ & 0.861 & 0.818 & 0.852 & 4.767 & 4.767 & $0.00 \%$ \\
\hline $30 \%$ & 0.875 & 0.834 & 0.870 & 4.850 & 4.867 & $0.35 \%$ & $30 \%$ & 0.870 & 0.818 & 0.861 & 4.808 & 4.833 & $0.52 \%$ \\
\hline $35 \%$ & 0.884 & 0.848 & 0.889 & 4.916 & 4.917 & $0.02 \%$ & $35 \%$ & 0.880 & 0.834 & 0.870 & 4.867 & 4.883 & $0.33 \%$ \\
\hline $40 \%$ & 0.896 & 0.864 & 0.908 & 4.992 & 4.983 & $0.18 \%$ & $40 \%$ & 0.889 & 0.848 & 0.889 & 4.933 & 4.942 & $0.18 \%$ \\
\hline $45 \%$ & 0.903 & 0.871 & 0.926 & 5.041 & 5.050 & $0.18 \%$ & $45 \%$ & 0.898 & 0.864 & 0.908 & 5.000 & 5.000 & $0.00 \%$ \\
\hline $50 \%$ & 0.917 & 0.886 & 0.944 & 5.125 & 5.117 & $0.16 \%$ & $50 \%$ & 0.908 & 0.879 & 0.926 & 5.067 & 5.067 & $0.00 \%$ \\
\hline $55 \%$ & 0.926 & 0.902 & 0.972 & 5.200 & 5.200 & $0.00 \%$ & $55 \%$ & 0.921 & 0.894 & 0.944 & 5.150 & 5.150 & $0.00 \%$ \\
\hline $60 \%$ & 0.940 & 0.916 & 0.991 & 5.283 & 5.300 & $0.32 \%$ & $60 \%$ & 0.933 & 0.909 & 0.972 & 5.233 & 5.233 & $0.00 \%$ \\
\hline $65 \%$ & 0.958 & 0.939 & 1.000 & 5.383 & 5.433 & $0.92 \%$ & $65 \%$ & 0.949 & 0.925 & 0.991 & 5.326 & 5.350 & $0.45 \%$ \\
\hline $70 \%$ & 0.977 & 0.955 & 1.019 & 5.484 & 5.550 & $1.19 \%$ & $70 \%$ & 0.968 & 0.939 & 1.009 & 5.424 & 5.467 & $0.79 \%$ \\
\hline $75 \%$ & 0.995 & 0.977 & 1.037 & 5.591 & 5.625 & $0.60 \%$ & $75 \%$ & 0.986 & 0.962 & 1.019 & 5.525 & 5.567 & $0.75 \%$ \\
\hline $80 \%$ & 1.012 & 1.000 & 1.056 & 5.692 & 5.700 & $0.14 \%$ & $80 \%$ & 1.002 & 0.985 & 1.037 & 5.624 & 5.650 & $0.46 \%$ \\
\hline $85 \%$ & 1.028 & 1.015 & 1.074 & 5.784 & 5.783 & $0.02 \%$ & $85 \%$ & 1.019 & 1.000 & 1.064 & 5.725 & 5.733 & $0.14 \%$ \\
\hline $90 \%$ & 1.046 & 1.038 & 1.092 & 5.892 & 5.875 & $0.29 \%$ & $90 \%$ & 1.037 & 1.030 & 1.092 & 5.849 & 5.817 & $0.55 \%$ \\
\hline \multirow[t]{3}{*}{$95 \%$} & 1.074 & 1.075 & 1.130 & 6.067 & 6.017 & $0.83 \%$ & $95 \%$ & 1.060 & 1.061 & 1.130 & 6.001 & 5.950 & $0.86 \%$ \\
\hline & \multicolumn{6}{|c|}{ Segment Travel Times (Moderate Congestion) } & & \multicolumn{6}{|c|}{ Segment Travel Times (High Congestion) } \\
\hline & $\begin{array}{l}\text { Seg } \\
39-9\end{array}$ & $\begin{array}{l}\text { Seg } \\
9-10\end{array}$ & $\begin{array}{c}\text { Seg } \\
10-11\end{array}$ & Sum & $\begin{array}{l}\text { Route } \\
39-11\end{array}$ & Diff & Percentile & $\begin{array}{l}\text { Seg } \\
39-9\end{array}$ & $\begin{array}{l}\text { Seg } \\
9-10\end{array}$ & $\begin{array}{c}\text { Seg } \\
10-11\end{array}$ & Sum & $\begin{array}{l}\text { Route } \\
39-11\end{array}$ & Diff \\
\hline $5 \%$ & 0.810 & 0.743 & 0.778 & 4.434 & 4.500 & $1.47 \%$ & $5 \%$ & 0.861 & 0.773 & 0.814 & 4.683 & 4.767 & $1.76 \%$ \\
\hline $10 \%$ & 0.829 & 0.773 & 0.797 & 4.550 & 4.583 & $0.72 \%$ & $10 \%$ & 0.884 & 0.803 & 0.833 & 4.816 & 4.867 & $1.05 \%$ \\
\hline $15 \%$ & 0.838 & 0.788 & 0.814 & 4.617 & 4.650 & $0.71 \%$ & $15 \%$ & 0.903 & 0.818 & 0.852 & 4.917 & 4.967 & $1.01 \%$ \\
\hline $20 \%$ & 0.847 & 0.795 & 0.833 & 4.675 & 4.700 & $0.53 \%$ & $20 \%$ & 0.919 & 0.818 & 0.870 & 4.991 & 5.050 & $1.17 \%$ \\
\hline $25 \%$ & 0.858 & 0.803 & 0.842 & 4.729 & 4.767 & $0.81 \%$ & $25 \%$ & 0.938 & 0.834 & 0.889 & 5.092 & 5.150 & $1.13 \%$ \\
\hline $30 \%$ & 0.866 & 0.818 & 0.852 & 4.784 & 4.817 & $0.69 \%$ & $30 \%$ & 0.958 & 0.848 & 0.908 & 5.200 & 5.250 & $0.95 \%$ \\
\hline $35 \%$ & 0.875 & 0.834 & 0.870 & 4.850 & 4.867 & $0.35 \%$ & $35 \%$ & 0.977 & 0.856 & 0.926 & 5.292 & 5.367 & $1.40 \%$ \\
\hline $40 \%$ & 0.884 & 0.841 & 0.889 & 4.908 & 4.917 & $0.18 \%$ & $40 \%$ & 1.000 & 0.864 & 0.926 & 5.383 & 5.483 & $1.82 \%$ \\
\hline $45 \%$ & 0.894 & 0.848 & 0.908 & 4.967 & 4.967 & $0.00 \%$ & $45 \%$ & 1.026 & 0.879 & 0.944 & 5.509 & 5.583 & $1.33 \%$ \\
\hline $50 \%$ & 0.903 & 0.864 & 0.926 & 5.033 & 5.033 & $0.00 \%$ & $50 \%$ & 1.051 & 0.886 & 0.963 & 5.625 & 5.700 & $1.32 \%$ \\
\hline $55 \%$ & 0.917 & 0.879 & 0.944 & 5.117 & 5.117 & $0.00 \%$ & $55 \%$ & 1.086 & 0.894 & 0.981 & 5.774 & 5.783 & $0.16 \%$ \\
\hline $60 \%$ & 0.928 & 0.894 & 0.963 & 5.192 & 5.200 & $0.15 \%$ & $60 \%$ & 1.120 & 0.909 & 1.000 & 5.933 & 5.883 & $0.85 \%$ \\
\hline $65 \%$ & 0.942 & 0.916 & 0.981 & 5.283 & 5.317 & $0.64 \%$ & $65 \%$ & 1.153 & 0.925 & 1.019 & 6.084 & 6.000 & $1.40 \%$ \\
\hline $70 \%$ & 0.961 & 0.939 & 1.000 & 5.391 & 5.450 & $1.08 \%$ & $70 \%$ & 1.185 & 0.939 & 1.037 & 6.233 & 6.117 & $1.90 \%$ \\
\hline $75 \%$ & 0.981 & 0.955 & 1.019 & 5.500 & 5.550 & $0.90 \%$ & $75 \%$ & 1.218 & 0.955 & 1.074 & 6.400 & 6.233 & $2.68 \%$ \\
\hline $80 \%$ & 0.999 & 0.970 & 1.037 & 5.595 & 5.633 & $0.67 \%$ & $80 \%$ & 1.259 & 0.970 & 1.092 & 6.583 & 6.378 & $3.21 \%$ \\
\hline $85 \%$ & 1.014 & 1.000 & 1.074 & 5.717 & 5.700 & $0.30 \%$ & $85 \%$ & 1.301 & 0.993 & 1.130 & 6.792 & 6.550 & $3.69 \%$ \\
\hline $90 \%$ & 1.033 & 1.015 & 1.092 & 5.817 & 5.800 & $0.29 \%$ & $90 \%$ & 1.352 & 1.023 & 1.176 & 7.049 & 6.750 & $4.43 \%$ \\
\hline $95 \%$ & 1.060 & 1.061 & 1.139 & 6.009 & 5.950 & $0.99 \%$ & $95 \%$ & 1.431 & 1.075 & 1.259 & 7.466 & 7.100 & $5.15 \%$ \\
\hline
\end{tabular}

Note: Seg = segment; Diff = percentage difference. 
times shown to their left. The sixth column shows the percentile travel times obtained when the travel times for the overall route are used as the basis for developing the percentile-related travel times. The far-right column shows that the percentage differences between the naïve sums and the empirically derived results are nearly identical for uncongested and low and moderate congestion conditions. When congestion on the facility is high, the differences in almost every percentile are more than $1 \%$, and the difference for all percentiles greater than $70 \%$ varies between $2 \%$ and $6 \%$.

Not only does comonotonicity seem to hold, but it does so in spite of the fact that the density functions are multimodal. Figure 6.12 shows density functions synthesized from individual segment percentiles and observed values for four operating regimes. In all four instances, the density functions are bimodal. Except for highly congested conditions, the match is strong between the density function obtained by adding the percentiles and that which was actually observed.

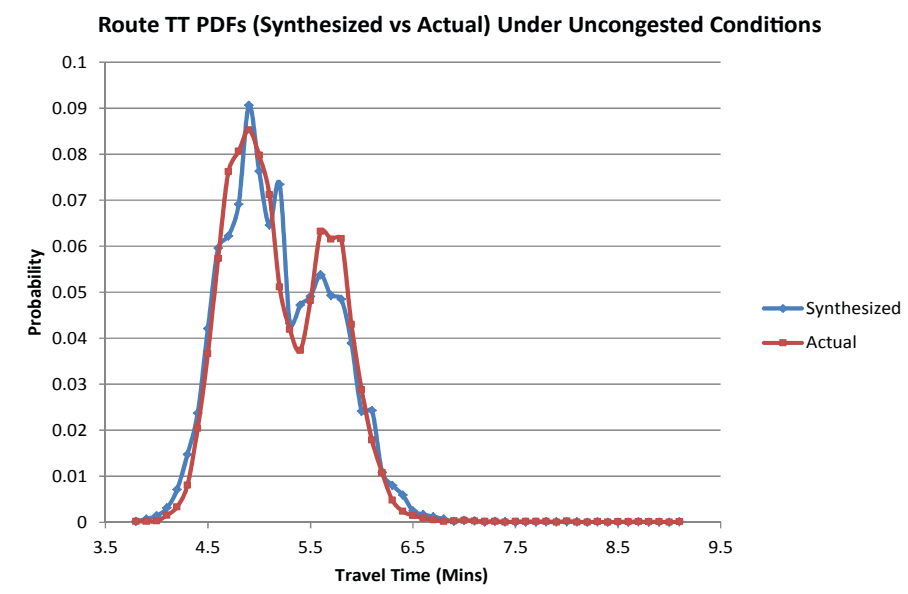

(a)

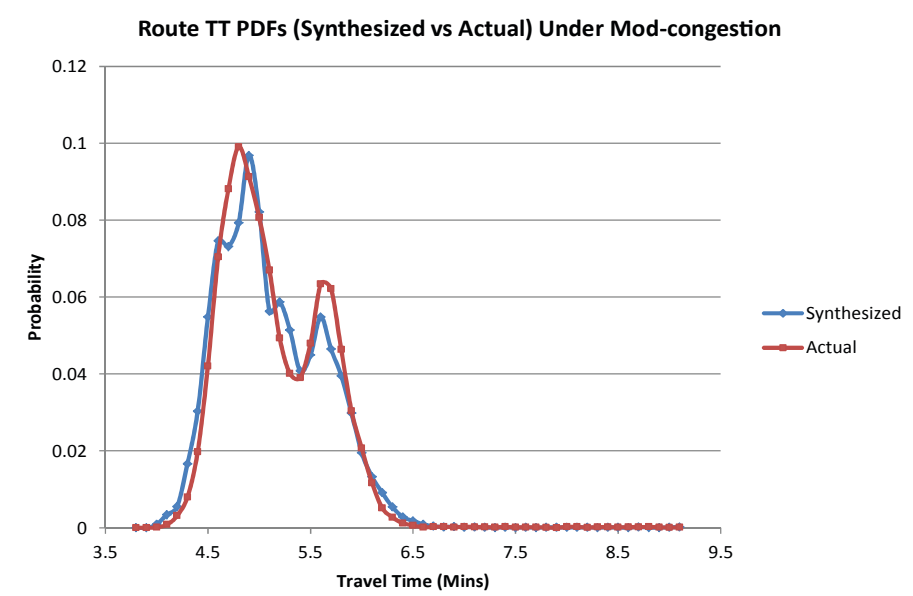

(c)

\section{PDFs for Route-Level Average Travel Times or Rates}

A common procedure for computing average travel times from infrastructure-based sensor speeds involves the following steps:

1. Calculate the average travel time for the first route segment using the average travel time at a specific point in time.

2. Obtain the average speed for the next segment at the time the vehicle is expected to arrive at that segment as estimated by the calculated average travel time for the first route section.

3. Repeat Step 2 until the average travel time for the entire route has been computed.

Put a slightly different way, this procedure involves "walking" the time-space matrix for the detectors. That is, the travel time

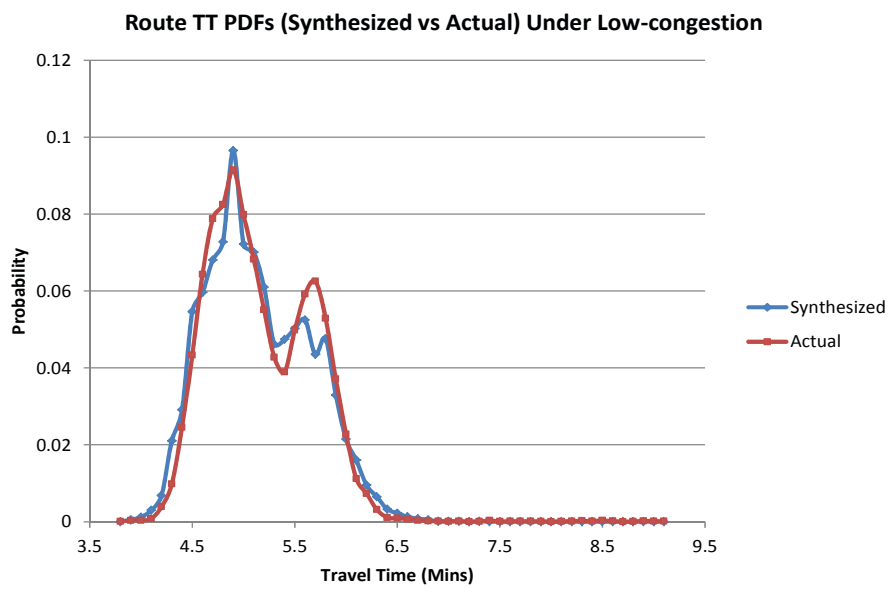

(b)

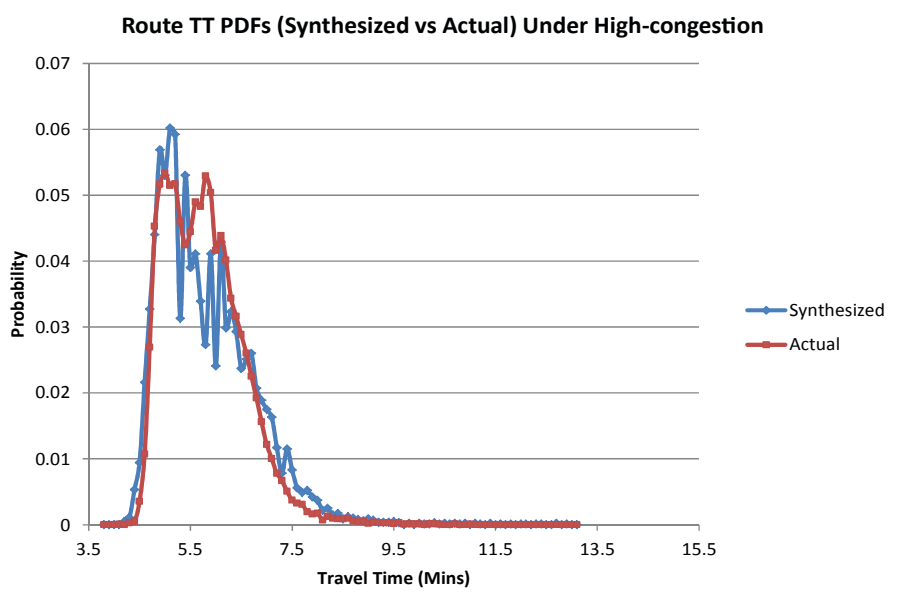

(d)

Figure 6.12. Comparisons between route TT-PDFs synthesized from individual segment percentiles (squares) and observed values (dots) for (a) uncongested and (b) low-, (c) moderate-, and (d) high-congestion conditions. Color figure available online at www.trb.org/Main/Blurbs/168765.aspx. 
employed for the $n$th subsegment is the value in the time-space matrix that pertains at the time that subsegment is reached given that the initial start time at the initial subsegment is at the beginning (or middle) of the initial 5-minute time period.

A slightly more sophisticated approach developed by $\mathrm{Hu}$ (2011) combines the travel rates for the applicable time periods (based on the time-space matrix) in a way that ensures the best possible contribution to the travel rate between adjacent sensors is obtained. The intent is to capture the effects of variations in congestion levels (e.g., due to merges, diverges, and lane drops) between the segments.

The approach computes the arithmetic average of the two spot rates and adjusts that result by a factor $\gamma$, as shown in Equation 6.1:

$$
\tau_{s}=\gamma\left[\frac{\tau_{1}+\tau_{2}}{2}\right]
$$

where $\tau_{s}$ is the travel rate for the segment, and $\tau_{1}$ and $\tau_{2}$ are the travel rates for the upstream and downstream detectors, respectively. The value of $\gamma$ is dependent on the traffic flow conditions on the segment; that is, it is dependent on the regime that is extant at the time for which $\tau_{s}$ is desired (e.g., the level of congestion present). The appropriate value of $\gamma$ can be obtained from a lookup table once the values have been calibrated for the regimes.

An alternative equation uses parameters $\alpha$ and $\beta$ to combine the spot rates, as shown in Equation 6.2:

$$
\tau_{s}=\alpha \tau_{1}+\beta \tau_{2}
$$

Again, the values of $\alpha$ and $\beta$ are dependent on the traffic flow conditions on the segment; that is, the values are dependent on the regime that is extant at the time for which $\tau_{s}$ is desired. These values can be obtained from a lookup table once the values have been calibrated for the regimes.

\section{Influencing Factor Analysis}

A major purpose of a TTRMS is to empower agencies to improve the reliability of their systems. The objective is to guide agencies toward actions that can be taken to improve reliability. For example, if an agency's facilities are experiencing unreliable travel times largely due to incidents, the agency might choose to increase spending on incident management systems or on roadway safety improvements (Tsubota et al. 2011). Influencing factor analysis can also help agency administrators set benchmark goals against which they can test future improvements.

The process for conducting these analyses includes the following steps:

1. Select the region or facilities of interest.

2. Select a time frame of interest.
3. Assemble travel rate data for each facility.

4. Generate TR-PDFs for each facility.

5. Understand variations in reliability due to congestion.

6. Develop TR-CDFs for each combination of recurring congestion level and nonrecurring event(s).

The aim in Step 4 is to create separate TR-PDFs for each combination of (1) type of nonrecurring event, including normal (i.e., no nonrecurring event) and (2) recurring congestion level (i.e., low, moderate, high). The technique for doing this involves two substeps:

- Identify types of nonrecurring events in the data.

- Identify the reliability impacts of congestion.

The first substep in the fourth step is to identify types of nonrecurring events in the data. The data for each route are plotted against time of day and vehicle miles traveled (VMT) per hour to identify outliers. Starting with the most extreme (largest) outliers, web-based databases should be queried to see if an explanatory nonrecurring event can be identified for the date and time when the unusual travel rate occurred. For an operational TTRMS, this process should be automated and conducted in real time because event information tends to be perishable data. Categories of nonrecurring events may include incident, weather, special event, and demand. Data points not falling into any one of these categories should be classified as being normal.

When identifying categories of nonrecurring events, demand should always be the last category considered, after explanations related to weather, special events, or incidents are identified. The latter three categories always trump the demand designation. Values in the demand category are extracted from those remaining in the normal category after those explained by weather, special events, or incidents have been removed. This removal process should be iterative; there is nothing permanent about the demand designation, unlike the other three categories.

When identifying data points in the demand category, the VMT per hour value for a given 5-minute observation should be compared against the average for that 5-minute time period. If the value is more than two standard deviations above the mean, the data point should be given a demand designation. A second analysis should be conducted because this technique does not work during highly congested time periods when VMT per hour is constrained by capacity (because the VMT per hour cannot be higher).

The second analysis seeks sequences of 5-minute time periods when the VMT per hour is high and the travel rate is high. This analysis identifies conditions when the demandto-capacity ratio is higher than the volume-to-capacity ratio, implying there are queues in the system. 
The second substep in the fourth step involves labeling each observation based on the nominal loading of the system expected for each observation. This is done by analyzing the observations that remain once the nonrecurring events have been removed.

The purpose of the congestion-level designations is to differentiate the observations based on the reliability performance to be expected based on system loading, such as congestion. Many metrics could be used to assess this impact (such as the buffer time index, the planning time index, or the travel time index), but the research team used the semivariance (SV) measure because SV is sensitive to how the data are distributed above the minimum value. SV $\sigma_{r}^{2}$ is a one-sided variance metric that uses a reference value $r$ instead of the mean as the basis for the calculation, and only observations $x_{i}$ that are greater or less than that reference value are used:

$\sigma_{r}^{2}=\frac{1}{n} \sum_{i=1}^{n}\left(x_{i}-r\right)^{2} \quad$ and $\quad \sigma_{r}=\sqrt{\sigma_{r}^{2}} \quad \exists x_{i} \geq r$

Based on this analysis, the normal data can be broken down into recurring congestion-related categories.

The fifth step involves looking at the SV trends so that the variations in reliability due to congestion can be understood. Low SV values indicate high reliability on a route. The comparison of SV values throughout the day can be used to identify peak time periods and how reliability changes throughout the day.

The sixth step involves developing TR-CDFs for each combination of recurring congestion that would normally occur (from the analysis above) and nonrecurring event (from the first categorical analysis). These combinations are the regimes in which the facility operates according to the definition of that terminology presented above. The TR-CDFs are created by appropriately binning the 5-minute travel time observations.

An example application of this procedure is contained in the Guide's Appendix D: Use Case Analyses. Figure 6.13 shows the system that was studied, which comprises three freeway routes from Segment A to Segment B in San Diego: I-5, I-805/ SR-15/I-5, and I-805/SR-163/I-5.

In subsequent text, these three routes are identified more succinctly as I-5, SR-15, and SR-163. The time frame of interest was 2011, all weekdays, and all 24 hours during those days. The data were average travel rates from Segment A to Segment B for each route based on system detector data obtained by walking the time-space matrix for hypothetical trips that started every 5 minutes during the day on all three routes.

The travel rates for each route are displayed in Figure 6.14 plotted against time of day and in Figure 6.15 plotted against VMT per hour (system loading). Since the data for the entire year are shown, there are 72,000 values for each route, and the total number of data points in the combined graphs is 216,000 . Travel rates are needed because normalizing by distance makes it possible to compare the performance of one route with the others without having differences in length confound the analysis.

Step 4 involves labeling each observation-all 216,000 in this case-in terms of its operative regime. Because regime labels were added ex post facto, the process involved three substeps. The first substep was to add a nonrecurring event

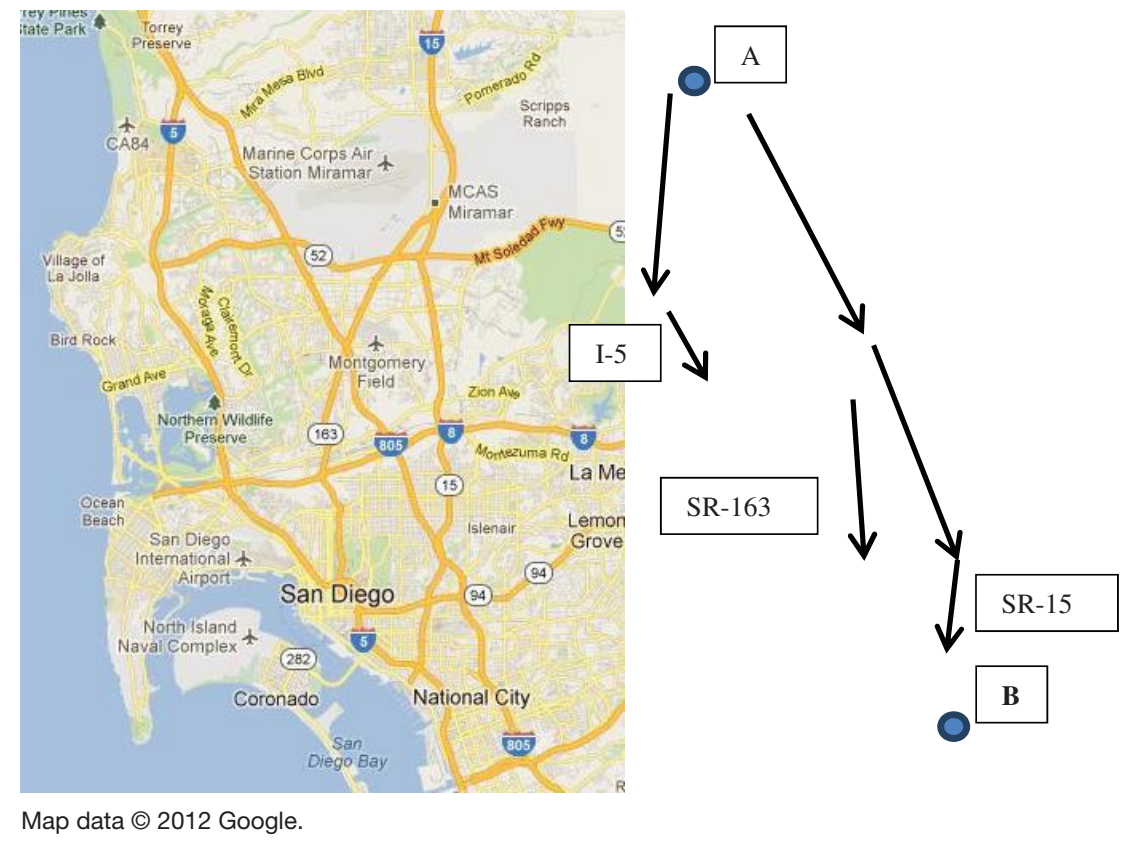

Figure 6.13. Three routes examined in Use Case AE1. Color figure available online at www.trb.org/Main/Blurbs/168765.aspx. 

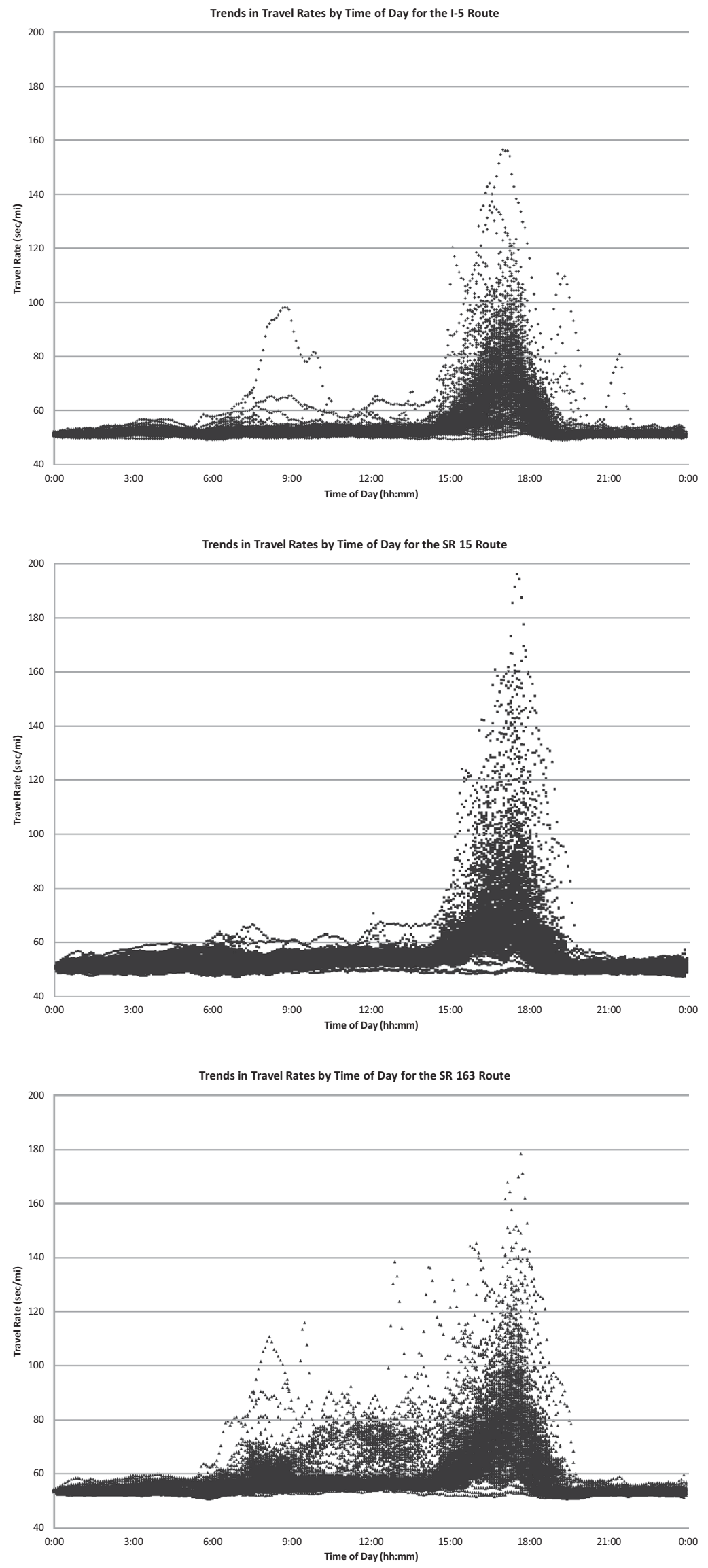

Figure 6.14. Five-minute average weekday travel rates for three routes in San Diego. 
Trends in Travel Rates versus VMT/Hour for the I-5 Route

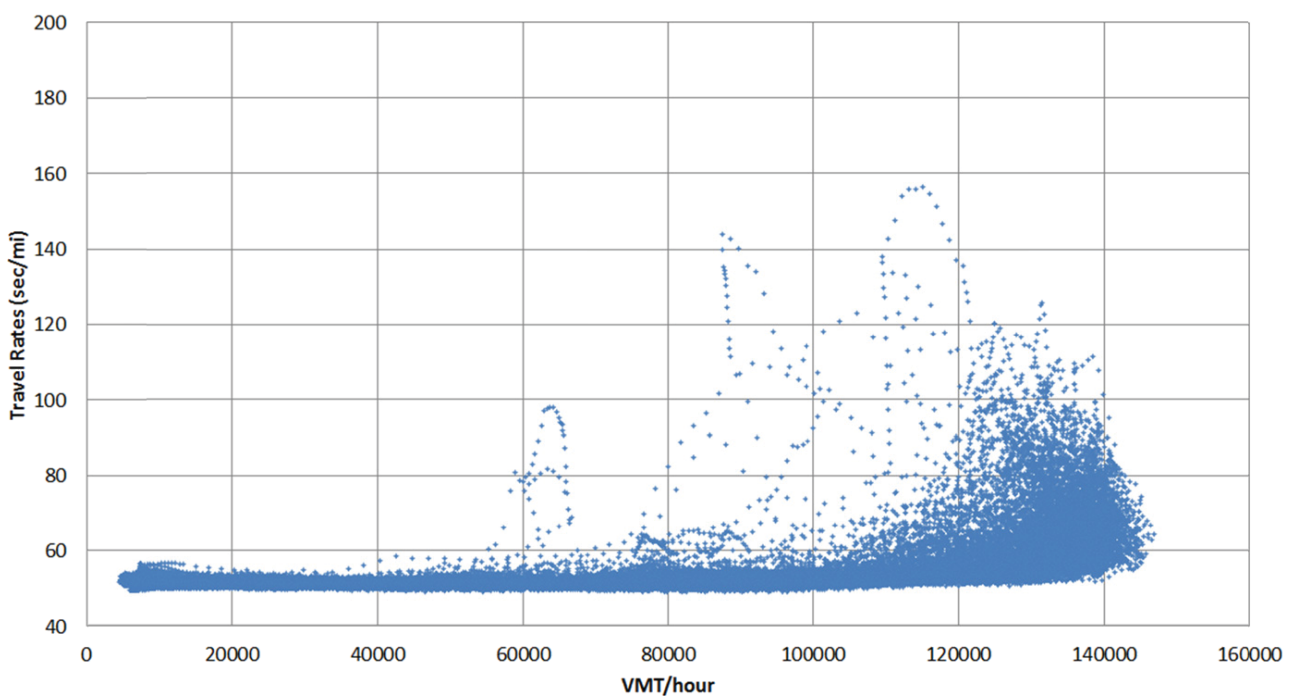

Trends in Travel Rates versus VMT/Hour for the CA-15 Route

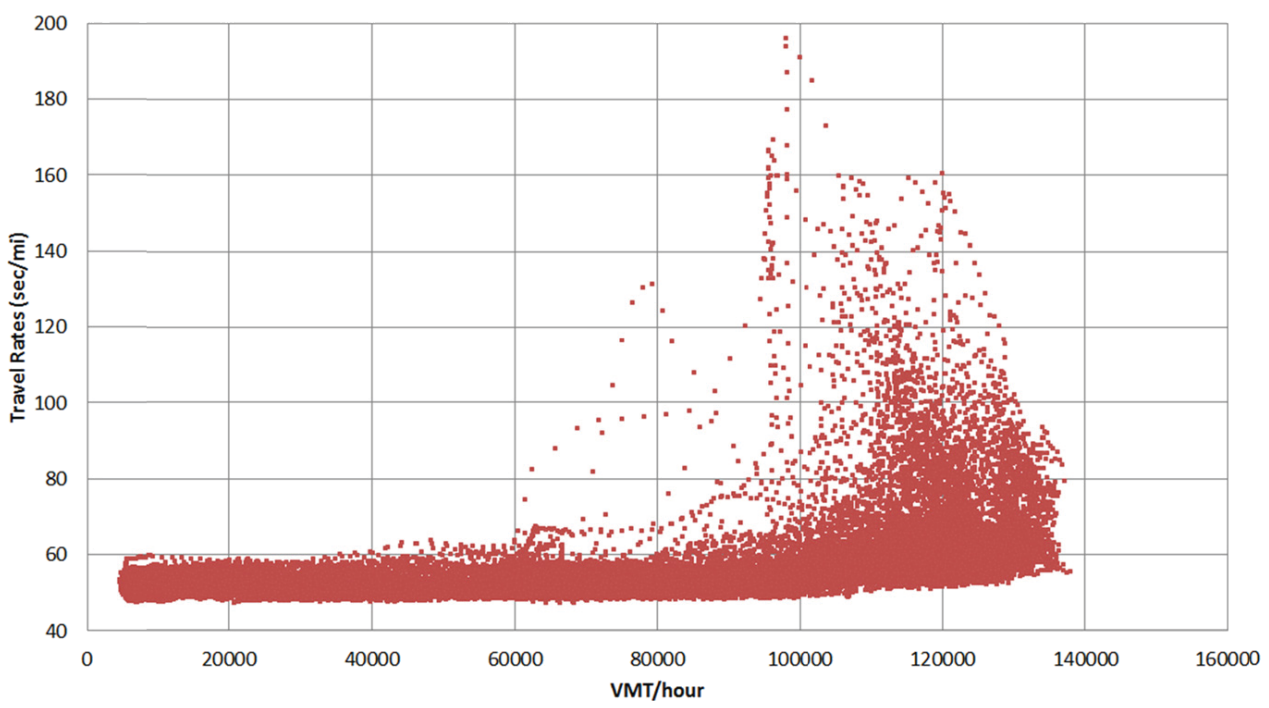

Trends in Travel Rates versus VMT/Hour for the CA-163 Route

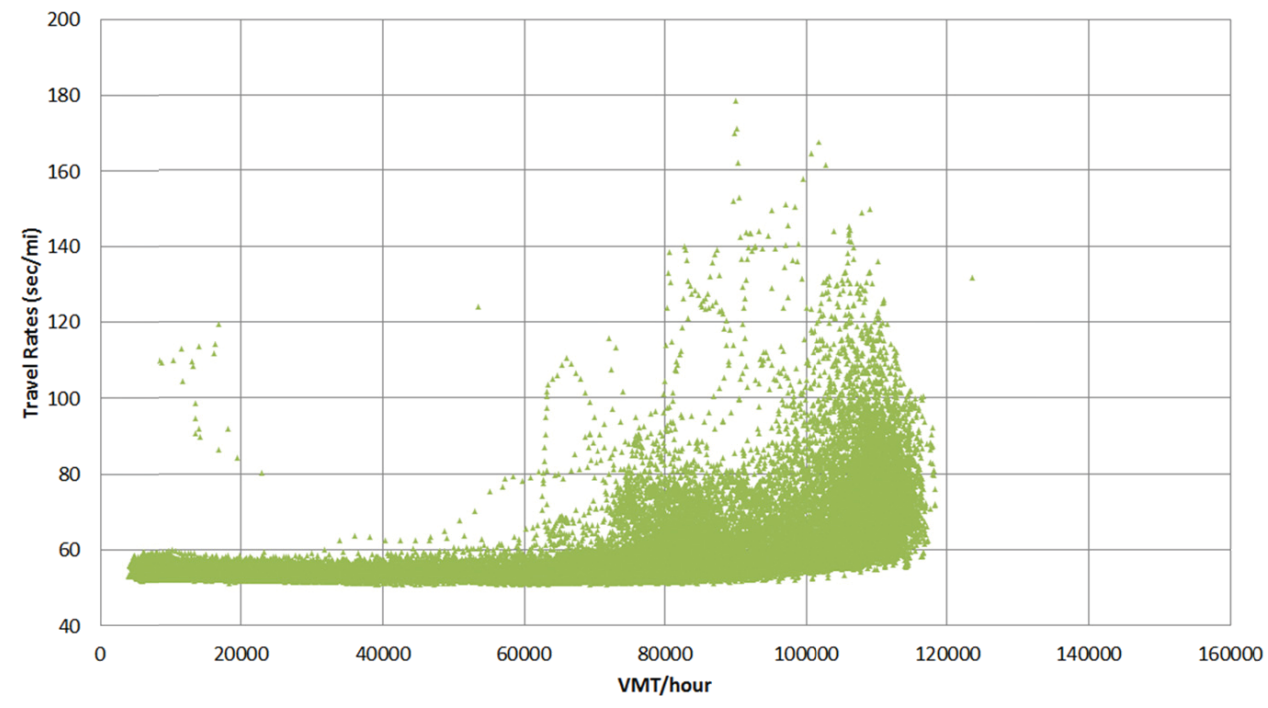

Figure 6.15. Five-minute average weekday travel rates plotted against VMT per hour for three routes in San Diego. 
designation. Hourly VMT data (effectively VMT per hour) were obtained from the Performance Measurement System (PeMS). The actual hourly values were assigned to the sixth 5-minute observation in each hour (25 minutes), and the other 5 -minute values were generated by interpolating between these values. Starting with the most extreme (largest) outliers, web-based databases were queried to see if explanatory nonrecurring events could be identified for the dates and times when the unusual travel rates occurred. For this particular system, the types of nonrecurring events were incidents, weather, special events, and demand. An incident was an accident or some other disruptive traffic event that was recorded in the PeMS database or some other source; weather was an inclement weather event; special event was an unusual event, often sports related; and demand was a condition in which VMT (implicitly, the traffic flows) was higher than normal for the time of day at which the high travel rate arose. Data points not falling into any of these categories remained in the normal category. A weakness of this approach is that nonrecurring events that do not create outliers might be missed.

The demand designation was always the last one added. Explanations were sought related to weather, special events, or incidents before using demand as the explanation, and the former three categories always superseded demand. Values in the demand category were extracted from those remaining in the normal category after those explained by weather, special events, incidents, or other nonrecurring events (e.g., work zones) were removed. This removal process was iterative; there was nothing permanent about the demand designation, unlike the other three.

The identification of the demand category data points had two facets. The first involved comparing the VMT per hour value for a given 5-minute observation with the average for that 5-minute time period. If the value was more than two standard deviations above the mean, it was given a demand designation. Because this technique did not work during highly congested time periods when VMT per hour was constrained by capacity (because VMT per hour could not be higher), a second analysis was conducted.

Sequences of 5-minute time periods should be sought when the VMT per hour is high and the travel rate is high. Effectively, these are conditions when the demand-to-capacity ratio is higher than the volume-to-capacity ratio, implying there are standing queues in the system. In this particular instance, the values used were $75,000 \mathrm{VMT} / \mathrm{h}, 80 \mathrm{~s} / \mathrm{mi}$, and $30 \mathrm{~min}$ utes. That means that 5 -minute time periods were labeled as being in the demand category if their VMT per hour exceeded $70,000 \mathrm{VMT} / \mathrm{h}$, their travel rate was greater than $80 \mathrm{~s} / \mathrm{mi}$, and at least the next five 5-minute time periods (30 minutes total) were in the same condition.
Changing these criteria affects the selection process by changing the separation between observations that are considered normal, high congestion and those that are attributed to high demand on top of high congestion. The values were chosen because 70,000 VMT/h, especially for the SR-163 route, was the point at which there was a step change in the variability of the travel rates; $80 \mathrm{~s} / \mathrm{mi}$ is the same as $45 \mathrm{mph}$, which is often the prevailing speed when freeways are operating at capacity; and 30 minutes was deemed to be a reasonable system recovery time. It is effectively how long one assumes it takes the system to recover from a normal, high-demand regime and return to a status in which the travel rate is less than $80 \mathrm{~s} / \mathrm{mi}$. Higher values imply that it is acceptable for the system to take longer; shorter values assume it should take less time. Setting it at zero, for example, would imply that the system should be able to recover from travel rates above $80 \mathrm{~s} / \mathrm{mi}$ in 5 minutes.

The second substep involved labeling each observation based on the nominal loading of the system expected for each observation. This is done by analyzing the observations that remain once the nonrecurring events have been removed. In this instance, $S V$ values were computed for every 5 -minute interval for each of the three routes. Figure 6.16 presents the results. The value of $r$ employed for each route was the minimum travel rate observed for the entire year. Because the number of observations varied from one 5-minute period to another, the SVs were divided by the number of observations by $n$ as shown in the equation above (effectively creating an average per observation so that the results would be comparable among the 5-minute time periods).

Notice that reliability becomes worse as the traffic levels increase. This should be expected: reliability should be best when the traffic volumes are low, such as late at night or early in the morning. It should be poorer when traffic volumes are higher (when the vehicles interact more) such as during the midday, and it should be poorest when traffic volumes are the highest (as in the p.m. peak), when the varying lengths of the standing queues has an impact. The maximum SV values (not shown) reached about 1,000.

Although no right answer exists for the number of categories to use, four were selected here: uncongested, low, moderate, and high. Uncongested meant the SV was below 20; low meant 20 to 40; moderate, 40 to 120 ; and high, above 120 . Thus, the I-5 route was classified as uncongested all day except from 2:15 to 6:50 p.m., when it was classified as high. The SR-15 route was classified as uncongested from midnight to 2:10 a.m., low from 2:15 to 6:45 a.m., uncongested from 6:50 to 8:15 a.m., low from 8:20 to 9:05 a.m., moderate from 9:10 a.m. to 2:10 p.m., high from 2:15 to 7:20 p.m., and uncongested from 7:25 p.m. to midnight. The SR-163 route was classified as uncongested from midnight to 6:45 a.m., moderate from 6:50 a.m. to 2:15 p.m., 


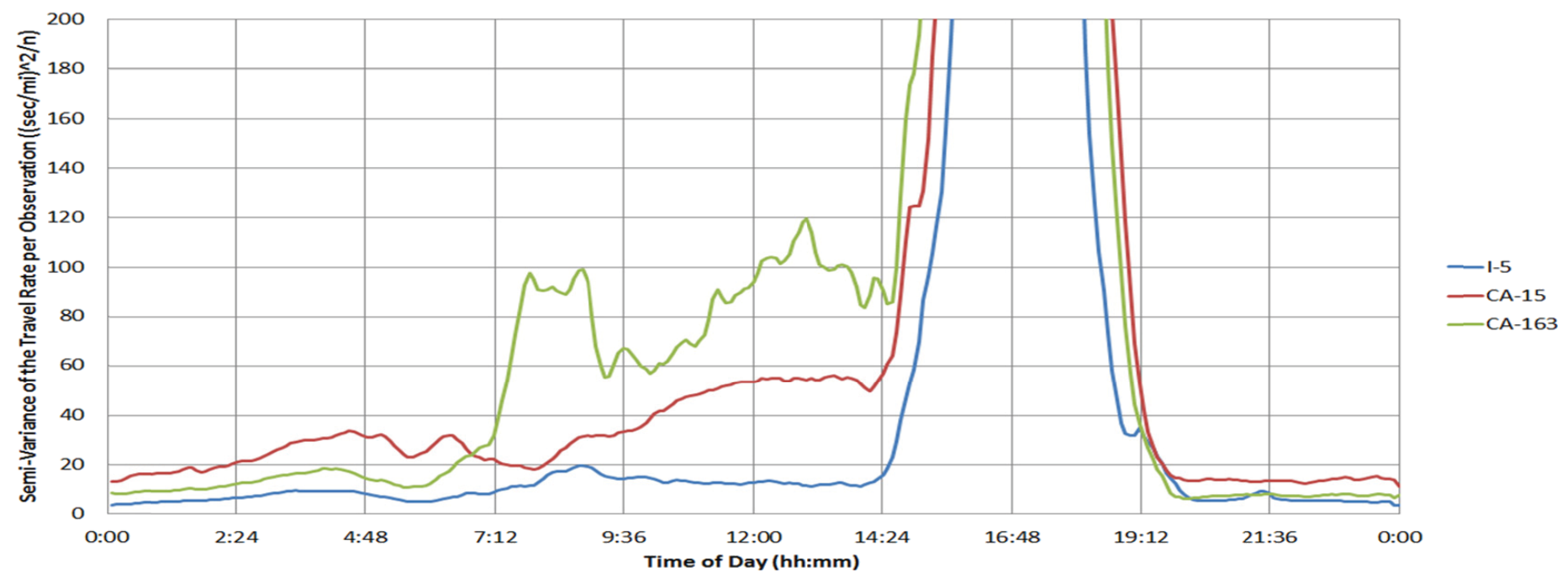

Figure 6.16. Semivariances for every 5-minute period/weekday average travel rates for the normal condition for three routes in San Diego.

Color figure available online at www.trb.org/Main/B/urbs/168765.aspx.

high from 2:20 to 7:20 p.m., and uncongested from 7:25 p.m. to midnight.

Step 5 involves developing TR-CDFs for each regime; that is, each combination of nominal loading (from the analysis above) and nonrecurring event (from the first categorical analysis), including none. The TR-CDFs are created by appropriately binning the 5 -minute travel time observations. Figure 6.17 presents the results.

Step 6 involves interpreting the results in terms of the effects on reliability of the various factors. But because that overlaps with the next use case, the results are presented there.

The objective in this use case is to determine how various factors affect system reliability. Such information helps inform decisions about how to improve performance: geometric treatments, capacity enhancements, operational changes, better signage, improved roadway striping, resurfacing, or better lighting. It can also help managers determine which facilities need better real-time traveler information (such as changeable message signs displaying alternate routes and travel times).

Figure 6.16 shows that the three routes have somewhat different daily patterns of reliability. The I-5 route has high reliability (a low SV value) throughout the day except during the p.m. peak. In contrast, the SR-15 route has an increase in its SV (a drop in reliability) across the midday (a higher SV). The SR-163 route has an even more dramatic increase in its SV across the midday but a lower SV during the early morning hours. In addition, the SR-163 route has a discernible a.m. peak, but the other two routes do not.

From an interpretation standpoint, this means the I-5 route is probably the most reliable. It is still challenged during the peak, but consistently has the lowest SV values except for a few 5-minute periods around 7 to 9 p.m. Interestingly, this means that even though Figure 6.14 suggests the SR-15 route may have the lowest average travel rates most of the day, I-5 is the most reliable route.

Figure 6.16 also suggests that SR-163 is the least reliable route. It has the highest SV during the day (except in the early morning, when the SR-15 route has higher values), and its $\mathrm{SV}$ is significantly higher, especially during the morning and midday time periods.

Figure 6.17 provides additional insights. Although the plots are rather dense, they tell a story about the performance of these three routes. The TR-CDF for I- 5 for the uncongested, normal condition is at the far left, and it is almost vertical. This means it has very reliable travel rates during this condition. During uncongested conditions, even the nonrecurring events affect only the top $30 \%$ of the 5-minute periods, and in the worst case (related to incidents) they double the travel rate at the 100th percentile from about $50 \mathrm{~s} / \mathrm{mi}$ up to $100 \mathrm{~s} / \mathrm{mi}$ (the CDF fourth from the left and the most jagged of the group).

The performance of I-5 during congested conditions is quite different. In Figure 6.17, even when there are no identifiable nonrecurring events, larger travel rates are involved, as shown by the smooth red-colored CDF having travel rates from about 50 to $100 \mathrm{~s} / \mathrm{mi}$. Moreover, when nonrecurring events occur during high congestion, the impacts are severe: the travel rates are substantially higher than for normal, highcongestion conditions. The TR-CDFs for three of these conditions (incidents, special events, and weather) largely overlap, and no one CDF dominates the other. However, the TR-CDF for the demand, high-congestion condition is strikingly different. It has much larger travel rates even at low percentiles, a kink at about $82 \mathrm{~s} / \mathrm{mi}$ (when the demand events during the high-congestion condition begin to affect the CDF), and a 


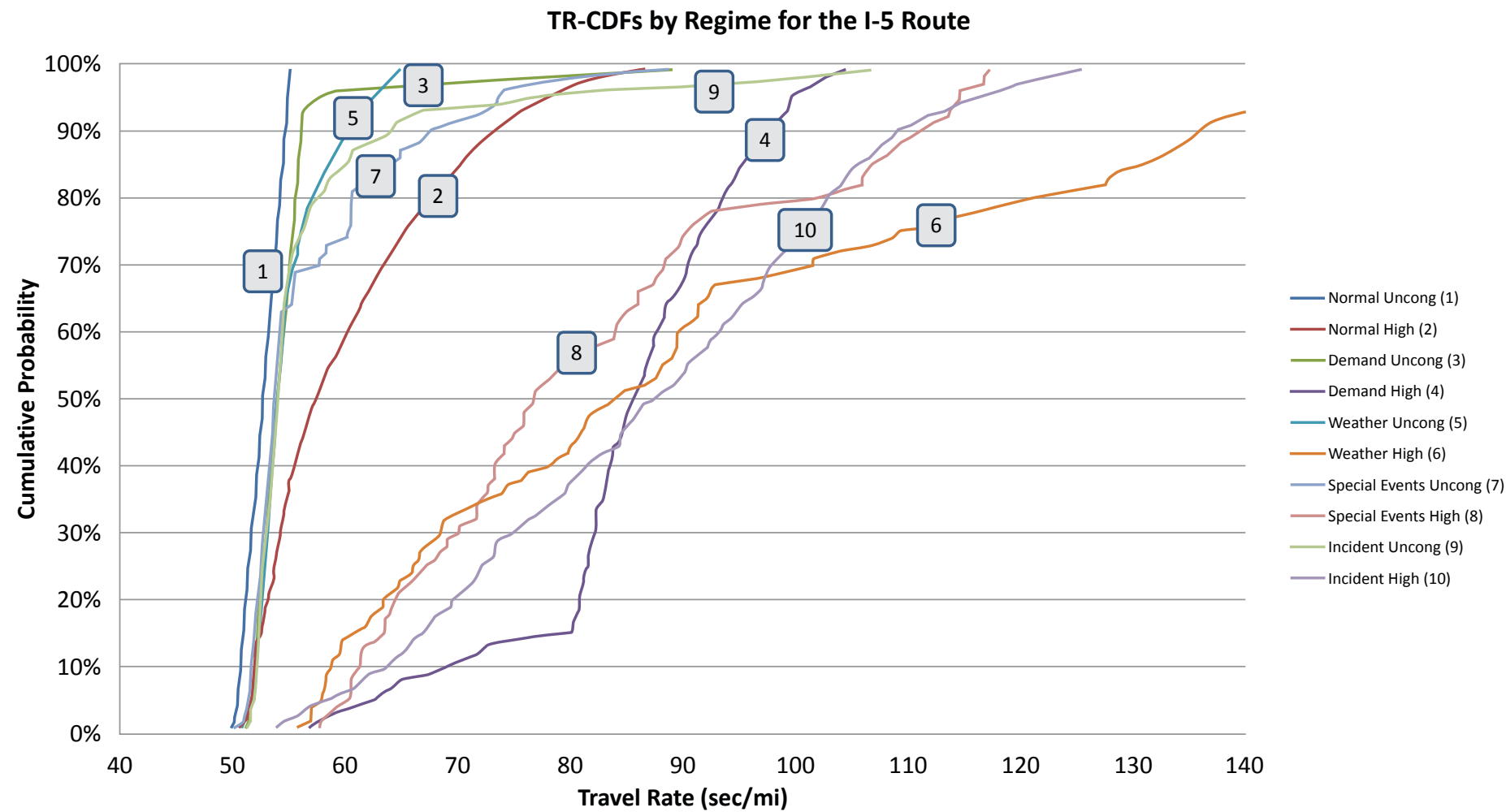

TR-CDFs by Regime for the CA-15 Route

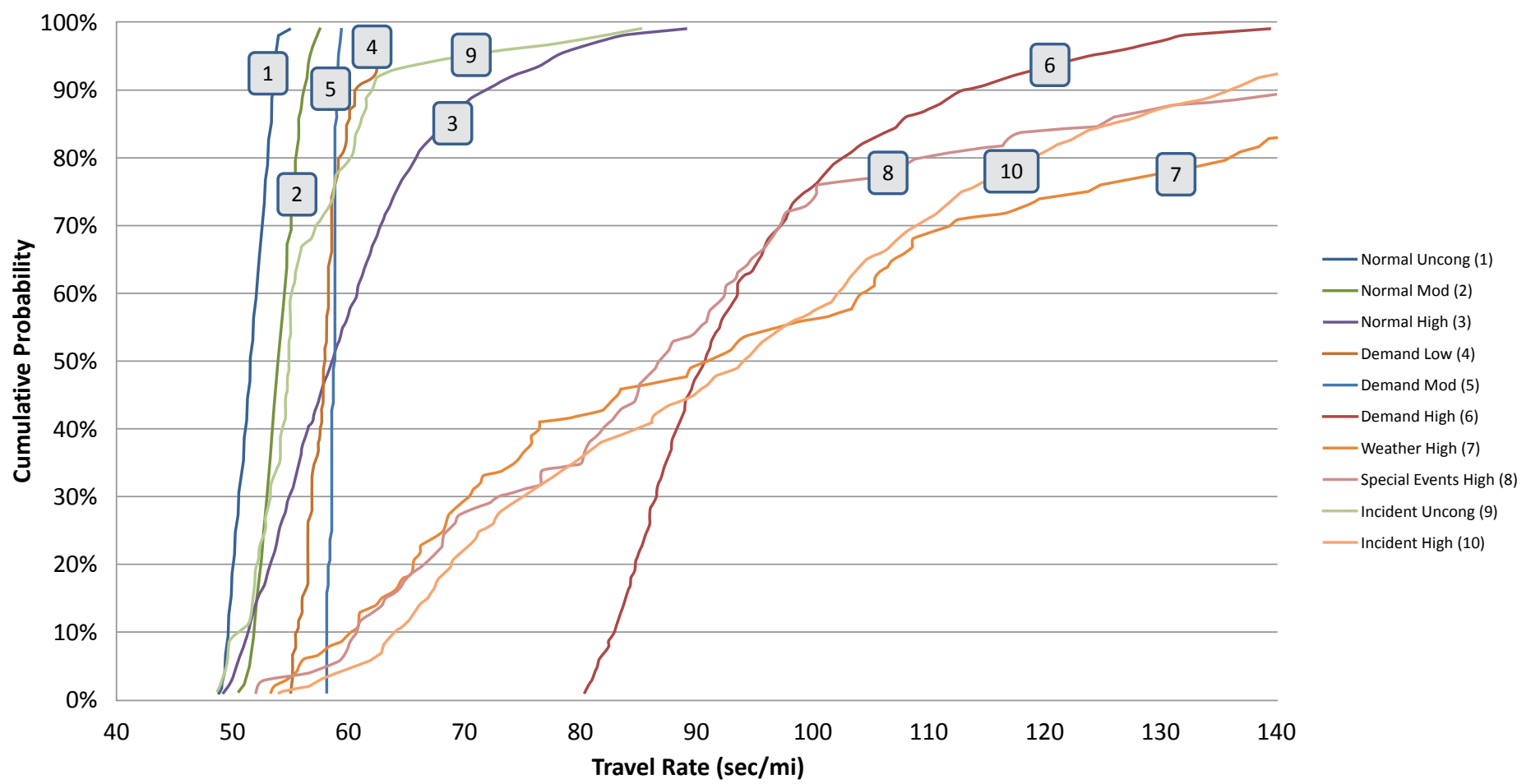

Figure 6.17. CDFs by regime for the three routes in San Diego. (Continued on next page.)

Color figure available online at www.trb.org/Main/Blurbs/168765.aspx. 
TR-CDFs by Regime for the CA-163 Route

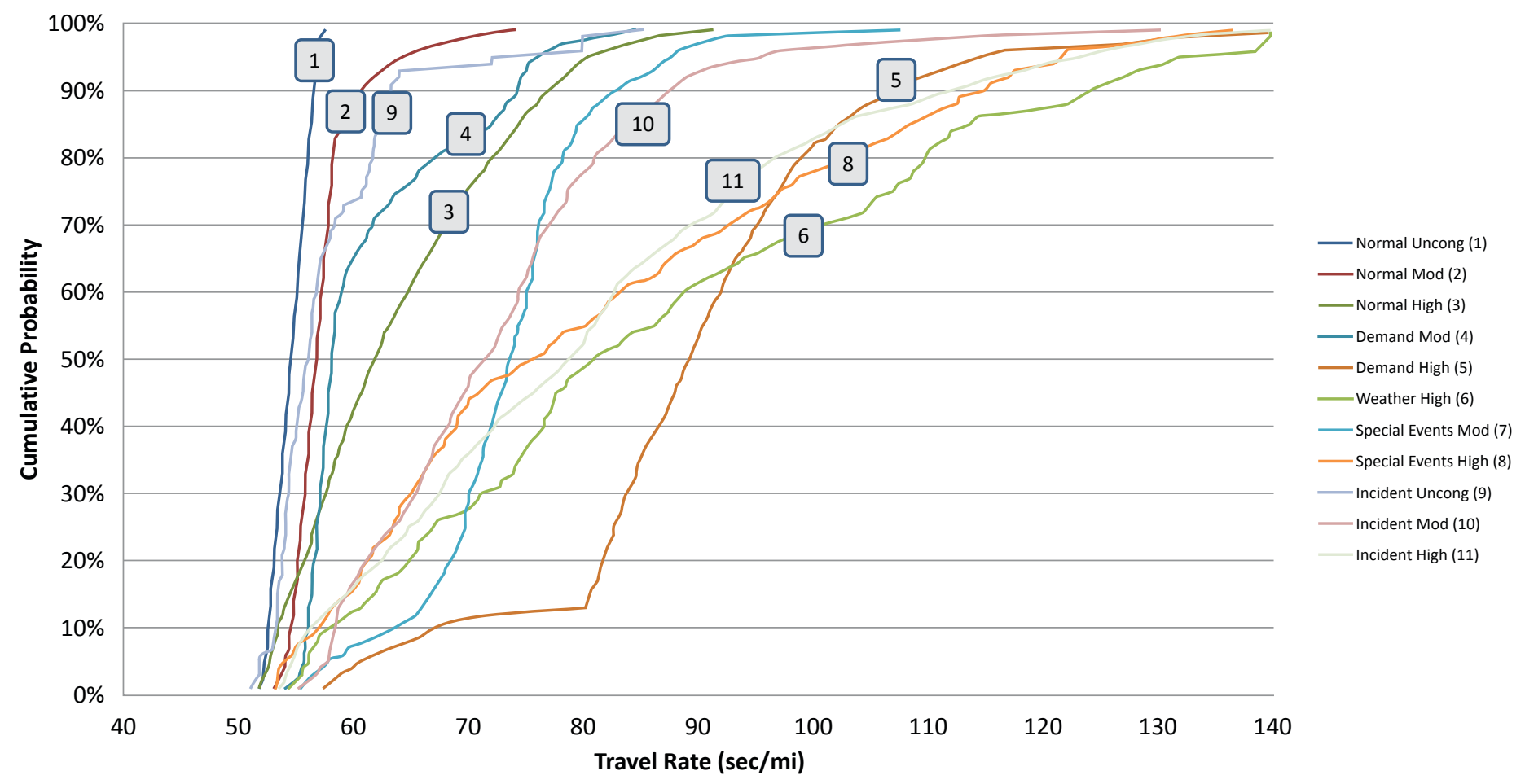

Figure 6.17. (continued)

maximum value that is substantially smaller than that of the other three nonrecurring categories. The implication is that demand needs to be a cause for concern. Reducing the rates for low-percentile values may be possible through geometric improvements, but reducing the tail may not be that important. It may be more important to focus on the tail for the three other conditions, which involve much higher travel rates, even above the 50 th or so percentile.

The story for the SR-15 route is similar. Almost all of the regimes involving no or low congestion have similar TRCDFs. There is some spread between 50 to $60 \mathrm{~s} / \mathrm{mi}$, but the TR-CDFs are all nearly vertical: not much variation in the travel rate occurs. The one notable exception is the TR-CDF for uncongested conditions when incidents arise. As with the I-5 TR-CDFs, incidents produce a major shift for the travel rates at the higher percentiles (in this case, above about the 90 percentile). The TR-CDF for the high-congestion, normal condition is the very smooth curve on the right-hand edge of the large cluster. Like the I-5 TR-CDF, it involves a much larger range of travel rates, from 50 to $85 \mathrm{~s} / \mathrm{mi}$, and more change in the travel rate as the percentiles increase.

The four TR-CDFs that are strikingly different are those for incidents, special events, weather, and demand during periods that would normally involve high congestion. This is not surprising, but it does reinforce the importance of taking actions that help manage the severity of these events when they occur during congested operation. In this case, for the demand conditions there is a significant shift in the travel rates from 50 to $80 \mathrm{~s} / \mathrm{mi}$ even at the zero percentile.

The story for the SR-163 route is quite different. It obviously has problems. Its TR-CDFs are widely scattered, and nonrecurring events have an impact under all levels of congestion. The most important details to notice are that (1) the most significant impacts (the CDFs farthest to the right) all occur during high congestion, and come from (right to left) weather, special events, and incidents; (2) the next two CDFs (light blue and dark red) are for weather under moderate congestion and demand during high congestion; and (3) the next three CDFs (right to left) are incidents, special events, and demand under low, not moderate, congestion conditions.

With these differences noted, the SR-163 route's reliability performance is otherwise similar to the other two. More specifically, it has a travel rate performance very similar to the other two routes under uncongested, normal conditions, but it struggles to maintain that performance either when the congestion levels get higher or nonrecurring events occur.

The fact that the SR-163 route has more significant shifts in the TR-CDFs for various conditions leads to a conclusion that there are problems with this route between I-805 and I-5. It is not too difficult to see why, by either physically or virtually driving the route and observing its physical features and congestion. The highway has many curves, its geometry is tight, 
Table 6.5. Semivariances for Each Regime for Three Routes in San Diego

\begin{tabular}{|c|c|c|c|c|c|c|c|c|c|c|c|c|c|}
\hline \multirow[b]{2}{*}{ Route } & \multirow[b]{2}{*}{ Condition } & \multicolumn{2}{|c|}{ Normal } & \multicolumn{2}{|c|}{ Demand } & \multicolumn{2}{|c|}{ Weather } & \multicolumn{2}{|c|}{$\begin{array}{c}\text { Special } \\
\text { Event }\end{array}$} & \multicolumn{2}{|c|}{ Incident } & \multirow{2}{*}{$\begin{array}{c}\Sigma(S V * n) \\
(000)\end{array}$} & \multirow{2}{*}{$\begin{array}{c}\text { Facility } \\
\text { Total }\end{array}$} \\
\hline & & sv & $n$ & sv & $n$ & SV & $n$ & sv & $n$ & sv & $n$ & & \\
\hline \multirow[t]{2}{*}{$1-5$} & Uncongested & 7 & 55,533 & 60 & 1,250 & 46 & 797 & 111 & 135 & 172 & 285 & 573 & \multirow[t]{2}{*}{5,278} \\
\hline & High & 205 & 12,783 & 1,415 & 472 & 2,563 & 175 & 1,399 & 104 & 1,769 & 466 & 4,705 & \\
\hline \multirow[t]{4}{*}{ SR-15 } & Uncongested & 15 & 24,491 & 47 & 147 & 68 & 229 & 29 & 77 & 139 & 55 & 400 & \multirow[t]{4}{*}{9,465} \\
\hline & Low & 27 & 15,931 & 118 & 102 & 106 & 193 & 0 & 0 & 97 & 25 & 457 & \\
\hline & Moderate & 46 & 14,863 & 127 & 13 & 151 & 271 & 0 & 0 & 93 & 103 & 740 & \\
\hline & High & 241 & 13,918 & 2,415 & 665 & 3,751 & 162 & 3,113 & 168 & 3,032 & 587 & 7,868 & \\
\hline \multirow[t]{3}{*}{ SR-163 } & Uncongested & 11 & 32,823 & 13 & 1,019 & 61 & 277 & 21 & 29 & 54 & 102 & 386 & \multirow[t]{3}{*}{9,561} \\
\hline & Moderate & 56 & 20,950 & 169 & 519 & 399 & 333 & 601 & 344 & 684 & 354 & 1,841 & \\
\hline & High & 261 & 12,764 & 1,789 & 1,028 & 1,924 & 254 & 1,424 & 243 & 1,385 & 961 & 7,333 & \\
\hline
\end{tabular}

and there are closely spaced interchanges. Between I-8 and I-5, this old facility has tight geometry and is only two lanes wide in each direction. Although it is not the purpose of L02 to determine what geometric and other treatments would help alleviate reliability problems (that is the focus of other SHRP 2 projects, such as L07), it is obvious that this section of SR-163 is one where geometric improvements and expedient response to incidents would likely have a significant impact on reliability.

Step 6 involves rank ordering the facilities based on the relative impacts so that those most affected can receive mitigating treatments. Table 6.5 provides a way to develop the rankings. Columns 3 to 12 report the average SV values for each regime and the frequency $(n)$ with which that regime occurs. The 13th column (second from the far right-hand side of the table) shows the SV totals for each congestion condition (e.g., 573,000 for I-5 during uncongested conditions and 4,705,000 during congested conditions). These values are based on the sum-product of the SV and $n$ values. The far-right column (Facility Total) in Table 6.5 reports the total SV in the travel rate for the year.

Inspection of the facility totals suggests that the least reliable facility is SR-163. This is consistent with the impression one gains from the scatterplots shown in Figures 6.14 and 6.15. The SR-15 route is the next most unreliable (9,465 versus 9,561$)$, but its distribution of the SV is slightly different. As Table 6.6 shows, a higher percentage can be attributed to incidents and special events during nominally high-congestion conditions.

A summary of this analysis is that all three routes exhibit variations in reliability depending on the recurring congestion condition and nonrecurring event. Evidence of these differences is most significant for the SR-163 route, and it seems apparent that its problems are due to the geometric conditions on the section of SR-163 from I-805 to I-5. All three routes

Table 6.6. Percentages for Semivariances for Each Regime for Three Routes in San Diego

\begin{tabular}{|c|c|c|c|c|c|c|c|c|}
\hline Route & Condition & $\begin{array}{c}\text { Normal } \\
(\%)\end{array}$ & $\begin{array}{c}\text { Demand } \\
(\%)\end{array}$ & $\begin{array}{c}\text { Weather } \\
\text { (\%) }\end{array}$ & $\begin{array}{c}\text { Special Event } \\
(\%)\end{array}$ & $\begin{array}{c}\text { Incident } \\
(\%)\end{array}$ & $\begin{array}{c}\Sigma(S V * n) \\
(000)(\%)\end{array}$ & $\begin{array}{l}\text { Facility } \\
\text { Total }\end{array}$ \\
\hline \multirow[t]{2}{*}{$1-5$} & Uncongested & 8 & 1 & 1 & 0 & 1 & 11 & \multirow[t]{2}{*}{1} \\
\hline & High & 50 & 13 & 8 & 3 & 16 & 89 & \\
\hline \multirow[t]{4}{*}{ SR-15 } & Uncongested & 4 & 0 & 0 & 0 & 0 & 4 & \multirow[t]{4}{*}{1} \\
\hline & Low & 4 & 0 & 0 & 0 & 0 & 5 & \\
\hline & Moderate & 7 & 0 & 0 & 0 & 0 & 8 & \\
\hline & High & 35 & 17 & 6 & 6 & 19 & 83 & \\
\hline \multirow[t]{3}{*}{ SR-163 } & Uncongested & 4 & 0 & 0 & 0 & 0 & 4 & \multirow[t]{3}{*}{1} \\
\hline & Moderate & 12 & 1 & 1 & 2 & 3 & 19 & \\
\hline & High & 35 & 19 & 5 & 4 & 14 & 77 & \\
\hline
\end{tabular}


are significantly affected by high congestion, even under normal conditions. The TR-CDF for that condition is dramatically different from the CDFs for normal operation under less-congested conditions. Incidents, weather, special events, and higher-than-normal demand all have a significant effect on reliability during highly congested conditions. Finally, it is clear that these TR-CDFs provide guidance about actions that might be useful to help correct the reliability problems.

\section{Considerations for Transit}

Most of the discussion in the Guide and its appendices focuses on vehicle (effectively auto) travel times. The figures are dominated by auto travel; the discussions about travel time and travel rates predominantly focus on automobile trips; and the commentary about diagnostic ideas relate to automobile trips.

Transit and freight trips are different. Transit passengers do not control what the vehicles do. They board and alight from the vehicles and make transfers. Their travel times are strongly influenced by the headways at which the vehicles operate and the reliability of the transfers.

Freight trips are similar. Packages get picked up and carried from shipper to terminal, terminal to terminal, and terminal to receiver. The travel times they experience are heavily influenced by the operating plans being followed by the freight providers and the reliability of their operations. Packages are similar to transit passengers in that they ride on one vehicle after another and their travel time is influenced by the headway between pick-ups (not often thought about that way, but often once a day) and the reliability of the connections between vehicles (i.e., trucks). Unlike transit passengers, the packages cannot influence the reliability of their trips. If they get placed on the dock in the loading area for the wrong truck they cannot move themselves to the area for the right truck. Hence, the reliability of their trip times is likely to be worse than that of the transit riders. However, freight companies only earn revenues if they deliver packages on time, so they tend to pay attention to whether the packages are being handled correctly. Transit agencies are not particularly sensitive to whether the passengers route themselves correctly: if a transit passenger gets delayed or reaches the wrong destination, culpability rests with the passenger, as well as the service provider.

In spite of these differences, a strong similarity exists between transit trips and package trips. They are both dependent on the headway between vehicle arrivals and the reliability of connections.

The observability of the trips is a different issue. Transit trips are largely unobservable. Many transit agencies do not track the movements of their passengers. Even the transit agencies with the most sophisticated data, such as the Washington Area Metropolitan Transit Authority, only know where and when the passengers entered and left the system; this is similar to AVI-type information. They do not know the path followed unless they were to track Bluetooth devices or cell phones, which they could do.

Packages, on the other hand, tend to be tracked carefully by many freight service providers. Public agencies may not have access to this information, but many carriers know where the packages are at all times. In some instances this is because the package's bar code was just read (i.e., it was picked up or received at a distribution center), or sometimes it is by inference (the package was scanned as it was loaded on the delivery truck, and the delivery truck is en route to the receiver). In this sense, package data are similar to AVI-type data. In selected (but very few) instances, the packages have radio frequency identification (RFID) tags that are being read constantly, so the package location data are like AVL data.

Because the carriers rarely share their package-level information except with the stakeholders who have a need-to-know interest (the shipper and receiver), providing reliable service to freight carriers becomes functionally similar to dealing with reliable travel times for autos. Trucks need to be able to traverse the highway network with reliable travel times. They do not want to be delayed so their deliveries are late. Unlike person trips, however, they often do not want to be early because they will have to wait until they were supposed to arrive. Early arrivals mean another activity could have been inserted, which represents a lost opportunity for better efficiency, more costeffective operation, or more revenue.

This discussion now focuses on transit trips because they are more often under the purview of the agencies responsible for operating the highway system.

Transit data were only obtained during the San Diego case study. However, those data are representative of the information available to the most progressive transit operators. Selected vehicles were equipped with AVL-like devices that could monitor the latitude-longitude location of the bus in real time, the times at which the bus doors opened and closed, and the number of people who boarded or alighted from the bus.

Were all the buses instrumented, then a technique similar to that used to generate the freeway travel times could have been used. It could have been assumed that hypothetical passengers boarded a bus B1 at time T1 at stop S1 bound for stop S2. By simulating a large number of trips from S1 to S2 during different times of the day (operating conditions), PDFs of the transit travel times could have been created. For trips on a single line this would have been simple. For trips that involve transfers, the process would have been slightly more complicated. The hypothetical passenger would have boarded bus $\mathrm{B} 1$ at time $\mathrm{T} 1$ and stop S1, traveled to transfer location X1, alighted at T2, and waited for a bus B2 that arrived at X1 at some time T3 > T2. The traveler would then have boarded bus $\mathrm{B} 2$, traveled to $\mathrm{S} 2$, and alighted at some time T4. The difference $\mathrm{T} 4-\mathrm{T} 1$ would be the travel time, and the reliability of these trips could also be assessed. 
In the case of San Diego, where not all of the buses were instrumented, a more complex analysis procedure had to be employed. The process involved two steps: (1) preprocessing the bus trip data to develop information needed to conduct the analysis and (2) generating a synthesized set of hypothetical, representative trips through Monte Carlo simulation. For other techniques, see Bertini and El-Geneidy $(2003,2004)$ and Yang et al. (2010).

\section{Developing Transit Rider PDFs for Trips}

Figure 6.18 shows the process used to synthesize the trip times. The flow chart at the top of the figure provides an overview. The bottom flow chart provides more detail. The whole figure is annotated with letters from A to J to provide reference markers for the description that follows. It is also couched in the context of a trip on bus Routes 11 and 7, but the bus route numbers are not relevant to this discussion. It is sufficient to recognize that two separate bus routes are involved with a transfer between them.
The overview starts with Marker A, focused on the initial bus boarding process. The passenger $(\mathrm{Px})$ arrives, as does a bus on Route 11. Depending on when they arrive, the passenger either gets on the first Route 11 bus or the next (second) one. If the passenger gets on the second bus, the passenger incurs a delay of one headway (what this delay means is described in more detail below). In either event, as shown by the blocks near Marker B, the passenger travels to and arrives at the transfer point (Xfer), as shown near Marker C. Arriving separately is the first Route 7 bus. An analysis of when that bus arrives relative to when the passenger arrives on the Route 11 bus determines whether the passenger gets on the first Route 7 bus or has to wait for the next (second) one. If the passenger gets on the second Route 7 bus, an additional delay is incurred. (Later text will describe this in more detail.) In either event, as shown by the blocks near Marker D, the passenger then arrives at the destination.

The detailed description starts with Marker E. Near it are shown the PDFs for the arrival of the passenger and the first
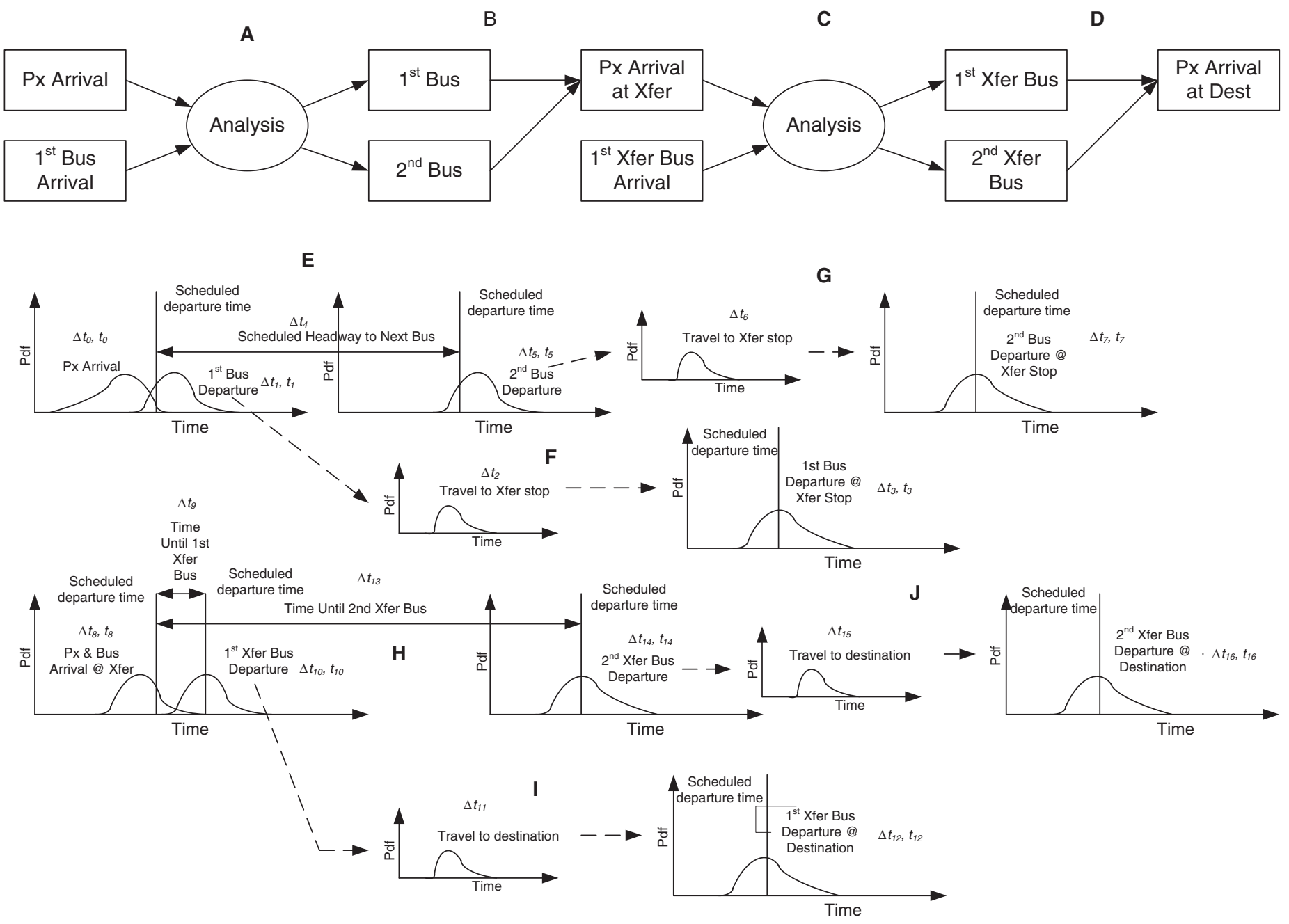

Figure 6.18. Analysis flow chart for transit trips involving transfers. 
Route 11 bus. Consistent with Bowman and Turnquist (1981), the passenger $\operatorname{PDF}\left(\Delta t_{0}\right)$ tends to favor early arrivals with a small probability of being late. Separately, consistent with the San Diego data, the Route 11 bus $\left(\Delta t_{1}\right)$ follows a second PDF. The distribution for the bus indicates a small probability of departing early (earlier than the scheduled departure time) and a much larger probability of departing late. If the passenger arrives before the Route 11 bus departs, then the passenger boards the first Route 11 bus. If that happens, the descending dashed line toward Marker $\mathrm{F}$ indicates that the passenger incurs a travel time $\left(\Delta t_{2}\right)$ to reach the transfer stop, and the passenger (on the Route 11 bus) arrives at the transfer stop at $t_{1}$, which is at some point in time relative to the scheduled departure time $\left(\Delta t_{3}\right)$. (Departure times have been used as the reference because they are worst-case times; it is known for sure that the passenger has arrived when the bus departs.) If the passenger misses the first Route 11 bus, then a schedule delay $\left(\Delta t_{4}\right)$ is incurred until the next Route 11 bus arrives (to the right of Marker E). A second Route 11 bus arrives $\left(\Delta t_{5}\right)$, the passenger boards, and the Route 11 bus travels to the transfer location $\left(\Delta t_{6}\right)$ shown by Marker G. The passenger arrives at the transfer stop at $t_{2}$, which is at some time relative to its scheduled departure $\left(\Delta t_{7}\right)$.

Whichever arrival time governs $\left(t_{1}\right.$ or $\left.t_{2}\right)$ becomes the start of the second part of the trip (Marker $\mathrm{H})$. Moreover, the corresponding relative arrival time $\left(\Delta t_{4}\right.$ or $\left.\Delta t_{7}\right)$ becomes the basis $\left(\Delta t_{8}\right)$ for determining which transfer bus is caught. If the passenger's relative arrival time on the Route 11 bus $\left(\Delta t_{8}\right)$ is less than the sum of the scheduled connection time $\left(\Delta t_{9}\right)$ and the relative departure time for the Route 7 bus $\left(\Delta t_{10}\right)$, then the first Route 7 bus is caught. This leads to a travel time to the destination $\left(\Delta t_{11}\right)$, an arrival time $\left(t_{3}\right)$, and a relative arrival time compared with the schedule $\left(\Delta t_{12}\right)$ (Marker I). However, if the Route 11 bus arrives late $\left(\Delta t_{8}\right)$ or the Route 7 bus departs early $\left(\Delta t_{9}+\Delta t_{10}\right)$, then the passenger may miss the first Route 7 bus, incur a delay $\left(\Delta t_{13}\right)$ until the next Route 7 bus arrives $\left(\Delta t_{14}\right)$, then incur a travel time $\left(\Delta t_{15}\right)$ to the destination and arrive at $t_{4}$ with a relative arrival time $\Delta t_{16}$ (Marker $\left.\mathrm{J}\right)$.

Table 6.7 presents four numerical examples to help illustrate the analysis. In the first, no bus is missed. In the second, the connection bus is missed. In the third, the first Route 11 bus is missed, but the subsequent connection is made. In the fourth, both the first Route 11 bus is missed and the first Route 7 transfer bus is missed. In all cases the reference time when $t=0$ is the scheduled departure time of the first Route 11 bus. All the values are in seconds. Results obtained from actually working with the transit data obtained in the San Diego case study can be found in Appendix $\mathrm{C}$ of the Guide.

The first example starts with $\Delta t_{0}<\Delta t_{1}(-120<30)$, which means the passenger gets to catch the first Route 11 bus. The starting time for the trip $\left(t_{0}\right)$ becomes -120 seconds (i.e., the passenger arrived 2 minutes before the scheduled departure time, which is the reference point for $t=0$ ). The travel time to the transfer point is $\Delta t_{2}=1,570$, the arrival time is $t_{3}=t_{8}=1,600$,
Table 6.7. Four Numerical Examples of Estimating Travel Times for Transit Trips Involving a Transfer

\begin{tabular}{|c|c|c|c|c|}
\hline Metric & No Miss (s) & Miss 2 (s) & Miss 1 (s) & Miss Both (s) \\
\hline$\Delta t_{0}$ & -120 & -90 & -30 & 50 \\
\hline$\Delta t_{1}$ & 30 & 15 & -50 & -100 \\
\hline$\Delta t_{2}$ & 1,570 & 1,730 & - & - \\
\hline$\Delta t_{3}$ & 20 & 350 & - & - \\
\hline$\Delta t_{4}$ & - & - & 900 & 900 \\
\hline$\Delta t_{5}$ & - & - & -30 & 40 \\
\hline$\Delta t_{6}$ & - & - & 1,400 & 1,800 \\
\hline$\Delta t_{7}$ & - & - & -100 & 400 \\
\hline$\Delta t_{8}$ & 20 & 350 & -100 & 400 \\
\hline$\Delta t_{9}$ & 240 & 240 & 240 & 240 \\
\hline$\Delta t_{10}$ & 50 & -100 & 70 & -100 \\
\hline$\Delta t_{11}$ & 190 & - & 210 & - \\
\hline$\Delta t_{12}$ & -10 & - & 20 & - \\
\hline$\Delta t_{13}$ & - & 720 & - & 720 \\
\hline$\Delta t_{14}$ & - & 10 & - & -30 \\
\hline$\Delta t_{15}$ & - & 180 & - & 190 \\
\hline$\Delta t_{16}$ & - & -10 & - & 30 \\
\hline$t_{0}$ & -120 & -90 & -30 & 50 \\
\hline$t_{1}$ & 30 & 15 & - & - \\
\hline$t_{3}$ & 1,600 & 1,745 & - & - \\
\hline$t_{5}$ & - & - & 870 & 940 \\
\hline$t_{7}$ & - & - & 2,270 & 2,740 \\
\hline$t_{8}$ & 1,600 & 1,745 & 2,270 & 2,740 \\
\hline$t_{10}$ & 1,870 & - & 2,680 & - \\
\hline$t_{12}$ & 2,060 & - & 2,890 & - \\
\hline$t_{14}$ & - & 2,365 & - & 3,270 \\
\hline$t_{16}$ & - & 2,545 & - & 3,460 \\
\hline$t t$ & 2,180 & 2,635 & 2,920 & 3,410 \\
\hline
\end{tabular}

and the relative arrival time at the transfer point (relative to the scheduled departure at that location) is $\Delta t_{3}=\Delta t_{8}=20$.

Next, the connection is analyzed. The relative arrival time is $\Delta t_{8}=20$, the transfer time is $\Delta t_{9}=240$, and the first Route 7 bus is late $\Delta t_{10}=50$, so the passenger has no problem catching the first transfer bus $\left(\Delta t_{8}<\Delta t_{9}+\Delta t_{10}\right)$. The passenger then departs the transfer stop at $t_{10}=t_{8}-\Delta t_{8}+\Delta t_{9}+\Delta t_{10}=1,600$ $-20+240+50=1,870$, travels to the destination $\Delta t_{11}=190$, and arrives at the destination at $t_{12}=t_{10}+\Delta t_{11}=1,870+190$ $=2,060$, with an arrival relative to the scheduled arrival time of $\Delta t_{12}=-10$ (10 seconds early) and an overall travel time of $t t=t_{12}-t_{0}=2,060-(-120)=2,180$ seconds (36.3 minutes). 
In the second example, the first Route 11 bus is caught, but the first Route 7 transfer bus is missed. The example starts with $\Delta t_{0} \leq \Delta t_{1}(-90 \leq 15)$, which means the passenger catches the first Route 11 bus. The starting time for the trip $\left(t_{0}\right)$ becomes -90 . The travel time to the transfer point is $\Delta t_{2}=1,730$, the arrival time is $t_{3}=t_{8}=1,745$, and the relative arrival time at the transfer point (relative to the scheduled departure time) is $\Delta t_{3}=\Delta t_{8}=350$. The transfer time is $\Delta t_{9}=240$, and the first Route 7 bus leaves early $\Delta t_{10}=-100$, so the passenger misses the first transfer bus $\left(\Delta t_{8} \geq \Delta t_{9}+\Delta t_{10}\right.$, or $\left.350 \geq 240+[-100]\right)$. The passenger has to wait for the second transfer bus, which has a scheduled time $\Delta t_{13}=720$. This is 12 minutes later than the first transfer bus, and it arrives a little late $\Delta t_{14}=10$. This means it leaves at $t_{14}=t_{8}-\Delta t_{8}+\Delta t_{9}+\Delta t_{13}+\Delta t_{14}=1,745-350+240+720$ $+10=2,365$. The Route 7 bus then travels to the destination $\Delta t_{15}=180$ and arrives a little early $\Delta t_{16}=-10$ at $t_{16}=2,545$. The overall trip time is $t t=t_{16}-t_{0}=2,645$ (43.9 minutes).

In the third example, the first Route 11 bus is missed and the first Route 7 transfer bus is caught. The example starts with $\Delta t_{0}>\Delta t_{1}(-30>-50)$, so the passenger misses the first Route 11 bus. The starting time for the trip $\left(t_{0}\right)$ becomes -30 . The passenger has to wait for the next bus $\Delta t_{4}=900$, which is a little early $\Delta t_{5}=-30$. The travel time to the transfer point is $\Delta t_{6}=1,400$, the arrival time is $t_{7}=t_{8}=2,270$, and the arrival time at the transfer point relative to the scheduled departure time is $\Delta t_{7}=\Delta t_{8}=-100$. The transfer time is $\Delta t_{9}=240$, and the first Route 7 bus leaves late $\Delta t_{10}=70$, so the passenger catches the first transfer bus $\left(\Delta t_{8} \leq \Delta t_{9}+\Delta t_{10}\right.$, or $-100 \leq 240$ $+70)$. The passenger departs the transfer stop at $t_{10}=t_{8}-\Delta t_{8}$ $+\Delta t_{9}+\Delta t_{10}=2,270-(-100)+240+70=2,680$, travels to the destination $\Delta t_{11}=210$, arrives at the destination at $t_{12}=$ $t_{10}+\Delta t_{11}=2,680+210=2,890$, with an arrival relative to the scheduled arrival time of $\Delta t_{12}=20$ (20 seconds late) and an overall travel time of $t t=t_{12}-t_{0}=2,890-(-30)=2,920$ seconds (48.7 minutes).

In the fourth example, both the first Route 11 bus and the first Route 7 transfer bus are missed. The example starts with $\Delta t_{0}$ $>\Delta t_{1}(50>-100)$, so the passenger misses the first Route 11 bus. The starting time for the trip $\left(t_{0}\right)$ becomes 50 . The passenger has to wait for the next bus $\Delta t_{4}=900$, which is a little late $\Delta t_{5}=40$. The travel time to the transfer point is $\Delta t_{6}=1,800$, the arrival time is $t_{7}=t_{8}=2,740$, and the arrival time at the transfer point relative to the scheduled departure time is $\Delta t_{7}=\Delta t_{8}=400$. The transfer time is $\Delta t_{9}=240$, and the first Route 7 bus leaves early $\Delta t_{10}=-100$, so the passenger misses this bus $\left(\Delta t_{8} \geq \Delta t_{9}+\Delta t_{10}\right.$, or $400 \leq 240+[-100])$ and has to catch the second one. The added wait for the next bus is $\Delta t_{13}=720$, which is 12 minutes later than the first transfer bus, and that bus arrives a little early $\Delta t_{14}=-30$. This means the departure time from the transfer stop is $t_{14}=t_{8}-$ $\Delta t_{8}+\Delta t_{9}+\Delta t_{13}+\Delta t_{14}=2,740-400+240+720+(-30)=3,270$. The Route 7 bus then travels to the destination $\Delta t_{15}=190$ and arrives a little late $\Delta t_{16}=30$ at $t_{16}=3,460$. The overall trip time is $t t=t_{16}-t_{0}=3,460-50=3,410$ (56.8 minutes).

\section{Summary}

Data processing and analysis is essential in using a TTRMS. The ultimate objective is to prepare distributions of the travel times that can be displayed in histograms, PDFs, and CDFs. This chapter described how raw travel time information can be analyzed and summarized to create the travel time distributions.

An important observation is that no single processing strategy seems to work for all situations. Although the methods all culled and summarized the raw data to create the distributions, the detailed manner in which this is done depends on the data sources available.

Another important observation is that the analyst needs to decide what should be analyzed. At one extreme, it may be the entire year. At the other, it may be a set of 5-minute time slices during the morning or afternoon peak on weekdays in the winter. The methods will work in all instances.

It is obvious that any analysis requires an understanding of the causal factors involved. System operators need to know and understand the impacts of congestion, incidents, weather, and so forth. Deciding how to attribute these influences is a major element of the analysis. Attribution may seem simple at first, but the L02 study team found it was fairly complex. This is because nonrecurring events can have impacts on segments well beyond the one on which they occur, including upstream and downstream, in the opposing direction, and on intersecting facilities. For example, an incident on an intersecting freeway can cause back-ups through ramps onto other facilities. An understanding of the network is critical in determining what events affect what segments.

It is also critically important that influences not be confounded. For example, mixing data from different congestion levels and nonrecurring events can confound the analyst's ability to see clear effects. If the impacts of the causal factors were separable and additive, this might not be a problem, but such is not the case. For example, the L02 team found that weather can have a dramatic impact during high congestion, but during times of low or no congestion, the impact is far less dramatic. The L02 team's use of regimes to bin the data was particularly valuable in parsing the influence of various causal factors.

Finally, it will be helpful in the future if monitoring system modules can capture data for nonrecurring events as they occur, rather than ex post facto. Although the L02 team demonstrated that ex post facto analyses can be done, explanatory information is only sought when it is obvious through outlier analysis that the travel times have been affected, so instances are missed when the nonrecurring events took place and no travel time impact occurred. 


\section{ОНА⿰тев 7 Case Studies}

This section describes the case studies and use cases employed to test the ideas presented in the Guide for a travel time reliability monitoring system (TTRMS). The case studies were performed in San Diego, California; Northern Virginia; Sacramento-Lake Tahoe, California; New York and New Jersey; and Atlanta, Georgia. Figure 7.1 shows the case study locations. The five main case studies are presented first, followed by additional applications in other locations.

The L02 team implemented a prototype TTRMS at each of the five case study sites. These systems collect sensor data in real time from a variety of transportation networks, process these data inside a large data warehouse, and generate reports on travel time reliability to help agencies better operate and plan their transportation systems.

The TTRMS realizations used in the case studies were based on the existing Performance Measurement System (PeMS) monitoring system, a web-based software system for the state of California that collects traffic data from more than 30,000 loop detectors every 30 seconds, filters and cleans the raw data, computes performance measures, and aggregates and archives the data to enable detailed analysis. PeMS is a traffic data collection, processing, and analysis tool that extracts information from real-time intelligent transportation systems data, saves it permanently in a data warehouse, and presents it in various forms to users via the web.

PeMS was linked with various existing monitoring systems in the case studies outside California. Because it can calculate many different performance measures, the requirements for linking PeMS with an existing system depend on the features being used. PeMS needs to acquire both roadway network information and equipment configuration metadata before traffic data can be stored in the database. PeMS has a strict equipment configuration framework that is described in the TTRMS resource document. Different methodologies were applied, and specific use cases were demonstrated in each case study based on the existing data and monitoring systems.
The investigations presented in each case study are categorized as system integration experiments, integration of sources of nonrecurring congestion experiments, and other use cases. Systems integration experiments relate to activities that occur before the development of a probability density function (PDF) for travel time reliability and include investigations into data integration considerations, comparison with probe data, and development of travel time reliability functions. The Northern Virginia, Sacramento-Lake Tahoe, Atlanta, and New York and New Jersey case studies include system integration experiments.

Integration of sources of nonrecurring congestion experiments include system integration aspects and specific use case demonstrations related to analyzing the seven sources of congestion. The San Diego, Sacramento-Lake Tahoe, Atlanta, and New York and New Jersey case studies include investigations of sources of nonrecurrent congestion.

Other use case investigations demonstrate specific use cases after a PDF has been created. The use cases and the various types of users are described in the Guide, Appendix D: Use Case Analyses. The San Diego case study includes investigations of use cases including using planning-based reliability tools.

\section{San Diego, California}

This case study focuses on using a mature reliability monitoring system in San Diego to illustrate the state of the art for existing practice. Led by the San Diego Association of Governments (the regional metropolitan planning organization) and the California Department of Transportation (Caltrans), the San Diego region has developed one of the most sophisticated regional travel time monitoring systems in the United States. This system is based on an extensive network of sensors on freeways, arterials, and transit vehicles. It includes a data warehouse and software system for calculating travel times automatically. Regional agencies use these data in sophisticated ways to make operations and planning decisions. 


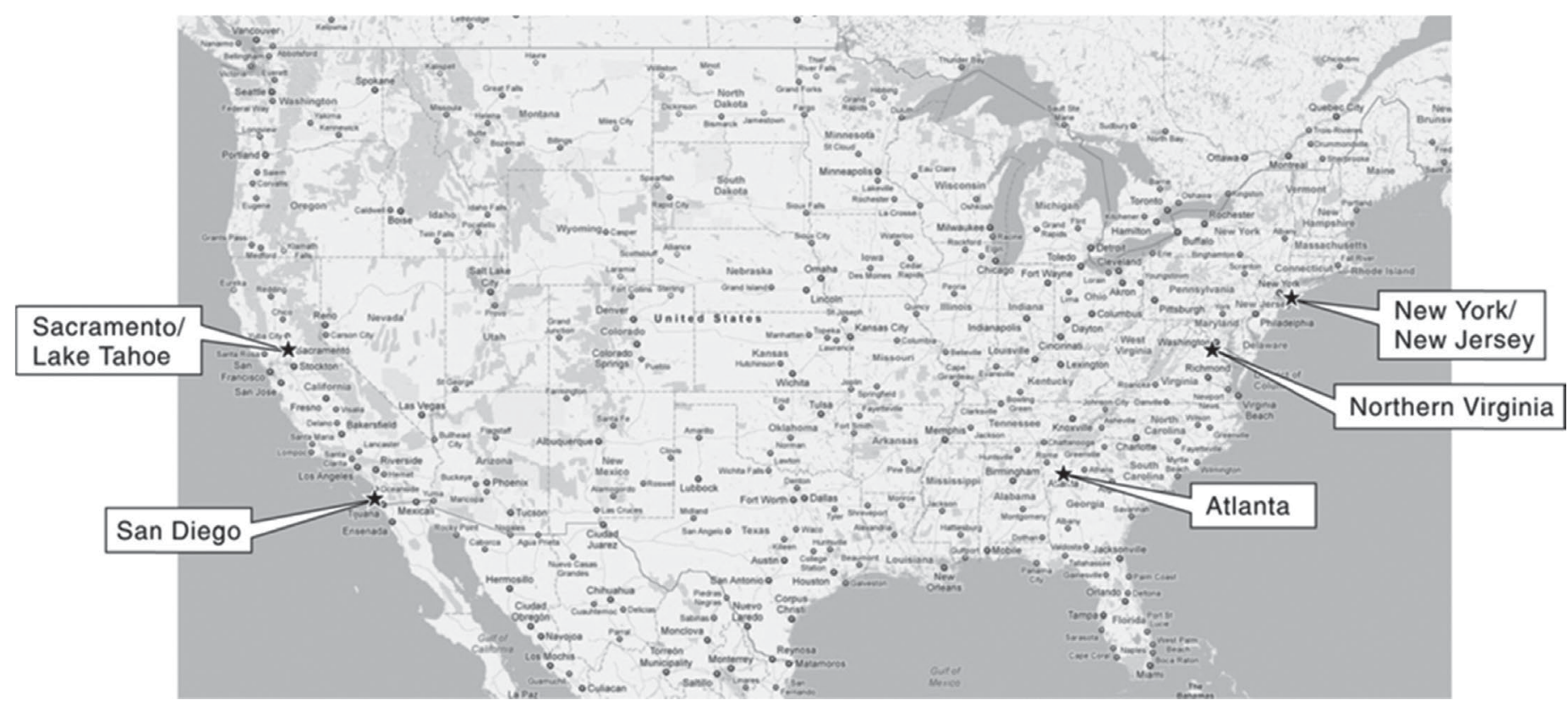

Map data (๑) 2012 Google.

\section{Figure 7.1. Case study locations.}

Because this technical and institutional infrastructure was already in place, the team focused on generating sophisticated reliability use case analyses. The rich, multimodal nature of the San Diego data presented numerous opportunities for state-of-the-art reliability monitoring, as well as challenges in implementing Guide methodologies on real data.

The purpose of this case study was as follows:

- Assemble regimes and travel time PDFs (TT-PDFs) from individual vehicle travel times.

- Explore methods to analyze transit data from automated vehicle location (AVL) and automated passenger count (APC) equipment.

- Demonstrate high-level use cases encompassing freeways, transit, and freight systems.

- Relate travel time variability to the seven sources of congestion.

Figure 7.2 shows the study area for the San Diego case study.

Caltrans District 11 encompasses San Diego and Imperial counties and the metropolitan area of San Diego. A variety of detection systems are used in the study area to monitor freeways, arterials, and the transit fleet. District 11 has 3,592 sensors, which are a mix of loop detectors and radar detectors, located at 1,210 locations on its freeways. District 11 also has 17 wireless vehicle sensors deployed to monitor intersection approaches on its arterials.

The San Diego Metropolitan Transit System is currently supplying data from their real-time computer-aided dispatch (CAD) system into an archived data user service. Over one-third of the bus fleet is equipped with AVL transponders, and over one-half of the fleet has APC equipment.

All Caltrans districts use PeMS for data and performance measure archiving and reporting. District 11 uses an arterial extension of PeMS (A-PeMS) to collect and store its arterial data. District 11 also uses a transit extension of PeMS (T-PeMS) to obtain schedule, AVL, and APC data from its existing real-time transit management system, compute performance measures based on these data, and aggregate and store them for further analysis.

Caltrans uses other management systems in conjunction with PeMS to operate its transportation network. For example, the California Highway Patrol's CAD system provides an automated incident data feed that is fed into PeMS in real time. Caltrans also keeps a nonautomated database of incidents through its Traffic Accident Surveillance and Analysis System (TASAS). TASAS data are incorporated into PeMS with a 2-year lag.

In the San Diego case study, the research team opted to pursue a less-sophisticated but more-accessible approach than had previously been developed because it provides meaningful and actionable results without requiring agency staff to have advanced statistical knowledge.

The San Diego case study demonstrated seven high-level use cases that broadly encompass reliability information of interest to various users of the transportation system. The specific use cases were developed to be well suited for demonstration using the San Diego data sources. These use cases, which apply to roadway, transit, and freight users, are described in detail in Appendix $\mathrm{C}$ of the Guide and in the subsections below. 


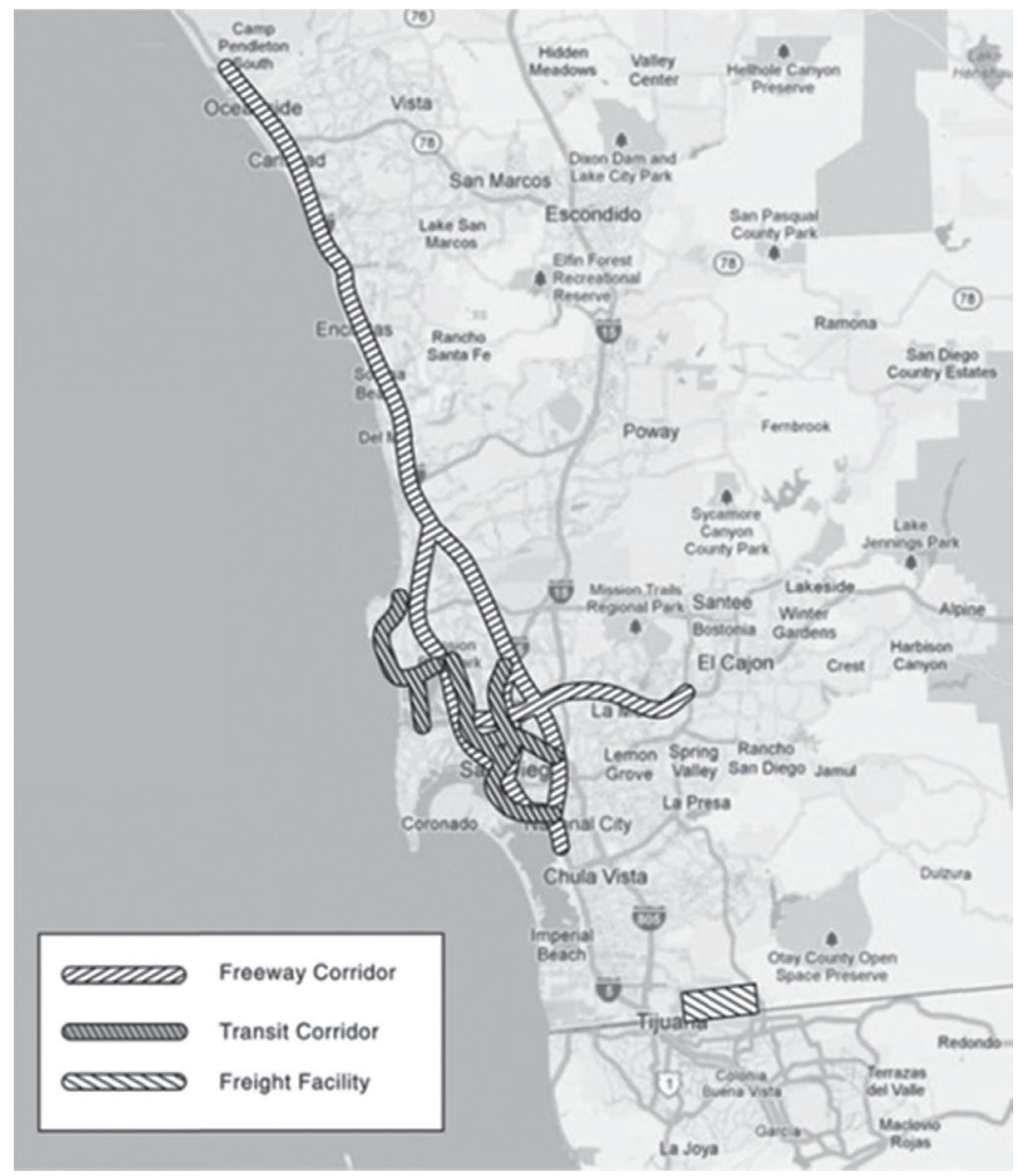

Map data () 2012 Google.

Figure 7.2. San Diego case study area.

\section{Freeway Analyses}

Freeway Use Case 1: Conducting offline analysis on the relationship between travel time variability and the seven sources of congestion. This use case is primarily for the system planner and roadway manager user types. To perform this analysis, methods were developed to create TT-PDFs from large data sets of travel times that occurred under each congested condition. This use case analysis illustrates one potential method for linking travel time variability with the sources of congestion. The application of the methodology to the two study corridors in San Diego revealed key insights into how this type of analysis should be performed.

Freeway Use Case 2: Using planning-based reliability tools to determine departure time and travel time for a trip. This use case represents a function that would be used by drivers. The use case demonstration shows the route that is the fastest on average is not always the route that consistently gets travelers to their destination on time.

Freeway Use Case 3: Combining real-time and historical data to predict travel times in real time. This use case is primarily for the operations manager user type. This use case demonstration shows that it is possible to provide predictive travel time ranges and expected near-term travel times by combining real-time and archived travel time data. The travel time predictions for both study routes proved very similar to the actual travel times measured on the sample day.

\section{Transit Analyses}

The biggest data challenge in the San Diego case study was processing the transit data, which are stored in a newly developed performance measurement system. This case study represented the first research effort to use these data and this system. The research team found that data quality is a major issue when processing transit data to compute travel times. Many of the records reported by equipped buses had errors that had to be programmatically filtered out.

Assembling route-based reliability statistics using a drastically reduced subset of good data presented the next challenge. From this experience, the research team concluded that transit travel time reliability monitoring requires a robust data processing engine that can programmatically filter data to ensure that archived travel times are accurate. 
In addition, transit reliability analysis requires a long timeline of historical data, because typically only a subset of buses is monitored, and a large percentage of obtained data points will prove invalid.

Transit Use Case 1: Conducting offline analysis on the relationship between travel time variability and the seven sources of congestion. This use case serves a function primarily used by transit planners and operators. This use case analysis illustrates one method for exploring the relationship between travel time variability and the seven sources of congestion. The application of the methodology to the three San Diego routes revealed key insights into how this type of analysis should be performed.

Transit Use Case 2: Using planning-based reliability tools to determine departure times and travel times for a trip. This use case primarily serves the transit passenger user type. This use case demonstration resulted in departure times and corresponding planning times for two bus routes. The demonstration of this use case concluded that the most direct analysis would be achieved by restricting the date range to dates with identical schedules.

Transit Use Case 3: Analyzing the effects of transfers on the travel time reliability of transit trips. This use case primarily serves the transit operator user type. It was concluded that unusually long in-vehicle travel times can have a larger effect on traditional reliability measures than missed transfers, potentially hiding the existence of missed transfers on a route.

\section{Freight Analyses}

Freight Use Case: Using freight-specific data to study travel times and travel time variability across an international border crossing. This use case represents a functionality that would primarily be used by freight service providers. This use case demonstration represented an initial use of truck travel time data from the Otay Mesa border crossing to evaluate travel time reliability for different aspects of a border crossing. By understanding where the bottlenecks are in the border crossing process and how they affecting travel times and reliability, managers can begin to take steps to improve operations.

\section{Northern Virginia}

This case study provides an example of a more traditional transportation data collection network operating in a mixture of urban and suburban environments. Northern Virginia was selected as a case study site because it provided an opportunity to integrate a reliability monitoring system into a preexisting, extensive data collection network. The focus of this case study, which is described in detail in Appendix $\mathrm{C}$ of the Guide, was to describe the required steps and considerations for integrating a TTRMS into existing data collection systems.

The purpose of this case study was as follows:

- Describe the data acquisition and processing steps needed to transfer information between the existing system and the PeMS reliability monitoring system.

- Demonstrate methods to ensure the data quality of infrastructure-based sensors by comparing probe vehicle travel times using the procedures described in Chapter 3.

- Develop multistate travel time reliability distributions from traffic data.

The study area for this investigation comprises I-66 from Manassas to Arlington, Virginia, and I-395 from Springfield to Arlington, Virginia. Figure 7.3 shows the study corridors for the Northern Virginia case study.

The Northern Virginia (NOVA) District of the Virginia DOT includes over 4,000 miles of roadway in Fairfax, Arlington, Loudoun, and Prince William counties. Traffic operations in the district are managed from the Northern Virginia Traffic Operations Center, which manages more than 100 miles of instrumented roadways, including high-occupancy vehicle (HOV) facilities on I-95/I-395, I-295, I-66, and the Dulles Toll Road. The Northern Virginia Traffic Operations Center has deployed a wide range of technologies to support its activities, including cameras, dynamic message signs, ramp meters, and lane control signals.

In Northern Virginia, the Virginia DOT has deployed an extensive network of point-based detectors (primarily inductive loops and radar-based detectors), which are described in Chapter 1 of the Guide, to facilitate real-time collection of volume, occupancy, and (limited) speed data on freeways. A key component of the case study is ensuring the data quality of infrastructure-based sensors, as described in Chapter 2 of the Guide.

To monitor regional travel conditions, the NOVA District collects data from a wide range of sources on area freeways, including multiple types of traffic sensors and third parties such as Inrix, Trichord, and Traffic.com. The Northern Virginia case study contains details about the types of traffic sensors and their specific locations.

Northern Virginia's freeway management system is operated by Virginia DOT staff located at the Traffic Operations Center. Staff members use the freeway management system to monitor and manage traffic, respond to incidents, and disseminate traveler information. In addition to managing freeway-related operations, Virginia DOT staff use the NOVA Smart Traffic Signal System to manage surface street and arterial systems in the region, monitoring, controlling, and maintaining over 1,000 traffic signals within their jurisdiction. 


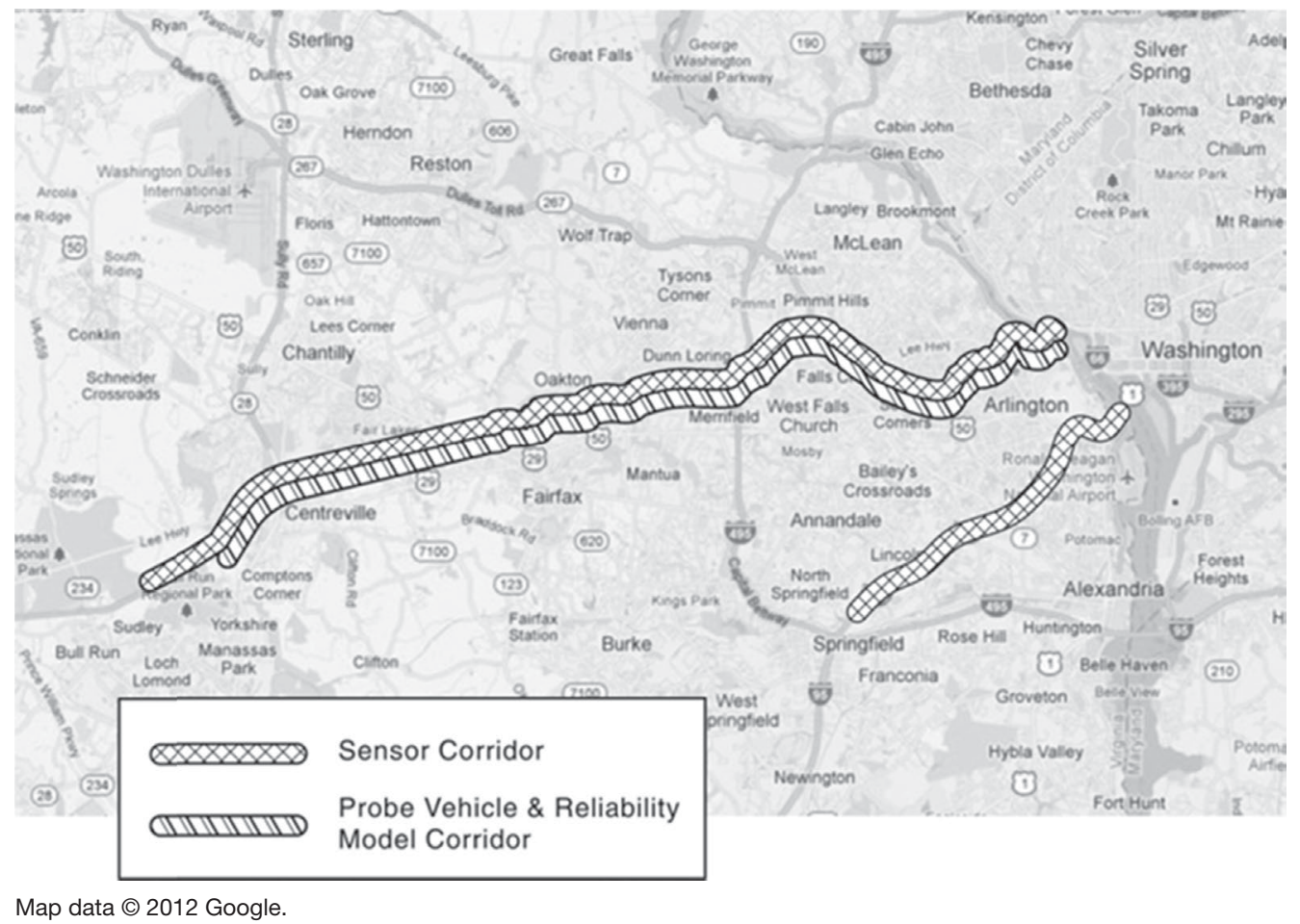

Figure 7.3. Northern Virginia study area.

\section{System Integration}

For the purposes of this case study, data from NOVA's data collection network and management system were integrated into a developed archived data user service and TTRMS. The steps and challenges encountered in enabling the information and data exchange between these two large and complex systems are described in detail in Appendix C of the Guide. The goal of this experiment was to provide agencies with a real-world example of the resources needed to accomplish data collection and monitoring system integration and the likely challenges that will be encountered when procuring a monitoring system.

NOVA equipment configuration information was obtained from an XML file posted on the Regional Integrated Transportation Information System (RITIS) website. The issues with fitting the data into the PeMS configuration related to conflicting terminologies, information required by PeMS that was missing from the configuration file, and equipment types not supported by PeMS. The Northern Virginia case study describes these issues in more detail, as well as the metadata quality control steps that were used to insert NOVA configuration information into PeMS.

Configuring PeMS to receive NOVA data helped define the requirements for complex traffic systems integration and illustrate what agencies can do to facilitate the process of implementing reliability monitoring. The process of fully integrating the NOVA data with PeMS took several weeks.
Agencies interested in acquiring PeMS or a similar system can take steps to make this integration go more smoothly and quickly.

First, it is important that the implementation and maintenance of a traffic data collection system be carried out with a broad audience in mind. Often, increasing access to data outside of an organization can help to further agency goals; for example, providing data to mobile application developers can help agencies distribute information in a way that increases the efficiency of the transportation network.

One of the ways that agencies can facilitate the distribution of data from their data collection system is by establishing one or more data feeds. Maintaining multiple data feeds can be a challenge. If agencies want to provide a feed of processed data, it will save resources in the long run to document the processing steps performed on the data (Soriguera 2011). This will allow implementers of external systems to evaluate them and undo them, if needed.

Aside from the processing documentation, maintaining clear documentation on the format of data files and units of data will greatly facilitate the use of data outside of the agency. Documentation on the path of data from a detector through the agency's internal systems can also be of value to contractors and other external data users. Clearly explaining this information in a text file minimizes timeconsuming back-and-forth communication between agency staff and contractors and prevents inaccurate assumptions from being made. 


\section{Probe Vehicle Comparisons}

The team performed a quality control procedure to better understand the implications of the data quality issues on travel times. In particular, the team wanted to know how well the probe data aligned with the traffic speed and travel time estimates provided by the sparsely deployed point-based detectors. Probe vehicle runs were conducted along I-66 to amass ground-truth data that could be compared with the sensor data. In addition to analyzing speed data, the team analyzed the differences between the travel times experienced by the probe vehicle during each trip versus the estimated travel times generated from the sensor speeds. It was determined that the steadiness of the travel time estimates from the sensors is not ideal for computing travel time reliability, which relies on the ability of the system to detect variability in traffic conditions over time. As a result, it is highly unlikely that these sensors would provide accurate travel times under most congested conditions.

The team's analysis of the data available from these sensors yielded a number of findings of potential interest to a wide variety of agencies, particularly those facing maintenance and calibration issues associated with older sensor systems, as well as those agencies with more sparsely spaced spot sensors. Five primary factors were identified that accounted for differences between the probe vehicle data and speed or estimated travel times generated based on Virginia DOT sensor data. These factors are described in Appendix C of the Guide. Public agency staff should consider these factors when making decisions concerning the deployment of new data collection infrastructure and the maintenance and expansion of existing systems.

\section{Analyses of PDFs with Multiple Statistical Modes}

Because of the type of data available in the Northern Virginia case study and previous investigations in the I-66 corridor, the research team elected to experiment with travel time reliability monitoring ideas that are being developed in SHRP 2 Project L10, Feasibility of Using In-Vehicle Video Data to Explore How to Modify Driver Behavior That Causes Nonrecurrent Congestion. L10 researchers are experimenting with a multistate travel time reliability modeling framework using mixed-mode normal distributions to represent the PDFs of travel time data from a simulation model of eastbound I-66 in Northern Virginia. This case study adopted that technique and applied it to the travel times calculated from the freeway loop detectors on eastbound I-66.

The goal of this study was to generate, for each hour of the day, two outputs: the percentage chance that a traveler would encounter a certain condition and the average and 95th percentile travel times for each condition. The methodological findings of this investigation are that multistate normal distribution models can approximate travel time distributions generated from loop detectors better than normal or lognormal distributions. During the peak hours on a congested facility, three states are generally sufficient to balance a good model (distribution) fit with the need to generate information that can be easily communicated to interested parties. During off-peak hours, two states typically provide a reasonable model or distribution fit. The outputs of this method can inform travelers of the percentage chance that they will encounter moderate or severe congestion and, if they do, what their expected and 95th percentile travel times will be.

\section{Sacramento-Lake Tahoe, California}

This case study illustrates an example of a rural transportation network with a fairly sparse data collection infrastructure. The purpose of this case study was as follows:

- Examine vehicle travel time calculation and reliability using Bluetooth and RFID reidentification systems.

- Filter out travel times from trip times collected by Bluetooth and electronic toll collection (ETC) devices.

- Explore the following aspects of the Lake Tahoe region ETC and Bluetooth reader (BTR) networks: detailed locations and mounting structures, lanes and facilities monitored, percentage of traffic sampled, and percentage and number of vehicles reidentified between readers.

- Quantify the effects of adverse weather- and demandrelated conditions on travel time reliability using data derived from Bluetooth and ETC systems.

The study area for this case study comprises I-5 through Sacramento and the two highways leading east to Lake Tahoe: I-80 and US-50. Figure 7.4 shows the study corridors for the Sacramento-Lake Tahoe case study.

This case study is located in Caltrans District 3, which encompasses the Sacramento metropolitan area and the Sacramento Valley and Northern Sierra regions of California. District 3 includes urban, suburban, and rural areas, including areas near Lake Tahoe where weather is a serious travel time reliability concern and there is heavy recreational traffic. Two major Interstates pass through the district: I-80, which is oriented generally east-west, and I-5, which is oriented generally north-south along the west side of the Sacramento and San Joaquin Valleys. Other major freeway facilities include US-50, which connects Sacramento and South Lake Tahoe, and SR-99, which runs north-south along the east side of the Sacramento and San Joaquin Valleys. 


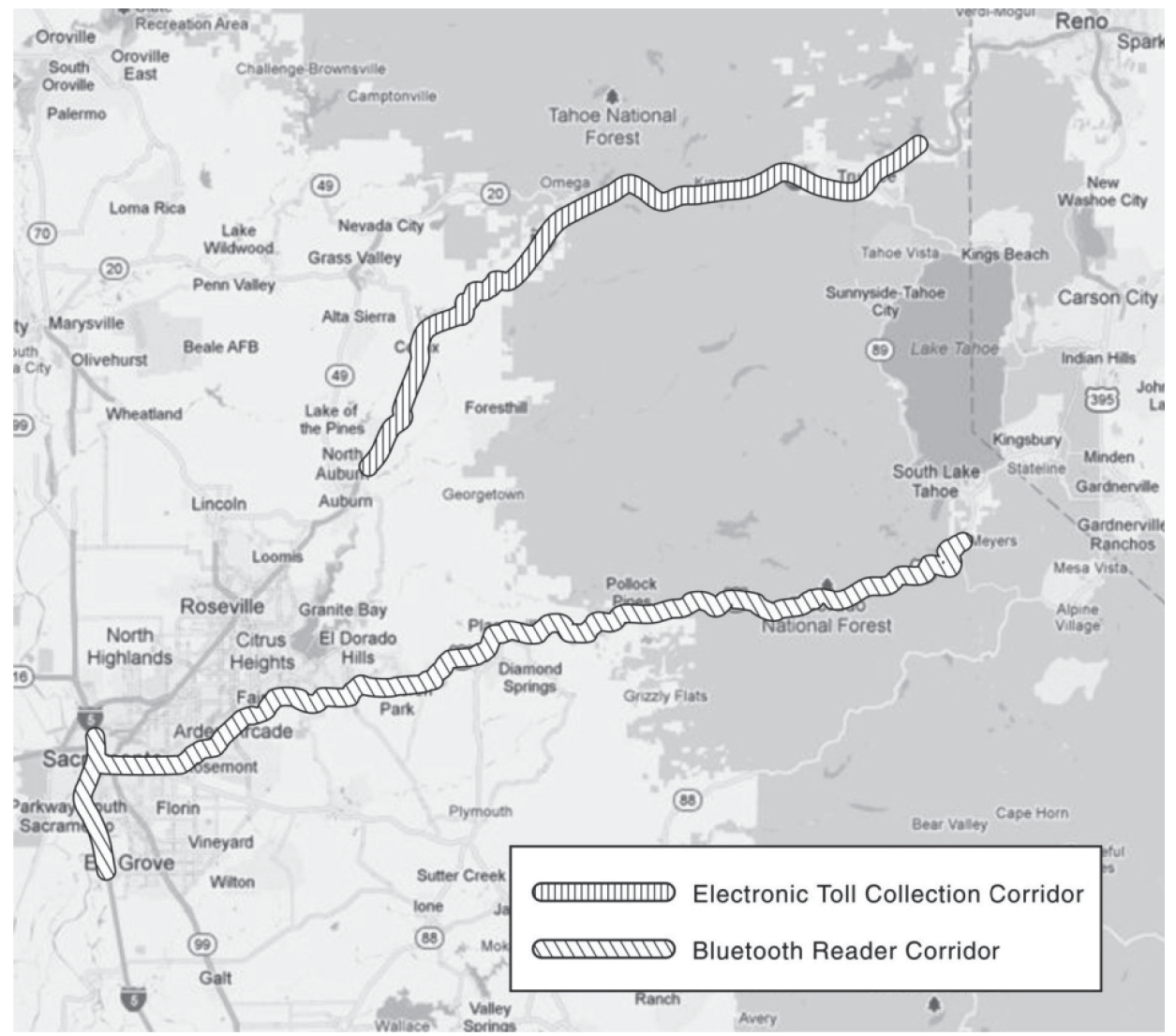

Map data $\odot 2012$ Google.

Figure 7.4. Sacramento-Lake Tahoe study area.

Caltrans District 3 only collects traffic data along freeway facilities. It operates 2,251 point detectors (either radar detectors or loop detectors) located in over 1,000 roadway locations in the district. To supplement the point detection network, the district has installed 32 nonrevenue generating ETC readers ( 25 on I-80 and seven on US-50) in rural portions of the Sierra Nevada Mountains near Lake Tahoe. Details about the locations of these ETC readers can be found in the SacramentoLake Tahoe case study in Appendix C of the Guide.

All Caltrans districts use PeMS for data and performance measure archiving and reporting, as described at the beginning of this chapter. Caltrans uses other management systems in conjunction with PeMS to operate its transportation network. The California Highway Patrol's CAD system provides an automated incident data feed that is fed into PeMS in real time. Caltrans also keeps a nonautomated database of incidents through TASAS.

\section{Automated Vehicle Identification Sensor Deployment}

The two sources of data used in support of this case study, which are based on the movement of vehicles equipped with
ETC and Bluetooth devices, are extremely new and are not currently integrated into Caltrans District 3's existing PeMS data feed. Consequently, it was necessary to incorporate these data sets into project-specific instances of PeMS for analysis as part of this project. The prerequisite data collection through monitoring system integration-related activities included ETC and Bluetooth data as described in the Sacramento-Lake Tahoe case study in Appendix C of the Guide.

This case study explored four aspects of the ETC and BTR networks used in the Sacramento-Lake Tahoe case study: (1) detailed locations and mounting structures, (2) lanes and facilities monitored, (3) percentage of traffic sampled, and (4) percentage and number of vehicles reidentified between readers. As a whole, it showed that vehicle reidentification technologies are suitable for monitoring reliability in rural environments, provided traffic volumes are high enough to generate a sufficient number of samples.

For rural areas with heavy recreational or event traffic, vehicle reidentification technologies such as ETC and Bluetooth can provide sufficient samples to calculate accurate average travel times at a fine granularity during high-traffic time periods. During these high-volume periods, vehicle reidentification technologies can be used to monitor travel 
times and reliability over long distances, such as between the rural region and nearby urban areas.

For agencies deploying vehicle reidentification monitoring networks, it is necessary to understand that the quality of the collected data is highly dependent on the decisions made regarding ETC and Bluetooth technologies during the design and installation process. For agencies leveraging existing networks, it is important to fully understand the configuration of the network before using its data.

\section{Travel Time Calculations}

Due to the significant amounts of Bluetooth-based travel time data available for analysis as part of this case study, the research team elected to focus its methodological efforts on this data set rather than on data generated by the ETC-based system.

The primary goal of BTR-based data analysis is to characterize segment travel times between BTRs based on the reidentification of observations derived from unique mobile devices. Generally, the data processing procedures associated with the calculation of BTR-to-BTR travel times can be broadly broken down into three processes, which are discussed in detail in the Sacramento-Lake Tahoe case study: (1) identification of passage times, (2) generation of passage time pairs, and (3) generation of segment travel time histograms.

The various methodological approaches and processes for estimating ground-truth segment travel times based on Bluetooth data that were evaluated for this case study are described in Appendix C of the Guide. A number of factors were identified that influence travel time reliability and guided the development of methods for processing reidentification observations and calculating segment travel times. The results show that smart filtering and processing of Bluetooth data to better identify likely segment trips increase the quality of calculated segment travel time data. This approach helps preserve the integrity of the data set by retaining as many points as possible and basing decisions to discard points on the physical characteristics of the system rather than their statistical qualities.

For either of the data collection technologies described in this report to be successful over the long term, safeguards must be put in place to ensure that the privacy of individual drivers being sampled is protected (Karr et al. 2007; National Institute of Statistical Sciences 2004). It is recommended that any probe data collection program implemented by public agencies or private sector companies on their behalf adhere to a predetermined set of privacy principles (Briggs and Walton 2000) aimed at maintaining the anonymity of specific users. In addition, any third-party data provider working for a public agency to implement a travel time data collection solution based on either of the technologies described in this case study should be required to submit an affidavit indicating that they will not use data collected on the agency's behalf in an inappropriate manner.

\section{Integration of Sources of Nonrecurring Congestion}

The purpose of this use case was to quantify the impact of adverse weather- and demand-related conditions on travel time reliability using data derived from the case study's Bluetooth- and ETC-based systems deployed in rural areas. To examine travel time reliability within the context of this use case, methods were developed to generate PDFs from large quantities of travel time data representing different operating conditions. To facilitate this analysis, travel time and flow data from ETC readers deployed on I-80 westbound and BTRs deployed on US-50 eastbound and westbound were obtained from PeMS and compared with weather data from local surface observation stations. PDFs were subsequently constructed to reflect reliability conditions along these routes during adverse weather conditions, as well as according to time of day and the day of the week. The PDFs of travel times under different operating conditions consistently demonstrated the unreliability associated with low visibility, rain, and travel under high-demand conditions.

\section{Atlanta, Georgia}

The team selected the Atlanta metropolitan region to provide an example of a mixed urban and suburban site that primarily relies on video detection cameras for real-time travel information. The main objectives of the Atlanta case study were as follows:

- Demonstrate methods to resolve integration issues by using real-time data from Atlanta's traffic management system for travel time reliability monitoring.

- Compare probe data from a third-party provider with data reported by agency-owned infrastructure.

- Fuse the regime estimation and nonrecurring congestion analysis methodologies to inform on the reliability impacts of nonrecurring congestion.

Figure 7.5 shows the study corridors investigated in the Atlanta case study.

In the Atlanta region, the Georgia DOT collects data from over 2,100 roadway sensors, which include a mix of video detection sensors and radar detectors. Both types of sensors consist of single devices that monitor traffic across multiple lanes. The majority of active sensors monitor freeway lanes, with some limited coverage of conventional highways. Sensors in the active network are manufactured by four vendors. 


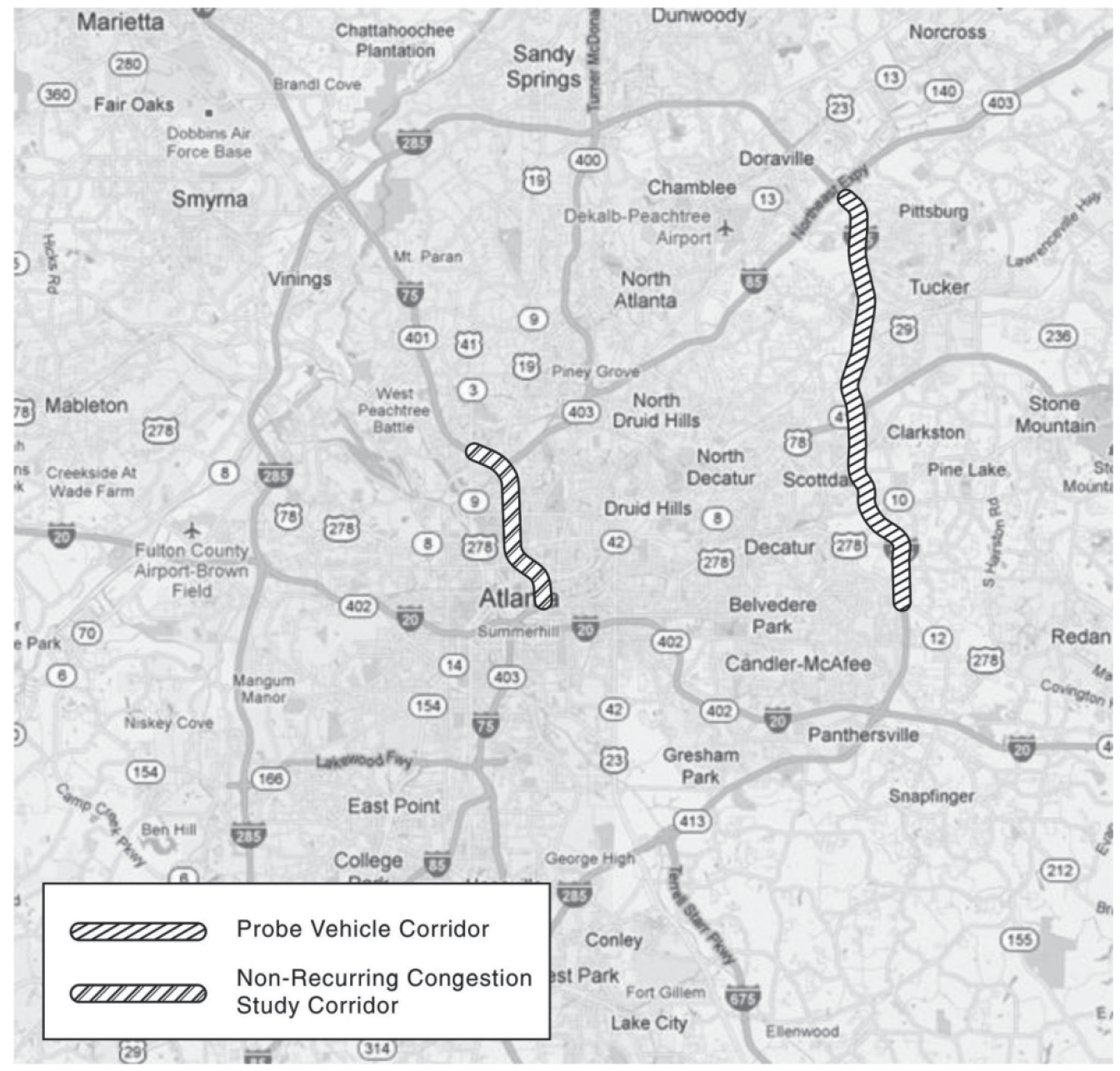

Map data @ 2012 Google.

Figure 7.5. Study area for Atlanta case study.

In general, the different types of sensors are divided up by freeway. Appendix $\mathrm{C}$ of the Guide provides more details about the sensor vendors and the location of active mainline sensors in the Georgia DOT network categorized by manufacturer. To deepen the case study analysis and explore alternative data sources, the project team acquired a parallel, probe traffic data set from NavTeq. The data set covers the entirety of the I-285 ring road and is reported by traffic message channel ID. One use case of this case study focuses on comparing probe data from a third-party provider with data reported by agency-owned infrastructure.

Georgia DOT monitors traffic in the Atlanta metropoli$\tan$ area in real time through Navigator, its advanced traffic management system (ATMS). The Transportation Management Center (TMC), located in Atlanta, is the headquarters and information clearinghouse for Navigator. Georgia DOT's traffic management system integrates with traffic sensors, closed circuit televisions, changeable message signs, ramp meters, weather stations, and highway advisory radio.
Navigator was initially deployed in metropolitan Atlanta in preparation for the 1996 Summer Olympic Games. Navigator collects lane-specific volume, speed, and occupancy data in real time and stores it in a database table for 30 minutes. Every 15 minutes, the raw Navigator traffic data samples are aggregated up to lane-specific 15-minute volumes, average speeds, and average occupancies and are archived for each detector station. The data are not filtered or quality controlled before being archived.

Aside from the traffic data, Navigator also maintains a historical $\log$ of incidents. When the TMC receives a call about an incident, TMC staff log it as a potential incident in Navigator until it can be confirmed through a camera or multiple calls. Once the incident has been confirmed, its information is updated in Navigator to include the county, type of incident, and estimated duration. This incident information is archived and stored.

For the purposes of this case study, data from the Navigator system were integrated into PeMS, a developed archived data 
user service and TTRMS. Two aspects of the Navigator framework presented major challenges for incorporating the traffic data into PeMS. First, the frequency of data reporting differs for different device types; and second, many video detection system device data samples were missing. One experiment of this case study focused on resolving these integration issues to ensure data quality.

\section{System Integration}

The first system integration experiment details how the integration issues of using ATMS data for travel time reliability monitoring were resolved. The experiment showed that unstructured configuration information obtained from an ATMS requires careful analysis when mapping to the data model of a reliability monitoring system. It also highlights the importance of understanding the reporting frequency and form of detector data for ensuring accurate aggregation and travel time calculation.

The second experiment compared the speed data reported by agency-owned infrastructure with probe data obtained from a third-party provider on the I-285 ring road. Results showed the speeds between data types to be similar during peak hours, but that the third-party provider artificially capped speeds to remain below a certain threshold. The experiment also investigated the speed error introduced by the differences in locations between the agency-owned infrastructure and the midpoint of its associated third-party link (defined by traffic message channel ID). Some difference in reported speeds was attributed to the distance of the agency-owned detection devices from the midpoint of the third-party provider link.

\section{Integration of Sources of Nonrecurring Congestion}

The use case analysis applied the methodological advancement techniques established and demonstrated in previous case studies to travel time data on a downtown Atlanta corridor to interpret the impact of the seven sources of nonrecurring congestion on travel time reliability.

Two of the main themes of the case study demonstrations are estimating the quantity and characteristics of the operating travel time regimes experienced by different facilities and calculating the impacts of the seven sources of nonrecurring congestion on travel time reliability. The methodological goal of the Atlanta case study was to fuse the previously developed regime estimation and nonrecurring congestion analysis methodologies by using multistate models to inform on the reliability impacts of nonrecurring congestion. This developed method consisted of three steps:

1. Regime characterization, to estimate the number and characteristics of each travel time regime measured along the facility;
2. Data fusion, to link travel times with the causal factor (such as weather or incident) active during their measurement; and

3. Seven sources analysis, to calculate the contributions of each source to each travel time regime.

Analysis showed that the study corridor operates with two regimes during the peak period, with the more-congested and variable regime composed of many travel times influenced by traffic incidents. This case study showed that, with proper quality control and integration measures, ATMS data can be used for travel time reliability monitoring, including the linking of travel time variability with the sources of nonrecurring congestion.

\section{New York and New Jersey}

The New York City site was chosen to provide insight into travel time monitoring in a high-density urban location. The 2010 U.S. Census revealed New York City's population to be in excess of 8 million residents, at a density near 28,000 people per square mile. Although New York City has a low rate of auto ownership compared with other U.S. cities, more than half of all commute trips are still made in singleoccupancy vehicles. In 2010, these factors contributed to New York City having the longest average commute time of any United States city, at 31.3 minutes.

The main objectives of the New York and New Jersey case study were as follows:

- Obtain time-of-day travel time distributions for a study route based on probe data.

- Identify the cause of bimodal travel time distributions on certain links.

- Explore the causal factors for travel times that vary significantly from the mean conditions.

The route analyzed in this case study begins in the Boerum Hill neighborhood of Brooklyn and ends at JFK International Airport, traversing three major freeways: the BrooklynQueens Expressway (I-278), the Queens-Midtown Expressway (I-495), and the Van Wyck Expressway (I-678). Figure 7.6 shows the study route from origin to destination.

In addition to providing a high-density urban location study site, the New York and New Jersey area was selected because it is covered by a probe data set that was provided to the research team by ALK Technologies, a third-party data provider. These data are composed of GPS traces collected from mobile devices inside individual vehicles. This detection technology provides high-density information along the vehicle's entire path, as opposed to infrastructure-based sensors, which measure traffic only at discrete points. This probe 


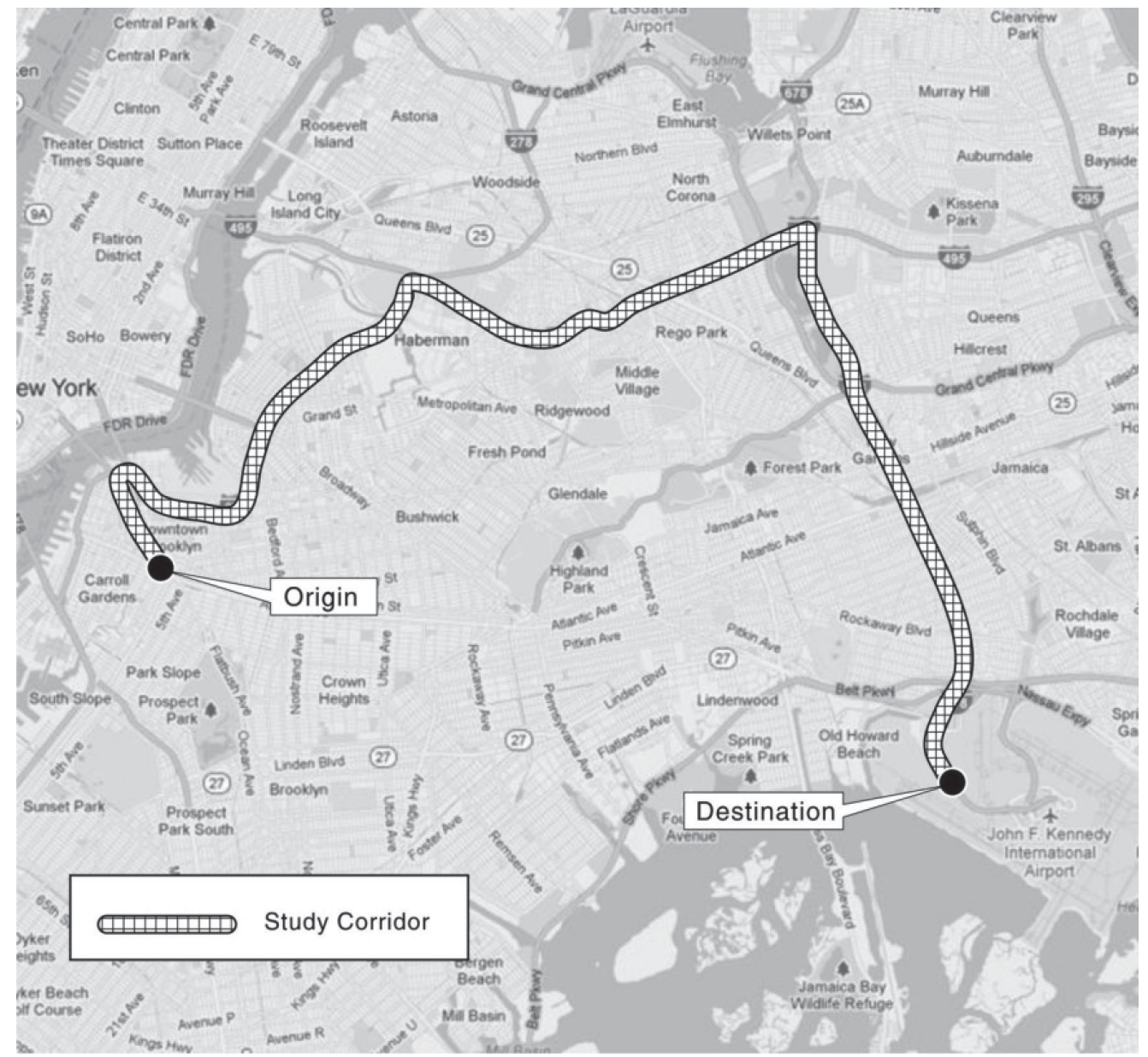

Map data $\odot 2012$ Google.

Figure 7.6. Study area for New York and New Jersey case study.

data set was analyzed at two levels: at the individual GPS trace level and through aggregation into single per link speed values. The raw GPS trace data set is the only case study data set that traces the entire path of vehicle trips. The aggregated speeds are similar in format to the traffic message channel path-based data analyzed in the Atlanta case study. The data obtained for this case study cover a rectangular region around the study route.

A static collection of historical probe data provided the basis for analysis in this case study. No real-time data were acquired or analyzed. Unlike the other case studies, this case study did not specifically deploy an archived data user service.

\section{System Integration}

The first investigation describes how to obtain route travel time distributions from the probe data set. This experiment discusses the data density along the route, presents methods for visualizing individual probe trips within the context of historical conditions, and details three techniques for constructing route-level travel time distributions. The central outcome of this experiment is the comparison of time-ofday travel time distributions along the route constructed using each of the three techniques. Methods were developed to compare a particular probe vehicle's path with the 25th percentile, 75th percentile, and median speed profile along the route by time of day. Probe traces are also visualized within historical speed bounds based on location and time of day. This methodology makes it possible to simulate the upper and lower bound of expected trip trajectories from a particular point along the route on the basis of historical travel times.

The raw ALK probe data are in the form of standard National Marine Electronics Association GPS sentences taken directly from the probe vehicles. These data are further processed by ALK into link-based speed measurements. Although each data point contains rich information, the data set is sparse in that few probe vehicles traverse the entire route from beginning to end. As a result, the route 
travel time distribution must be constructed piecemeal from individual link data. Obtaining composite travel time distributions from vehicles that only traveled on a portion of the route is a complex process, most notably because this project has shown that travel times on consecutive links have a strong linear dependence. This linear dependence must be accounted for when combining individual link travel times into an overall route travel time distribution. This is the core methodological challenge of this case study.

Three methods for computing route PDFs from the available probe data are compared:

1. Constructing the PDFs carefully from direct measurements. This method begins by determining the distribution of speed measurements on the first link of the route. This distribution is combined with the travel time distributions of longer trips that also traversed the initial link. Incrementally, longer trips are added to the distribution until a speed distribution for the entire route is obtained. Trips are grouped by time of day, at an hourly granularity when the data density allows.

2. Constructing the PDFs with a Monte Carlo simulation. This method considers consecutive pairs of links along the route (e.g., Link 1 and Link 2, Link 2 and Link 3). It constructs the full route PDF out of a large number of simulated trips. Each simulation begins with the sampling of a travel time on the first link. Next, the correlation between travel times on Link 1 and Link 2 is examined, and a travel time sample on Link 2 is taken based on this correlation and the original Link 1 sample. This procedure is repeated for Link 3, based on the previous Link 2 sample and the correlation between Links 2 and 3, and continues until a single trip along the entire route has been simulated. A large number of these simulated trips form the full travel time distribution for the route.

3. Constructing the PDFs assuming link speed independence. This method ignores the linear dependence between consecutive links and directly computes the route travel time distribution as if all link travel times were independent. It works by simply convolving the distributions of travel times on consecutive links. For example, the frequency distribution of travel times on the first link will be added to the frequency distribution of travel times on the second link, and so on until a full travel time distribution for the entire route is obtained.

This case study showed that it is possible to obtain trip reliability measures based on probe data, even when the probe data are sparse. The travel time distribution for the route is constructed from vehicles that only travel on a portion of the route and takes into account the linear dependence of speeds on consecutive links. This case study also contributes techniques for creating time-space contour plots based on probe speeds. These contour plots can be made to represent any measured speed percentile, so that contours for the worst observed conditions can be compared with typical conditions.

\section{Travel Time Distributions}

The second system integration experiment details an investigation into the cause of bimodal travel time distributions on certain links. Time of day, day of week, and nonrecurring congestion sources are explored as a source of the bimodality.

\section{Integration of Sources of Nonrecurring Congestion}

The use case analysis explores the associated factors for travel times that vary significantly from the mean conditions. This use case represents this case study's investigative analysis of the seven sources of nonrecurring congestion on travel time reliability.

\section{Berkeley Highway Laboratory}

One objective of the case studies was to test and refine the methods developed for defining and identifying segment and route regimes for freeway and arterial networks. The team's research to date has focused on identifying operational regimes based on individual vehicle travel times and determining how to relate these regimes to system-level information on average travel times. Because individual vehicle travel times on freeways were not available in the San Diego metropolitan region, data from the Berkeley Highway Laboratory (BHL) were used in this analysis. Details about the BHL applications can be found in the San Diego case study in Appendix C of the Guide. Figure 7.7 shows the BHL location.

BHL is a 2.7-mile section of I-80 in west Berkeley and Emeryville, California, that includes 14 surveillance cameras and 16 directional dual-inductive loop detector stations dedicated to monitoring traffic for research purposes. The sensors are a unique resource because they provide individual vehicle measurements. The corridor was also temporarily instrumented with two BTR stations along eastbound I-80 to record the time stamps and MAC addresses of Bluetooth devices in passing vehicles.

\section{System Integration}

Data from the BHL section of I- 80 were used in this case study. This section is valuable because it has colocated 


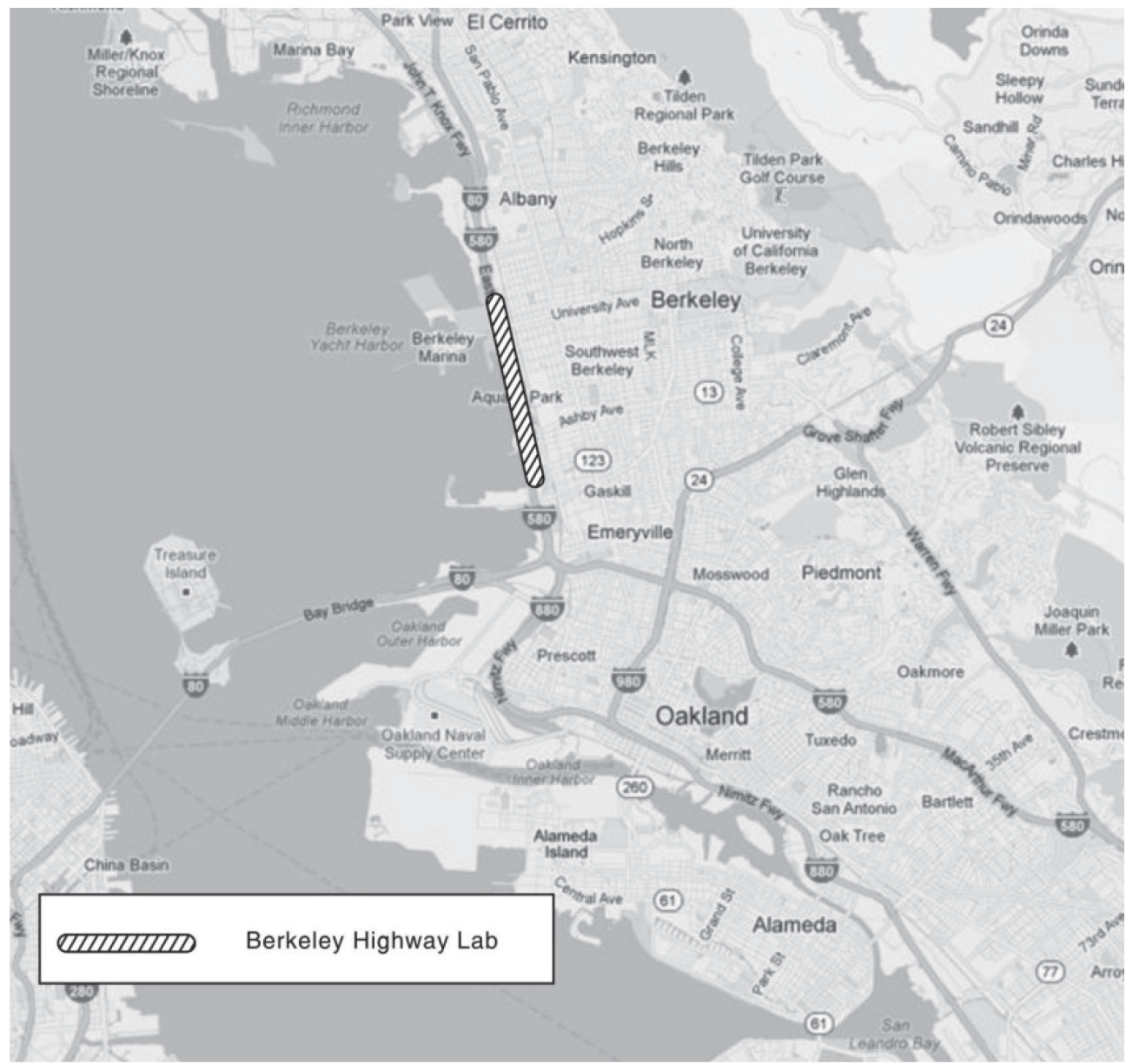

Map data () 2012 Google.

Figure 7.7. Study area for Berkeley Highway Laboratory data investigations.

dual-loop detectors and Bluetooth sensors. This data set provided an opportunity for the team to begin to assemble regimes and TT-PDFs from individual vehicle travel times. These TT-PDFs are needed to support motorist and traveler information use cases. Because the majority of the case study sites did not provide data on individual traveler variability, it was important for the research team to study the connection between individual travel time variability and aggregated travel times and whether the former can be estimated from the latter.

Analysis was performed on a day's worth of BHL data from the BTRs and loop detector stations to see if operative regimes for individual vehicle travel times can be identified from Bluetooth data. The research team concluded that this can, indeed, be done. Based on more than 5,000 observations of individual travel times, three regimes can be identified: (1) off peak or uncongested, (2) peak or congested, and (3) transition between congested and uncongested. All three can be characterized by three-parameter Gamma density functions, as demonstrated in the San Diego case study.

\section{Use Cases}

A functioning reliability monitoring system must meet the needs of many types of users because different users perceive and value deviations from the expected travel time in different ways. Each user class has different motivations for monitoring travel time reliability, and these needs have to be accounted for in the types of analysis that the system can support through the user interface. Use cases are a formal systems engineering construct that transforms user needs into short, descriptive narratives that describe a system's behavior. Use cases capture a system's behavioral requirements by detailing scenario-driven threads through the functional requirements. The collective use cases define the monitoring system by capturing its functionalities and applications for various users.

Appendix D: Use Case Analyses provides a series of use cases to help readers of the Guide determine what information a TTRMS needs to produce and what applications it needs to satisfy their specific situation. Once the appropriate users and their needs for reliability information are defined, 
the Guide reader can determine the performance measures, spatial coverage, data interface needs (i.e., weather, crashes, construction activity, special events), and archival requirements for their monitoring system.

The use cases are organized around the various stakeholders who use or manage aspects of the surface transportation system. Table 2.13 in Chapter 2 lists each use case and the type of stakeholder most interested in the use case problem. Use cases are organized into four groups: system administrators and planners, roadway network managers and users, transit systems, and freight systems. Each of these four groups is further subdivided into providers (supply) and consumers (demand). Appendix D describes several use cases for each of these user types.

Each use case in Appendix D of the Guide is described by specific parameters: a user, a statement of the question being posed, the steps involved in answering the question, a description of the inputs needed to answer the question, and the result to be obtained. Table 2.11 in Chapter 2 shows a template for the parameters provided for each use case. 


\section{CHAPTER 8}

\section{Summary and Conclusions}

Reliability Project L02 within SHRP 2 was undertaken to create methods by which travel time reliability can be monitored, assessed, and communicated to end users of the transportation system. The project developed guidance for operating agencies about how they can put reliability measurement methods into practice by enhancing existing monitoring systems or creating new ones. The project's main product is a guide that describes how to develop and use a TTRMS. A set of supporting appendices provide additional detail not found in the Guide.

Travel time reliability is the absence of variation in travel times. If a system is reliable, people can get to where they want to go, when they want to be there, all the time. If a freeway is reliable, then its travel times are the same under all conditions, all year long. It is similar to a vehicle that always starts when the key is turned on. Of course, no system or roadway is perfectly reliable; this project is intended to address this challenge.

L02 focused on how to measure reliability, how to understand what makes a system unreliable, and how to pinpoint mitigating actions. For example, a TTRMS will indicate the effects of congestion and whether operational actions mitigate the impacts. TTRMS analysis methods will let managers know if and how traffic incidents, weather, and other nonrecurring events affect reliability, and the extent of the effect. When actions are taken to mitigate unreliability, such as widening the shoulders or deploying more roadside assistance trucks, the TTRMS will show the effects of those mitigations. For a discussion about selecting mitigation strategies, see Margiotta (2010); for a guide to effective freeway performance measurement, see Margiotta et al. (2006).

Figure 8.1 shows the travel times for a specific trip in the San Diego area that would have been experienced by someone who left at exactly the same time every weekday.

It is clear from this figure that the travel times on this roadway segment are not always the same; the system is unreliable.
Not only does the travel time vary, but the spread in the times varies. At about midnight, the minimum and maximum are only 5 minutes different ( 50 minutes versus 55 minutes), but they differ by 110 minutes during the weekday afternoon peak (50 minutes versus 160 minutes). It is also clear that nonrecurring events have an impact. A good example is adverse weather, especially during the peak period. Traffic incidents also have an effect on travel time reliability, as do special events and unusually high demand. Even when no nonrecurring event is happening (the "no events" data points), the travel times can vary widely. The TTRMS helps indicate when, why, and by how much travel time will vary.

A TTRMS is designed to be an add-on to an existing traffic management system; its structure is shown in Figure 8.2. Inside the dotted line box are the three major modules of the TTRMS: a data manager, a computational engine, and a report generator. The data manager assembles incoming information from traffic sensors and other systems, such as weather data feeds and incident reporting systems, and places them in a database that is ready for analysis as "cleaned data." The computational engine works off the cleaned data to prepare pictures of the system's reliability: when it is reliable, when it is not, to what extent, under what conditions, and so forth. In the figure this is illustrated by "regime TT-PDFs." The report generator responds to inquiries from users-system managers or travelers-and uses the computation engine to analyze the data and provide information that can then be presented to the inquirer or decision maker.

Each of these modules is discussed and described in the Guide. In addition, case studies and use cases illustrate how these modules work together to produce answers to questions that managers would likely pose. The appendices provide further details about how each of the modules should work together and separately.

Figure 8.3 shows an example of what to expect as a report from the TTRMS. The plot shows the distribution of travel 


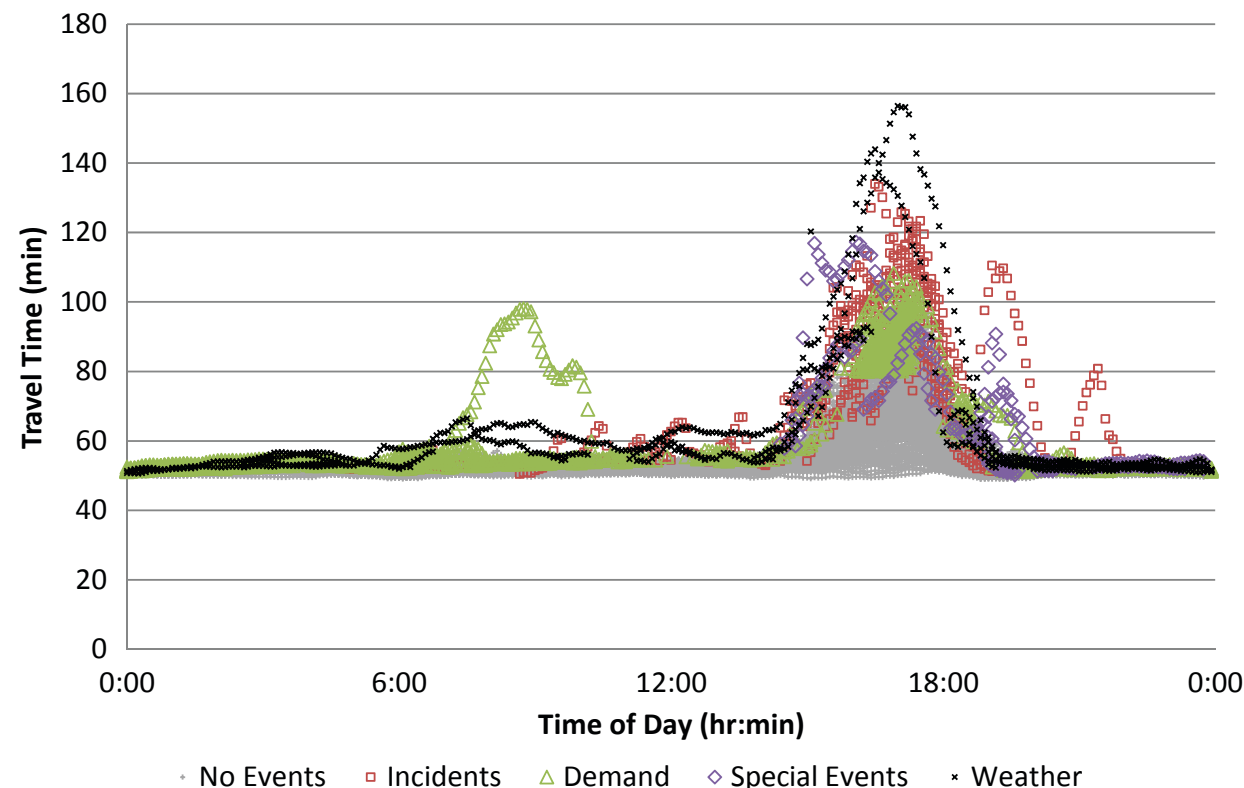

Figure 8.1. Variation in travel times by time of day across a year. Color figure available online at www.trb.org/Main/Blurbs/168765.aspx.

times on I-8 westbound in San Diego across a 3-month period under various operating conditions. The distributions are shown in a cumulative fashion; the location of each line shows how many travel times are that value or shorter. For example, when traffic incidents occur during heavy (recurrent) congestion, one-half (50\%) of the travel rates (in seconds per mile) are up to $70 \mathrm{~s} / \mathrm{mi}$. That is, $50 \%$ of the travel rates are this long or smaller. The 90th percentile travel rate is $110 \mathrm{~s} / \mathrm{mi}$. Or put another way, nine out of every 10 vehicles is traveling at that rate or faster.

The value in the results comes from comparing one distribution with another. For example, analysts can compare the distribution for high recurrent congestion and traffic incidents with high recurrent congestion without incidents. Without incidents, $50 \%$ of the vehicles are traveling at $58 \mathrm{~s} / \mathrm{mi}$ instead of $70 \mathrm{~s} / \mathrm{mi}$ - considerably faster. And at the 90th percentile, the difference is even more dramatic: $65 \mathrm{~s} / \mathrm{mi}$ versus $110 \mathrm{~s} / \mathrm{mi}$.

Not only does the figure indicate that the difference between the two conditions is dramatic, but it also suggests that taking actions to mitigate these impacts would produce significant benefits in terms of improving reliability. The mitigating actions would be intended to cause the travel times (or travel rates) during incidents to get much closer to those when there are no incidents. Moreover, after the mitigating actions were taken, the TTRMS would be able to show how reliability improved.

In conclusion, a TTRMS will help an agency understand the reliability performance of their systems and monitor how

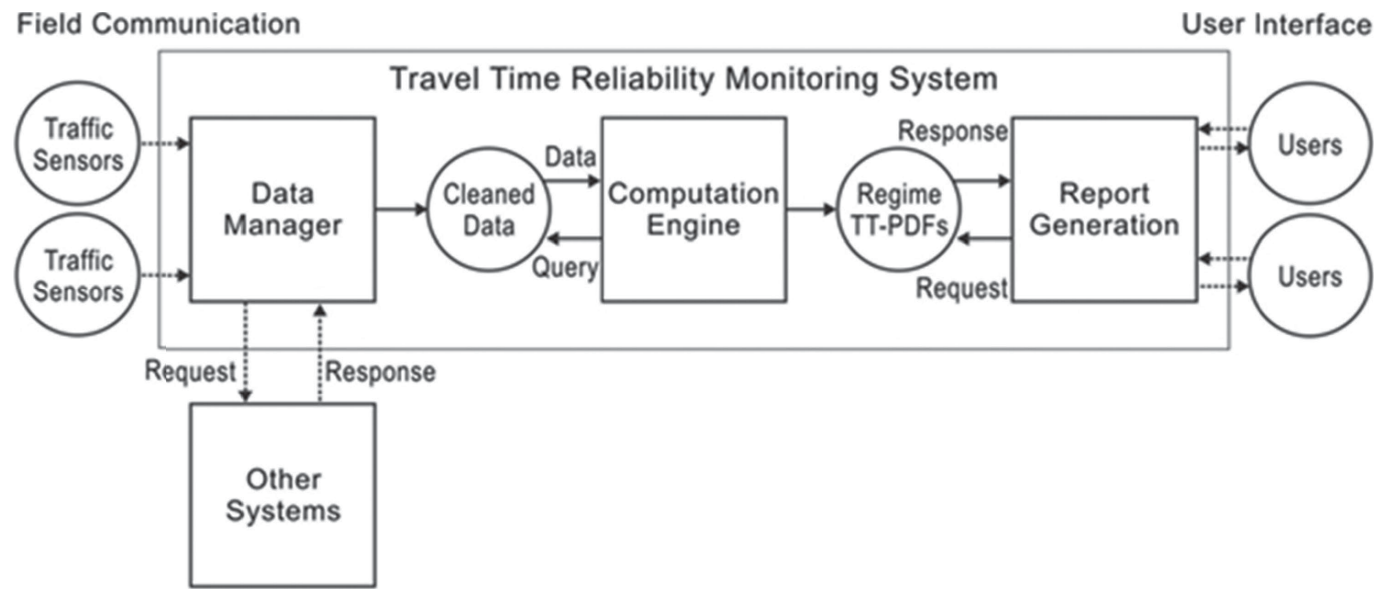

Figure 8.2. Reliability monitoring system overview, with boxes for modules and circles for inputs and outputs. 


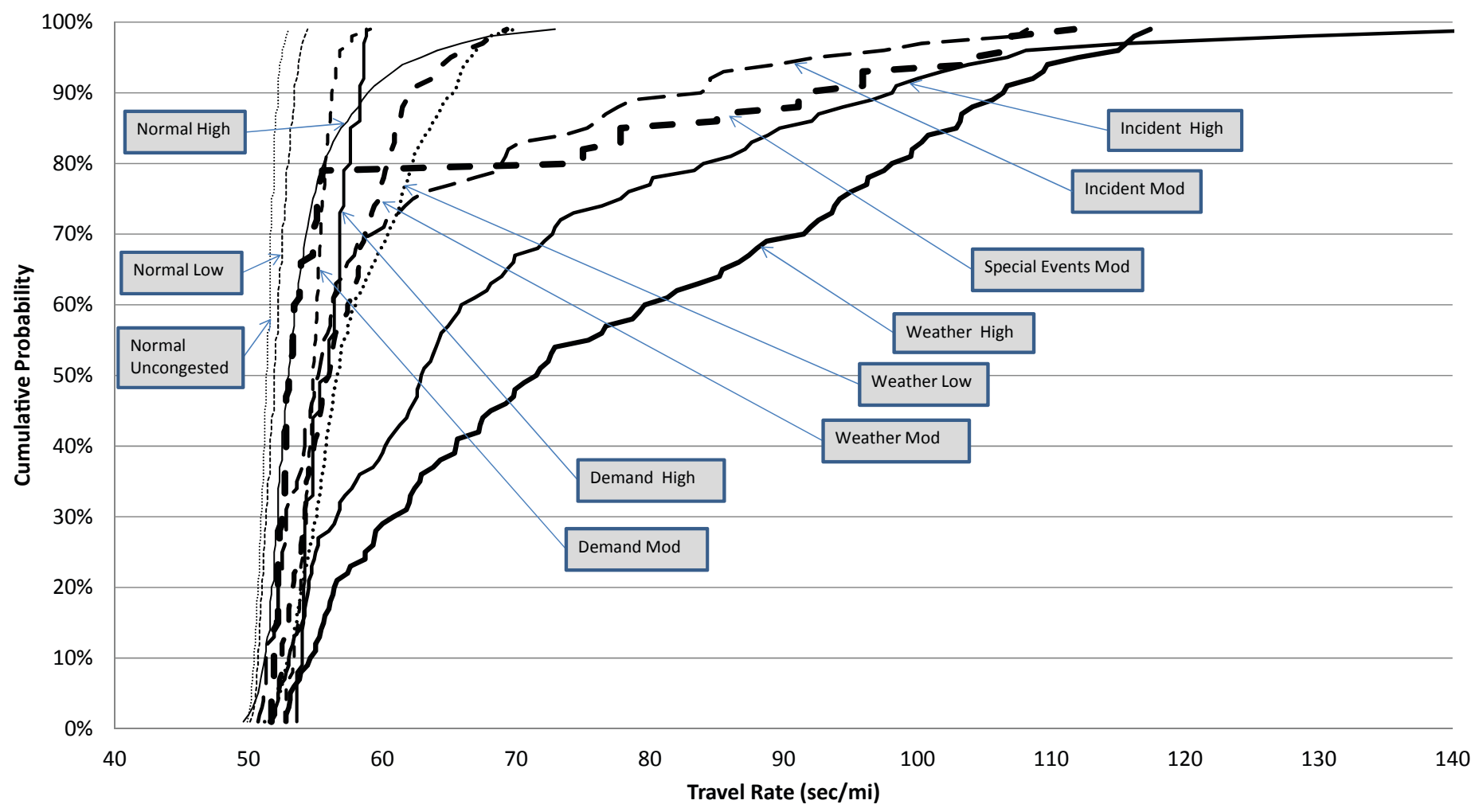

Figure 8.3. Effect on travel rates of congestion and nonrecurring incidents.

reliability improves over time by answering the following questions:

- What is the distribution of travel times in the system?

- How is the distribution affected by recurrent congestion and nonrecurring events?
- How are freeways and arterials performing relative to performance targets set by the agency?

- Are capacity investments and other improvements really necessary given the current distribution of travel times?

- Are operational improvement actions and capacity investments improving the travel times and their reliability? 


\section{References}

Arezoumandi, M., and G. H. Bham. 2011. Use of Median Travel Time As Measure of Central Tendency. Integrated Transportation and Development for a Better Tomorrow. Proc., 1st Congress of the Transportation and Development Institute of ASCE, pp. 59-68.

Barkley, T., R. Hranac, and K. Petty. 2012. Relating Travel Time Reliability and Nonrecurrent Congestion with Multistate Models. In Transportation Research Record: Journal of the Transportation Research Board, No. 2278, Transportation Research Board of the National Academies, Washington, D.C., pp. 13-20.

Bates, J., J. Polak, P. Jones, and A. Cook. 2001. The Valuation of Reliability for Personal Travel. Transportation Research Part E, Vol. 37, pp. 191-229.

Batley, R., and J. N. Ibanez. 2009. Randomness in Preferences, Outcomes and Tastes: An Application to Journey Time Risk. Proc., International Choice Modelling Conference, Harrogate, United Kingdom.

Berkow, M., M. Wolfe, C. Monsere, and R. Bertini. 2008. Using Signal System Data and Buses As Probe Vehicles to Define the Congested Regime on Arterials. Presented at 87th Annual Meeting of the Transportation Research Board, Washington, D.C.

Bertini, R. L., and A. El-Geneidy. 2003. Generating Transit Performance Measures with Archived Data. In Transportation Research Record: Journal of the Transportation Research Board, No. 1841, Transportation Research Board of the National Academies, Washington, D.C., pp. 109-119.

Bertini, R. L., and A. El-Geneidy. 2004. Modeling Transit Trip Time Using Archived Bus Dispatch System Data. Journal of Transportation Engineering, Vol. 130, No. 1, pp. 56-67.

Bertini, R. L., G. J. Cameron, and J. Peters. 2005. Evaluating Traffic Signal Improvements Using Archived Transit AVL Data. ITE Journal, Vol. 75, No. 2, pp. 69-75.

Bo, L., and M. Hiroaki. 2008. Discussion of Traffic Signal Effect on Calculating Link Travel Time and Field Test Evaluation. Proc., 8th International Conference on Intelligent Transport System Telecommunications, pp. 112-115.

Bowman, L. A., and M. A. Turnquist. 1981. Service Frequency, Schedule Reliability and Passenger Wait Times at Transit Stops. Transportation Research Part A, Vol. 15A, No. 6, pp. 465-471.

Briggs, V., and C. M. Walton. 2000. The Implications of Privacy Issues for Intelligent Transportation Systems (ITS) Data. Research report 472840-00075. Center for Transportation Research, Texas A\&M Transportation Institute, College Station.

Bureau of Transportation Statistics. 2010.
Byon, Y.-J., A. Shalaby, and B. Abdulhai. 2006. Travel Time Collection and Traffic Monitoring via GPS Technologies. Proc., IEEE Intelligent Transportation Systems Conference, Toronto, Ontario, Canada.

Cambridge Systematics, and Texas Transportation Institute. 2005. Traffic Congestion and Reliability: Trends and Advanced Strategies for Congestion Mitigation. Office of Operations, Federal Highway Administration, Washington, D.C. http://ops.fhwa.dot.gov/ congestion_report/.

Cambridge Systematics, Texas Transportation Institute, University of Washington, and Dowling Associates. 2003. Providing a Highway System with Reliable Travel Times. NCHRP Project 20-58. Future Strategic Highway Research Program, Transportation Research Board of the National Academies, Washington, D.C.

Carrion, C., and D. Levinson. 2010. Value of Reliability: High-Occupancy Toll Lanes, General Purpose Lanes, and Arterials. Proc., 4th International Symposium on Transportation Network Reliability, Minneapolis, Minn.

Carrion, C., and D. Levinson. 2011. A Model of Bridge Choice Across the Mississippi River in Minneapolis, Presented at 90th Annual Meeting of the Transportation Research Board, Washington, D.C.

Cetin, M., G. F. List, and Y. Zhou. 2005. Factors Affecting Minimum Number of Probes Required for Reliable Estimation of Travel Time. In Transportation Research Record: Journal of the Transportation Research Board, No. 1917, Transportation Research Board of the National Academies, Washington, D.C., pp. 37-44.

Chakroborty, P., and S. Kikuchi. 2004. Using Bus Travel Time Data to Estimate Travel Times on Urban Corridors. In Transportation Research Record: Journal of the Transportation Research Board, No. 1870, Transportation Research Board of the National Academies, Washington, D.C., pp. 8-25.

Chang, X., and P. Stopher. 1981. Defining the Perceived Attributes of Travel Modes for Urban Work Trips. Transportation Planning and Technology, Vol. 7, pp. 55-65.

Chen, C., J. Kwon, A. Skabardonis, and P. Varaiya. 2003. Detecting Errors and Imputing Missing Data for Single Loop Surveillance Systems. In Transportation Research Record: Journal of the Transportation Research Board, No. 1855, Transportation Research Board of the National Academies, Washington, D.C., pp. 160-167.

De Fabritiis, C., R. Ragona, and G. Valenti. 2008. Traffic Estimation and Prediction Based on Real Time Floating Car Data. Proc., IEEE Conference on Intelligent Transportation Systems, Beijing, pp. 197-203.

Demers, A., G. F. List, W. A. Wallace, E. E. Lee, and J. Wojtowicz. 2006a. Probes as Path Seekers: A New Paradigm. In Transportation Research 
Record: Journal of the Transportation Research Board, No. 1944, Transportation Research Board of the National Academies, Washington, D.C., pp. 107-114.

Demers, A., G. F. List, W. Wojtowicz, A. Kornhauser, W. A. Wallace, E. E. Lee, and P. Salasznyk. 2006b. Experimenting with Real-Time ATIS: Stepping Forward from ADVANCE. Proc., 9th International Conference on Applications of Advanced Technology in Transportation, Chicago, Ill.

Dhaene, J., M. Denuit, M. J. Goovaerts, R. Kaas, and D. Vyncke. 2002a. The Concept of Comonotonicity in Actuarial Science and Finance: Theory. Insurance: Mathematics and Economics, Vol. 31, No. 1, pp. 3-33.

Dhaene, J., M. Denuit, M. J. Goovaerts, R. Kaas, and D. Vyncke. 2002b. The Concept of Comonotonicity in Actuarial Science and Finance: Applications. Insurance: Mathematics and Economics, Vol. 31, No. 2, pp. 133-161.

Dion, F., and H. Rakha. 2006. Estimating Dynamic Roadway Travel Times Using Automatic Vehicle Identification Data for Low Sampling Rates. Transportation Research Part B, Vol. 40, No. 9, pp. 745-766.

Dong, J., and H. S. Mahmassani. 2011. Stochastic Modeling of Traffic Flow Breakdown Phenomenon: Application to Predicting Travel Time Reliability. Proc., 14th International IEEE Conference on Intelligent Transportation Systems, Washington, D.C., pp. 2112-2117.

Ebeling, C. E. 1997. Introduction to Reliability and Maintainability Engineering. McGraw-Hill.

Elefteriadou, L., and X. Ciu. 2007. A Framework for Defining and Estimating Travel Time Reliability. Presented at 86th Annual Meeting of the Transportation Research Board, Washington, D.C.

Enam, E., and H. Al-Deek. 2006. Using Real-Life Dual-Loop Detector Data to Develop New Methodology for Estimating Freeway Travel Time Reliability. In Transportation Research Record: Journal of the Transportation Research Board, No. 1959, Transportation Research Board of the National Academies, Washington, D.C., pp. 140-150.

Ernst, J. M., C. M. Day, and J. V. Krogmeier. 2012. Probe Data Sampling Guidelines for Characterizing Arterial Travel Time. In Transportation Research Record: Journal of the Transportation Research Board, No. 2315, Transportation Research Board of the National Academies, Washington, D.C., pp. 173-181.

Federal Highway Administration. 2008. Travel Time Reliability: Making It There On Time, All the Time. ops.fhwa.dot.gov/publications/ tt_reliability/TTR_Report.htm\#WhatisTTR.

Feng, Y., G. A. Davis, and J. Hourdos. 2011. Arterial Travel Time Characterization and Real-Time Traffic Condition Identification Using GPS-Equipped Probe Vehicles. Presented at 90th Annual Meeting of the Transportation Research Board, Washington, D.C.

Feng, Y., J. Hourdos, and G. A. Davis. 2012. Bayesian Model for Constructing Arterial Travel Time Distributions Using GPS Probe Vehicles. Presented at 91st Annual Meeting of the Transportation Research Board, Washington, D.C.

Fontaine, M. D., and B. L. Smith. 2005. Probe-Based Traffic Monitoring Systems with Wireless Location Technology. In Transportation Research Record: Journal of the Transportation Research Board, No. 1925, Transportation Research Board of the National Academies, Washington, D.C., pp. 3-11.

Fosgerau, M., and L. Engelson. 2011. The Value of Travel Time Variance. Transportation Research Part B, Vol. 45, pp. 1-8.

Fosgerau, M., and A. Karlstrom. 2010. The Value of Reliability. Transportation Research Part B, Vol. 44, pp. 38-49.

Fraley, C., and A. E. Raftery. 2009. MCLUST Version 3 for R: Normal Mixture Modeling and Model-Based Clustering. Technical Report
No. 504. Department of Statistics, University of Washington. http:// www.stat.washington.edu/fraley/mclust/tr504.pdf.

Gaver, D. 1968. Headstart Strategies for Combating Congestion. Transportation Science, Vol. 2, pp. 172-181.

Guo, F., Q. Li, and H. Rakha. 2012. Multistate Travel Time Reliability Models with Skewed Component Distributions. In Transportation Research Record: Journal of the Transportation Research Board, No. 2315, Washington, D.C., pp. 47-53.

Guo, F., H. Rakha, and S. Park. 2010. Multistate Model for Travel Time Reliability. In Transportation Research Record: Journal of the Transportation Research Board, No. 2188, Transportation Research Board of the National Academies, Washington, D.C., pp. 46-54.

Haas, R., M. Carter, E. Perry, J. Trombly, E. Bedsole, and R. Margiotta. 2009. iFlorida Model Deployment Evaluation Report. Report No. FHWA-HOP-08-050. Federal Highway Administration, U.S. Department of Transportation, Washington, D.C.

Haghani, A., M. Hamedi, K. F. Sadabadi, S. Young, and P. Tarnoff. 2010. Data Collection of Freeway Travel Time Ground Truth with Bluetooth Sensors. In Transportation Research Record: Journal of the Transportation Research Board, No. 2160, Transportation Research Board of the National Academies, Washington, D.C., pp. 60-68.

Hainen, A. M., S. M. Remias, T. M. Brennan, C. M. Day, and D. M. Bullock. 2012. Probe Vehicle Data for Characterizing Road Conditions Associated with Inclement Weather to Improve Road Maintenance Decisions. Proc., IEEE Intelligent Vehicles Symposium, Alcalá de Henares, Spain, pp. 730-735.

Hall, R., and V. Nilesh. 2000. Buses As a Traffic Probe Demonstration Project. In Transportation Research Record: Journal of the Transportation Research Board, No. 1731, Transportation Research Board of the National Academies, Washington, D.C., pp. 96-103.

Hansson, S. O. 2005. Decision Theory: A Brief Introduction. Royal Institute of Technology, Stockholm, Sweden.

Haseman, R. J., J. S. Wasson, and D. M. Bullock. 2010. Real-Time Measurement of Travel Time Delay in Work Zones and Evaluation Metrics Using Bluetooth Probe Tracking. In Transportation Research Record: Journal of the Transportation Research Board, No. 2169, Transportation Research Board of the National Academies, Washington, D.C., pp. 40-53.

Hellinga, B. R., and L. Fu. 2002. Reducing Bias in Probe-Based Arterial Link Travel Time Estimates. Transportation Research Part C, Vol. 10, No. 4, pp. 257-273.

Hesham, R., E.-S. Ihab, A. Mazen, and F. Dion. 2006. Estimating Path Travel-Time Reliability. Proc., Intelligent Transportation Systems Conference, Toronto, Ontario, Canada, pp. 236-241.

Higatani, A., T. Kitazawa, J. Tanabe, Y. Suga, R. Sekhar, and Y. Asakura. 2009. Empirical Analysis of Travel Time Reliability Measures in Hanshin Expressway Network. Journal of Intelligent Transportation Systems: Technology, Planning, and Operations, Vol. 13, No. 1, pp. 28-38.

Hoeitner, A., R. Herringy, A. Bayenz, Y. Hanx, F. Moutardex, and A. de La Fortellex. 2012. Large-Scale Estimation of Arterial Traffic and Structural Analysis of Traffic Patterns Using Probe Vehicles. Presented at 91st Annual Meeting of the Transportation Research Board, Washington, D.C.

Houston TranStar. 2013. http://traffic.houstontranstar.org/speedcharts/. Accessed June 22, 2009.

Hu, Jia. 2011. Estimation of Segment Travel Rates. Master's thesis. Department of Civil, Construction, and Environmental Engineering, North Carolina State University, Raleigh, N.C.

Ishak, S., S. Kondagari, and C. Alecsandru. 2007. Probabilistic DataDriven Approach for Real-Time Screening of Freeway Traffic Data. 
In Transportation Research Record: Journal of the Transportation Research Board, No. 2012, Transportation Research Board of the National Academies, Washington, D.C., pp. 94-104.

Jackson, W., and J. Jucker. 1982. An Empirical Study of Travel Time Variability and Travel Choice Behavior. Transportation Science, Vol. 16, pp. 460-475.

Jenelius, E., L. G. Mattsson, and D. Levinson. 2011. Traveler Delay Costs and Value of Time with Trip Chains, Flexible Activity Scheduling and Information. Transportation Research Part B, Vol. 45, pp. 789-807.

Jintanakul, K., L. Chu, and R. Jayakrishnan. 2009. Bayesian Mixture Model for Estimating Freeway Travel Time Distributions from Small Probe Samples from Multiple Days. In Transportation Research Record: Journal of the Transportation Research Board, No. 2136, Transportation Research Board of the National Academies, Washington, D.C., pp. 37-44.

Kaparias, I., M. G. H. Bell, and H. Belzner. 2008. A New Measure of Travel Time Reliability for In-Vehicle Navigation Systems. Journal of Intelligent Transportation Systems: Technology, Planning, and Operations, Vol. 12, No. 4, pp. 202-211.

Karr, A. F. 1993. Probability. Springer-Verlag, New York.

Karr, A. F., W. J. Fulp, X. Lin, J. P. Reiter, F. Vera, and S. S. Young. 2007. Secure, Privacy-Preserving Analysis of Distributed Databases. Technometrics, Vol. 49, No. 3, pp. 335-345.

Karr, A. F., A. P. Sanil, and D. L. Banks. 2006. Data Quality: A Statistical Perspective. Statistical Methodology, Vol. 3, No. 2, pp. 137-173.

Khattak, A. J., Y. Fan, and C. Teague. 2008. Economic Impact of Traffic Incidents on Businesses. In Transportation Research Record: Journal of the Transportation Research Board, No. 2067, Transportation Research Board of the National Academies, Washington, D.C., pp. 93-100.

Khattak, A. J., L. S. Joseph, and F. S. Koppelman. 1994. Effect of Traffic Information on Commuters' Propensity to Change Route and Departure Time. Journal of Advanced Transportation, Vol. 29, No. 2, pp. 193-212.

Khattak, A., Y. Youngbin, and S. Linda. 2003. Willingness to Pay for Travel Information. Transportation Research Part C, Vol. 11, No. 2, pp. 137-159.

Kwon, J., B. Coifman, and P. Bickel. 2000. Day-to-Day Travel-Time Trends and Travel-Time Prediction from Loop-Detector Data. In Transportation Research Record: Journal of the Transportation Research Board, No. 1717, TRB, National Research Council, Washington, D.C., pp. 120-129.

Kwon, J., K. Petty, and P. Varaiya. 2007. Probe Vehicle Runs or Loop Detectors? Effect of Detector Spacing and Sample Size on Accuracy of Freeway Congestion Monitoring. In Transportation Research Record: Journal of the Transportation Research Board, No. 2012, Transportation Research Board of the National Academies, Washington, D.C., pp. 57-63.

Lam, T., and K. Small. 2001. The value of time and reliability: measurement from a value pricing experiment. Transportation Research, Part E, Vol. 37, pp. 231-251.

Leng, J., Y. Zhang, and Y. Leng. 2009. Assessment Methodology for Road Network Travel Time Reliability Under Ice and Snowfall Conditions. Proc., 9th International Conference of Chinese Transportation Professionals, Harbin, China, Vol. 358, pp. 1124-1130.

Li, R., G. Rose, and M. Sarvi. 2006. Using Automatic Vehicle Identification Data to Gain Insight into Travel Time Variability and Its Causes. In Transportation Research Record: Journal of the Transportation Research Board, No. 1945, Transportation Research Board of the National Academies, Washington, D.C., pp. 24-32.
Lin, W., A. Kulkarni, and P. Mirchandani. 2003. Arterial Travel Time Estimation for Advanced Traveler Information Systems. Presented at 82 nd Annual Meeting of the Transportation Research Board, Washington, D.C.

List, G. F., and A. Demers. 2006. Estimating Highway Facility Performance from AVL Data. Proc., 5th International Symposium on Highway Capacity and Quality of Service, Osaka, Japan, pp. 319-328.

List, G. F., A. Demers, W. A. Wallace, E. E. Lee, and J. Wojtowicz. 2005a. ATIS via Wireless Probes: Smart Vehicles for Smart Travelers. INFORMS Annual Meeting, San Francisco, Calif.

List, G. F., W. A. Wallace, A. Demers, P. Salasznyk, E. E. Lee, and J. Wojtowicz. 2005b. Field Experiment with a Wireless GPS-Based ATIS System. Proc., 12th World Congress on ITS, San Francisco, Calif.

Liu, H., L. Sang, K. Zhang, and Y. Yuan. 2010. An Evaluation of Obtaining Travel Time Observations via New Technology: A Case Study in Tianjin. Proc., 10th International Conference of Chinese Transportation Professionals, Beijing, Vol. 382, pp. 2380-2388.

Liu, K., T. Yamamoto, and T. Morikawa. 2007. Feasibilities and Challenges of Probe Technologies for Real-Time Traffic Data Collection. Proc., 7th International Conference of Chinese Transportation Professionals Congress, Shanghai, China, pp. 328-340.

Lomax, T., D. Schrank, S. Turner, and R. Margiotta. 2003. Selecting Travel Reliability Measures. http://ttitamuedu/documents/474360-1pdf.

Lyman, K., and R. L. Bertini. 2008. Using Travel Time Reliability Measures to Improve Regional Transportation Planning and Operations. In Transportation Research Record: Journal of the Transportation Research Board, No. 2046, Transportation Research Board of the National Academies, Washington, D.C., pp. 1-10.

Ma, X., and H. N. Koutsopoulos. 2010. Estimation of the Automatic Vehicle Identification-Based Spatial Travel Time Information Collected in Stockholm. IET Intelligent Transport Systems, Vol. 4, No. 4, pp. 298-306.

Ma, Y., M. Chowdhury, A. Sadek, and M. Jeihani. 2009. Real-Time Highway Traffic Condition Assessment Framework Using Vehicle Infrastructure Integration (VII) with Artificial Intelligence (AI). IEEE Transactions on Intelligent Transportation Systems, Vol. 10, No. 4, pp. 615-627.

Maginn, J. L., D. L. Tuttle, D. W. McLeavey, and J. E. Pinto. 2007. Managing Investment Portfolios: A Dynamic Process, 3rd ed. CFA Institute Investment Series, John Wiley \& Sons.

Margiotta, R. 2010. Analytical Procedures for Determining the Impacts of Reliability Mitigation Strategies. Report S2-L03-RR-1. Second Strategic Highway Research Program, Transportation Research Board of the National Academies, Washington, D.C.

Margiotta, R., T. Lomax, M. Hallenbeck, S. Turner, A. Skabardonis, C. Ferrell, and B. Eisele. 2006. NCHRP Project 3-68: Guide to Effective Freeway Performance Measurement. Final report. National Cooperative Highway Research Program, Transportation Research Board, Washington, D.C.

Martchouk, M., F. Mannering, and D. Bullock. 2011. Analysis of Freeway Travel Time Variability Using Bluetooth Detection. Journal of Transportation Engineering, Vol. 137, No. 10, pp. 697-704.

Morris, A. G., A. L. Kornhauser, and M. J. Kay. 1998. Urban Freight Mobility: Collection of Data on Time, Costs, and Barriers Related to Moving Product into the Central Business District. In Transportation Research Record 1613, TRB, National Research Council, Washington, D.C., pp. 27-32.

National Institute of Statistical Sciences. 2004. Data Confidentiality, Data Quality and Data Integration for Federal Databases: Foundations to Software Prototypes. www.niss.org/dgii. 
Noland, R., and K. Small. 1995. Travel-Time Uncertainty, Departure Time Choice, and the Cost of Morning Commutes. In Transportation Research Record 1493, TRB, National Research Council, Washington, D.C., pp. 150-158.

Pan, C., J. Lu, D. Wang, and B. Ran. 2007. Data Collection Based on Global Positioning System for Travel Time and Delay for Arterial Roadway Network. In Transportation Research Record: Journal of the Transportation Research Board, No. 2024, Transportation Research Board of the National Academies, Washington, D.C., pp. 35-43.

Park, M., S. Kim, C. Park, and K. Chon. 2007. Transportation Network Design Considering Travel Time Reliability. Proc., 10th International IEEE Conference on Intelligent Transportation Systems, Bellevue, Wash., pp. 496-502.

Prashker, J. 1979. Direct Analysis of the Perceived Importance of Attributes of Reliability of Travel Modes in Urban Travel. Transportation, Vol. 8, pp. 329-346.

$\mathrm{Pu}$, W. 2011. Analytic Relationships Between Travel Time Reliability Measures. In Transportation Research Record: Journal of the Transportation Research Board, No. 2254, Transportation Research Board of the National Academies, Washington, D.C., pp. 122-130.

Quiroga, C. A., and D. Bullock. 1998. Travel Time Studies with Global Positioning and Geographic Information Systems: An Integrated Methodology. Transportation Research Part C, Vol. 6, No. 1-2, pp. 101-127.

Ramezani, M., and N. Geroliminis. 2012. Estimation of Arterial Route Travel Time Distribution with Markov Chains. Presented at 91st Annual Meeting of the Transportation Research Board, Washington, D.C.

Reliability Focus Area Overview: Providing Reliable Travel Times on the Highway System. 2009. Second Strategic Highway Research Program, Transportation Research Board of the National Academies, Washington, D.C. http://onlinepubs.trb.org/onlinepubs/shrp2/ RRPJune2009.pdf. Accessed Sept. 2, 2012.

Rice, J., and E. van Zwet. 2004. A Simple and Effective Method for Predicting Travel Times on Freeways. IEEE Transactions on Intelligent Transportation Systems, Vol. 5, No. 3, pp. 200-207.

Rosenblatt, M. 1956. Remarks on Some Nonparametric Estimates of a Density Function. Annals of Mathematical Statistics, Vol. 27, pp. 832-837.

Shen, L., and M. Hadi. 2011. Practical Approach for Travel Time Estimation from Point Traffic Detector Data. Journal of Advanced Transportation. DOI: 10.1002/atr.180.

Silverman, B. W. 1986. Density Estimation for Statistics and Data Analysis. Chapman \& Hall, London.

Small, K. 1982. The Scheduling of Consumer Activities: Work Trips. American Economic Review, Vol. 72, pp. 467-479.

Small, K., and E. Verhoef. 2007. The Economics of Urban Transportation. Routledge.

Small, K., C. Winston, and J. Yan. 2005. Uncovering the Distribution of Motorists' Preferences for Travel Time and Reliability. Econometrica, Vol. 73, pp. 1367-1382.

Small, K. A., R. Noland, X. Chu, and D. Lewis. 1999. NCHRP Report 431: Valuation of Travel-Time Savings and Predictability in Congested Conditions for Highway User-Cost Estimation. TRB, National Research Council, Washington, D.C.

Soriguera, F. 2011. Highway Travel Time Accurate Measurement and Short-Term Prediction Using Multiple Data Sources. Transportmetrica, Vol. 7, No. 1, pp. 85-109.

Soriguera, F., and L. Thorson. 2007. Travel Time Measurement Using Toll Infrastructure. In Transportation Research Record: Journal of the
Transportation Research Board, No. 2027, Transportation Research Board of the National Academies, Washington, D.C., pp. 99-107.

Sun, H., and Z. Gao. 2012. Stochastic Traffic Equilibrium Based on Travel Time Robust Reliability. Journal of Transportation Systems Engineering and Information Technology, Vol. 12, No. 2, pp. 76-84.

Susilawati, S., M. A. P. Taylor, and S. V. C. Somenahalli. 2011. Distributions of Travel Time Variability on Urban Roads. Journal of Advanced Transportation. DOI: 10.1002/atr.192.

Tilahun, N., and D. Levinson. 2010. A Moment of Time: Reliability in Route Choice Using Stated Preference. Journal of Intelligent Transportation Systems, Vol. 14, pp. 179-187.

Traffic.com. 2013. www.traffic.com. Accessed June 22, 2009.

Transport Research Centre. 2009. Improving Reliability on Surface Transportation Networks: Summary Document. International Transport Forum, Organisation for Economic Co-operation and Development.

Transport Research Centre. 2010. Improving Reliability on Surface Transportation Networks. International Transport Forum, Organisation for Economic Co-operation and Development.

Travel Midwest. 2013. www.travelmidwest.com. Accessed July 28, 2009.

Tseng, Y., and E. Verhoef. 2008. Value of Time by Time of Day: A Stated-Preference Study. Transportation Research Part B, Vol. 42, pp. 607-618.

Tsubota, T., H. Kikuchi, K. Uchiumi, H. Warita, and F. Kurauchi. 2011. Benefit of Accident Reduction Considering the Improvement of Travel Time Reliability. International Journal of Intelligent Transportation Systems Research, Vol. 9, No. 2, pp. 64-70.

Tu, H., H. Van Lint, and H. Van Zuylen. 2008. The Effects of Traffic Accidents on Travel Time Reliability. Proc., 11th International IEEE Conference on Intelligent Transportation Systems, Beijing, pp. 79-84.

Uno, N., F. Kurauchi, H. Tamura, and Y. Iida. 2009. Using Bus Probe Data for Analysis of Travel Time Variability. Journal of Intelligent Transportation Systems: Technology, Planning, and Operations, Vol. 13, No. 1, pp. 2-15.

Vanajakshi, L., S. C. Subramanian, and R. Sivanandan. 2009. Travel Time Prediction Under Heterogeneous Traffic Conditions Using Global Positioning System Data from Buses. IET Intelligent Transport Systems, Vol. 3, No. 1, pp. 1-9.

Van Hinsbergen, C. P. I. J., and J. W. C. Van Lint. 2008. Bayesian Combination of Travel Time Prediction Models. In Transportation Research Record: Journal of the Transportation Research Board, No. 2064, Transportation Research Board of the National Academies, Washington, D.C., pp. 73-80.

van Lint, J. W. C., and H. J.van Zuylen. 2005. Monitoring and Predicting Freeway Travel Time Reliability Using Width and Skew of Day-toDay Travel Time Distribution. In Transportation Research Record: Journal of the Transportation Research Board, No. 1917, Transportation Research Board of the National Academies, Washington, D.C., pp. 54-62.

van Lint, J. W. C., H. J. van Zuylen, and H. Tu. 2008. Travel Time Unreliability on Freeways: Why Measures Based on Variance Tell Only Half the Story. Transportation Research Part A, Vol. 42, No. 1, pp. 258-277.

van Zwet, E., C. Chen, Z. Jia, and J. Kwon. 2003. A Statistical Method for Estimating Speed from Single Loop Detectors. University of California, Berkeley, 2003. http://pems.eecs.berkeley.edu/Papers/ vanzwet_gfactor.pdf.

Vaziri, M., and T. N. Lam. 1983. Perceived Factors Affecting Driver Route Decisions. Journal of Transportation Engineering, Vol. 109, pp. 297-311. 
Vickrey, W. 1969. Congestion Theory and Transport Investment. American Economic Review, Vol. 59, pp. 251-260.

Wang, J., J. He, and L. Wu. 2011. Evaluating Approach of Travel Time Reliability for Highway Network Under Rain Environment. Journal of Transportation Systems Engineering and Information Technology, Vol. 11, No. 6, pp. 117-123.

Wang, J., G. Sun, and X. Hu. 2009. Analysis of City Transportation Networks' Travel Time Reliability During Adverse Weather. Proc., 9th International Conference of Chinese Transportation Professionals, Harbin, China, Vol. 358, pp. 1536-1542.

Wang, J., N. Zou, and G. Chang. 2008. Travel Time Prediction: Empirical Analysis of Missing Data Issues for Advanced Traveler Information System Applications. In Transportation Research Record: Journal of the Transportation Research Board, No. 2049, Transportation Research Board of the National Academies, Washington, D.C., pp. 81-91.

Washington State Department of Transportation. 2013. www.wsdot .com/traffic/seattle/default.aspx. Accessed June 22, 2009.

Wasson, J. S., J. R. Sturdevant, and D. M. Bullock. 2008. Real-Time Travel Time Estimates Using Media Access Control Address Matching. ITE Journal, Vol. 78, No. 6, pp. 20-23.

Wojtowicz, J., R. I. Murrugarra, B. Bertoli, W. A. Wallace, P. Manuel, W. He, and C. Body. 2008. RFID Technology for AVI: Field Demonstration of a Wireless Solar Powered E-ZPass Tag Reader. Proc., 15th World Congress on Intelligent Transport Systems, New York.

Wosyka, J., and P. Pribyl. 2012. Real-Time Travel Time Estimation on Highways Using Loop Detector Data and License Plate Recognition. Proc., 9th International Conference, ELEKTRO, Rajecké Teplice, Slovakia, pp. 391-394.

Xiaoliang, M., and H. N. Koutsopoulos. 2008. A New Online Travel Time Estimation Approach Using Distorted Automatic Vehicle Identification Data. Proc., 11th International IEEE Conference on Intelligent Transportation Systems, Beijing, pp. 204-209.
Xiong, Z., C. Shao, and Z. Yao. 2007. The Framework of Assessment on Travel Time Reliability. Proc., International Conference on Transportation Engineering, Chengdu, China, pp. 223-228.

Yamamoto, T., K. Liu, and T. Morikawa. 2006. Variability of Travel Time Estimates Using Probe Vehicle Data. Proc., 4th International Conference on Traffic and Transportation Studies, pp. 278-287.

Yamazaki, H., N. Uno, and F. Kurauchi. 2012. The Effect of a New Intercity Expressway Based on Travel Time Reliability Using Electronic Toll Collection Data. IET Intelligent Transportation Systems, Vol. 6, No. 3, pp. 306-317.

Yan, Y., X. Guo, Y. Li, Z. Kong, and M. He. 2012. Bus Transit Travel Time Reliability Evaluation Based on Automatic Vehicle Location Data. Journal of Southeast University, Vol. 28, No. 1, pp. 100-105.

Yang, M., Y. Liu, and Z. You. 2010. The Reliability of Travel Time Forecasting. IEEE Transactions on Intelligent Transportation Systems, Vol. 11, No. 1, pp. 162-171.

Yang, Y., E. Yao, D. Qu, and Y. Zhang. 2011. Study on Travel Time Reliability of Probe Vehicle System Based on Minimum Sample Size Analysis. Multimodal Approach to Sustained Transportation System Development_-Information, Technology, Implementation. Proc., 1st International Conference on Transportation Information and Safety, Wuhan, China, pp. 1680-1686.

Zou, N., J. Wang, and G. Chang. 2008. A Reliable Hybrid Prediction Model for Real-Time Travel Time Prediction with Widely Spaced Detectors. Proc., 11th International IEEE Conference on Intelligent Transportation Systems, Beijing, pp. 91-96.

Zou, N., J. Wang, G. Chang, and J. Paracha. 2009. Application of Advanced Traffic Information Systems: Field Test of a Travel-Time Prediction System with Widely Spaced Detectors. In Transportation Research Record: Journal of the Transportation Research Board, No. 2129, Transportation Research Board of the National Academies, Washington, D.C., pp. 62-72. 


\section{TRB OVERSIGHT COMMITTEE FOR THE STRATEGIC HIGHWAY RESEARCH PROGRAM 2*}

CHAIR: Kirk T. Steudle, Director, Michigan Department of Transportation

\section{MEMBERS}

H. Norman Abramson, Executive Vice President (retired), Southwest Research Institute

Alan C. Clark, MPO Director, Houston-Galveston Area Council

Frank L. Danchetz, Vice President, ARCADIS-US, Inc.

Malcolm Dougherty, Director, California Department of Transportation

Stanley Gee, Executive Deputy Commissioner, New York State Department of Transportation

Mary L. Klein, President and CEO, NatureServe

Michael P. Lewis, Director, Rhode Island Department of Transportation

John R. Njord, Executive Director (retired), Utah Department of Transportation

Charles F. Potts, Chief Executive Officer, Heritage Construction and Materials

Ananth K. Prasad, Secretary, Florida Department of Transportation

Gerald M. Ross, Chief Engineer (retired), Georgia Department of Transportation

George E. Schoener, Executive Director, I-95 Corridor Coalition

Kumares C. Sinha, Olson Distinguished Professor of Civil Engineering, Purdue University

Paul Trombino III, Director, Iowa Department of Transportation

\section{EX OFFICIO MEMBERS}

Victor M. Mendez, Administrator, Federal Highway Administration

David L. Strickland, Administrator, National Highway Transportation Safety Administration

Frederick "Bud" Wright, Executive Director, American Association of State Highway and Transportation Officials

\section{LIAISONS}

Ken Jacoby, Communications and Outreach Team Director, Office of Corporate Research, Technology, and Innovation Management, Federal Highway Administration

Tony Kane, Director, Engineering and Technical Services, American Association of State Highway and Transportation Officials Jeffrey F. Paniati, Executive Director, Federal Highway Administration

John Pearson, Program Director, Council of Deputy Ministers Responsible for Transportation and Highway Safety, Canada Michael F. Trentacoste, Associate Administrator, Research, Development, and Technology, Federal Highway Administration

* Membership as of July 2014.

\section{RELIABILITY TECHNICAL COORDINATING COMMITTEE*}

ChAIR: Carlos Braceras, Deputy Director and Chief Engineer, Utah Department of Transportation VICE CHAIR: John Corbin, Director, Bureau of Traffic Operations, Wisconsin Department of Transportation VICE ChalR: Mark F. Muriello, Assistant Director, Tunnels, Bridges, and Terminals, The Port Authority of New York and New Jersey

\section{MEMBERS}

Malcolm E. Baird, Consultant

Mike Bousliman, Chief Information Officer, Information Services Division, Montana Department of Transportation

Kevin W. Burch, President, Jet Express, Inc.

Leslie S. Fowler, ITS Program Manager, Intelligent Transportation Systems, Bureau of Transportation Safety and Technology,

Kansas Department of Transportation

Steven Gayle, Consultant, Gayle Consult, LLC

Bruce R. Hellinga, Professor, Department of Civil and Environmental Engineering, University of Waterloo, Ontario, Canada

Sarath C. Joshua, ITS and Safety Program Manager, Maricopa Association of Governments

Sandra Q. Larson, Systems Operations Bureau Director, Iowa Department of Transportation

Dennis Motiani, Executive Director, Transportation Systems Management, New Jersey Department of Transportation

Richard J. Nelson, Nevada Department of Transportation

Richard Phillips, Director (retired), Administrative Services, Washington State Department of Transportation

Mark Plass, District Traffic Operations Engineer, Florida Department of Transportation

Constance S. Sorrell, Chief of Systems Operations, Virginia Department of Transportation

William Steffens, Vice President and Regional Manager, McMahon Associates

Jan van der Waard, Program Manager, Mobility and Accessibility, Netherlands Institute for Transport Policy Analysis

John P. Wolf, Assistant Division Chief, Traffic Operations, California Department of Transportation (Caltrans)

\section{FHWA LIAISONS}

Robert Arnold, Director, Transportation Management, Office of Operations, Federal Highway Administration Joe Conway, SHRP 2 Implementation Director, National Highway Institute

Jeffrey A. Lindley, Associate Administrator for Operations, Federal Highway Administration

\section{U.S. DEPARTMENT OF TRANSPORTATION LIAISON}

Patricia S. Hu, Director, Bureau of Transportation Statistics, U.S. Department of Transportation

\section{AASHTO LIAISON}

Gummada Murthy, Associate Program Director, Operations

\section{CANADA LIAISON}

Andrew Beal, Manager, Traffic Office, Highway Standards Branch, Ontario Ministry of Transportation

${ }^{\star}$ Membership as of July 2014. 


\section{Related SHRP 2 Research}

Analytical Procedures for Determining the Impacts of Reliability Mitigation

Strategies (LO3)

Incorporating Travel Time Reliability into the Highway Capacity Manual (L08)

Incorporating Reliability Performance Measures into Operations and Planning

Modeling Tools (LO4)

Pilot Testing of SHRP 2 Reliability Data and Analytical Products (L38) 